\title{
KENO IV
}

\section{An Improved Monte Carlo Criticality Program}

\author{
L. M. Petrie \\ N. F. Cross
}

\section{OAK RIDGE NATIONAL LABORATORY}

\author{
OPERATED BY UNION CARBIDE CORPORATION - FOR THE U.S. ATOMIC ENERGY COMMISSION
}




\section{DISCLAIMER}

This report was prepared as an account of work sponsored by an agency of the United States Government. Neither the United States Government nor any agency Thereof, nor any of their employees, makes any warranty, express or implied, or assumes any legal liability or responsibility for the accuracy, completeness, or usefulness of any information, apparatus, product, or process disclosed, or represents that its use would not infringe privately owned rights. Reference herein to any specific commercial product, process, or service by trade name, trademark, manufacturer, or otherwise does not necessarily constitute or imply its endorsement, recommendation, or favoring by the United States Government or any agency thereof. The views and opinions of authors expressed herein do not necessarily state or reflect those of the United States Government or any agency thereof. 


\section{DISCLAIMER}

Portions of this document may be illegible in electronic image products. Images are produced from the best available original document. 
ORNL-4938

UC-32 - Mathematics and Computers

Contract No. W-7405-eng-26

COMPUTER SCIENCES DIVISION

KENO IV - AN IMPROVED MONTE CARLO CRITICALITY PROGRAM

L. M. Petrie N. F. Cross

NOVEMBER 1975

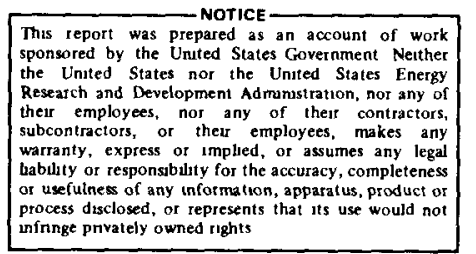

process disclosed, or represents that its use would not

ininnge privately owned rights

OAK RIDGE NATIONAL LABORAIORY

Oak Ridge, Tennessee, 37830

operated by

UNION CARBIDE CORPORAIION

for the

U.S. ENERGY RESEARCH AND DEVELOPMENT ADMINISTRATION

$\therefore .1, \quad, \quad 3$ 
0 


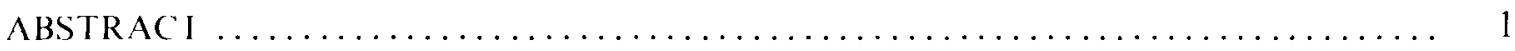

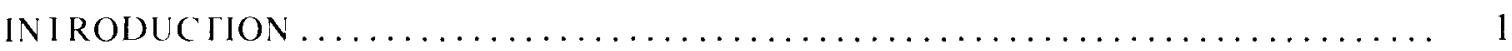

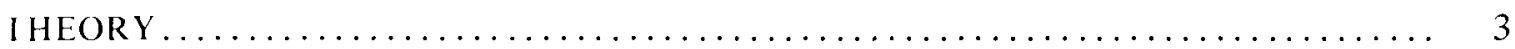

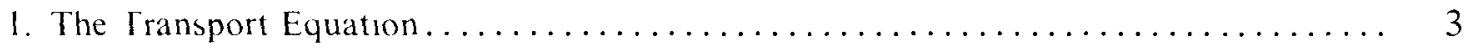

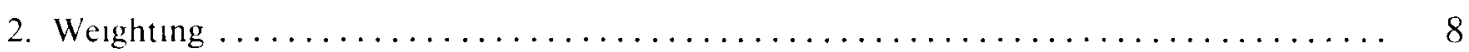

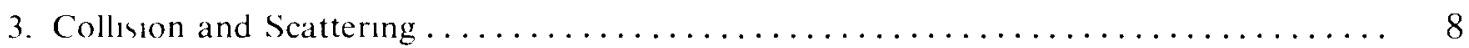

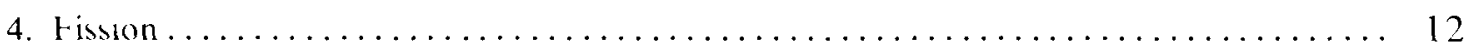

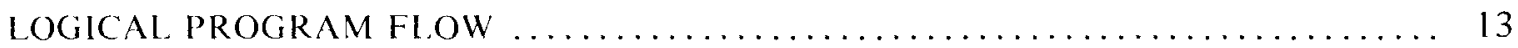

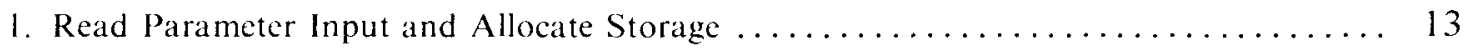

2. Read Cross Section and Velocity Input Data ...................... 13

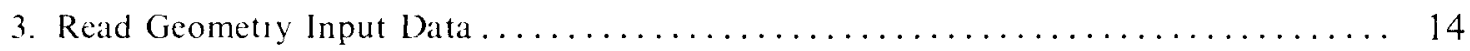

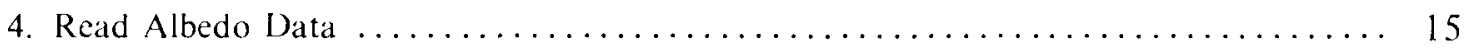

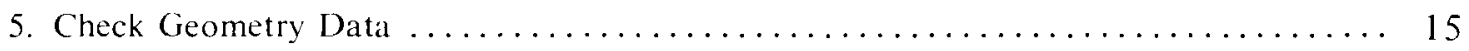

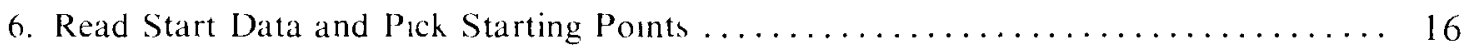

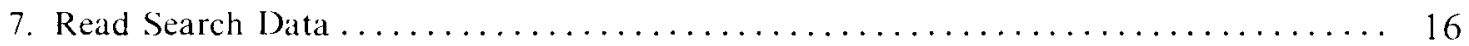

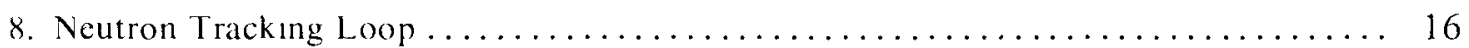

8.1 General Loop Flow ....................................... 16

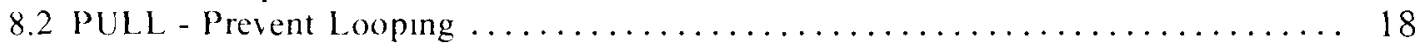

8.3 FSTART - Start Fission Neutron ................................ 18

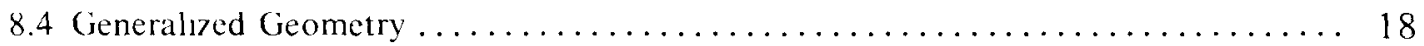

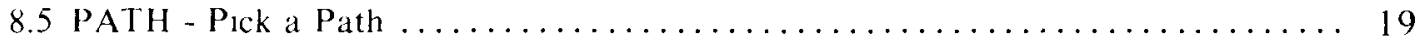

8.6 FINBOX - Determine Box Position ............................. 19

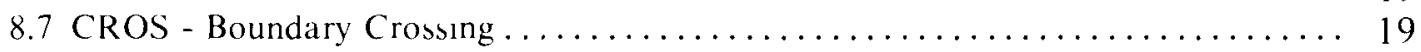

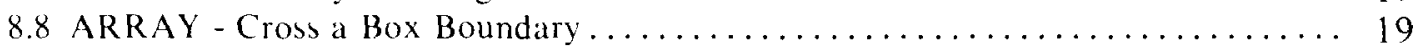

8.9 ALBEDO - Albedo Reflector I reatment ........................ 19

8.10 LEAK - Remove Neutron from System ........................ 20

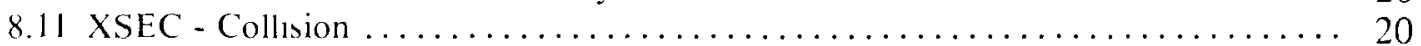

8.12 Store Fission Points for the Next Generation ...................... 20

8.13 Compute Results for Generation ........................... 20

8.14 NSTART - Fission Source for Next Generation ................... 21

815 Print Generation Results................................... 21

8.16 WRTRST - Save Restart Data ............................. 21

8.17 Complete Number of Generations ........................ 21

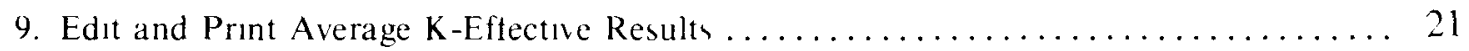

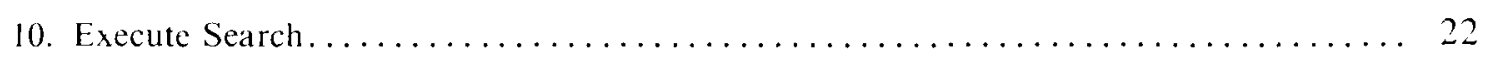

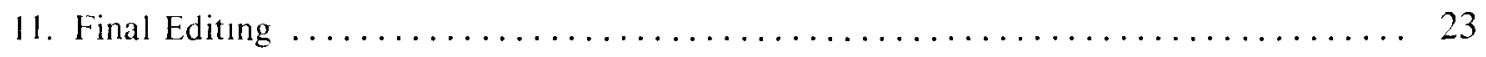

ALPHABEIICAL SUBROUTINE SUMMARY.......................... 25

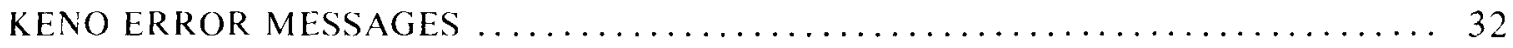




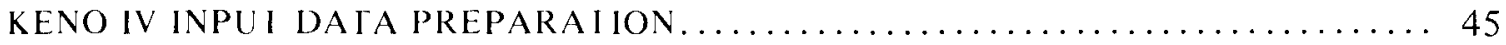

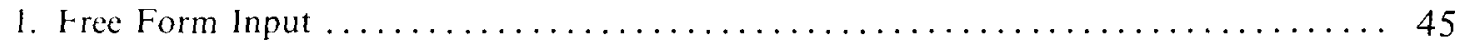

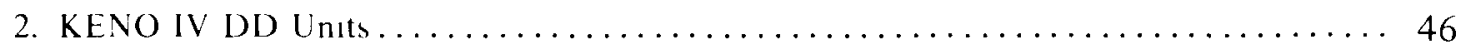

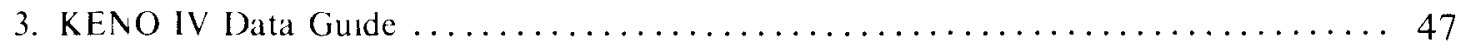

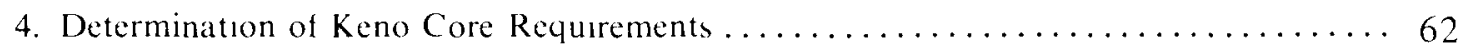

APPENDIX I: ANISN Cross Section Input.............................. 65

APPENDIX II Generalıed Geometry Input ............................. 66

APPENDIX III: Standard KENO Librares............................ 70

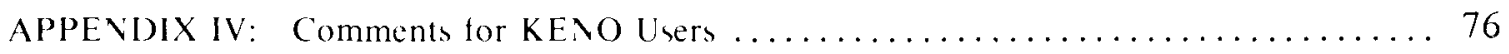

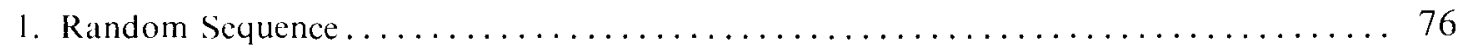

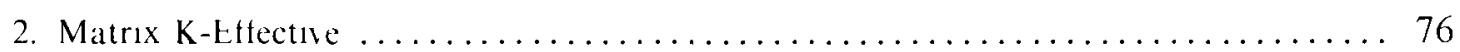

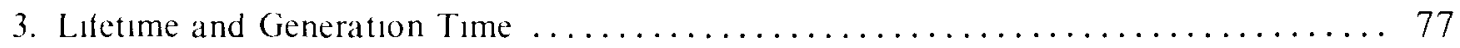

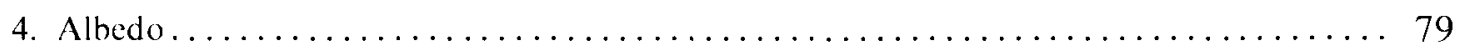

5. $\sigma_{t}$ Resonance Corrected Cross Sections for Homogeneous

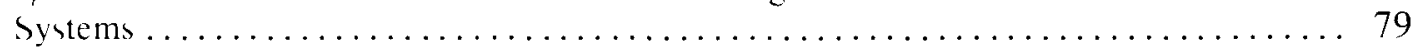

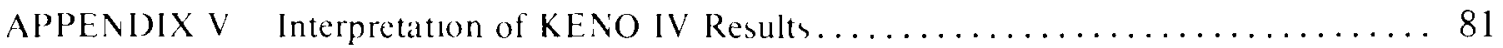

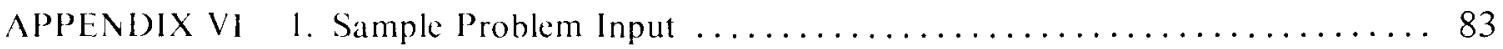

2 Sample Problem Output .......................... 94 


\title{
KENO IV - AN IMPROVED MONTE CARLO CRITICALITY PROGRAM
}

\author{
L M Petrie N F Cross
}

\begin{abstract}
ABS I RAC I
KE \O IV is a multigroup Monte (arlo criticalits progiam written for the IBM 360 computess It executes rapidly and is flcxibly dimensioned so the allowed ste of a problem (te the number of energy groups, number of geometiy cards etc is abitiary) is limited only by the total data storage required I he input data with the cxception of cross sections fission spectia and albedos, mas be entered in tree form I he geometiy input is yuite simple to piepare and complicated three-dimensional sistems can often be described with a minimum of effort

I he results calculated bi KF $\searrow \mathrm{O}$ IV include $\mathrm{k}$-effective lifetime and generation time energv-dependent leakages and absorptions, energy-and region-dependent fluxes and region-dependent lission densitics (riticalits searches can be made on unit dimensions or on the number of units in an arral I his repoit includes a summats of the theors utilied br KE VO IV a section descilbing the logical program flow a compilation of the ertot messages printed by the code and a comprehensive data guide for preparing input to the code
\end{abstract}

\section{INIROIDUCTIOV}

KENO IV is an improvement and extension of KENO - A Multigroup Monte Carlo Criticalits Program' written for the IBM 360 computers It is flexibly dimensioned, utilyes frec-form input and ofters more geometr options than KE\O The geometri input for KE\O IV consists of geometty key words representing simple types of three-dimensional contigurations (SPHI RL (UBE, CYI INDER, etc) A geometr, shape detines a region I hese regions can be nested one outside another to construct a desired object Each region must be completelv enclosed br the next larger region (tangency and common taces ate allowed but intersecting tegions ate not) I his procedure is used to describe box types, each of which may contan a different geometis configuration The box tvpes can then be stacked togethei to form a three-dimensional arrat of units When stacking box types, the adjacent faces of adjacent box tipes must be the same saze Once an array has been described, a reflector can be bult around the arral by using the automatic reflector option building tt of geometrs ket words enclosing the entire arras or using the albedo options KENO IV can calculate k-effectıve matrix k-effectıve, lifetıme, generation time leakages absorptions, fluxes, and fission densities It can do a forward calculation or an adjoint calculation a dimension search or an arrav search It can also use a different albedo reflector material on each face of an array It difterential albedos are used, the lifetime and generation time will be incorrect Cross sections, albedos, and or geometiy data can be used from the preceding case if so desired

KE\O IV executes extensive check, for input data errors and if it finds ans, will print an ertor message and not execute that case However, it does continue reading and checking the input data If it does get lost in the input data, an attempt is made to read to a special end-of-case flag so 11 can execute the next case If an error is found in a case, KE VO IV will not execute ant subrequent case that uses data from that case 
The principal result trom KENO IV is an estimate of criticality (k-effective) An optional alternate method of determining k-effective is the matrix method and yields a matrix k-effective (the largest eigentalue of the matrix of fission probabilities) by unit, box type, or both The matrix method also yields cofactor $k$-effectives by unit, box type, or both The cotactor k-eftective of a unit is the k-effective of the array as though that unit were removed, but using the fission distribution that exists if the unit were there The average unit self-multiplication the source vector, and the Iission probability matrix by box type are always printed if a matrix k-effective calculation is made, but the fission probability matrix by unit position may be suppressed

The leakage absorption and fission production by energy group are calculated and printed An option to print leakage and absorption by both energy group and geometry region is avalable If specified KE VO IV will compute fluxes by region and group and or fission densities by region

Criticality searches can be made on the dimensions of a unit the spacing between units, or on the number of units in an array In a dimension sedrch, edch surface of edch region can be altered independently of the other surfaces (hecks are made to see that no geometry restrictions have been wolated In an array search, the number of units in an array is increased or decreased, and, it a reflector is present, the dimensions of the reflector regions are altered to maintain the reflector thickness A search is conducted in an iterative manner until the desired value of k-effective is achieved or unt 1 the allowed number of iterations have been made

KENO-IV utılıes a weighted tracking method and the weights are specified by region and group I he default weight (if a weight is specified ds zero) is 05 I he weight above which splitting occurs is three times the average weight and the weight below which Russian roulette is played is one-third of the average weight

Seven different starting options are avalable for starting the initid generation I his helps avoid source convergence problems by adequately describing the neutron distribution in the initial generation The source distribution for each successive generation is chosen trom the fission neutrons generdted in the previous generation

The cross-sections and group-dependent data used by KENO IV are not limited to Hansen Roach cross sections or to 16 energy groups The Hansen Rodch 16 group cross section data set and compatible weighting functions and albedo data dre included in this report Weighting functions and albedo datd can be generated for any desired energy group structure 


\section{THEORY}

\section{The Transport Equation}

The equation KENO IV solves may be derived in the following manner, startıng with the Boltzman neutron transport equation which may be written as ${ }^{2}$

$\frac{1}{\mathrm{v}} \frac{\partial \Phi}{\partial \mathrm{t}}(\mathrm{X}, \mathrm{E}, \Omega, \mathrm{t})+\Omega \cdot \nabla \Phi(\mathrm{X}, \mathrm{E}, \Omega, \mathrm{t})+\Sigma_{\mathrm{t}}(\mathrm{X}, \mathrm{E}, \Omega, \mathrm{t}) \Phi(\mathrm{X} \mathrm{E}, \Omega \mathrm{t})=$

$$
\mathrm{S}(\mathrm{X}, \mathrm{E}, \Omega, \mathrm{t})+\int_{\mathrm{F}} \int_{\Omega} \Sigma,\left(\mathrm{X}, \mathrm{E}^{\prime} \rightarrow \mathrm{E}, \Omega^{\prime} \rightarrow \Omega, \mathrm{t}\right) \Phi\left(\mathrm{X} \mathrm{E}^{\prime}, \Omega^{\prime} \mathrm{t}\right) \mathrm{d} \Omega^{\prime} \mathrm{d} \mathrm{E}^{\prime}
$$

where

$\Phi(\mathrm{X}, \mathrm{E}, \Omega, \mathrm{t})=$ neutron flux (neutrons $/ \mathrm{cm}^{2} / \mathrm{sec}$ ) per unit energy at energy $\mathrm{E}$ per steradian about direction $\Omega$ at position $\mathrm{X}$ at time $\mathrm{t}$ moving at speed $\mathrm{v}$ corresponding to $\mathrm{E}$,

$\Sigma_{\mathrm{t}}(\mathrm{X}, \mathrm{E}, \Omega, \mathrm{t})=$ macroscopic total cross section of the media $\left(\mathrm{cm}^{-1}\right)$ at position $\mathrm{X}$, energy $\mathrm{E}$, direction $\Omega$ and tıme $\mathbf{t}$,

$\Sigma_{\mathrm{s}}\left(\mathrm{X}, \mathrm{E}^{\prime} \rightarrow \mathrm{E}, \Omega^{\prime} \rightarrow \Omega, \mathrm{t}\right)=$ macroscopic differential cross section of the medid $\left(\mathrm{cm}^{-1}\right)$ dt position $\mathrm{X}$, and time $t$, for scattering from energy $E^{\prime}$ and direction $\Omega^{\prime}$ to energy $E$ and direction $\Omega$,

$\mathrm{S}(\mathrm{X}, \mathrm{E}, \Omega, \mathrm{t})=$ neutrons $/ \mathrm{cm}^{3} / \mathrm{sec}$ born at position $\mathrm{X}$ and time $\mathrm{t}$ per unit energy at energy $\mathrm{E}$ per steradian about direction $\Omega$ (excludes scatter source)

Defining $\mathrm{q}(\mathrm{X}, \mathrm{E}, \Omega, \mathrm{t})$ as the total source resulting from the external source, scattering, fission and all other contributions, the following relationship can be written

$$
\mathrm{q}(\mathrm{X}, \mathrm{E}, \Omega, \mathrm{t})=\mathrm{S}(\mathrm{X}, \mathrm{E}, \Omega, \mathrm{t})+\int_{\mathrm{E}^{\prime}} \int_{\Omega^{\prime}} \Sigma_{\mathrm{s}}\left(\mathrm{X}, \mathrm{E}^{\prime} \rightarrow \mathrm{E}, \Omega^{\prime} \rightarrow \Omega, \mathrm{t}\right) \Phi\left(\mathrm{X}, \mathrm{E}^{\prime}, \Omega^{\prime}, \mathrm{t}\right) \mathrm{d} \Omega^{\prime} \mathrm{dE} \mathrm{E}^{\prime}
$$

Combining Eqs [1] and [2], assuming the media to be isotropic, ignoring the time dependence of the cross sections and converting the equation to multigroup form yields

$$
\frac{1}{\mathrm{v}_{\mathrm{g}}} \frac{\partial \Phi_{\mathrm{g}}}{\partial \mathrm{t}}(\mathrm{X}, \Omega, \mathrm{t})+\Omega \cdot \nabla \Phi_{\mathrm{g}}(\mathrm{X}, \Omega, \mathrm{t})+\Sigma_{\mathrm{t}_{\mathrm{g}}}(\mathrm{X}) \Phi_{\mathrm{g}}(\mathrm{X}, \Omega, \mathrm{t})=\mathrm{q}_{\mathrm{g}}(\mathrm{X}, \Omega, \mathrm{t})
$$


where

$\mathrm{g}$ is the energy group of interest,

$\mathrm{v}_{\mathrm{g}} 1 \mathrm{~s}$ the average velocity of the neutrons in group $\mathrm{g}$,

$\Phi_{\mathrm{g}}(\mathrm{X}, \Omega, \mathrm{t})$ is the angular flux of neutrons having their energies in group $\mathrm{g}$, at position $\mathrm{X}$ and time $\mathrm{t}$, $\Sigma_{t_{\mathrm{g}}}(\mathrm{X})$ is the macroscopic total cross section of the media at position $\mathrm{X}$ for group $\mathrm{g}$, corresponding to

$\Sigma_{\mathrm{t}_{\mathrm{g}}}(\mathrm{X})=\frac{\int_{\Delta \mathrm{Eg}} \Sigma_{\mathrm{t}}(\mathrm{X}, \mathrm{E}) \Phi(\mathrm{X}, \mathrm{E}, \Omega, \mathrm{t}) \mathrm{dE}}{\int_{\Delta \mathrm{Lg}} \Phi(\mathrm{X}, \mathrm{E}, \Omega, \mathrm{t}) \mathrm{dE}}$ where $\Delta \mathrm{Eg}$ defines group g, and

$\mathrm{q}_{\mathrm{g}}(\mathrm{X}, \Omega, \mathrm{t})$ is the total source contributing to energy group $\mathrm{g}$ at position $\mathrm{X}$, and time $\mathrm{t}$ in direction $\Omega$

Utılizing the relationship $\mathrm{X}^{\prime}=\mathrm{X}-\mathrm{R} \Omega$, definıng the problem to be non-time dependent and using an integrating factor ${ }^{3}$ on both sides of $\mathrm{Eq}$ [3], the following equation can be written

$$
\Phi_{\mathrm{g}}(\mathrm{X}, \Omega)=\int_{0}^{\infty} \mathrm{q}_{\mathrm{g}}(\mathrm{X}-\mathrm{R} \Omega, \Omega) \mathrm{e}^{-\int_{0}^{\mathrm{R}} \Sigma_{\mathrm{t}_{\mathrm{g}}}(\mathrm{X}-\mathrm{R} \Omega) \mathrm{dR}} \mathrm{dR}
$$

At this point, the problem becomes an eigenvalue problem If there is no external source, the source may be defined as

$$
q_{\mathrm{g}}(\mathrm{X}, \Omega)=\sum_{\mathrm{g}^{\prime}} \int \mathrm{d} \Omega^{\prime} \Phi_{\mathrm{g}}\left(\mathrm{X}, \Omega^{\prime}\right) \Sigma_{\mathrm{s}}\left(\mathrm{X}, \mathrm{g}^{\prime} \rightarrow \mathrm{g}, \Omega^{\prime} \cdot \Omega\right)+\frac{1}{\mathrm{k}} \mathrm{Q}_{\mathrm{g}}^{\prime}(\mathrm{X}, \Omega)
$$

where

$\mathrm{k}$ is the largest eigenvalue of the integral equation,

$\mathrm{Q}_{\mathrm{g}}^{\prime}(\mathrm{X}, \Omega)$ is the fission source at position $\mathrm{X}$ for energy group $\mathrm{g}$ and direction $\Omega$ (all fission contributions to group $g$ from all energy groups in the previous generation ),

$\Sigma_{s}\left(\mathrm{X}, \mathrm{g}^{\prime} \rightarrow \mathrm{g}, \Omega^{\prime} \cdot \Omega\right)$ is the scattering cross section for scattering at position $\mathrm{X}$ from group $\mathrm{g}^{\prime}$ and direction $\Omega^{\prime}$ to group $\mathrm{g}$ and direction $\Omega$

In terms of energy, the scatter can be defined as

$$
\Sigma_{\mathrm{s}}\left(\mathrm{X}, \mathrm{g}^{\prime} \rightarrow \mathrm{g}, \Omega^{\prime} \cdot \Omega\right)=\frac{\int_{\Delta \mathrm{Eg}} \int_{\Delta \mathrm{Eg}^{\prime}} \Sigma_{\mathrm{s}}\left(\mathrm{X}, \mathrm{E}^{\prime} \rightarrow \mathrm{E}, \Omega^{\prime} \cdot \Omega\right) \Phi\left(\mathrm{X}, \mathrm{E}^{\prime}, \Omega^{\prime}\right) \mathrm{d} \mathrm{E}^{\prime} \mathrm{dE}}{\int_{\Delta \mathrm{Eg}^{\prime}} \Phi\left(\mathrm{X}, \mathrm{E}^{\prime}, \Omega^{\prime}\right) \mathrm{d} \mathrm{E}^{\prime}}
$$


where

$\Delta \mathrm{E}_{\mathrm{g}}$ is the energy range defining energy group $\mathrm{g}$ and $\Delta \mathrm{E}_{\mathrm{g}}{ }^{\prime}$ is the energy range defining energy group g'

Assuming the fission neutrons to be isotropic, the fission source $Q_{g}^{\prime}(X)$ can be written as

$$
\mathrm{Q}_{\mathrm{g}}^{\prime}(\mathrm{X} \Omega)=\frac{1}{4 \pi} \sum_{\mathrm{g}^{\prime}} \int_{\Omega} \mathrm{d} \Omega^{\prime} \Phi_{\mathrm{g}}\left(\mathrm{X} \Omega^{\prime}\right) \chi\left(\mathrm{X}, \mathrm{g}^{\prime} \rightarrow \mathrm{g}\right) \nu_{\mathrm{g}}(\mathrm{X}) \Sigma_{\mathrm{f}_{\mathrm{g}}}(\mathrm{X})
$$

where

$\chi\left(X, g^{\prime} \rightarrow g\right)$ is the fraction of neutrons born in energy group $g$ from fission in energy group $\mathrm{g}^{\prime}$ in the media at position X,

$\nu_{\mathrm{g}}{ }^{\prime}(\mathrm{X})$ is the number of neutrons resulting from a fission in energy group $\mathrm{g}^{\prime}$ at position $\mathrm{X}$,

$\Sigma_{f_{g}}(X)$ is the macroscopic fission cross section of the material at position $\mathrm{X}$ for a neutron in energy group $g^{\prime}$

Substituting Eq [5] into Eq [4] y1elds the following equation

$$
\begin{aligned}
\Phi_{\mathrm{g}}(\mathrm{X}, \Omega)=\int_{0}^{\infty} \mathrm{dR} \mathrm{e}^{\left.\int_{0}^{\mathrm{R}} \Sigma_{\mathrm{t}_{\mathrm{g}}(\mathrm{X}} \mathrm{R} \Omega\right) \mathrm{dR}}\left\{\frac{1}{\mathrm{k}} \mathrm{Q}_{\mathrm{g}}^{\prime}(\mathrm{X}-\mathrm{R} \Omega, \Omega)\right. \\
\left.+\sum_{\mathrm{g}}\left[\int_{\Omega} \mathrm{d} \Omega^{\prime} \Phi_{\mathrm{g}}\left(\mathrm{X}-\mathrm{R} \Omega, \Omega^{\prime}\right) \Sigma_{\mathrm{s}}\left(\mathrm{X}-\mathrm{R} \Omega \mathrm{g}^{\prime} \rightarrow \mathrm{g}, \Omega^{\prime} \cdot \Omega\right)\right]\right\}
\end{aligned}
$$

The definition of $\mathrm{k}$ may be given as the ratio of the number of neutrons in the $\mathrm{n}+1$ generation to the number of neutrons in the $n$ generation or the largest eigenvalue of the integral equation Using Eq [7], Eq [8] can be written as

$$
\begin{aligned}
\Phi_{\mathrm{g}}(\mathrm{X}, \Omega)= & \int_{0}^{\infty} \mathrm{dR} \mathrm{e}^{-\int_{0}^{\mathrm{R}} \Sigma_{\mathrm{t}_{\mathrm{g}}}\left(\mathrm{X}-\mathrm{R}^{\prime} \Omega\right) \mathrm{d} \mathrm{R}} . \\
& \left\{\sum_{\mathrm{g}^{\prime}} \frac{1}{\mathrm{k}} \int_{\Omega} \nu_{\mathrm{g}}(\mathrm{X}-\mathrm{R} \Omega) \Sigma_{\mathrm{f}_{\mathrm{g}}}(\mathrm{X}-\mathrm{R} \Omega) \chi\left(\mathrm{X}-\mathrm{R} \Omega, \mathrm{g}^{\prime} \rightarrow \mathrm{g}\right) \Phi_{\mathrm{g}}\left(\mathrm{X}-\mathrm{R} \Omega, \Omega^{\prime}\right) \frac{\mathrm{d} \Omega^{\prime}}{4 \pi}+\right. \\
& \left.\sum_{\mathrm{g}^{\prime}} \int_{\Omega} \mathrm{d} \Omega^{\prime} \Sigma_{\mathrm{tg}_{\mathrm{g}}}(\mathrm{X}-\mathrm{R} \Omega) \Phi_{\mathrm{g}}\left(\mathrm{X}-\mathrm{R} \Omega, \Omega^{\prime}\right) \frac{\Sigma_{\mathrm{s}}\left(\mathrm{X} \mathrm{R} \Omega \mathrm{g}^{\prime} \rightarrow \mathrm{g} \Omega^{\prime} \cdot \Omega\right)}{\Sigma_{\mathrm{tg}_{\mathrm{g}}}(\mathrm{X}-\mathrm{R} \Omega)}\right\}
\end{aligned}
$$


Writıng Eq. [9] in "generation notation", multıplying and dividıng certain terms by $\Sigma_{\mathrm{t}_{\mathrm{g}}}(\mathrm{X})$ and multiplyıng both sides of the equation by $\nu_{\mathrm{g}}(\mathrm{X}) \Sigma_{\mathrm{f}_{\mathrm{g}}}(\mathrm{X})$, yield the following equation, which is solved by KENO.

$$
\begin{gathered}
\frac{\nu_{\mathrm{g}}(\mathrm{X}) \Sigma_{\mathrm{f}_{\mathrm{g}}}(\mathrm{X})}{\Sigma_{\mathrm{t}_{\mathrm{g}}}(\mathrm{X})} \Sigma_{\mathrm{t}_{\mathrm{g}}}(\mathrm{X}) \Phi_{\mathrm{g}, \mathrm{n}}(\mathrm{X}, \Omega)=\frac{\nu_{\mathrm{g}}(\mathrm{X}) \Sigma_{\mathrm{f}_{\mathrm{g}}}(\mathrm{X})}{\Sigma_{\mathrm{t}_{\mathrm{g}}}(\mathrm{X})} \Sigma_{\mathrm{t}_{\mathrm{g}}}(\mathrm{X}) \int_{0}^{\infty} \mathrm{dR} \mathrm{e}^{-\int_{0}^{\mathrm{R}} \Sigma_{\mathrm{t}_{\mathrm{g}}}\left(\mathrm{X}-\mathrm{R}^{\prime} \Omega\right) \mathrm{d} \mathrm{R}^{\prime}}, \\
\left\{\frac{1}{\mathrm{k}} \sum_{\mathrm{g}} \int_{\Omega^{\prime}} \frac{\nu_{\mathrm{g}^{\prime}}(\mathrm{X}-\mathrm{R} \Omega) \Sigma_{\mathrm{f}_{\mathrm{g}^{\prime}}(\mathrm{X}-\mathrm{R} \Omega)}}{\Sigma_{\mathrm{t}_{\mathrm{g}}}(\mathrm{X}-\mathrm{R} \Omega)} \chi\left(\mathrm{X}-\mathrm{R} \Omega, \mathrm{g}^{\prime} \rightarrow \mathrm{g}\right) \Sigma_{\mathrm{t}_{\mathrm{g}^{\prime}}(\mathrm{X}-\mathrm{R} \Omega) \Phi_{\mathrm{g}^{\prime}, \mathrm{n}-1}\left(\mathrm{X}-\mathrm{R} \Omega, \Omega^{\prime}\right) \frac{\mathrm{d} \Omega^{\prime}}{4 \pi}}\right. \\
\left.+\sum_{\mathrm{g}^{\prime}} \int_{\Omega^{\prime}} \frac{\Sigma_{\mathrm{S}}\left(\mathrm{X}-\mathrm{R} \Omega \cdot \mathrm{g}^{\prime} \rightarrow \mathrm{g}, \Omega^{\prime} \cdot \Omega\right)}{\Sigma_{\mathrm{t}_{\mathrm{g}^{\prime}}}(\mathrm{X}-\mathrm{R} \Omega)} \Sigma_{\mathrm{tg}_{\mathrm{g}}}(\mathrm{X}-\mathrm{R} \Omega) \Phi_{\mathrm{g}, \mathrm{n}}\left(\mathrm{X}-\mathrm{R} \Omega, \Omega^{\prime}\right) \mathrm{d} \Omega^{\prime}\right\},
\end{gathered}
$$

where $\mathrm{n}$ indicates the $\mathrm{n}$ th generation and $\mathrm{n}-1$ is the $(\mathrm{n}-1)$ th generation. Note that the left hand side of the equation, $\nu_{\mathrm{g}}(\mathrm{X}) \Sigma_{\mathrm{f}_{\mathrm{g}}}(\mathrm{X}) \Phi_{\mathrm{g}, \mathrm{n}}(\mathrm{X}, \Omega)$, is the fission production for the $\mathrm{n} t h$ generation

The solution strategy utilized by KENO IV solves Eq. [10] by using an iterative procedure and defines the following important quantities

$\frac{1}{\mathrm{k}} \sum_{\mathrm{g}^{\prime}} \int_{\Omega} \frac{\nu_{\mathrm{g}}(\mathrm{X}) \Sigma_{\mathrm{f}_{\mathrm{g}^{\prime}}(\mathrm{X})}}{\Sigma_{\mathrm{t}_{\mathrm{g}^{\prime}}}(\mathrm{X})} \chi\left(\mathrm{X}, \mathrm{g}^{\prime} \rightarrow \mathrm{g}\right) \Sigma_{\mathrm{t}_{\mathrm{g}}}(\mathrm{X}) \Phi_{\mathrm{g}^{\prime}, \mathrm{n}-1}\left(\mathrm{X}, \Omega^{\prime}\right) \frac{\mathrm{d} \Omega^{\prime}}{4 \pi}$ is the fission production at point $\mathrm{X}_{\text {in }}$ energy group g due to neutrons in the $(\mathbf{n}-1)$ th generation, normalized to the system multiplication.

$\mathrm{e}^{-\int_{0}^{\mathrm{R}} \Sigma_{\mathrm{t}_{\mathrm{g}}}\left(\mathrm{X}-\mathrm{R}^{\prime} \Omega\right) \mathrm{d} \mathrm{R}^{\prime}}$ is the probability of transport from any position $\mathrm{X}-\mathrm{R} \Omega$ to position $\mathrm{X}$ The collision points used in KENO are chosen according to this relationship in the portion of subroutine BEGIN that is called PATH

$$
\begin{aligned}
& \Sigma_{\mathrm{t}_{\mathrm{g}}}(\mathrm{X}) \int_{0}^{\infty} \mathrm{dR} \mathrm{e}^{-\int_{0}^{\mathrm{R}} \Sigma_{\mathrm{tg}_{\mathrm{g}}}\left(\mathrm{X}-\mathrm{R}^{\prime} \Omega\right) \mathrm{d} \mathrm{R}^{\prime}} \frac{1}{\mathrm{k}} \cdot \\
& \quad \int_{\Omega^{\prime}} \sum_{\mathrm{g}^{\prime} \mid} \frac{v_{\mathrm{g}^{\prime}}(\mathrm{X}-\mathrm{R} \Omega) \Sigma_{\mathrm{f}_{\mathrm{g}^{\prime}}(\mathrm{X}-\mathrm{R} \Omega)}}{\Sigma_{\mathrm{t}_{\mathrm{g}^{\prime}}(\mathrm{X}-\mathrm{R} \Omega)}^{\mathrm{R}} \Omega\left(\mathrm{X}-\mathrm{R} \Omega, \mathrm{g}^{\prime} \rightarrow \mathrm{g}\right) \Sigma_{\mathrm{t}_{\mathrm{g}}}(\mathrm{X}-\mathrm{R} \Omega) \Phi_{\mathrm{g}^{\prime}, \mathrm{n}-1}\left(\mathrm{X}-\mathrm{R} \Omega, \Omega^{\prime}\right) \frac{\mathrm{d} \Omega^{\prime}}{4 \pi}}
\end{aligned}
$$

is the first collision density of neutrons in group g per unit solid angle about $\Omega$ resulting from the fission source produced by the $(\mathrm{n}-1)$ th generation, normalized to the system multiplication. 


$$
\sum_{\mathrm{g}^{\prime}} \int_{\Omega^{\prime}} \frac{\Sigma_{\mathrm{S}}\left(\mathrm{X}, \mathrm{g}^{\prime} \rightarrow \mathrm{g} \Omega^{\prime} \cdot \Omega\right)}{\Sigma_{\mathrm{t}_{\mathrm{g}}}(\mathrm{X})} \Sigma_{\mathrm{t}_{\mathrm{g}}}(\mathrm{X}) \Phi_{\mathrm{g}} \mathrm{n}_{\mathrm{n}}\left(\mathrm{X}, \Omega^{\prime}\right) \mathrm{d} \Omega^{\prime} \text { is the scatterning source dt position } \mathrm{X}
$$

emerging in group $g$ and direction $\Omega$ resultıng from previous collisions in the same generation

$$
\begin{aligned}
\Sigma_{\mathrm{t}_{\mathrm{g}}}(\mathrm{X}) & \int_{0}^{\infty} \mathrm{dR} \mathrm{e}^{-\int_{0}^{\mathrm{R}} \Sigma_{\mathrm{t}_{\mathrm{g}}}(\mathrm{X} \quad \mathrm{R} \Omega) \mathrm{d} \mathrm{R}} \\
& \sum_{\mathrm{g}^{\prime}} \int_{\Omega} \frac{\Sigma_{\mathrm{S}}\left(\mathrm{X} R \Omega, \mathrm{g}^{\prime} \rightarrow \mathrm{g}, \Omega^{\prime} \cdot \Omega\right)}{\Sigma_{\mathrm{t}_{\mathrm{g}}}(\mathrm{X}-\mathrm{R} \Omega)} \Sigma_{\mathrm{t}_{\mathrm{g}}}(\mathrm{X}-\mathrm{R} \Omega) \Phi_{\mathrm{g}}\left(\mathrm{X}-\mathrm{R} \Omega, \Omega^{\prime}\right) \mathrm{d} \Omega^{\prime} \text { is the collision }
\end{aligned}
$$

density in group g, per solıd angle about $\Omega$ and is the relationship used by KENO to process collisions

$$
\text { The total collision density times } \frac{v_{\mathrm{g}}(\mathrm{X}) \Sigma_{\mathrm{f}_{\mathrm{g}}}(\mathrm{X})}{\Sigma_{\mathrm{t}_{\mathrm{g}}}(\mathrm{X})} \text { is the relationship from which KENO IV }
$$
picks the source points for the next generdtion 
The purpose of weighting is to improve the statistical accuracy of keffective per unit tracking tıme $^{4}$ The values of the average weight, WTAVG, the weight cutoff, WTLOW, and the weight at which splitting occurs, WTHIGH, which should be used depend on the importance of neutrons in a region and the relative cost of tracking a low weight neutron compared to the cost of starting a new neutron The default options used in KENO IV are as follows

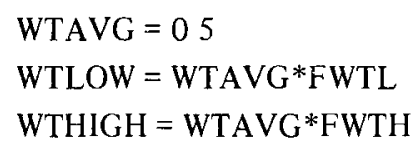

where FWTH $=30$ and FWTL $=10 / \mathrm{FWTH}$ These values ${ }^{1}$ were chosen after studyng a system where neutrons engaged in a large number of collisions before being absorbed or escaping from the system Figure 1 illustrates the estımated standard devidtion ds a function of statistical weight cut off WTLOW given a fixed amount of computer time

To reduce the computing tıme for a reflected system, a judgment is made about the relative importance of a neutron in the reflector to the average neutron in the system The importance of a neutron in the reflector usually varies as a function of energy and distance from the core Therefore a space or region and energy dependent weighting function is used to reduce the amount of time spent tracking neutrons in the reflector One means of obtaining this weighting function for a given core material and reflector material is to use the adjoint solution from the $S_{n}$ type programs for a similar (usually simplified) problem This adjoint flux gives the relative contribution of a neutron at a given energy and position to the total fissions in the system The weighting function for KENO is thus proportional to the reciprocal of the adjoint flux Although such a function can be difficult to obtain, the savings gained usually makes the effort worthwhile The use of weightıng to minimize the error in $\mathrm{k}$ effective per unit computer time will usually increase the error in other parameters such as leakage or absorption in the reflector

Examples of the 16 group and 123 group weighting functions for some reflector materials can be found in, "16 and 123 Group Weighting Functions for KENO '5

\section{Collision and Scattering}

When a neutron being tracked has not moved into a different geometrical region as determined by the subroutines POSIT or CROS, it has undergone a collision in the material comprising that region The absorption weight and the fission weight are calculated by multiplying the weight of the neutron by the absorption and nu fission probabilities of the material, respectively The neutron weight, WT, is then multiplied by the non absorption probability of that material and the new weight is checked against WTHIGH (the weight at which splitting occurs) If WT is larger than WTHIGH, the neutron is split and stored until WT is less than WTHIGH If WT is less than the statistical weight cutoff, WTLOW, Russian roulette is applied If the neutron loses a game of Russian roulette, it exits from the collision processing section and the fission weight and absorption weight are summed into the dccumulators for that generation If the neutron survives Russian roulette, its weight is set to WTAVG and it undergoes scattering If WT is greater than WTLOW and less than WTHIGH, the neutron scatters Scattering from any energy group to any other energy group is allowed by proper selection from the transfer or downscatter matrix The energy group after the collision (the energy group the neutron scatters to) is found by picking from the normalized cumulative transfer probability matrix, FSP KENO IV accounts for anisotropic scattering by using a $P_{1}$ Legendre polynomal expansion of the differential scattering cross section, $\Sigma_{\mathrm{s}}$ 


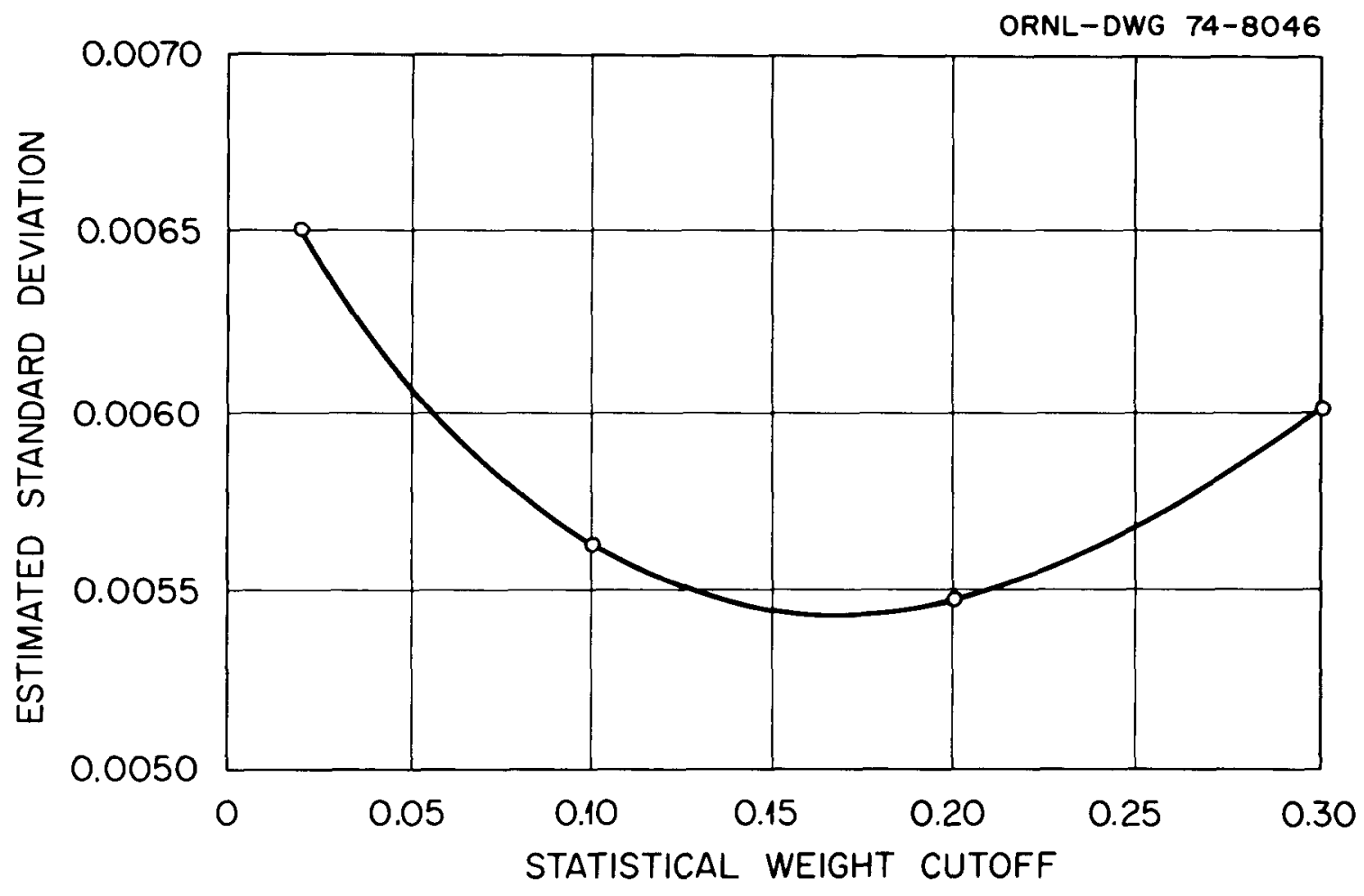

Figure 1. 
For $\Sigma_{\mathrm{s}}(\mu)$ where $(-1 \leqslant \mu \leqslant 1)$ the $\mathbf{P}_{1}$ expansion gives

$$
\Sigma_{\mathrm{s}}(\mu)=\sum_{n=0}^{1} C_{n} P_{n}(\mu)=C_{0}+C_{1} \mu
$$

where $\Sigma_{s}$ is the macroscopic scattering cross section, $C_{n}$ are coefficients of Legendre polynomials and $P_{n}(\mu)$ are Legendre polynomials.

The zero and first order coefficients are defined as

$$
C_{n}=\frac{2 n+1}{2} \int_{1}^{1} \Sigma_{S}(\mu) P_{n}(\mu) d \mu
$$

Because a $P_{1}$ representation can be negative over part of the angular range, making sampling difficult, a MUBAR or $\bar{\mu}_{\mathrm{j}, 1, \mathrm{k}}$ is defined as

$$
\bar{\mu}_{\mathrm{j}, 1, \mathrm{k}}=\frac{\int_{-1}^{1} \mu \Sigma_{\mathrm{S}_{1,1, \mathrm{k}}}(\mu) \mathrm{d} \mu}{\int_{-1}^{1} \Sigma_{\mathrm{S}_{\mathrm{j}, 1, \mathrm{k}}}(\mu) \mathrm{d} \mu},
$$

where $\bar{\mu}_{1,1, \mathrm{k}}$ is the average scattering angle for a neutron in mixture $\mathrm{k}$ scattering from energy group 1 to $\mathrm{J}$. $\Sigma_{\mathrm{S}_{\mathrm{j}, \mathrm{l}, \mathrm{k}}}(\mu)$ is the macroscopic transfer cross section of mixture $\mathrm{k}$ for scattering from group $\mathrm{i}$ to $\mathrm{j}$ while scattering through an angle $\cos ^{-1}(\mu)$.

Substituting equation [11] into [13] yields

$$
\overline{\mu_{1,1, k}}=\frac{C_{1}}{3 C_{0}}=\frac{\sum_{\mathrm{n}=1}^{\mathrm{N}_{\mathrm{k}}} \rho_{\mathrm{n}} \sigma_{\mathrm{J}, \mathrm{l}, \mathrm{n}}^{1}}{\sum_{\mathrm{n}=1}^{\mathrm{N}_{\mathrm{k}}} \rho_{\mathrm{n}} \sigma_{\mathrm{J}, 1, \mathrm{n}}^{0}}
$$

where $\sigma^{0}$ and $\sigma^{1}$ are the $\mathrm{P}_{0}$ and $\mathrm{P}_{1}$ coefficients of the transfer cross section and $\rho_{\mathrm{n}}$ 1s the number density of the $\mathrm{n}$ th scatterer in mixture $\mathrm{k} . \mathrm{N}_{\mathrm{k}}$ is the number of scatterers in mixture $\mathrm{k}$. 
If the anisotropic scattering data, $\operatorname{MUBAR}(\bar{\mu})$ is zero, the new direction cosines are chosen from an isotropic distribution If the scattering data are nonzero, the direction cosines are calculated according to the following relationship where $u, v$, and $w$ are the initial direction cosines and $u^{\prime}, v^{\prime}$, and $w^{\prime}$ are the direction cosines after the collision

$$
\begin{aligned}
& \mathrm{u}^{\prime}=\mathrm{u} \cos \psi-\sqrt{1-\mathrm{u}^{2}} \sin \psi \cos \eta \\
& \mathrm{v}^{\prime}=\mathrm{v} \cos \psi+\frac{\mathrm{uv}}{\sqrt{1-\mathrm{u}^{2}}} \cos \eta \sin \psi-\frac{\mathrm{w}}{\sqrt{1-\mathrm{u}^{2}}} \sin \psi \sin \eta \\
& \mathrm{w}^{\prime}=\mathrm{w} \cos \psi+\frac{\mathrm{uw}}{\sqrt{1-\mathrm{u}^{2}}} \cos \eta \sin \psi+\frac{\mathrm{v}}{\sqrt{1-\mathrm{u}^{2}}} \sin \psi \sin \eta
\end{aligned}
$$

where

$\sin \psi=\sqrt{1-\bar{\mu}^{2}}$

$\cos \psi=\bar{\mu}=$ cosine of the scattering angle

$\eta=\mathrm{a}$ random dzimuthal angle between 0 and $2 \pi$ 
In order for a fission to occur, a neutron must first have a collision The fission weight, FISW, is defined as the neutron weight WT times the $\nu$-fission probability, FNFP(KR,IG) of the material KR in which the collision occurred, at the energy of the incident neutron, IG

$\mathrm{FISW}=\mathrm{WT} * \mathrm{FNFP}(\mathrm{KR}, \mathrm{IG})$

Two important variables that are used in the processing of fission points are FWR which is defined as the fission weight, FISW, divided by a random number, and RAKBAR which is defined as 085 times the running average value of k-effective, AKBAR The 085 is an arbitrary factor and was chosen because it appears to produce an adequate number of independent fission points and does not produce so many that an excessive amount of time is spent choosing from the fission points that are produced If experience proves that enough independent fission points are not produced for more than a relatively few generations, it may be necessary to use a reduction factor somewhat lower than 085

A fission point is generated only if FWR is greater than RAKBAR Multiple fissions at the same point are allowed only if FISW is greater than RAKBAR If FISW is greater than RAKBAR, a fission point is stored with FWR set equal to RAKBAR divided by a random number and FISW is decremented by RAKBAR The above procedure is repeated until FISW is less than RAKBAR, at which time a point is selected with FWR equal to the remaining FISW divided by a random number The $x, y$, and $\angle$ position, the location of the box within the array, the region number and the value of FWR are the quantities that are stored in the appropriate arrays if a fission occurs However, only NPB (the number per generation) fission points are kept to be used as fission positions for the next generation Therefore, if a fission occurs and the fission counter, NN, is less than the number per generation, the fission point information is stored If a

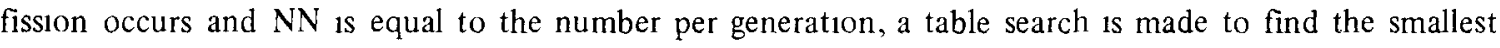
stored value of FWR If FWR of the newly fissioned neutron is less than the smallest FWR in the table, it is discarded Otherwise, the information from the newly fissioned neutron replaces that associated with the smallest value of FWR found in the table

When the next generation is ready to be processed. subroutine NSTART transfers the fission positions into another array to be used as starting positions for the fission neutrons If too few fission positions were stored (less than the number per generation), a message to that effect is printed and additional fission points are randomly chosen from those that were stored until the number of fission starting points is equal to the number of neutrons per generation The energy of each fission neutron is chosen randomly from the fission spectrum of the mixture in which the fission occurred 


\section{LOGICAL PROGRAM FLOW}

\section{Read Parameter Input and Allocate Storage}

In the solution of a KENO IV problem, MAIN calls subroutine MESAGE to print a header page The information contained thereon is the program name, "KENO", followed by the date the problem was run and the time execution was begun MESAGE is called with two arguments, an eight chardcter hollerith argument and an output unit Subroutine FHI PR is called from MESAGE to print the hollerith argument in block letters (eight chardcters is the maximum number of block characters that can be printed across a page) MESAGE then calls DATIM which returns the date and time of day (each eight characters) FHLPR is then called twice to print out the date and the time execution was begun in block letters The first card is read and checked to determine whether it is an "END CASE", "END KENO", or a tutle card It the card is an "FND KENO" or an end of tile was encountered, execution is terminated If it is an "END CASF" (ard, it reads the next card and checks in the same manner When a card is encountered that is not an "END CASE" or "I ND) KE\O" card, it is assumed to be the title card The next card that is read is the parameter card(s) I he parameter intormation is used to determine which input and output units will be used and butfer space is allocated for them

Subroutine ALOCAI is called to determine the maximum dvaldable space for running the problem, based on the amount of core requested for the job, the sle of the program and the amount of space required for the buffers At this point the starting storage location determined br ALOCA $\Gamma$ is passed to KE $\backslash \mathrm{O}$, which prints the title card and parameters If albedos are to be used and the problem is not a restart problem, subroutine RDREF is called to read the reflector constants Then KFNO computes the starting indices for the arrays based on data already read in I he number of storage locations required for the problem and the number of remanning atalable locations are calculated and printed If the latter number is negatise, the problem is too large for the amount of core requested and execution is terminated by executing a $\$ I O P$ If the problem fits in the avalable space, subroutine CLEAR is called and certain of the diravs are zeroed

If velocit, cross-section or albedo datd from the previous case is to be used subroutine SAVI is called to testore the appropriate data

\section{Read Cross Section and Velocity Input Data}

Subroutine INPUI is called and reads velocities from cards if thes are expected If cross sections are to be redd. INPUI calls subroutine XSTAPE which in turn prints the title reads the mixing table cards, prints the mixing table and reads the appropriate microscopic cross section data (including fission spectra, energy levels and lethargy) from the appropiate unit (disc, tape, or caids) In whatever format the parameters indicate (KENO IV, AMPX, or ANISN) If KF NO IV of AMPX format is specitied velocities are calculated trom the energs bounds If AMPX format is used, subroutine S IID is called to store the AMPX 1-dimensional cross section atidis in the proper positions REA is called to store the AMPX $P$ and $P_{1}$ tiansfer ariab in the approprate postions If ANISN format is used, READSG is used to read the cross section data and SIORE is used to store them Depending on the input parameters, the microscopic cross sections will be printed. or a list of their titles will be printed The macroscopic cross sections are then computed for each mixture It any mixing table errors are recognized, an erior message is printed Upon teturning to subroutine INPUT, subroutine AIOINI may be called to create adjont cross sections from the forward cross sections created in XSTAPE if an adjoint problem is to be run I he 
macroscopic cross sections are then used to create cumulative probabilities for use in the calculation At this point, options are avalable to (1) print only the one-dimensional probability tables for edch mixture, (2) print both the one-dimensional and two-dimensional probabilities for each mixture, or (3) bypass printing mixture probability tables the one-dimensional part of the probabilities is printed in INPUT and the two-dimensional part is printed in WARR If a fissionable mixture does not have a fission spectrum associated with it, an error message is printed

\section{Read Geometry Input Data}

It the parameters specify that new geometry datd is to be read, subroutine KENOG is called KENOG prints the problem title and the word "GEOMETRY DESCR IPIION" It then reads the geometry data and the group dependent weight average for each geometry region, numbers the regions inside each box type, writes out the geometry data and stores the geometry data in the proper arrays WTHIGH and WTLOW are calculated from WI AVG as each geometry card is read, and all three arrays dre stored

It the automatic reflector option is to be used, subroutine MAKREF is called it the problem Involves more than one box type, subroutine FILBOX is called from MAKREF to read the mixed box orientation data. At this point. MAKREF calculates a reflector of the desired material and applies the designated thicknesses to the appropridte faces. It dutomatically supplies the weight dverages for the reflector material or can read them from cards At the conclusion of the automatic reflector operation, the program returns to KENOG After all the geometry cards have been read, KENOG calls FILBOX if more than one box type exists and the automatic reflector option has not been invoked FILBOX reads the mixed box orientation data and loads the array that stores the arrangement of the box types If any errors are recognised while reading the mixed box data, error messages are printed Control is then returned to the calling subroutine KENOG prints the geometry information and then prints weight low, weight average, and weight high for each geometry region and energy group

Checks are made to be sure the mixture designation for each geometry region does not fall outside the allowable range and to be sure that certain simple rules governing geometry dimensions or specifications are not violated

If KENOG encountered the geometry word "GENERAl" when reading the geometry description, INPUT calls JOMIN to read the generalized geometry $(05 R)^{8}$ input data. The dimensions on the last "GENERAI" card read by KENOG are automatically set equal to the outer zone boundaries from the generalized geometry data

FILBOX is called from INPUI only if geometry from the previous case is expected and the problem involves more than one box type

It the problem involves more than one box type, subroutine BOX is then called from INPUT BOX prints the problem title and the words "ARRAY DESCRIPTION" The box type arrangement is printed for each $Z$ ldyer with the X-position incredsing from left to right across the page and the $Y$-position increasing from bottom to top If any position in the array contains a box type value less than or equal to zero or greater than NBOX, an error message is printed At this point, control is returned to INPUT and all the geometry data except generalızed geometry data from the previous case is restored, if desired This is done by calling subroutine SAVE If an adjoint problem is to be run, the velocities are inverted unless they came from the previous case.

Subroutine CORSIZE is called by INPUT to calculate the overall array dimensions and check to see that adjacent faces of neighboring box types are the same size. If they are not, an appropriate 
error message is written INPUT then checks to be sure the mixture number for each geometry region is within the allowable range and the core boundary card, if any, exactly encloses the array Control is then returned to KENO. If geometry from the previous case is to be used, KENO calls SAVE to relodd the generalized geometry data

\section{Read Albedo Data}

If albedo data is to be read, KENO calls subroutine ALBIN which in turn reads the expected albedo data from the proper unit and converts it into the probability tables necessary for a differential albedo calculation If any input errors or inconsistencies are encountered, an error message is printed. After returning to subroutıne KENO, the program checks to see if enough space is avallable to calculate the desired number of k-effectives If there is not enough room, the number of k-effectives to be calculated is reduced to fit in the avallable space and a message indicating this tact is printed If the number of k-effectives that can be calculated was reduced to less than 25 , the problem will not be executed Space is now allocated for the arrays that depend on the number of generations that are to be run If the problem is a generalized geometry problem, subroutine LOKSET is called to initialize the generalized geometry subroutines Then KENO calls CLEAR to zero some arrays preceding the generalized geometry data, calculates the array length for the k-effective data and calls CLEAR to zero that array If the restart option is to be used and the number of generations between writing restart data is greater than zero, subroutine RESTRT is called If the problem is not to be restarted from an older run, control is returned immediately to KENO If this is a restart problem, the necessary restart data is read, the starting batch is incremented by I and control is returned to KENO At this point SAVE is called to save data on the scratch unit for any subsequent case that may need it Velocity data, macroscopic cross sections, albedo data and geometry data are included in the saved arrays After rewinding the scratch unit, subroutine JOMCHK is called

\section{Check Geometry Data}

JOMCHK is the geometry checkıng routıne for KENO IV lts function is to make sure that no intersecting regions exist withın a given box type or the reflector. Concentric or nested geometry regions may be tangent and may have faces in common, but they CANNOT intersect Conceptually, JOMCHK simply checks the th region against the $(1+1)$ th region for each box type and the reflector. If intersecting regions are encountered, an error message is written, and the program contınues with its checking until all geometry regıons have been checked, then control returns to KENO

KENO immediately calls subroutine VOLUME which checks to be sure the positive dimension of a given geometry region is greater than the corresponding negative dimension It then prints the title and the word "volumes", calculates and prints the incremental and cumulative volumes for each region in each box type and the reflector and checks to be sure that no incremental volume is negative. It also calculates and prints the total volume occupied by each geometry region in the entıre array This is simply the product of the volume of a given region and the number of times that box type appears in the array The result is printed under the heading "total volumes". If a nonallowable geometry type (the geometry data was incorrect or destroyed) is encountered for the last geometry region, an error message is printed Otherwise, the parameter BIG is set A check is also made to be sure the last geometry card in every box type is a cube or cuboid if it is not, an error message is printed. 
6 Redd Start Data and Pick Starting Points

As soon as control returns to KENO, ITIME is called to determine the time at which subroutine START is called, then control goes to START which prints the start type to be used in this problem If the type of start specified requires more data, it is read using FREAD, IREAD, or both Checks are made to be sure a proper start type was specified for single unit and mixed box problems The startıng points are determined in terms of the $x, y$, and $z$ coordinates of a point, the $\mathrm{X}, \mathrm{Y}$, and $\mathrm{Z}$ index of the box position in the array, and the region number Neutrons are allowed to start only in fissionable material, unless $x, y$, and $z$ are specified, in which case the neutron is started at that point It is required that the same number of neutrons be started as are to be followed for edch generation If too few are started in the maximum number of tries, (the maximum of (100 times the number of neutrons per generation) or (three times the number of neutrons per generation/volume fraction of fissionable material)), the remaining starting points are randomly picked from those already determined A message is printed pertaining to the type of start used and another message tells how many neutrons were started

\section{Read Search Data}

If a search has been specified and it is the first time through START, the sedrch constants are read for each geometry region

After returning to KENO, ITIME is agdin called and the amount of time spent in subroutine SIART is printed At this point KENO checks to see if any errors were encountered in all the operations already completed If errors were found, a message is printed statıng that the problem will not be run, and control returns to MAIN, where the entire procedure is begun again If no input errors were encountered, KENO calls subroutıne BEGIN

\section{Neutron Tracking Loop \\ 81 General Loop Flow}

Subroutıne BEGIN comprises the main body of the program In essence, it consists of two concentric DO loops (the outer one being over the number of generations to be run and the inner one being over the number of neutrons in each generation) inside of which all the neutron tracking takes place The neutron is tracked until it has a collision or escapes from the system The general flow of the tracking procedure is illustrated in Figs 2 and 3 The starting point, region, material, energy and direction cosines for a neutron are determined in the fission starting section, FSTART The path length and end point of the path are then determined in PATH If the neutron is in a generalized geometry region, GEOM is cdlled to return the fraction of the path used If all the path was used without changing regions, a collision occurred, and the section called XSEC is entered to process the collision If the neutron changed medid internal to the generalized geometry region, then $x, y$, and $z$ are updated and PATH is entered as before If the neutron crossed out of the generalized geometry region and into a KENO geometry region, then $x, y$, and $z$ are set and PATH picks new end points If the last crossing was in the outward direction, POSIT determines if the end point is within the same region It it is, a collision occurred and is processed in the XSEC section of BEGIN Fission neutrons are created as described in the FISSION section of THEORY Russian roulette is played and if the neutron survives, a new path is chosen and tracking continues If the neutron falls Russian roulette, it is removed from the tracking procedure and any previously stored split neutrons are tracked 


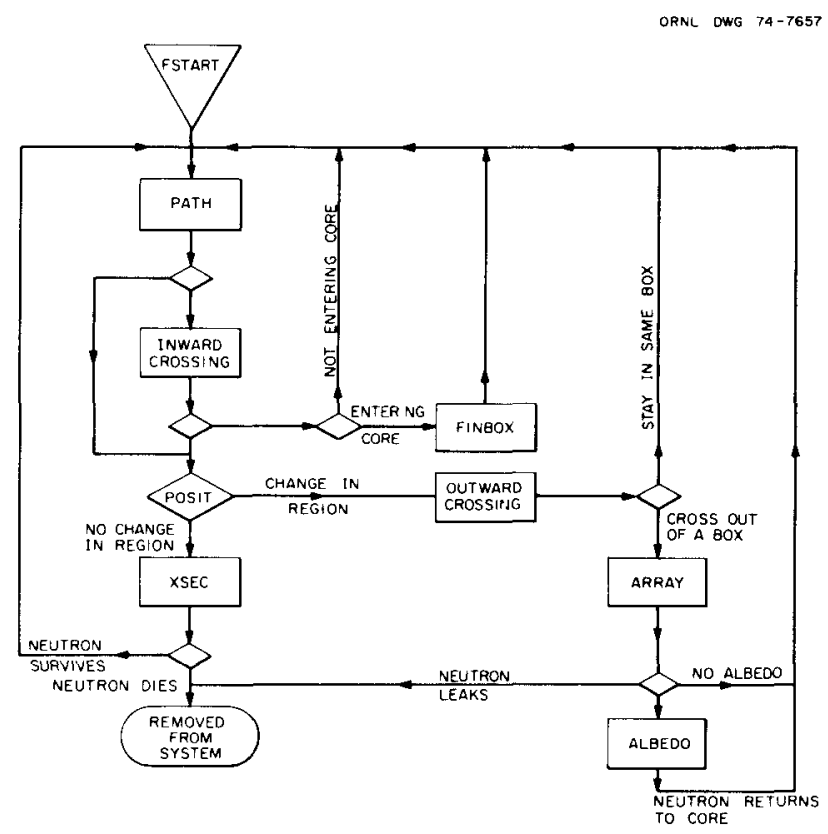

Figure 2. Neutron tracking loop internal to subroutine BEGIN.

ORNL- DWG $74-7658 R$

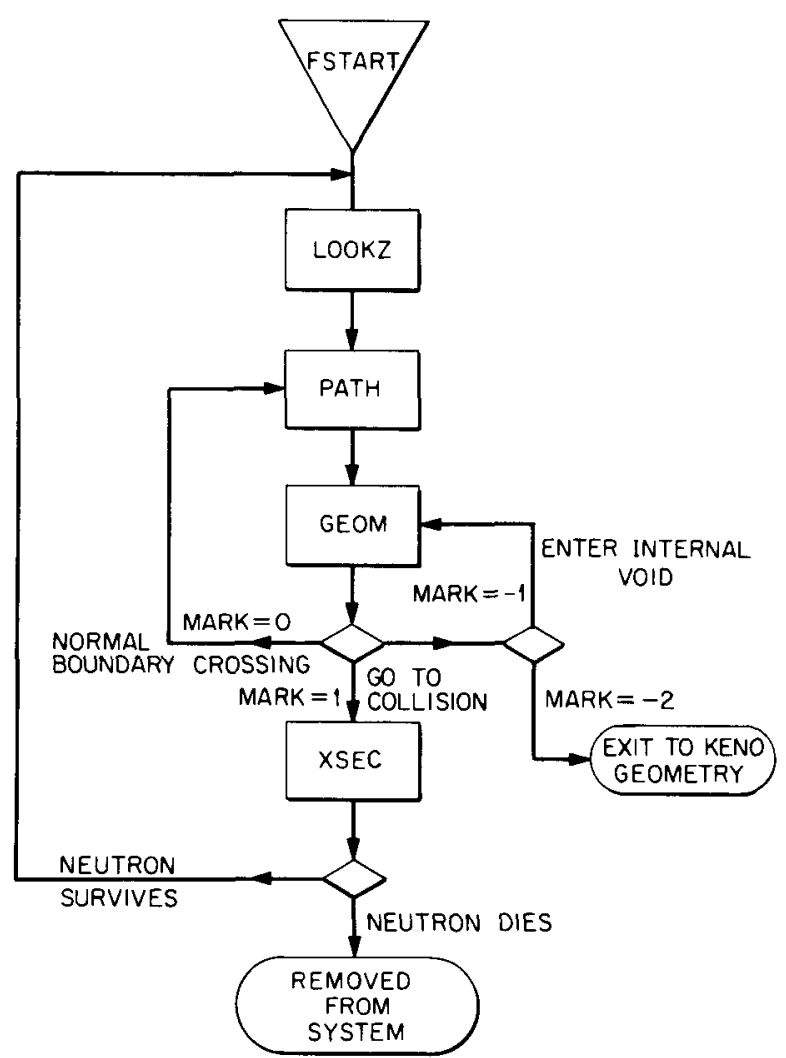

Figure 3. Neutron tracking loop in subroutıne BEGIN for Generalızed Geometry 
If POSIT determines that the neutron's end point is exteinal to the region it was in, subroutine CROS is called CROS determines the point at which a boundary crossing occurred After an outward crossing has taken place, the ARRAY section of BEGIN checks to see if the boundary crossing just indicated by CROS took place on a box boundary Tracking returns to PATH if the crossing was not on a box boundary If the crossing was on a box boundary, the new box type is determined and a transformation of coordinates is made to determine the neutron's position relative to the origin of the new box If the new region number is less than or equal to the maximum for the problem, tracking returns to PATH If the new region number is larger than the maximum, the neutron has left the core through that face A check is made to determine if an albedo reflector was specified on that face, and, if not, the neutron has leaked and is removed from the system The presence of an albedo reflector on that face causes traching to proceed through the ALBEDO TREATMENT portion of BEGIN This section determines if the neutron has leaked or returns the neutron to the system at the same point that it exited The returning energy and angle are determined by ALBEDO If the neutron did not leak, tracking returns to PATH and a new path is chosen

At the time a neutron leaves PATH, if its last crossing was inward and it has moved into another region, a check is made for an inward crossing If an inward crossing did not occur, control goes to POSIT to check for a collision If an inward crossing occurred within a box, tracking returns to PATH If an inward crossing occurred into the core from the reflector, the FINBOX section determines the box coordinates, transforms the coordinates according to the "new" origin, and determines the box type and the new $\mathrm{x}, \mathrm{y}$, and $\angle$ position Tracking then returns to PATH and proceeds as before

\section{PULL - Prevent Looping}

Immediately after entering the number of generdtions loop, subroutine PULL is called from BEGIN at the beginning of each generation to generate a maximum time interval for that generation If this time interval is exceeded, PULL seizes control, writes a message and terminates the problem This helps eliminate the possibility of a problem getting into a loop and wasting large amounts of time

\section{FSTART - Start Fission Neutron}

The first identifiable area inside the number per generation loop is the fission starting section, FSTART Here the neutron starting point, region and material are obtained from the data generated by the previous generation (or subroutıne START for the first generation) The starting energy is chosen using FLTRN and the fission distribution The direction cosines are returned from GTISO which picks from an isotropic distribution

\section{Generalized Geometry'}

Immediately following the fission start section is an area involving operations undertaken if a neutron is in a generalized geometry region Subroutines LOOKZ and GEOM are called to determine the media, the fraction of the path used, whether a collision occurred, and the end point of the path If the starting coordinate and end coordinate of the path are identical in any direction, the end point is changed by a small amount in the proper direction to prevent computational difficulties in the code 


$$
85 \text { PATH - Pick a Path }
$$

In the section called PAIH, if all the path length has been used up, EXPRN choosts a new number of mean free paths from an exponential distribution if the neutron is in a vold. the distance traveled is set equal to three times the maximum chord length of the sistem (BIG) It the neutron is not in a vold, the distance traveled is equal to the path length remaning. divided by the total cioss section The ending coordinates ate determined from the starting coordinates, the distance talseled and the direction cosines Again, if the starting and ending coordinates are identical in any given direction the end point is changed bi a vert small amount in the proper direction

\section{FINBOX - Determine Box Position}

During the tracking procedure. BEGIN utilizes a section called FI\BOX that performs the tiansformation of coordinates that is necessary when a neutron crosses from the reflector into the cole It also determines the $X, Y$ and $Z$ indices of the box the neution is in and uses this information to determine the box type and the region numbers defining the box type

I he section called POSIl determines whether the end point of the path stass within the same geometry region (has a collision) or attempts to cross the boundarv into anothes region

\section{CROS - Boundary Crossing}

Subroutine CROS is called if a boundary crossing is indicated CROS is used tor both inward and outward crossings It determines whether a neutron actualls crosed into the next region If a crossing occuired, the $x, y$, and $/$ coordinates are upgraded to reflect the crosing point, and the fraction of the path length that was used is determined

\section{ARRAY - Cross d Box Boundary}

Another section of BEGI boundary This can occur only when a neutron is moving in an outward direction Each face of the box is checked in order to assure proper posttioning for face, edge and coiner crossings The $\mathrm{X}, \mathrm{Y}$, and or $\mathrm{Z}$ index of the box is updated, a logical flag is set to indicate if the neutron is exiting from the core, and the $x, y$, and or $/$ coordinate of the crossing is set equal to the proper face dimension of the box It the neutron remains within the core, the box type is determined I he code then goes through a transtormation of coordinates to correct for crossing into a new box tvpe of crossing out of the core

\section{ALBEDO - Albedo Reflector Treatment}

It an albedo reflector was present on any face of the array, a section entitled "PSEUDO REFLECTOR TREATMENT" is entered The logic employed in this section is very similar to that in "ARRAY" where each face is checked in sequence If the neutron crossed any given face, subroutine ALBEDO is called to supply the energy group, weight and direction cosines for the neutron returning from the albedo reflector The box index in that direction is reset to the prope value It the weight of the neutron is less than WIL OW (neight low) from the last collision, Russian roulette is used to determine if the neutron survives If it does, its weight is set equal to WTAVG, (weight average) and tracking contınues 


\section{I EAK - Remove Neutron from System}

If the neutron crosses out of the core and no reflector, elther real or albedo, is present, the neutron leaks from the system A neutron also leaks from the system if it passes out of the outer-most region of the reflector in an outward direction If a neutron leaks, its weight is summed into an energy-dependent varlable called FLEAK

Whenever a neutron undergoes a boundary crossing or has a collision, flux and lifetime information is collected based on the path length of the neutron in the region

\section{XSEC - Collision}

If a neutron has a collision, the section called "XSEC" is entered If fluxes ate to be calculated, the new flux contribution is added in The absorption weight and fission weight are calculated based on macroscopic cross section data and weight. WT WT 1 then redetined as WI times the nonabsorption probability If matrix k-effective information is desired, the fission weight is summed into the proper arrays If WI is greater than WTHIGH (weight high), the neutron is split and the necessarv information is stored for later use (This intormation includes weight energi, region box position, neutron position and lifetime) This splitting procedure is continued until the neutron's weight is les than or equal to WIHIGH If the neutron's weight is less than WTI OW Russian roulette is played It the neutron is killed, the tission weight, absorption weight and lifetime information are added into the appropriate banks if it survives, the group to which the neutron satters is determined If that group is larger than the numbet of energv groups an upsatter has taken place and the energy group must be redefined properly If the anisotropk scattering data ( $P_{1}$ datd) is zeio the neutron direction after collision is chosen from an isotropic distribution using GIISO If anisotropic scattering occurred ( $P_{1} d_{d} d a w_{d}$ non/ero) the a/muthal angle is chosen randomls using AZIRN and the sine and cosine of that angle are returned to BEGIN to use in calculating the new direction cosines Now the collision mechanism has been completed and the tission weight, absorption weight and litetime information are added into the appropriate banks

\section{Store Fission Points for the Vext Generation}

If the fission weight divided bi a random number is greater than RAKBAR, 085 times the average k-eftective determined to this point, the collision position is stored to be used as the fission source for the next generation Ihe fission weight is then decremented by RAKBAR I he same test is applied to the remaining fission weight to allow for the possibilitv of storing multiple fission neutrons at the same point If the number of fission points generated exceeds the needed number (number per generation) a test is made to determine whether to save that fission position if it is to be saved, it is stored over the point having the lowest existing value of FWR (tission weight divided by a random number)

If by this time the neutron has not escaped from the system or has not been killed, tracking contunues by picking a new path and contınuing as betore If the neution tracking has been followed to completion, any neutrons that were produced as the result of splitting are followed, one at a time. until they have all been processed in the same manner as the original neutron

\section{Compute Results for Generation}

Alter all neutrons in a given generation have been followed to completion, k-effective for that generation is calculated, lifetime and generation time information is collected, matrix k-effective 
information is generated if it was desired, the running average of $k$-effective is generated (AKBAR), and a test is made to determine if any fission neutrons were generated. If not, a message is written and control is returned to subroutine KENO.

\subsection{NSTAR T - Fission Source for Next Generation}

It no tission neutrons were generated, an error message is printed and execution of the problem is terminated. If fission neutrons were generated, subroutıne NSTART checks to see that the proper number of fission source points to run the next generation were provided If too few fission source points were generated in BEGIN, a message to that effect is printed and the remaining positions are fılled by randomly pıckıng from those that were generated untıl "number per generation" startıng positions are avalable.

\section{Print Generation Results}

If flux and fission density information was requested, the appropriate information is summed into the proper banks. The amount of tıme required to process the generation of neutrons is computed and the generation number, k-effective, elapsed tıme, average k-effective, deviation, and matrix k-effectne are printed

\subsection{WRTRST - Save Restart Data}

If restart information is to be saved and a multiple of NRSIR $\Gamma$ generations (the number of generations between the writing of restart data) have been processed. WR IRS I is called to write the necessary restart intormation on the proper input-output unit

\section{Complete Number of Generations}

A test is then made to determine if the maximum time for the problem has been exceeded If not, the next generation of neutrons is processed just like the previous generation If time was exceeded, the problem is considered completed, the number of generations is redefined as the number completed, and subroutine PULL is called to cancel the last time interial that was set. Control is returned to subroutıne KENO, which immediately calls subroutine KEDII to do the final a nalysis and printing.

\section{Edit and Print Average K-Elfective Results}

KEDIT executes a loop to calculate the average value of $k$-effective and its associated deviation. the range of $\mathrm{k}$-effective for the 67,95 , and $99 / 6$ confidence intervals and the number of historles that were run On the first pass through the loop, it prints the problem title at the top of the page, calculates and prints the generation time, lifetıme, and their associated deviations, and prints a heading for the $k$-effective data. The title and heading are printed at the top of each subsequent page of k-eftective data that is printed. The loop runs from the number of generations to be skıpped to the number of generations that were run. The results of the first 10 times through the loop are printed followed by the results of every fifth pass after that. When the printing is finished, control is returned to KENO. 
10 Execute Search

If $a$ search is to be made, subroutine XXMOD is called XXMOD will not execute if $a$ recognized error has occurred or if less than 10 generations were run A table search is made to determine where the minimum deviation occurred and the k-eftective corresponding to it is used in the calculations done by XXMOD. A check is made to determine if the calculated k-effective is within the specified number of deviations of the desired value of k-effective It it 1 , the search is considered complete, and the converged search data is printed and control is returned to KENO It a coarse-fine search is being made (search type 3 ), the number of allowable iterations is updated, the convergence flag is set true, the search type and number of generations to be executed are updated, the converged dimensions are stored in the OLDXX array and control is returned to KENO If the calculated k-effective did not conform to the convergence criteria, the iteration number is incremented, a message stating the iteration number and maximum allowed iterations is printed, and delta $\mathrm{k}$ is determıned At this point, a check is made to determıne whether to do an array sedrch or a dimension search An explanation of both kinds of searches follows

If the search data specified an array search, subroutine ARAMOD is called to calculate the new array size Upon entering ARAMOD, a check is made on the number of box types If it is a mixed box problem, an error message is printed, the search type is set to zero and control returns to XXMOD If only one box type exists, ARAMOD calculates the number of units in the array, stores it in the proper position, and calculates delta $k$ If it is the first iteration, the number of units in the $X, Y$, and $Z$ directions are stored in the OLDXX array $I$ he multipleer is set to +1 if the calculated $k$ is less than the desired $k$ and to -1 if the calculated $k$ is greater than the desired $k$ If all the sedrch constants are zero, a message is printed, the search parameter is set to zero, and control is returned to XXMOD

If iteration (INTRTN) is the second or any subsequent iteration and the search has not converged, the coefficients necessary for the solution of a linear, quadratic or cubic equation are calculated based on the number of directions in which the array is to be altered The type of equation to be solved is determined on the basis of which coefficients are zero and nonzero (A /ero coefficient in a given direction indicates that the number of units stacked in that direction shall remain unchanged.) If the search has converged, the coefficient calculations and linear, quadratic or cubic equation solution are skipped The new array size is calculated, checks are made to be sure the results fall within the allowable range (an error message is printed if they do not), and the search constants and updated array size information are printed The new array information is stored in OLDXX, and checks are made to be sure the new array size is difterent from all previous iteration results. (If they are not, a message is printed, the search type is set to zero, and control is returned to XXMOD.) If the maximum allowable number of iterations has been exceeded, the search type is set to zero and control is returned to XXMOD Otherwise, the last value of $k$-effective is stored for use in the next iteration and control returns to XXMOD At this point, the iteration is complete. If convergence was achieved, control is returned to KENO Otherwise, subroutine CORSIZE is called to redefine certain geometry data If no reflector is present or the reflector thickness is not to be maintained, control is returned to KENO If reflector thickness is to be maintained, the new reflector dimensions are calculated before returning to KENO

If the search data specified a dimension search, a loop is executed over the number of geometry regions. The number of dimensions involved for each region is determined. If it is the first iteration, the key governing whether the reflector is to be altered is set, and the key indicating convergence for the search type 3 is set. The original dimensions are stored in the OLDXX array. The region number 
is written out, the new dimensions for that region a re calculated based on delta $k$ (the change in k-effective) and the search constants, the new dimensions are stored in the OLDXX array, $d$ check is made to be sure these exact dimensions have not been calculated in a previous iteration, and the new geometry data for that region is printed It the dimensions for the region are the same as those for a previous iteration, a message is printed, the search type is set to zero to terminate the search and control is returned to KENO. (Regions having a zero search constant are exempt trom this condition I herefore, a search should never be made with all search constants set to zero) If the same dimensions had not been calculated previously, the search constants for that region are printed The new value of k-effective is stored for use in the next iteration If the iteration number is equal to the maximum allowed, the search type is set to zero, CORSIZE is called to redefine certain geometry information, and if reflector thickness is to be maintained, the proper operations are executed. Control is then returned to subroutine KENO

It the iteration is the second or a subsequent iteration, the same operations are carried out except the search constants are redefined based on a linear extrapolation using the two previous dimensions and k-effectives and the desired value of k-effective before calculating the new dimensions

When XXMOD returns control to KENO, a check is made to be sure no recognizable errors were encountered If errors were encountered, the search type is set to rero, an error message is written, and subroutine AREAD is called to read cards until it encounters an END KENO, END CASE or "end of file" card If an END KENO card is found, a STOP is executed If an END CASE card is encountered, control is returned to MAIN and the program attempts to execute the next problem

If the error flag is zero, subroutine FINAI E is called to do the final printing and editing for the problem

\section{Final Editing}

Upon entering FINALE, control is immediately returned to KENO if the number of generations executed is less than or equal to the number of generations to be skipped The number of groups that will be written on a page is determined (the maximum is 27) and the title and heading are printed at the top of each page Fissions and absorptions by energy group and region are calculated and the totals are collected If a search is being made and has not converged, only the total leakages, absorptions and fissions are printed. If no seaich is being made or the search has converged, the leakage, absorptions and fissions are printed for each energy group If region-dependent fissions and absorptions were specified, they are printed for each energy group If albedo reflection was specified, a message is printed stating that leakages and absorptions occurring in the albedo portion of the problem are not included in the totals. The total elapsed time is printed.

If a search is being made and has not converged, the calculation and printing of matrix k-effective, fission density, and flux are bypassed. Otherwise, if matrix k-effective by unit was specified, the problem title is printed at the top of a page followed by a heading for the unit number, the $\mathrm{x}, \mathrm{y}$, and $\mathrm{z}$ position, box type, and cofactor $\mathrm{k}$-effective Then three concentric loops running from 1 to NBZMAX, 1 to NBYMAX and 1 to NBXMAX are executed and the unit number, position, box type and cofactor k-effective are printed for each position in the mixed box orientation array. If the unit interaction matrix is to be printed, the heading "FISSION PROBABILITY MATRIX by UNIT" is printed followed by the interaction matrix The problem title is printed at the top of the page followed by the source vector by unit. The average unit self-multiplication and its associated deviation are calculated and printed 
If matrix k-effective by box type was specified, the necessary calculations are done inside two nested loops running from 1 to the number of box types I he problem title, the box type k-effective, and the fission probability matrix by box type are printed If the number of box types is greater than one, the headings "BOX TYPE" and "SOURCE" are printed, followed by each box type and its associated source The problem title is printed, and the heddings "BOX TYPE" and "COFACTOR K-EFFECTIVE" are printed, followed by all the box types and their associated cofactor k-effectives The matrix k-effective, cofactor k-effectıve and source vectors are calculated in subroutine MATK, which uses an iterative method of solving for the principal eigenvalue and eigenvector of a matrix I he source vectors are printed in subroutine I ABI

The fission densities and their associated deviations are calculated for each geometry region It they are to be printed, the problem title is printed, followed by the heading "FISSION DENSIIIES" Each box type is printed, each region within a box is numbered and the fission density, its deviation, and the total fissions are printed for each region in every box type and for each region in the reflector If a generalıed geometry region was encountered a warning message is printed regarding the volume used in the calculation if fluxes are to be calculated, they are calculated and printed in a manner parallel to that used for fission densities The arravs used in the calculation of the flux and fission densities are reroed, and subroutine FREAK is called to print a histogram of the trequency distribution of k-effective

In FREAK, the interval width is set to 4 divided by the number of generations run Halt of this value is added to the average value of k-effective to get the upper interval boundary and hall of it is subtracted trom the average value of k-effective to get the lower interial boundars The number of k-effectives falling within this range is counted and the highest and lowest values of k-effective in the range are stored Some calculations are made to prevent the frequency distribution from exceeding the width of a page by dividing up the storage bins The title 1 s printed at the top of the page A total of four frequency distributions is printed The number of k-effectives falling in each interial is tallied and printed I he first frequency distribution contans the k-effectives for all the generations, the second one contains the last three-fourths of the generations, the third contains the last halt of the generations, and the fourth one contans the last one-fourth of the generations

Control is returned to FINAI E, which in turn ieturns to KENO It no turther search passes are expected, an error message is written if any recognizable errors were found if no errors were found, control returns to MAIN, otherwise, AREAD is called as it was after returning from XXMOD

If a coarse-fine search (search ty pe 3) was being made and the codrse pass converged, the indices used for the number of generation loops in BEGIN are altered and KENO transfers to the point where it calls BEGIV This enables the code to do the first fine pass without wasting the calculations that were done on the coarse pass that converged Otherwise KENO transfers to the point where JOMCHK is called and proceeds as before 


\title{
ALPHABE TICAL SUBROUTINE SUMMARY
}

\begin{abstract}
ADJOIN I
This subroutine is called from INPUT only if an adjoint problem was specified It inverts the cross-section data, the fission spectrum, the energy bounds and the lethargy bounds in the proper manner
\end{abstract}

\section{ALBIN}

If albedo data is expected for a given problem, subroutine AI BIN is called from KENO to read In the necessary datd trom cards or tape It then converts the data to usable probability tables

ALBEDO is an entry point in AI BIN AI BEDO returns the weight, direction cosines and returning energy to subroutıne BEGIN whenever a neutron enters a face having an albedo reflector

\section{ALOCAT}

This subroutine is called from MAIN It determines the maximum storage avalable for a KENO problem based on the amount of core requested and passes this information to subroutine KENO

\section{ARAMOD}

ARAMOD is the subroutine that calculdtes the new array swe for an array search problem it is called from XXMOD

AREAD

Subroutine AREAD is used to read card input datd for KENO IV AREAD reads alphanumeric character datd It is called from KENO, KE VOG and MAKREF

IREAD is an entry point in AREAD It redds free-torm fixed point (integer) data IREAD is called from $P I L B O X, K E \backslash O$ KE\OG, MAIN, MAKREF, STARI and XSTAPE

FREAI) is an entry point in AREAD It reads free-form flodting point (decimal) data FREAI) is called from INPUT. KENO. KENOG, MAIN, MAKREF RDREF SIART and XSTAPF

\section{BEGIN}

Subroutine BEGIN is the main tracking routine for KENO IV It consists of two concentric DO loops, the outer one running over the number of generdtions and the inner one running over the number of neutrons per generation BEGIN is called from KE\O

\section{BOX}

This subioutine prints out the box type arrangement for each /-later in the box orientation arrat It also checks the box orientation for errors and prints out error messages for anv errors it finds BOX is called trom I $\backslash$ PUT 


\section{CLEAR}

Subroutine CLEAR is called from KENO It's function is to zero an array "A" that is of length "L".

\section{CORSIZ}

Subroutine CORSIZ calculates the overall array dimensions and checks to assure that the tangent taces of adjacent boxes are the same size CORSIZE is called from INPUT and XXMOD

\section{CROS}

This subroutine is called from BEGIN and calculates all the boundary crossing information needed by BEGIN in trackıng a neutron. It does both inward and outward boundary crossings

\section{DATIM}

A machıne language subroutıne that determınes the date and tıme and returns them as eight character alphanumeric data. DATIM is called from subroutine MESAGE

\section{FHLPR}

This subroutine is called from MESAGE to print eight block letter characters across a page

\section{FILBOX}

Subroutıne FILBOX reads the mixed box orientation data and stores the three-dimensional arrangement of the box types used in a problem. It is called from INPUT, KENOG, and MAKREF

\section{FINALE}

This subroutine collects and prints fissions, absorptions and leakages by region and energy group if so desired. It also prints the matrix k-effective, cofactor k-effectives, source vectors, the unit interaction matrix and the interaction matrix by box type if requested. Fluxes and fission densities are also calculated and printed FINALE is called from KENO.

\section{FREAK}

Subroutine FREAK is called by FINALE to print four frequency distributions for each problem. All k-effectives, the last three-fourths, the last one-half and the last one-fourth of the k-effectives calculated are used in the plots. The plots are scaled so they do not exceed the page width

\section{INPUT}

This subroutine reads velocities from cards if they are expected It calls XSTAPE to read cross sections and AJOINT to invert cross sections for an adjoint problem INPUT creates and stores the macroscopic cross sections and probabilities used in the problem solution. It sets the dimensions of the last general region equal to the outer zone boundaries. It also checks to be sure the mixture 
numbers on the geometry cards fall within the allowable range, and if a reflector is present, it makes sure the core boundary exactly encloses the array Input is called from KENO

\section{JOMCHK}

Subroutine JOMCHK is called by KENO to be sure that the regions within a given box type or the reflector do not contain intersecting surfaces Each successive geometry region must completely enclose the one before it They can have common faces or be tangent, but they must not intersect

\section{KEDIT}

Subroutine KEDIT is called from KENO after all the generations have been calculated for a given pass KEDIT calculates and prints the average $k$-effectives and their associated deviation for the 67,95 and $99 \%$ confidence intervals It also calculates and prints the number of histories used in calculating each $\mathrm{k}$-effective that is printed

\section{KENO}

Subroutine KENO computes the starting indices for the data arrays, prints the title and input parameters, calculates the amount of storage locations required for the problem and the amount of storage left over It also directs the calling of the basic subroutines governing the flow used in the solution of a problem

\section{KENOG}

This subroutine reads and prints the geometry description of a problem If the automatic reflector option is invoked, it calls MAKREF It checks to be sure each geometry type encountered is a valid one It also reads in the energy-dependent weight average for each geometry region and calculates and stores the values of weight high and weight low The weights are printed out after all the geometry data has been printed KENOG is called from INPUT

\section{LABL}

Subroutıne LABL is a printıng subroutıne It prints from one to a maximum of five sets of headings (two per set) across the page Under each heading is a column of up to 50 numbers Each set of numbers consists of an integer number and a floating point number LABL is called from subroutine FINALE to print the source vector by unit and the source vector by box type

\section{MAIN}

This subroutine prints the KENO IV header page, reads the title card and parameters, sets up buffer space for the necessary input and output units, and calls subroutine ALOCAT

\section{MAKREF}

Subroutine MAKREF is called from KENOG to calculate a reflector of the desired material and thickness on the designated faces It supplies the energy-dependent weights and weighting intervals, calculates all the necessary regions in the reflector and applies the approprate weights to each regıon 


\section{MATK}

MATK solves for the principal eigenvalue and eigenvector of a matrix using an iterative technique It is called from BEGIN to calculate matrix $k$-effective and from FINALE to provide cofactor k-effective and source vectors

\section{MESAGE}

Subroutine MESAGE is called from MAIN to print the hedder page It in turn calls FHI PR and DATIM

\section{NSTART}

NSTART is called from BEGIN at the end of each generdtion to provide neutron starting positions for the next generation This is accomplished by adjusting the number of fission neutrons to be equal to the number per generation by randomly repeating existing fission positions if too few were stored in BEGIN

\section{POSIT}

Subroutine POSIT is called from START to determine which region in a box a neutron at position $x, y, z$ is in

\section{PULL}

Subroutine PULL is an assembly language subroutine that interfaces the program with the system clock routines It sets the time interval supplied in the calling sequence When the interval expires, the program execution is interrupted and control is returned to the statement number supplied in the calling sequence as a nonstandard return This is done to prevent excessive time loss due to looping

Subroutine ITIME is an entry point in PULL It returns the current execution time in units of hundredths of a second

\section{RANDNUM}

RANDNUM is d random number package, written in machıne langudge, containing many entry points Entry points utilized in the solution of a KENO IV problem are listed and summaried below

AZIRN randomly picks an dzımuthal angle and returns the sine and cosine of that angle to the calling program AZIRN is called from START, BEGIN and ALBIN

EXPRN randomly picks from an exponential distribution EXPRN is called from BEGIN

FLTRN picks a random number between zero and I FLTRN is called from ALBIN, BEGIN, NSTART, and START

GTISO picks direction cosines from an isotropic distribution, and is called from BEGIN and STAR I 


\section{RDREF}

Subroutıne RDREF reads the reflector constants for an albedo problem, stores the kind of albedo to be used on each face, and determines how many different albedos are involved. It also checks to be certain that the albedo key NXX is consistent with the reflector constants read in. A message is printed statıng how many differential albedos will be read, whether albedos were used from the previous case, and the albedo ID number of the albedo that will be used on each face RDREF is called from KENO.

REA

Subroutine REA reorders the coefticients of the AMPX $P_{1}$ and $P_{1}$ transfer arrays to be compatible with KENO and is called from XSTAPE

\section{READSG}

READSG is called trom XSTAPE to read ANISN cross-section data from cards.

\section{RESTRT}

Subroutine RES I RT is responsible for reading and writing restart data The restart data is read If the start type is negative, the starting generation is incremented by $I$ and control is returned to the calling program RESTR $\Gamma$ is called from KENO.

WR TRSI is an entry point in RESIRT. It is called from BEGIN to write out and save restart data at given generation intervals so a problem can be restarted at the desiled point without losing the advantage of calculations that were already completed

FINRSI is an entry point in RESTRT It is called trom KENO if restart data is to be read It reads through the sets of saved restart data untıl it finds the designated starting point, reads and stores that data and check, to be sure the saved data is compatible with that specified in the problem to be restarted it discrepancies are encountered, error messages are written.

\section{SAVE}

This subroutine is used to write out data that may be used in a subsequent case and to read in data from the previous case for use in the current problem It is called from INPUT and KENO.

\section{STAR I}

Subroutine SIART is called from KENO to provide the starting positions for the first generation of neutrons Veutrons are allowed to start only in fissionable material unless $x, y$, and $I$ are specified, in which case the neutron is started at that point. I he starting positions are chosen from the desired starting distribution I he allowable distributions include flat over the array, cosine over the atray, an arbitraly fraction started in unit $\mathrm{N}$ with the remainder started in a cosme distribution about unit $\mathrm{N}$, all started at position $x . y$, in unit $N$, all started at position $x, y, z$ in box type $M$ with a flat distribution over units of box type $M$, a flat distribution in fissile material in units of box type $M$. and an arbitrary starting distribution in which all starting points are read fiom cards. 


\section{STORE}

This subroutine is called from XSTAPE to store the ANISN one-dimensional cross-section data

STOREl is an entry point in STORE It is called from XSTAPE to store the ANISN two-dimensional cross-section data

\section{STID}

I his subroutine is called from XSTAPE to store the AMPX one-dimensional cross-section data in the proper drrays

\section{TIMFAC}

This subroutine is called from KENO It is used specifically at ORNL to return a variable called FACTOR that is dependent on which local computer is being utilized FACTOR is then used to modify TMAX in subroutine KENO The non-ORNL KENO IV user should write a dummy TIMFAC that returns a FACTOR of 10

\section{VOLUME}

Subroutine VOLUME is called from KENO to calculate and print the incremental and cumulative volumes for each region in each box type and the reflector It also calculates the total volume in the entire array that is occupied by each region VOLUME also makes simple checks to be sure the input dimensions are not "wrong side out", that volumes do not become negative, that each box type contains at least one region, and that the last geometry region in every box type is a cube or cubold

\section{WARR}

This subroutine is called from INPUT and XSTAPE to print the two-dimensional part of the input cross section data (microscopic cross sections) and the two-dimensional probabilities for each mixture (macroscopic cross sections that have been summed and normalized to supply probabilities)

\section{XSTAPE}

Subroutine XSTAPE is called from INPUT to read and print the mixing table and to read the approprate microscopic cross-section data, fission spectra, energy levels and lethargies from disc, tape or cards in the desired format (KENO IV, AMPX, or ANISN)

\section{XXMOD}

Subroutine XXMOD is called from KENO It calculates new dimensions for specified geometry regions in a dimension search problem 


\section{KENO-GENERALIZED GEOMETRY INTERF ACE5}

The following subroutines are called from KENO if a generalized geometry region is encountered

GEOM - determines track length and boundary crossing information

JOMIN - reads generalized geometry input data

LOKSET - initializes the generalized geometry routines with array addresses

LOOKZ - locates $x, y$, and $z$ in generalızed geometry 


\section{KENO ERROR MESSAGES}

KENO IV prints error messages whenever an error is recognized If a severe error is encountered, an error flag, MFLAG, is incremented and data reading contınues When all the data has been read, MFLAG is checked and if a severe error was encountered, the code will not execute the problem There are a few errors that will cause termination of the data input at the time they occur rather than continuing on until all input data has been read The following table lists the subroutines and the type of data they process.

Table 1 Directory of the type of data processed by edch subroutine

\begin{tabular}{ll}
\hline Subroutine & Type of Data \\
\hline KENO & Parameters \\
AREAD & All data \\
RDREF & Parameters \\
INPUT & Cross section \\
XSTAPE & Cross sections \\
KENOG & Geometry \\
MAKRE & Geometry \\
CORSIZ & Geometry \\
TILBOX & Geometry \\
BOX & Geometry \\
ALBIN & Albedo \\
VOLUME & Geometry \\
RESTART & Restart data \\
START & Start \\
POSIT & Start \\
BLGIN & Lxecution \\
MATK & Execution \\
CROS & Lxecution \\
KEDIT & Summarization \\
XXMOD & Sedrch execution \\
ARAMOD & Search execution \\
I INALE & Summarization \\
\hline
\end{tabular}

I he error messages are more or less arranged in the order in which the subroutınes are called, and within each subroutıne, in the order the messages appear Error messages for errors encountered in processing the input parameters are printed by KENO, AREAD, and RDREF after printing the parameters and before the following messages

$S$ IORAGE LOCATIONS REQUIRED FOR THIS JOB =

REMAINING AVAILABLE LOCATIONS =

If the above messdges are written but none of the geometry data is printed, an error occurred in processing the input cross-section data in AREAD, INPUT, or XSTAPE

If the heading GEOMETRY DESCRIPIION is printed but STARI TYPE = _ has not been printed, an error occurred in processing the geometry data in AREAD, KENOG, MAKREF, CORSIZ, FILBOX, BOX, or VOL UME 
If the above message is printed but MINUTES WERE REQUIRED FOR SIARTING. was not printed, an error was encountered in using the start data or search data in subroutines AREAD, SIART, or POSIT. If the problem is a search problem, the heading READ SEARCH DATA is printed before an attempt is made read the search data.

At this point, all the input data has been read in. If the following message is written, a careful search through the printout prior to this message will reveal at least one other error message *********K-EFFECTIVES WERE NOT CALCULATED FOR I HIS PROBLEM BECAUSE ERRORS WERE ENCOUNTERED IN THE INPUI DATA*********

Even if the input data has been read in without triggering a fatal error flag, some error messages may be printed during execution if certain conditions are volated These messages will appear somewhere after the following heading

GENERATION, K-EFFECIIVE, ELAPSED IIME (MIN), AVG K-EFF, IDEVIAIION, MAIRIX, K-EFF

These messages will originate in BEGIN, MATK or CROS At completion of a problem a heading stating

LIFETIME $=\ldots \ldots \pm \ldots \ldots$ GENERAIION TIME $=\ldots \ldots \pm \ldots$ is printed unless the following message is printed

NUMBER OF BATCHES RUN IS INSUFFICIEN I TO FDI]

Any messages appearing after either of these messages originate in KEDII, XXMOD, ARAMOD. or FINALE

Always check through the computer printout to make sure no error messages were printed and the input data was entered correctly

Error messages as printed by each subroutine are listed as follows

I he following error messages are found in subroutine KENO

1 THE SEARCH TYPE WAS INCORRECTLY SPECIHIED, NO SEARCH WII I BE MADE

The search parameter NSCH was less than zero or greater than 3

2. **WARNING***WARNING***WARNING***WARNING***WARNING***WARNING** MATRIX CALCULATIONS CANNOI BE MADE FOR A SINGLE UNII, A $1 \times 1 \times 1$ ARRAY OR AN ARRAY SEARCH. THE MATRIX FLAG HAS BEEN SET TO ZERO

**WARNING***WARNING***WARNING***WARNING***WARNING***WARNI W $^{* *}$

A matrix calculation was specified for a single-unit problem, a one-unit array, or an array search problem.

3. **THIS PROBLEM SPECIFIED DATA FROM A PREVIOUS CASE WHICH CONTAINED ERRORS, DID NOT EXIST, OR TERMINATED WITH AN END CASE CARD.**

The error flag MFLAG is greater than 1, indicating that an "END CASE" card was encountered when attempting to read input data or an error was found in a case from which data was to be used for the present case Often this error simply indicates that the input parameters are out of order 
$4 * * * * *$ ALBEDOS CANNOT BE USED WITH A SINGLE UNIT PROBLEM. THIS PROBLEM WILL. NOT BE RUN.*****

The parameter NXX was not zero and the input parameter NBOX was cero It albedo is truly desired for a single-unit problem, the last geometry region must be a cube or cuboid, NBOX must be one, and NBXMAX $=$ NBYMAX $=$ NBZMAX $=1$.

5. *****AN ARRAY SEARCH CANNOJ BE SPECIFIED FOR A SINGLE UNII PROBLEM THIS PROBLEM WILL NOT BE RUN *****

NSCH was 2 and NBOX was zero on the parameter card (Beware NBOX prints as one on the computer printout because the single unit logical flag is set true if $\mathrm{NBOX}=0$. Then NBOX is set to 1). The parameters are out of order or the problem was incorrectly specified

6. \$\$\$NUMBER OF GEOMETRY CARDS ( ) DOES NOI AGREE WITH THE NUMBER ( ) SPECIFIED FOR THE PREVIOUS CASES\$S.

The problem specifled geometry from the preceding case, but the number of geometry regions, KREFM, specified on the parameter cards of the two cases does not agree The parameters may be out of order or the problem was incorrectly specified

7. \$\$\$I HE NUMBER OF BOX TYPES ( ) DOES NOT AGREE WITH THE NUMBER( ) SPECIFIED FOR THE PREVIOUS CASES\$S

The problem specitied geometry from the preceding case, but the number of box types, NBOX, does not agree for the two cases. The parameters are out of order or the problem was incorrectly specitied.

8 \$\$\$ALBEDOS FROM THE PREVIOUS CASE WERE SPECIFIED BUT NO ALBEDOS WERE USED IN THE PPEVIOUS CASE\$\$

I he parameters are out of order or the problem was incorrectly specified.

9. \$\$\$IHE NUMBER OF ENERGY GROUPS (, DOES NOT AGREE WITH IHE NUMBER ( ) SPECIFIED FOR THE PREVIOUS CASES\$S.

The number of energy groups, NGP, does not agree for the two cases. The parameters are out of order or the problem was incorrectly specified. The number of groups must always be the same as the previous case when using data from the previous case

10. \$\$ $\$$ THE NUMBER OF DOWNSCA I TERS（ ) DOES NOT AGREE WITH THE NUMBER ( ) SPECIFIED HOR THE PREVIOUS CASE\$\$

The number of downscatters, NDS, does not agree for the two cases. The parameters are out of order or the problem was incorrectly specified

11. **WAR NING***WAR NING***WARNING***WAR NING***WARNING***WARNING** DATA FROM THE PREVIOUS CASE WAS SPECIFIED BUT INCONSISTENCIES WERE ENCOUNTERED. EXECUTION HAS BEEN CANCELED.

**WARNING***WAR NING***WAR NING***WARNING***WARN ING***WARNING** The necessary parameters did not agree between the two cases when data from the preceding case was specified.

12. ${ }^{* * * * *}$ CROSS SECTIONS FROM THE PREVIOUS CASE CANNOT BE USED UNLESS BOTH PROBLEMS ARE FORWARD OR BOTH ARE ADJOINT.*****

The units digit of the parameter NADJ must agree if cross sections from the preceding case are specified. 
$13 * * * * *$ DIFFERENTIAI AI BEDOS CANNOT BE USED IN AN ADIOIVI PROBL EM $* * * * *$

The parameter VXX was incorrectls specified or the data was out of order specular reflection $(N X X=1)$ can be used in an adjoint problem but differentlal albedos $(N X X=2)$ cannot

14 TOO MANY STORAGE LOCAIIONS REQUIRED, THE PROBI EM IS IOO LARGF IO FIT I I HE AVAII ABLE SPACE

Increase the region allocated for this step sufficiently to contan the problem For IBM uscrs increase the region allocated for this step by four times the absolute value of the REMAIVING, AVAll ABLE LOCAIIONS which is printed out immediately preceding this message

15 *WARNING***WARNING****WARNING****WARNING****WARNING***WARNING* NUMBER OF GENERATIONS WAS REDUCED FROM TO TO FII AVAILABLE STORAGE

IF THIS REDUCTION ALLOWS LESS THAN 25 GENERAIIONS THE EXECUTION PHASE HAS BEEN CANCELED

*WARNING***WARNING****WARNING****WARNING****WARNING***WARNI ( ${ }^{*}$ To eliminate this problem, increase the region allocated for this step see KENO core $s / 4$ requirements

$16 * * * * * * * * *$ K-EFFECTIVES WERE NOT CAICULATED FOR THIS PROBI LM BECAUSE ERRORS WERE ENCOUNTERED IN THE INPUT DATA **********

Check through the printout prior to this message At least one other error message will bc printed Correct the input errors and this message will go away

The following error messages are printed in subroutıne AREAD

$1 * * * * *$ ERROR IN INPUT CARD IMAGE PRINTED ON NEXI LINE *****

An invalid character was encountered in the printed card Either a key punch error was found or the data is out of order

2 ON THE ABOVE CARD, CHARACTER NUMBER, , (IMAGE = ) IS NOT VALID IN AN IN TEGER FIELD

The card is mispunched or out of order

3 ON IHE ABOVE CARD, CHARACIER NUMBER, , (IMAGE = ) IS NOT VALID IN A FLOATING FIELD

The card is incorrectly punched or out of order

Subroutine RDREF prints the following error message

$1{ }^{* * * * *}$ NXX DID NOT SPECIFY DIFFERENTIAL ALBEDOS BUT THE SURFACE DID THE PROBLEM WILL NOT BE EXECUTED $* * * * *$

The parameter NXX was one but at least one reflector constant, REFCST, was positive The problem is incorrectly specified or the cards are out of order

The following error messages are printed in subroutine INPUT

1 MIXTURE ( ) CONTAINS A FISSIONABLE MATERIAL BUT NO FISSION SPEC TRUM WAS SPECIFIED THE PROBLEM WILL NOT BE EXECUTED

A fission cross section existed for the mixture specified but no material in that mixture was preceded by a minus sign 
2. THE MIXTURE NUMBER ON GEOMETRY CARD ( ) DOES NOT FALL IN THE SPECIFIED RANGE

MAT(I), the entry following the geometry word on the specified geometry card was negative or was larger than the number of mixtures (MATT) specified in the parameters

3. THE INSIDE REFLECTOR DIMENSION DOES NOT EQUAL THE NUMBER OF UNITS TIMES THE UNIT DIMENSIONS

The core boundary is calculated by summing the dimensions of each unit in the array in each direction If the dimensions thus computed do not agree with those specified on the CORE card, this message is printed Either the array sice (NBXMAX, NBYMAX, NBZMAX) was incorrectly specified, a box dimension was incorrectly specified, the mixed box orientation is incorrect or the CORE card is incorrect

The following error messages occur in subroutine XSTAPE

1. ***IHE NUMBER OF NUCLIDES REQUESTED FROM TAPE IS INCONSISIENT WITH THE TOTAL NUMBER SPECIFIED FOR THE PROBLEM ***

The parameter NIAPE, the number of cross sections to be read from tape, is larger than the parameter NMA I, the number of input nuclides The data is mispunched or out of order

2 THE MIXTURE NUMBER DOES NOT FALL IN THE SPECIFIED RANGE.

When reading the mixing table, one of the mixtures, $\mathrm{KKA}(\mathrm{I})$, was zero or negative or was larger than the number of mixtures, MATT, specified in the parameters Either the data is mispunched or is out of order

3 CHECK INPUT DATA AND TAPE FOR CONSIS IENCY EITHER IHE NUMBER OF GROUPS OR I HE NUMBER OF DOWNSCATTERS ARE IMPROPERI Y STATED
NDS $=$
$\operatorname{NDS} 1=$
$\mathrm{NGP}=$
VGPI =

I he wrong tape was mounted or the parameters are incorrectly specified NDS and NGP are parameters stated in the problem NDSI and NGPl are read from the tape

4. A $\Gamma$ LEAST ONE NUCLIDE WAS NOT FOUND ON THE LIBRARY I APE

A LIST OF THOSE REQUES TED FOLLOWS

The number of nuclides found on the tape is less than the parameter NTAPE (the number of nuclides to be read trom tape) Either NTAPE is incorrectly specified, one of the ID numbers was incorrectly specified, the wrong tape was mounted, or one of the nuclides requested was not on the tape

5 THE MIXING IABLE CONTAINS MORE NUCLIDES THAN REQUESTED IN IHE PARAMETERS

\section{A LIST OF THOSE REQUES IED FOLLOWS}

The number of requested nuclides is more than NMAI (the number of input nuclides) Either NMAT was incorrectly specified, or one or more of the input nuclide ID's were incorrectly specitied

The following error messages are tound in subroutine KFNOG

1. *****A SINGLE UNIT PROBLEM CANNOT HAVE A CORE BOUNDARY REGION *****

It a reflector exısts, simply include those regions in KREFM and remove the core boundary card An alternative is to change NBOX from 0 to 1 and set $\mathrm{NBXMAX}=\mathrm{NBYMAX}=$ NBZMAX $=1$ and leave the core boundary card in 
2. WARNING ... A CORE BOUNDARY CARD IS REQUIRED ONLY IF AN EXTERNAL REFLECTOR IS PRESENT.

NOIE . A CORE BOUNDARY CARD IS NOT REQUIRED FOR ALBEDO REFLECTION.

This is just a warning messsage and does not cause termination of the problem. It does cause the problem to run less efficiently.

3 UNRECOGNIZABLE GEOMETRY WORD MATERIAL

The geometry word is not one of those specified in the data guide. Either the card was mispunched or the data is out of order. Check to be sure the proper number of dimensions, the mixture number and the proper number of weights are on the preceding geometry region

4. AN ERROR WAS FOUND IN THE HEMISPHERE DESIGNATION.

The geometry word did not correctly specify the direction in which the hemisphere exists

5. **********ERROR ... NHCYL $=\quad * * * * * * * * *$.

The hemicylinder geometry word was incorrectly specified.

6 MIXTURE IS NOT SPECIFIED IN THE MIXING TABLE

The mixture number MAT (I) specified on the previous geometry card is less than zero or greater than the parameter MATT (the number of mixtures in the problem). The data was mispunched or is out of order

$7 * * * * * * * * *$ NEGA TIVE WEIGHTS ARE NOT ALLOWED. THE PROBLEM WILL NOT BE RUN **********

One of the input values of weight average was negative. I he data was mispunched or out of order.

8.

ALBEDOS CANNOT BE USED UNLESS THE OUTERMOST GEOMETRY REGION IS A CUBE, CUBOID, OR GENERAL REGION.

Either the albedo key NXX was incorrectly specified or the outermost geometry region was not a cube, cubold, or general region

9. NUMBER OF BOXES ON PARAMETER CARD DOES NOT AGREE WITH BOX DATA READ IN

NBOX $=\quad$ ITP $=$

NBOX is the parameter stating how many box types are in the problem ITP is the number of box types that were encountered when reading the geometry data. Either NBOX was incorrectly specified, the geometry data was incorrectly entered, or the parameter KREFM (the number of geometry cards to be read) was too small.

10 END OF CASE FLAG READ IN GEOMETRY DATA.

More geometry datd was specitied than was found. Either the parameter KREFM (the number of geometry cards to be read) was too large, too few geometry cards were included. or too few entries were made for the material, dimensions, or weights. The data may be incorrectly punched or improperly arranged.

11 END OF KENO FLAG READ IN GEOMETRY DATA.

The explanation is the same as 10 above. 
The following error messages appear in subroutine MAKREF

$1 * * * * *$ KREFM WAS NOT L ARGE ENOUGH TO ALLOW ANY REFLECTOR REGIONS I HE PROBLEM WILL NOT BE RUN *****

The geometry word REFIECTOR has been encountered, invoking the automatic reflector option However the parameter KREFM the number of geometry cards to be redd, is too small KREFM must include the number of regions you wish to be made in the reflector, just as though the cards were actually punched see the datd guide for full detals

$2 * * * * *$ A WEIGHTING ID OF WAS SPECIFIED USING ENERGY GROUPS BUI I $\Gamma$ WAS NOT FOUND ON I APE

The weighting ID, IDWT was greater than 10 but was not found on the tape with the specified energy group structure Either IDWT or NGP was incorrectly specified or the wrong tape was mounted

$3^{* * * * * A}$ WEIGHTING ID OF WAS SPECIFIED USING ENERGY GROUPS BUT II WAS NOT FOUND ON CARDS *****

The weighting ID, IDWT was less than 10 but was not found on the input cards with the specified energy group structure Either IDWT, NGP or the weights from cards are incorrect Check the data guide for more detals

The following error message appears in subroutıne COR SIZ

1 *****THE — DIMENSIONS OF BOX TYPE _ _ AT ( — _, — $)$ DO NOT MATCH THOSE OF BOX I YPE _ AT ( _ _ _ $)^{* * * * *}$ FOR BOX TYPE $\_+\ldots=\ldots$ AND $-\ldots=-$ WHILE FOR BOX TYPE $+\ldots=\ldots \mathrm{AND}-\ldots$

This message appears because the common faces of adjacent boxes are not the same suze One or more of the dimensions of one of the box types specified in the message may be incorrect or the mixed box orientation data mav be incorrect

The following error messages appedr in subrout me FILBOX

\section{ARRAY DESCRIPTION ERROR MESSAGES}

This message appedrs only if errors were encountered in the mixed box orientation data One of the following messages will also be printed

2 MIXED BOX ORIENTATION CARD NUMBER CONTAINS _ ERROR(S)

This message can appear no more than 10 times It tells which card is in error and occurs only if some of the conditions explaned in 3 , below, exist

$3 \mathrm{LTYPE}=\_\mathrm{IX} 1=-\mathrm{IX} 2=-\mathrm{INCX}=\_\mathrm{IY} 1=-\mathrm{IY} 2=-$
$\mathrm{INCY}=-\mathrm{IZ} 1=-\mathrm{IZ2}=\_\mathrm{INCZ}=-$

This message appears in conjunction with error message 2 , above, and is written if

(a) LTYPE (the box type) is less than or equal to zero or if LTYPE is greater than the parameter NBOX, the number of box types,

(b) If IX1, IY I, or IZI is less than one,

(c) if IX2 is less than IX1 or greater than NBXMAX, if IY2 is less than IY1 or greater than NBYMAX, or if IZ2 is less than IZ1 or greater than NBZMAX,

(d) if INCX, INCY, or INCZ is not positive

Any of the above may result from data being mispunched or out of order Further clarification may be derived from the data guide 
4 THE ABOVE MIXED BOX ORIENTATION CARD(S) CONTAIN(S) AT LEAST ONE OF THE FOLLOWING ERRORS

This message follows message 3 , above, if any errors wele found The messages listed in 5 , below, then follow

5 I IXI, IYI, IZI, INCX, INCY, or INCZ IS LESS THAN OR EQUAL TO ZERO

2 IX2 IS LESS THAN IX1, IY2 IS LESS THAN IY1, OR IZ2 IS LESS THAN IZ1

3 IX2 IS GREATER THAN NBXMAX, IY2 IS GREATER THAN NBYMAX, OR IZ2 IS GREATER THAN NBZMAX

4 LTYPE IS LESS THAN 1 OR GREATER THAN NBOX

These error messages are printed if errors are found in the mixed box orientation data The parameters NBOX, NBXMAX, NBYMAX, or NBZMAX may be incorrectly specified, but more than likely the mixed box orientation cards are incorrectly punched

The following error messages appear in subroutine BOX

$1 * * *$ AN ERROR EXISTS IN THE ARRAY DESCRIPTION ***

$X$ INDEX $=$

$\mathrm{Y}$ INDEX $=$

$\mathrm{Z}$ INDEX $=$

This message occurs if the box type stored in the mixed box onentation array, the array showing the position of each box type in the arrdy is less than or equal to zero, or greater than NBOX, the number of box types in the problem This error usually results from ledving some positions in the array unfilled or from mispunching the mixed box orientation data Check the mixed box orientation array printout at the position indicated in the message and correct the input data

The following error messages appear in subroutıne ALBIN

$1 * * * *$ WARNING THE NXX PARAMETER INDICATED DIFFERENTIAL ALBEDOS BUT NONE WERE SPECIFIED ON THE REFLECTED FACES *****

This error occurs if $N X X=2$ or 3 and the reflector constants are all entered as zero or negdtive ( 1 e, none of the reflector constants (card 4 ) are positive)

$2 * * * * * \quad$ DIFFERENTIAL AIBEDOS WERE

COULD BE FOUND *****

THE ALBEDOS SPECIFIED WERE

One of the albedo ID's was incorrectly specified or too few sets of albedo data were avallable

$3 * * * *$ DIFFERENTIAL ALBEDO WAS SPECIFIED TO BE USED FROM THE

PREVIOUS CASE, BUT COULD NOT BE FOUND *****

THE FOLLOWING DIFFERENTIAL ALBEDOS ARE SAVED FROM THE PREVIOUS CASE

$\mathrm{ID}=$ ID $=$ $\mathrm{ID}=$ ID $=$ , etc

This message occurs if the specified albedo was not found in the saved data The data is mispunched, incorrect or out of order

The following error messages appear in subroutine VOLUME

1 REGION NUMBER _ C CONTAINS AN ERROR IN THE DIMENSIONS

This message occurs if the positive $\mathrm{x}, \mathrm{y}$, or $\mathrm{z}$ dimension is smaller than the negative $\mathrm{x}, \mathrm{y}$, or $\mathrm{z}$ dimension The data is mispunched or out of order The positive dimension in a given direction must always be more positive than the negative dimension in that direction 
2 THE VOLUME DEFINED BY GEOMETRY CARD IS NEGATIVE

This message occurs if the volume of any region becomes negative This usually results from incorrect nesting of the regions

3 A BOX VOLUME MUST BE GREATER THAN ZERO

This message occurs if the cumulative volume over a given box type is negative, data is incorrectly punched, the data is out of order, or a box is specified with no geometry regions

4 INVALID GEOMETRY ENCOUNTERED FOR THE LAST GEOMETRY REGION $\mathrm{IGEO}=$

The last geometry card was not one of the allowed types The data was entered incorrectly or the storage arrays have been destroyed

5 THE LAST GEOMETRY CARD IN THE UNIT MUST BE A CUBE OR CUBOID

This message occurs if the last region in a given box type is not a cube or cubold The data is incorrectly punched or out of order

The following error messages occur in subroutıne RESTRT

1 THE NUMBER OF GENERATIONS SPECIFIED IN THE RESTART PROBLEM ( ) IS LESS THAN THE NUMBER OF GENERATIONS ALREADY CALCULATED ( )

In order to run a restart problem, you must ask for more generations (NBA) than were run when generatıng restart information

2

$* * * * *$ RESTART ERROR $* * * * *$

\section{INPUT SPECIFICATIONS OLD SPECIFICATIONS}

RESTART COUNT

NUMBER PER GENERATION

NUMBER OF GROUPS

NUMBER OF DOWNSCATTERS

NUMBER OF MIXTURES

NUMBER OF GEOMETRY CARDS

NUMBER OF BOX TYPES

NUMBER OF X UNITS

NUMBER OF Y UNITS

NUMBER OF Z UNITS

ALBEDO TYPE

SEARCH TYPE

FLUX FLAG

FISSION DENSITY FLAG

ADJOINT FLAG

MATRIX FLAG

KMAX

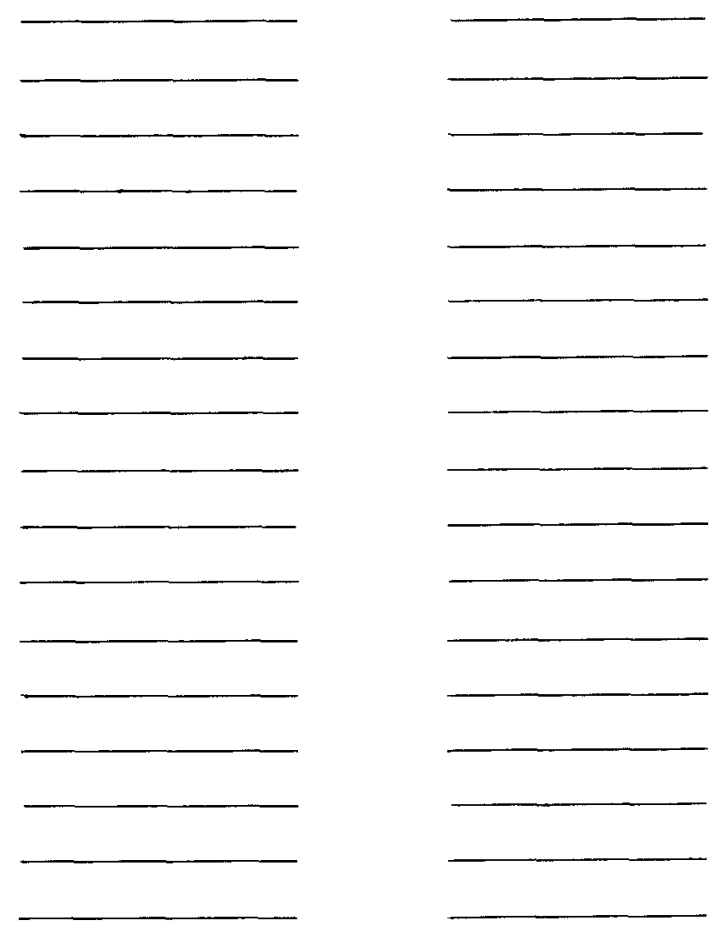

Check the input specifications and the old specifications They do not agree for one or more of the parameters listed 
The following error messages occur in subroutine START

1 AN ERROR HAS BEEN DETECTED IN THE DATA FOR START TYPE

An error was encountered when reading in the data for the specified start type For example, the box indices may fall outside the allowable range, the point where the neutron is to be started may not be within the specified box type, etc.

2 START TYPE IS NOT APPLICABLE FOR A SINGLE UNIT PROBLEM START TYPE 0 WILL BE USED

Only start type 0,3 , or 6 can be used with a single unit problem If a start type 0 was not acceptable, resubmit the problem with a start type 3 or 6

$3 * * * * *$ INVALID GEOMETRY TYPE IN START. IGEO $=$ $* * * * *$

An unrecognizable geometry type was encountered The storage arrays may have been destroyed

4 NO NEUTRON STARTING POSITIONS WERE FOUND YOU SHOULD SELECT ANOTHER STARTING OPTION

If after trying the allowed number of tries (the maximum of $(3$ times the number per generation/volume fraction of fissionable material) or ( 100 times the number per generation)), no starting positions were found, this message is printed Carefully check the input data to be sure fissionable material exists where it is expected and to be sure the starting information was correctly specified

5 THE CHOSEN START TYPE MAY NOT BE ADEQUATE TOO MANY ATTEMPTS MAY BE NEEDED TO START THE NEUTRONS

This message appears for start type 0,1 , or 5 if ( 3 times the number per generation)/(volume fraction of tissionable material) is greater than (100 times the number per generation) Look at the problem carefully and choose a better startıng distribution.

6 - NEUTRONS WERE INITIALLY STARTED HOWEVER, ONLY — WERE STARTED FROM INDEPENDENT POSITIONS

This message indicates that the code encountered some difficulty starting the necessary number of neutrons and was forced to fill the remaining startıng positıons from those already found Try to pick a better startıng distribution

The following error messages occur in subroutine POSIT

1 POSIT ERROR - ILLEGAL GEOMETRY TYPE

$\mathrm{X}=$ $\mathrm{Y}=$ $\mathrm{Z}=$ $\mathrm{K} 1=$ $\mathrm{K} 2=$ $\mathrm{K}=$ IGEO =

This message is printed if the geometry type, IGEO, is outside the allowable range It indicates that some of the storage array has been destroyed

2 POSIT ERROR

$\mathrm{X}=$ $\mathrm{Y}=$ $\mathrm{Z}=$ $\mathrm{K} 1=$ $\mathrm{K} 2=$

An error has been encountered in processing the neutrons Some of the storage arrays have probably been destroyed.

The following error messages appear in subroutine BEGIN

$1 \$ \$ \$ M A R K=$ IS NOT ALLOWED, $\mathrm{K}=$ $\mathrm{KOLD}=$ $\mathrm{KR}=$ $\$ \$ \$$

$\mathrm{X}=$ $\mathrm{Y}=$ $\mathrm{Z}=$ $\mathrm{X} 1=$ $\mathrm{Yl}=$ $\mathrm{Zl}=$

This message is printed only if the generalized geometry portion of the problem returns an invalid value for MARK 1 his message indicates that the program contains an error. 
2 SPLITTING BINS FULL

This message indicates that a neutron was split more than 25 times After printing the message 10 tımes, execution will be terminated Check the weighting values associated with the geometry regions

3 \$\$\$\$ERROR IN DOWNSCATTERS, KR = $\mathrm{IG}=$ IGKR $=$ NDS $=$ $\mathrm{FSP}=$ $\mathrm{R}=$

This error occurs only if the storage arrays have been destroyed FSP should be 1

4 JOB PULLED BATCH $=\ldots$ NEUTRON $=$

This message is printed when subroutine PULL has determined that the time interval for $a$ generation has been exceeded It usually means the program has gone into a loop Check the printed time intervals to determine whether this time interval is out of range If it is not, increase TMAX and resubmit the problem If it is looping, put in diagnostic print to locate the error if it cannot be found by checking the input data

5 EXECUTION TERMINATED DUE TO EXCESSIVE SPLITTING

This message is printed if the SPLITTING BINS FULL message was encountered more than 10 tımes

The following error messages are printed in subroutıne NSTART

1 NO FISSIONS

This message occurs if an entire generation was tracked without causing fission Check to be sure fissionable materials exist where they are supposed to be

2 WARNING - ONLY _ INDEPENDENT FISSION POINTS WERE GENERATED

This message indicates that less than NPB (number per generation) fission points were generated It may become necessary to lower the value of RAKBAR in subroutine BEGIN if this message occurs frequently and the number of independent fission points is very different from NPB

The following error message may originate from subroutıne MATK

1 The calculations done in subroutine MATK may result in exponent underflows for large unit matrices These are considered to be of no significance and may be ignored

The following error messages are printed in subroutıne CROS

$1 * * * * *$ CROSS ERROR

IGEO, $\mathrm{K}, \mathrm{X}, \mathrm{Y}, \mathrm{Z}, \mathrm{X} 1, \mathrm{Y} 1, \mathrm{Zl}$ are printed in that order This error indicates that the geometry type, IGEO, has been destroyed in the storage array

$2 * * * * * * * *$ ERROR $\quad \mathrm{NHCYL}=$ $* * * * * * * * *$

This message is printed if NHCYL is outside the allowable range Either the input data for hemicylinders was incorrect or the storage array has been destroyed

The following error messages are printed in subroutıne KEDIT

$1 * * * * *$ WARNING*** NO VELOCITIES WERE READ VELOCITIES WERE SET TO $10 * * * * *$

The lifetıme and generation tıme were calculated using velocities of 10 because the input data specified cross sections from cards but did not specify velocities from cards See the units digit of Parameter 26 of card 2 in the data guide 
IHE START TYPE WAS NOT ADEQUATE FOR THIS PROBLEM CHOOSE A BETTER STARTING DISTRIBUTION FOR ANY SIMILAR PROBLEM

$* * * * * * * * * * * * * * * * * * * * * * * * * * * * * * * * * * * * * * * * * * * * * * * * * * * * * * * * * * * * * * * * * * * * * * * * * * * * * * * * *$

This message indicates that subroutine START was unable to provide NPB, number per generation, independent starting positions For any similar problem, a different choice of start type, NTYPST, or a different choice of starting positions for the specified start type is recommended

3 NUMBER OF BATCHES RUN WAS INSUFFICIENT TO EDIT

This message is printed if the number of generations run was less than or equal to the parameter NSKIP + 1 Either increase the allowed time, TMAX, increase the parameter NBA, the number of generations to be run, or decrease the number of generations to be skipped, NSKIP

The following error messages occur in subroutine XXMOD

1 ***A SEARCH WILL NOT BE PERFORMED BECAUSE LESS THAN $10+$ NSKIP GENERATIONS WERE CALCULATED ***

In the calculation just completed, too few generations were calculated so the search option has been canceled If the parameter NBA is less than or equal to the parameter NSKIP +10 , incredse the value of NBA Otherwise, increase the value of TMAX

2 UNRECOGNIZABLE GEOMETRY WORD

This error occurs if the storage array was destroyed

$3 * * * * * * * * *$ ERROR NHCYL $=\ldots * * * * * * * * * *$

This error occurs if the storage array has been destroyed

4 THE SEARCH TYPE HAS BEEN INCORRECTLY SPECIFIED AS

The search type parameter, NSCH, was not 1,2, or 3 Correct the data and resubmit

5 GEOMETRY ERROR IN SEARCH PACKAGE

This error occurs if the geometry type, IGEO, is outside the allowable range It indicates that some of the storage array has been destroyed

6 A GENERALIZED REGION CAN NOT BE AL TERED

Nonzero search constants have been supplied for a generalized geometry region This is not alloned Either the problem was incorrectly specified, the data was mispunched, or cards are out of order

7 THIS DIMENSION HAS ALREADY BEEN CALCULATED FOR REGION

If this message occurs, the search has returned to a point it has already calculated and the problem is terminated Check input data and if it is correct, the search may be restarted with a different first guess or different search constants

8 THE GEOMETRY TYPE IS UNDEFINED OR A SEARCH WAS ATTEMPTED ON A GENERAL REGION

This error occurs if the geometry type, IGEO, is outside the allowable range, or if a search constant for a generalized geometry region is nonzero If IGEO is outside the allowable range, some of the storage array has been destroyed If the search constants are nonzero for a generalızed geometry region, set them to zero

9 *****ILLEGAL GEOMETRY TYPE FOR REFLECTOR REGION — IN THE SEARCH PACKAGE *****

The geometry type, IGEO, is outside the allowable range or a generalized geometry region was specified in the reflector Either a general card was out of order or some of the storage array was destroyed 
The following error messages occur in subroutine ARAMOD

1 THE SEARCH PACKAGE DOES NOT APPLY TO MIXED BOXES

This message is self-explanatory An array search cannot be made for a problem where NBOX is not 1

2 THE SEARCH TYPE FOR AN ARRAY SEARCH IS INCORRECT SEARCH TYPE WAS SPECIFIED

Either the search parameter NSCH was incorrectly entered or some of the storage array has been destroyed

3 ALL SEARCH CONSTANTS ARE ZERO NO SEARCH WILL BE MADE

All the search constants were entered as zero The data was incorrect or out of order

4 THIS CASE HAS ALREADY BEEN CALCULATED

If this message occurs, the search has returned to a point that has already been calculated and the problem is terminated If the input data is correct, the search may be restarted with a different initial guess or different search constants if desired

$5 * * * * * * *$ FURTHER CONVERGENCE IS IMPOSSIBLE USING THE SEARCH CONSTANTS SPECIFIED IN THIS PROBLEM $* * * * * * *$

THE NUMBER OF UNITS IN THE $X$ DIRECTION WERE —, IN THE $Y$ DIRECTION WERE — LAST SEARCH

The search cannot be converged with the data specified If the data is correct, nothing more can be accomplished

6 THERE IS NO FEASIBLE SOLUTION TO THE QUADRATIC EQUATION

Using the data supplied for this problem resulted in a negative discriminant when solving the quadratic equation Check input data carefully

The following error messages occur in subroutıne FINALE

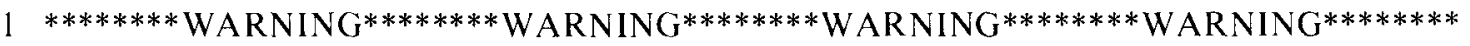

THE FISSION DENSITY AND FLUX WERE COMPUTED USING ARBITRARY VOLUMES (LISTED UNDER - TOTAL VOLUMES-) IN THE REGIONS DESCRIBED BY GENERALIZED GEOM THEY MUST BE MULTIPLIED BY THE TRUE VOLUME OVER THE ARBITRARY VOLUME TO OBTAIN THE CORRECT VALUES

This is a warning message It appears because KENO does not know the volumes of regions internal to the generalized geometry portion If fluxes and fission densities are to be used, thev must be multiplied as indicated in the message 


\section{KENO IV INPUT DATA PREPARATION}

\section{Free-Form Input}

The free-form version of KENO allows data to be entered in an unformatted manner by separatıng each data item by one or more blanks All 80 columns of any card may be used, and data, with certain exceptions noted below, can start or end in any column Decimal data may be entered as in FORTRAN input, e g, 1.733-4, 1733E-4 or 0001733, is the same as $1733 \times 10^{4}$. Note that no imbedded blanks are allowed within a given number representation Since blanks are ignored, all reros must be entered

Geometry description words, such as CYLINDER, SPHERE, etc, must begin in column 1 of a card and be separated by two or more blanks from the rest of the free-form data on the card Additional card(s) following the geometry description word may be used, with the data in any columns 1-80 inclusive Each new geometry description word must start in column 1 of a new card

Free-form KENO has provisions for multiple entries of the same data value I his is done by entering the number of repedts, followed by either $\mathrm{R},{ }^{*}$, or $\$$, followed by the datd value to be repeated For example, 5R2 or $5 * 2$ enters five successive 2 's in the input data There should be no blanks between the number of repeats and the repeat flag $\left(\mathrm{R},{ }^{*}\right.$, or $\left.\$\right)$, but each multiple entry must be separated from the rest of the data by 1 or more blanks Multiple reros may be specified as NZ where $N$ is the number of zeros to be repeated There should not be any blanks between the $N$ and the $\mathrm{Z}$ but the NZ must be separdted from the rest of the data by one or more blanks

Certain data items such as cross-section decks, fission spectra, and albedos are never entered in free form Proper formats for these items are given in the data guide The title card contains identification information only and no data The END CASE and END KE NO cards must start in column 1 and cannot contain any data

An END CASE card is really a flag to signal the end of data for a given problem This is particularly useful it one problem in a set of stacked cases contans an error, because it helps prevent the code from reading into the next problem Once the END CASE card is encountered, the program knows it has finished with the problem, whether or not it encountered all the expected data, and it immediately prepares to read the data for a new problem It should be noted that, if one problem expects to utılize data from the preceding problem, they MUST NOT be separated by an END CASE card Most errors encountered during the tracking procedure are presumed to be programming errors and result in termination of execution rather than continuing on to the next problem

The END KENO card causes the program to cedse execution

In KENO, the following unit numbers are used as stated in rable 2 
2 KENO IV Logical Unit Numbers

Table 2 Function of KENO IV logical units

\begin{tabular}{ll}
\hline Unit Number & \multicolumn{1}{c}{ I unction } \\
\hline 4 or NXCUTE & AMPX working library \\
5 & Input from cards \\
6 & Printed output \\
18 & Scratch unit \\
41 or NXCUTE & Master KENO cross section library \\
42 & Master KENO albedo library \\
43 & Master KENO WTAVG library for \\
44 & dutomatic reflector option \\
45 & Read restart data for KENO \\
\hline
\end{tabular}




\section{KENO IV Datd Guide}

Card 1 Title Card FORMAT(20A4) Contans title onls

Card(s) 2 Parameter Card (Parameters are separated by one or more blanks A new card mar be started after any parameter)

1 TMAX Maximum computer time (in minutes) to be allowed for problem, or for each iteration if a search is to be made

2 NBA Number of generations

3 VPB Number of neutrons per generation

4 NSKIP Number of generations to be skıpped

5 NGP Number of energy groups

6 VDS Vumber of downscatters or energy transfers (includes inscatter)

7 NMAT Number of input cross-section sets

8 MATI Number of mixtures

9 NMIX Number of mixing table entries (see card(s) 6)

10 KREFM Total number of geometry cards This includes the regions generated by the automatic reflector option, and the CORE BOUNDARY card, whether calculated by the automatic reflector option, or entered separately Do not count the REFLECTOR card from the dutomatic reflector option and do not count BOX TYPE cards All other geometry cards must be included

$11 \quad$ NBOX

The number of box types

NOTE NBOX must be zero for a single unit A single unit is a conflguration that does not hate to be enclosed in a cube or cubotd and cannot be stached into an arras

12 NBXMAX

Number of units in the $x$ direction of the array $A$ value must be entered for a single unit problem, but it is not used

13 NBYMAX

Number of units in the $y$ direction of the array A value must be entered for a single unit problem, but it is not used

14 NBZMAX

Number of units in the $r$ direction of the array A value must be entered for a single unit problem, but it is not used 
15 NTAPE

16

NXX

$\mathrm{NXX}=0$

$\mathrm{NXX}=1$

$\mathrm{NXX}=2$

$\checkmark X X=3$

$17 \mathrm{NSCH}$

$\mathrm{NSCH}=0$

$\checkmark S C H=1$

$\mathrm{NSC} \mathrm{H}=2$

$\mathrm{NSCH}=3$

18 LIS I

I HOUSANDS

DIG I I

HUNDREDS

DIGII

I ENS DIGIT
INTAPEl is the number of input cross-section sets to be read from a library If NTAPE $>0$, read a KENO cross-section library on logical unit 41 If NTAPE $<0$, read an AMPX working format cross-section library on logical unit 4

Specified albedo-k, options NOTE Albedo cannot be used for a single unt problem

No albedo or $k$, to be used

Uses specular reflection $\left(\mathrm{k}_{x}\right)$ Note that this consists of mirror image reflection, multiplying the weight (W I) by the absolute value of the reflector constant (card 4) for that face, and leaving the energy unchanged $\mathrm{NXX}=1$ cannot be used for a problem that utilizes both specular reflection and differentidl albedos

Read differential albedos trom cards or tape If a combination of difterential albedos and specular reflection are to be used VXX must be 2

Use differential albedos trom the previous case Cannot be used in the first case following an "END CASE" card

vOTE Differental albedos cannot be used for an adjount problem

Sedrch type

If no search

Search on dimensions

Search on the number of units (array search)

Use onll if $\mathrm{NBOX}=1$ (parameter 11 of card 2)

Search on dimensions using a small number of generations,

NBAl (given as parameter 4 of card 3) Once convergence has been achieved, an additional search is made using the number of generations read in as NBA (parameter 2 of card 2) for NUMBRF (parameter 5 of card 3) iterations This option enables the user to minimire the ha/drds of a poor starting guess and vet still obtain a significant number of histories in a relatively shorter time interval than required if run using $\mathrm{NSCH}=1$

Supplies print flags to KE VO (four-digit number)

$=0$ PRIN $\Gamma$ ALL macroscopic cross sections

$=1$ PRINI ONLY macroscopic l-D cross sections

$=2$, DO NO $\Gamma$ PRIN $\Gamma$ ant macroscopic cross sections

$=0$ DO NOI print array unit interaction matrix (Fission probability matrix by unit)

$=1$, PRIN I array unit interaction matrix Use only If MATRIX (parameter 26 of card 2) is 1 or 3

$=0$, DO NOГ print region-dependent fissions and absorptions

$=1$, PRINI region-dependent fissions and absorptions 
UNIIS DIGIT $=0$, DO NOT print input cross sections from tape

$=1$, PRINT input cross sections

NOTE For example, assume tou nish to print input cross

sectlons, macroscopk cross sections, and the arral unit

interaction matrix but not region-dependent fissions and

absorptions, then LIST $=0101$

19 NOXS

TENS DIGIT

UNIIS DIGIT

20 NTYPS $\Gamma$

NTYPST

NTYPS $\Gamma$

NTYPST

ITYPST

VIYPST
Specifies whether to reuse macro cross sections and or the geometry description from the preceding case (two-digit number) NOTE NOXS must alwais be zero for the first case following an END CASE card

$=0$, read new geometry

$=1$, use geometry from the preceding case However, the mixed box orientation data must be read in aga in if NBOX (parameter

11 , card 2) is greater than 1

$=0$, read new cross sections

$=1$, use cross sections from the preceding case It using cross sections from the preceding case, the units digit of NAD I (parameter 23, card 2) must be the same for both cases NOTE For example, to use cross sectlons from the preceding case and nen geometr., NOXS $=01$ To read nen cross sectrons and to use the geomu $m$ from the preceding case, NOXS $=10$

The type of starting distribution to be used NTYPST must be negative to redd restart ddta If NTYPS I is negative, the absolute value of it specifies which set of restart data is to be used The iestart data is written sequentidly on tape as described in NRSIRI. (parameter 25, card 2) Note that a problem that reads restait data consists only of a title card and parameter cards All other data is read in from the restart unit Restart data is written on unit 45 and is read in from unit 44

Note that, wherever $\mathrm{X}, \mathrm{Y}$, and $\mathrm{Z}$ are used in the start information, they are actually integer position indicators that detine the position of the specified unit in the array $1 \leqslant X \leqslant$ NBXMAX, $1 \leqslant Y \leqslant$ NBYMAX, and $1 \leqslant Z \leqslant$ NBZMAX $=0$, flat over the overall array dimensions, in fissile material only $=1$, cosine over the overall array dimensions, in tissile material only Not applicable for single-unit problems $=2$, arbitrary fraction started in fissile material in unit $(X, Y, Z)$, the rest started in fissle material with cosine distribution, over the array, about unit $(X, Y, Z)$ Not applicable for single-unit problems

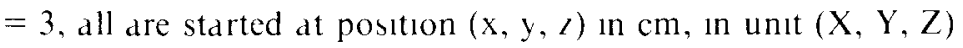
$=4$, all are started at position $(x, y, z) \mathrm{in} \mathrm{cm}$, with all units of box type NBOXSI (card 13) being equally probable Not applicable for single-unit problems 
NTYPST

NTYPST

21 NFLX

NFLX

NFLX

22 NFDEN

NFDEN

NFDEN

23 NADJ

UNITS DIGIT

24 NXCUTE

25 NRSTR I

26 MATRIX TENS DIGIT
$=5$, flat distribution in fissile material in units of box type NBOXST (card 13) Not applicable for single-unit problems $=6$, starting distribution is arbitrarily input This is the only way neutrons can be started in the reflector of an array

NOTE NTYPST must be 0, 3, or 6 for a single-unit problem

If an other lalue is specified, it will be run as a start tipe zero

Flux flag

$=0$, fluxes will be calculated

$\neq 0$, fluxes will not be calculated

Fission density flag

$=0$, fission densities will be calculated

$\neq 0$, fission densities will not be calculated

$=0, \mathrm{~d}$ forward calculation will be done

$=1$, an adjoint calculation will be done

$=0$, the logical device number, XSECS is set to 41 for the KENO cross-section librarv and 4 for AMPX cross-section library $\neq 0$, the logical device number for the input cross-section library, XSECS, is set equal to the absolute value of NXCUTE

Specifies the number of generations between writing of restart data The sets of restart data for edch problem are numbered sequentidlly startıng with 1

If NRSTRT $=0$, no restart data will be generated

Flag for input velocities and matrix calculations

$=0$, redd energy and lethargy from tape and calculate velocities

$=1$, read velocities from cards

$=2$, use velocities from the previous case Note that NADJ (parameter 23, card 2) must be the same for both cases Note that velocities are used to calculate lifetımes and generation tımes Lifetıme and generation time are incorrect if a differential albedo reflector is used

UNITS DIGIT $=0$, no matrix $k_{\text {, } / \text { will be calculated }}$

$=1$, matrix $\mathbf{k}_{\text {/// }}$ by array unit will be calculated

$=2$, matrix $\mathrm{k}_{f f}$ by box type will be calculated

$=3$, matrix $\mathrm{k}_{i f f}$ by both drray unit and box type will be calculated

NOTE The $k_{\text {eff }}$ and co-factor $k_{\text {eff }}$ will be printed If the unit interaction matrix is to be printed, LIST (parameter 18, card 2) must include a 1 in the hundreds digut 
27 NPST Position of $\sigma_{7}$ if ANISN format cross sections* are read from cards NPST $=0$ if cross sections other than ANISN format are to be used

28 NPSGG Position of $\sigma_{\delta, s}$ if ANISN format cross sections are read from cards NPSGG $=0$ if cross sections other than ANISN format are to be used

Card 3 Search Parameters Enter only if $\mathrm{NSCH}>0$ (parameter 17, card 2)

1 CONSTK The desired $\mathrm{k}_{\iota / f}$ for a search problem

2 NSIG The maximum number of standard deviations $\mathrm{k}_{\text {,ff }}$ may be from CONSTK for search completion

3 NUMBR If $\mathrm{NSCH}=1$ or 2 (parameter 17, card 2), NUMBR is the maximum number of iterations the search will run If $\mathrm{NSCH}=3, \mathrm{NUMBR}$ is the number of iterations dllowed for coarse convergence

4 NBXMA Enter onl if $\mathrm{NSCH}=2$ (parameter 17, card 2) The maximum number of units that will be allowed in the $\mathrm{X}$ direction during an array search

4(d) NBAl Enter only if $\mathrm{NSCH}=3$ (parameter 17, card 2) The number of batches to be run to achieve coarse convergence (See explanation for $\mathrm{NSCH}=3$ )

5 NBYMA Enter only if $\mathrm{NSCH}=2$ (parameter 17, card 2) Maximum number of units that will be allowed in the $\mathrm{Y}$ direction during an array sedrch

5(a) NUMBRF Enter onll if $\mathrm{NSCH}=3$ (parameter 17, card 2) The number of iterations to be run to achieve fine convergence (See explanation for $\mathrm{NSCH}=3$ ) If coarse convergence was not achieved, fine convergence will not be attempted

6 NBZMA Lnter only if $N S C H=2$ (parameter 17, card 2) Maximum number of units that will be allowed in the $Z$ direction during an array search

Card 4 Reflector Constants Enter only if NXX $\neq 0$ (pardmeter 16, card 2)

NOTE Reflector constants should be the POSITIVE albedo ID for the faces using

DIFFERENTIAL ALBEDOS, the NEGATIVE albedo ID for faces using

SPECULAR ALBEDOS, and zero for faces having no dlbedo treatment SPECULAR

ALBEDOS may be used on some faces and DIFFERENTIAL ALBEDOS on others in problems where the use of DIFFERENTIAL ALBEDOS has been indicated in NXX (parameter 26, card 2) The absolute value of the reflector constant entered for specular albedo is the fractional return for that face The value of the reflector constant is the albedo ID for differential albedo

*See Appendix I 


$\begin{array}{lll}1 & \text { REFCST(1) } & \text { Reflector constant for }+x \text { face of the array } \\ 2 & \text { REFCST(2) } & \text { Reflector constant for }-x \text { face of the array } \\ 3 & \text { REFCST(3) } & \text { Reflector constant for }+y \text { face of the array } \\ 4 & \text { REFCST(4) } & \text { Reflector constant tor }-y \text { face of the array } \\ 5 & \text { REFCST(5) } & \text { Reflector constant for }+z \text { face of the array } \\ 6 & \text { REFCST(6) } & \text { Reflector constant for }-z \text { face of the array }\end{array}$

Card(s) 5 Velocities Enter only if the TENS DIGIT of MATRIX is equal to I NGP (parameter 5, card 2) entries will be read A velocity must be entered for each energy group The units on the velocity $1 \mathrm{~s} \mathrm{~cm} / \mathrm{sec}$

Card(s) 6 Mixing Table Enter onl if the units digtt of NOXS $=0$ (parameter 19, card 2)

1 KKA Mixture number It must lie between 1 and MAII (parameter 8, card 2)

2 NMA Nuclide ID number A negative nuclide ID number indicates that the fission spectrum for that nuclide will be used for mixture KKA A negative nuclide ID MUST be specified in each mixture that contains fissionable material NOTE Nuclides read from cards are assigned sequential ID numbers starting w ith I

3 RHOA Number density (atoms/barn-cm), must be greater than zero

Repedt starting with KKA, for each nuclide Each set of KKA, NMA RHOA is a mixing table entry

NOTE There must be NMIX (parameter 9, (ard 2) sets of entrles

Card(s) 7 Cross Sections from Cards Enter only if units digit of NOXS $=0$ (parameter 19, card 2) and $\mid$ NTAPE $<$ NMAT (parameters 15 and 7, card 2) There will be NMAT-ןNTAPE| cross-section decks entered Each cross-section deck consists of the card sequence 7(a), 7(b), and 7(c) described below

NOTE Cross sections must be formatted

Card(s) 7-d Title Card Format (17A4,A3,11)

Cols 1-71 XST Nuclide identification

Cols 72 IORDER Enter 0 if $P_{0}$ component only, enter 1 if $P_{1}$ is present

Card(s) 7-b $\mathrm{P}_{0}$ and $\mathrm{P}_{1}$ cross-section sets

First enter the $\mathrm{P}_{0}$ component for all energy groups Next, it IORDER $=1$

(Card 7-d), enter the $P_{1}$ component for all energy groups

NOTE Both the $P_{0}$ and $P_{1}$ components must be entered in either KENO or ANISN format described under $\mathrm{A}$ and $\mathrm{B}$ below All cross-section sets from cards must be entered in the same format for a given problem

A KENO FORMAT, see next page

B ANISN FORMAT, enter only if NPST $\neq 0$ (parameter 27, card 2)

For a detalled description of this format, see Appendix 1 
A. KENO Format (6E12.5) ENTER ONLY IF NPST = 0 (parameter 27 of card 2).

\begin{tabular}{|c|c|c|c|c|c|c|}
\hline Cols. $\rightarrow$ & $1 \rightarrow 12$ & $13 \rightarrow 24$ & $25 \rightarrow 36$ & $37 \rightarrow 48$ & $49 \rightarrow 60$ & $61 \rightarrow 72$ \\
\hline \multicolumn{7}{|l|}{ GP $\downarrow$} \\
\hline \multirow[t]{2}{*}{1} & $\sigma_{\mathbf{a}}$ & $\nu \sigma_{\mathrm{f}}$ & $\sigma_{\mathrm{t}}$ & $\sigma_{1 \rightarrow 1}$ & $\sigma_{1 \rightarrow 2}$ & $\sigma_{1 \rightarrow 3}$ \\
\hline & $\sigma_{1 \rightarrow 4}$ & $\cdots$ & $\sigma_{1 \rightarrow 1+\mathrm{NDS}-1}$ & & & \\
\hline \multirow[t]{2}{*}{2} & $\sigma_{\mathbf{a}}$ & $\nu \sigma_{\mathrm{f}}$ & $\sigma_{t}$ & $\sigma_{2 \rightarrow 2}$ & $\sigma_{2 \rightarrow 3}$ & $\sigma_{2 \rightarrow 4}$ \\
\hline & $\sigma_{2 \rightarrow 5}$ & $\cdots$ & $\sigma_{2 \rightarrow 2+N D S}-1$ & & & \\
\hline \multicolumn{7}{|l|}{ - } \\
\hline \multicolumn{7}{|l|}{. } \\
\hline \multicolumn{7}{|l|}{ - } \\
\hline \multirow[t]{2}{*}{$\mathbf{J}=\mathrm{NGP}-\mathrm{NDS}+1$} & $\sigma_{d}$ & $\nu \sigma_{\mathrm{f}}$ & $\sigma_{\mathrm{t}}$ & $\sigma_{\mathrm{J} \rightarrow \mathrm{J}}$ & $\sigma_{\mathrm{J} \rightarrow \mathrm{J}+\mathbf{1}}$ & $\sigma_{\mathrm{J} \rightarrow \mathrm{J}+2}$ \\
\hline & $\sigma_{\mathrm{J} \rightarrow \mathrm{J}+3}$ & $\cdots$ & $\sigma_{\mathbf{J} \rightarrow \mathrm{NGP}}$ & & & \\
\hline \multirow[t]{2}{*}{$J+1$} & $a_{\mathrm{a}}$ & $\nu \sigma_{\mathrm{f}}$ & $\sigma_{\mathrm{t}}$ & $\sigma_{\mathbf{J}+1 \rightarrow \mathbf{J}+\mathbf{I}}$ & $\sigma_{\mathrm{J}+1 \rightarrow \mathrm{J}+2}$ & $\sigma_{\mathrm{J}+1 \rightarrow \mathrm{J}+\mathbf{3}}$ \\
\hline & $\sigma_{\mathrm{J}+1 \rightarrow \mathrm{J}+4}$ & $\cdots$ & $\sigma_{\mathrm{J}+1 \rightarrow \mathrm{NGP}}$ & $\sigma_{\mathrm{J}+1 \rightarrow \mathrm{I}}$ & & \\
\hline \multirow[t]{2}{*}{$\mathrm{J}+2$} & $\sigma_{\mathbf{a}}$ & $\nu \sigma_{\mathrm{f}}$ & $\sigma_{\mathrm{t}}$ & $\sigma_{\mathbf{J}+2 \rightarrow \mathbf{J}+2}$ & $\sigma_{\mathrm{J}+2 \rightarrow \mathrm{J}+3}$ & $\sigma_{\mathrm{J}+2 \rightarrow \mathrm{J}+4}$ \\
\hline & ${ }^{\sigma} \mathrm{J}+2 \rightarrow \mathrm{J}+5$ & $\cdots$ & $\sigma_{\mathrm{J}+2 \rightarrow \mathrm{NGP}}$ & $\sigma_{\mathbf{J}+2 \rightarrow \mathbf{J}+1}$ & $\sigma_{\mathbf{J}+2 \rightarrow \mathbf{J}}$ & \\
\hline \multicolumn{7}{|l|}{ - } \\
\hline \multicolumn{7}{|l|}{ - } \\
\hline \multicolumn{7}{|l|}{ • } \\
\hline \multirow[t]{2}{*}{$\mathrm{NGP}-1$} & $\sigma_{\mathrm{a}}$ & $\nu \sigma_{\mathbf{f}}$ & $\sigma_{t}$ & $\sigma_{\mathrm{NGP}-1 \rightarrow \mathrm{NGP}-1}$ & $\sigma_{\mathrm{NGP}}-1 \rightarrow \mathrm{NGP}$ & ${ }^{\sigma} \mathrm{NGP}-1 \rightarrow \mathrm{NGP}-2$ \\
\hline & $\cdots$ & $\sigma_{\mathrm{NGP}}-1 \rightarrow \mathrm{J}$ & & & & \\
\hline \multirow[t]{2}{*}{ NGP } & $\sigma_{\mathrm{a}}$ & $\nu \sigma_{f}$ & $\sigma_{\mathrm{t}}$ & $\sigma_{\mathrm{NGP} \rightarrow \mathrm{NGP}}$ & $\sigma_{\mathrm{NGP}} \rightarrow \mathrm{NGP} \rightarrow 1$ & ${ }^{\sigma} \mathrm{NGP} \rightarrow \mathrm{NGP}-2$ \\
\hline & $\cdots$ & $\sigma_{\mathrm{NGP} \rightarrow \mathrm{J}}$ & & & & \\
\hline
\end{tabular}

where the following table defines the terms

Table 3 Cross section symbol definitions

\begin{tabular}{lll}
\hline Symbol & \multicolumn{1}{c}{ Definition } & KENO Varlable Names \\
\hline$\sigma_{\mathrm{a}}$ & absorption cross section (barns) & $\mathrm{AC}$ \\
$\nu$ & neutron/fission & \\
$\sigma_{\mathrm{f}}$ & fission cross section (barns) & $\mathrm{F}$ \\
$\nu \sigma_{\mathrm{f}}$ & $\nu * \sigma_{\mathrm{f}}$ & $\mathrm{T}$ \\
$\sigma_{\mathrm{t}}$ & total cross section (barns) & $\mathrm{TSP}$ \\
$\sigma_{1 \rightarrow \mathrm{J}}$ & scattermg cross section from group & \\
& 1 to group j & NGP \\
NGP & number of energy groups & NDS \\
NDS & number of downscatters & \\
$\mathrm{J}$ & NGP-NDS+1 & \\
\hline
\end{tabular}

NOTE For the $\mathbf{P}_{1}$ component, $\sigma_{\mathrm{a}}, \nu \sigma_{\mathrm{f}}$, and $\sigma_{\mathrm{T}}$ are dummy variables whose value is ignored 
Card(s) 7-c Fission Spectrum FORMAT (6E12 5) Enter onll if $\nu \sigma_{t} \neq 0$ tor at least one energy group There must be NGP entries

WARNING Cross sections and fission spectrum cannot be read in free-form format

Card(s) 8 Geometry Cards and Weights Enter onls if the tens digut of NOXS $=0$ (parameter 19 card 2) Starting in column 1 on a new card, enter the geometry word, followed by at least two blanks Then the mixture number, dimensions and weights are entered. separated by one or more blanks This information may be carried over to a new card after any entry Note that the geometry type must $A L W A Y S$ start in column 1 A weight for each energy group must follow each geometry card (except BOX TYPE or REFLECTOR (ards which are not counted as geometr (ands) If NBOX $=1$ (parameter 11, card 2), no BOX TYPE cards are needed, if NBOX $>1$, start in column 1 and punch BOX or BOX TYPE, followed by two or more blanks Then enter the box type This card is followed by as many geometry cards and weights as are necessary to describe the box type Repeat this process until all box types have been described NOTE ALL REGIONS WITHIN A GIVEN BOX TYPE MUST BE DESCRIBED SO THAT EACH SUCCESSIVE REGION COMPLETELY ENCLOSES THE PREVIOUS REGION THE ADJACENT FACES OF BOXES IN CONTACT WITH EACH OTHER MUST BE 7 HE SAME SIZE

If an external reflector to an array is present, enter a CORE BOUNDARY card The CORE BOUNDARY card starts in column 1 and the first four chardcters must be CORE followed by two or more blanks The word CORE may be followed by a blank and the word BDY or BOUND, which then must be followed by two or more blanks The mixture field contains a zero and the remander of the field is punched with cuboid dimensions that fit tightly around the array Following the CORE card are weights for each energy group The remaining reflector regions are described as any approprate geometry type, in the manner illustrated under Card(s) 8-b NOTE EACH SUCCESSIVE REFLECTOR REGION MUST COMPLETELY ENCLOSE THE PREVIOUS REGION A weight for each energy group must follow each reflector region card

The REFLECTOR card starts in column 1 and says REFLECTOR, followed by two or more blanks followed by a mixture number The next six entries indicate the desired reflector thickness on each face $(+\mathrm{x},-\mathrm{x},+\mathrm{y},-\mathrm{y},+\mathrm{z}$, and $-\mathrm{z}$, respectively) The reflector thickness must be either zero or positive They cannot be negative Following the thicknesses is the ID number of the weights to be read from tape If the ID is less than 10, the weights will be read from cards ds given in card(s) type 10 The REFLECTOR card may replace the CORE BOUNDARY card or be placed at any point external to it if it replaces the CORE BOUNDARY card, it calculates the core boundary, supplies the weights for it, and fills in the reflector regions and their associated weights untı KREFM-I (parameter 10, card 2) regions contain data It then fills the last region with the remaining reflector thickness and supplies the weights associated with it The thickness of each region is governed by data associated with the weights read from tape or cards $(3 \mathrm{~cm}$ for water and paraffin, $5 \mathrm{~cm}$ for concrete, etc) It KREFM (parameter 10 , card 2) is too large so the maxımum reflector thickness is used up before reaching KREFM regions, it simply pads with zero thickness regions until it dccumulates KREFM regions If the REFLECTOR card is external to the CORE BOUNDARY card, it follows the same procedure except it does not calculate the core boundary but starts creating regions at the point where the REFLECTOR card was redd NOTE The first automatic reflector region aluais uses the weights for the first increment $(1 \mathrm{e}, 0-3 \mathrm{~cm}$ for water and paraffin, $0-5 \mathrm{~cm}$ for concrete, etc ) Therefore, exercise caution in choosing weights for any regions that occur between the CORE BOUNDARY card and the REFLECTOR card If the REFLECTOR card replaces the CORE BOUNDARY card, you need not be concerned 
Card(s) 8-d Box Type Card If NBOX $=0$, (parameter 11, card 2), do not enter a Box

Type Card If $\mathrm{NBOX}=1$, a Box Type Card may be entered but is not necessary

Start in Col 1 "BOX IYPE" (left adjusted)

Starting two or more spaces after the geometry word, enter the box number (between 1 and NBOX)

Card(s) 8-b Geometry Cards NOTE All geometh words start in Col I

FGEOM FGEOM may be one of the following and must be left adjusted

CUBE, CUBOID, SPHERE, CYLINDER, XCYLINDER,

YCYLINDER, HEMISPHERE, HEMISPHE+Z. HEMISPHE-Z,

HEMISPHE+X, HEMISPHE-X, GENERAI, XHEMICYI $+Y$,

XHEMICYL-Y, HEMISPHE $+Y$, HEMISPHE-Y, XHEMICYL $+Z$,

XHEMICYL-Z, YHEMICYL $+X, Y H E M I C Y L-X, Y H E M I C Y L+Z$,

YHEMICYL-Z, ZHEMICYL+X, ZHEMICYL-X, ZHEMICYL+Y,

ZHEMICYL-Y, CORE BDY, REFLECTOR

NOTE. FGEOM mal be no mole than 12 character, long

CUBE has $+X=+Y=+Z$ and $-X=-Y=-Z$ Note that the $+X$ dimension need not equal the $-X$ dimension of the cube, $1 \mathrm{e}$, the origin need not be at the center of the cube

CUBOID is a rectangular parallelepiped and may be described anywhere relative to the origin

SPHERE must be centered about the origin

CYLINDER has its length described a long the $Z$ axis and its center line must lie on the $Z$ axis

$X C Y L I N D E R$ has its length described along the $X$ axis and its center line must lie on the $X$ aXis

YCYLINDER has its length described along the $Y$ dxis and its center line must lie on the $Y$ axis

HEMISPHERE must have its flat portion centered about the origin at $Z=00$ and exists only in the positive $Z$ direction

HEMISPHE(B) (C) must have its flat portion centered about the origin at $(C)=00$ and exists only in the $B C$ direction $(B=+$ or $-, C=X, Y$, or $Z$ ). For example, HEMISPHE $+Z$ is the same as the previously described HEMISPHFRE and HEMISPHE-Z is the mirror image of HEMISPHE+Z, therefore existing only in the negative $Z$ direction

(B)HEMICYL(C)(D) is a half cylinder whose axis is the B axis (B =X, Y, or $Z$ ) and exists only in the CD direction $(\mathrm{C}=+$ or $-, \mathrm{D}=\mathrm{X}, \mathrm{Y}$, or $\mathrm{Z}$ ) (Examples ZHEMICYL+X, YHEMICYL-Z, XHEMICYL+Y).

GENERAL refers to generalızed geomery. ${ }^{\wp}$ A GENERAL card must be entered for each generalized geometry media The purpose of the GENERAL card is to set up a correspondence between each medium number and a mixture. The first GENERAL card should contain the KENO mixture number corresponding to medium 1 as defined in GEOM, the second should contain the KENO mixture number for medium 2, etc. The dimension specification portion of the GENERAL cards may be set to zero KENO IV automatically inserts the outer ZONE boundaries from the generalized geometry data for the dimensions of the last GENERAL card. Note that for a single-unit problem (NBOX $=0$, parameter 11 , card 2) a GENERAL card can be the last card entered However, for an array problem the last card must be a cube or cubold whose dimensions are as large or larger than the zone dimensions of the generalıed geometry region 
Starting two or more spaces after the geometry word, the following data is entered, separated by one or more blanks A new card may be started after any entry

MAT

$\mathrm{XX}(1)$

$\mathrm{XX}(2)$

$\mathrm{XX}(3)$

$\mathrm{XX}(4)$

$\mathrm{XX}(5)$

$\mathrm{XX}(6)$

Welghts

W TAVG
Mixture number (enter a zero for a void)

Radius for sphere, cylinders, hemispheres, hemicylinders,

$+\mathrm{x}$ dimension for cube, cuboid, or general region

-x dimension for cube, cuboid, or general region, $+>$ for cylınder,

$+\mathrm{x}$ for $\mathrm{x}$ cylinder, $+\mathrm{y}$ for $\mathrm{y}$ cylinder, + length for hemicylinder, omit

$\mathrm{XX}(2)$ for a sphere or hemisphere

ty dimension for cuboid or general region, -7 for cylınder, $-x$ for

$x$ cylinder, $-y$ for $y$ cylinder, - length for hemicylinder, omit XX(3) for a

sphere, hemisphere, or cube

-y dimension for cuboid or general region

+7 dimension for cuboid or general region

$-\ell$ dimension for cuboid or general region

omit for all other geometry types except CORE BDY

Card(s) 8-bl Core Boundary Card (must be cuboid) Enter onh if there are additional regions external to the core This card is needed only if one or more

of cards $8-\mathrm{b} 2$ are used

Starting in Col 1

CORE BDY (left adjusted)

MAT Enter a mixture number (usually zero), leave two on more blank, hetween CORE BDY and MAT

$\mathrm{XX}(1) \quad+\mathrm{x}$ dimension for a cubold or cube

$X X(2)$

-x dimension for a cuboid or cube

$X X(3)$

ty dimension for a cuboid, zero for a cube

$\mathrm{XX}(4)$

-y dimension for a cuboid, tero for a cube

$\mathrm{XX}(5)$

t7 dimension for a cuboid, rero for a cube

$\mathrm{XX}(6)$

-7 dimension for a cuboid, zero for a cube

NOTE These dimensions must fit tightl around the atrat

W IAVG

Enter a value for each energy group even though they are not used 
Card(s) 8-b2 Reflector Geometry Cards See card(s) 8-b

FGEOM

MAT

$\mathrm{XX}(1) \quad \mathrm{XX}(6)$

Werghts

Repeat the above card sequence untl all reflector regions have been described

Card(s) 8-b3 Automatic Reflector Card (must be cuboid) This card can be entered in the place of a core boundary card (in which case it calculates the core boundary and fills in any remaining regions) or it may be entered at any point external to the core boundary card (it then just fills in any remaining cuboidal regions) It must never he internal to ans other geometr tipe Use onll one Automatic Reflector card per problem NOTE All regions generated hi the automatic reflector optlon must be counted in KRF $K M$ (card 2 parameter 10)

Starting in $\mathrm{Col} 1$

REFLECTOR (left adjusted) Enter only if the automatic reflector option is to be exercised for puttıng an external reflector around an array

MAT Enter the mixture number of the materid comprising the reflector, leave two or more blank, between REFLECTOR and MAT

$\mathrm{XX}(1)$ The reflector thickness in the $+x$ direction

$\mathrm{XX}(2)$

$\mathrm{XX}(3)$

$\mathrm{XX}(4)$

$\mathrm{XX}(5)$

$\mathrm{XX}(6)$

IDW I The reflector thickness in the $-x$ direction The reflector thickness in the $+y$ direction I he reflector thickness in the $-y$ direction Non-negative numbers onls The reflector thickness in the $+z$ direction The reflector thickness in the $->$ direction

The ID of the appropriate set of WTs to be iead from library * If IDW I is less than 10, the werghts will be read from cards (See card(s) 10) NOTE DO NOT enter neights for the REFLFCTOR card Ther are automatisalh provided through reading $I D W T$

Card(s) 9 Mixed Box Orientation Cards Enter on/ If $N B O X>I$ (parameter 11, card 2)

The first field contains the box type, followed by three sets of three fields that are treated like FORTRAN DO loops, followed by a field that indicates whether another set of mixcd box datd is to be read The arrangement of boxes may be considered as consisting of a three-dimensional matrix of box type numbers, with the box position increasing in the positive $X, Y$ and $Z$ directions respectively Each set of mixed box orientation datd consists of the following parameters separated bv one or more blanks

\footnotetext{
*See Table 1113
} 
LTYPE The box type LTYPE must be greater than zero and less than or equal to NBOX (parameter 11, card 2)

IXI The starting point in the $X$ direction IX1 must be at least 1 and less than or equal to NBXMAX (parameter 12, card 2)

IX2 The ending point in the $X$ direction IX2 must be at least 1 and less than or equal to NBXMAX

INCX The number of boxes by which increments are made in the positive $X$ direction INCX must be greater than zero and less than or equal to NBXMAX

IY1 The starting point in the $Y$ direction IY I must be at least 1 and less than or equal to NBYMAX (pardmeter 13, card 2)

IY2 The ending point in the Y direction IY2 must be dt ledst 1 and less than or equal to NBYMAX

INCY The number of boxes by which increments are made in the positive $Y$

direction INCY must be greater than zero and less than or equal to NBYMAX

IZI The starting point in the $\mathrm{Z}$ direction IZ1 must be at ledst 1 and less than or equal to NBZMAX (parameter 14 , card 2)

IZ2 The ending point in the $Z$ direction $I Z 2$ must be at least $I$ and less than or equal to NBZMAX

INCZ The number of boxes by which increments are made in the positive $Z$ direction INCZ must be greater than zero and less than or equal to NBZMAX

ISTP Indicates whether to read another set of mixed box orientation data $=0$, read another set of data,

$\neq 0$, do not read any more mixed box orientation data

An important feature of this type of data description is that if any portion of an array is defined in a conflictıng manner, the last card to define that portion will be the one that determines the array's box type configuration To utilize this feature, one can fill an entire array with the most prevalent box type and then superimpose the other box types in their proper places to accurately describe the array The last set of mixed box orlentation data must have a nonzero entri in the last field

Card(s) 10 Reflector Weights from Cards Enter only if IDWT (card 8-b3) 1s less than 10

WTTITL Name of materid being used for the reflector weights Enter in Cols 1-12

IDWTT Weight ID number (usually the ID number that will be put on the library, but may be anything The code dutomatically sets it equal to the value of IDWT (card 8-b3))

ISUBST Number of sets of weights associated with this IDWTT Usually one since you need read in only 1 set of weights

THICK The thickness in $\mathrm{cm}$ of each weighting region or interval 
NUMINC The number of intervals in the set of weights (NUMINC*THICK = maximum thickness for which weights are given )

NGPWT The number of energy groups for this set of weights It must be equal to NGP

WTAVG(I,J) The weight average for each interval and energy group $\quad I=1$ to NUMINC and $\mathbf{J}=1$ to NGPWT There are NUMINC*NGPWT entries NOTE: If ISUBST I greater than 1, the data "THICK" through "WTAVG(I.J)" must he repeated ISUBST tmes

Card(s) 11 Generalıed Geometry Description, if any, as described in Appendix II

Card(s) 12 Albedo Deck Enter onl if $N X X=2$ (parameter 16, card 2)

NOTE. ALBEDO data must be formatted It consists of the following data

(1) A TITLE format (18A4) Title card for the albedo deck.

(2) $($ WTCOS $(I), I=1, N A N G)$ format $(6 \mathrm{E} / 25)$ WTCOS is the product of the fractional solid angle and the cosine of the polar angle for each polar angle NANG is the number of polar angles and for the existing KENO Albedos is 4

(3) (PLIM(I),I=1,NANG) format (6E12 5) PLIM is the cosines of the angular bounds for each of the poldr angles

(4) $(\mathrm{CPOL}(\mathrm{I}), \mathrm{I}=1, \mathrm{NANG})$ format $(6 \mathrm{E} 125)$. CPOL is the cosmes of the polar angles

(5) (SPOL(I),I=1,NANG) format (6E12 5) SPOL is the sines of the polar angles

(6) $((((A(I, J, K, L), L=1, N A N G), J=I, N G P), K=I, N A N G), I=1, N G P)$ format (18A4)

$A(I, J, K, L)$ is the albedo data in hexidecimal form and represents the relative angular return tables for each input angle and energy.

Card(s) 13 Data for special start options Input if NTYPST $\geqslant 2$ (parameter 20, card 2)

(Entered in free form.)

If NTYPST $=2 \quad$ (parameter 20, card 2) Enter the X. Y, and Z coordinates (in terms of boxes) of the box about which the starting distribution is given

NBXS

NBYS

NBZS

FX

if NTYPST $=3$

NBXS

NBYS

NBZS

TFX

TFY

TFZ
The $X$ index of the box

The $Y$ index of the box

The $Z$ index of the box.

The fraction of neutrons to be started as spike in box (NBXS, NBYS, NBZS) of the array

(parameter 20, card 2) Enter the $\mathrm{X}, \mathrm{Y}$, and $\mathrm{Z}$ indices

(in terms of boxes) of the box where the neutrons will be started as a

spike at the coordinates $x, y$, and $z$ in that box

The $\mathrm{X}$ index of the box

The $Y$ index of the box.

The $Z$ index of the box.

The $\mathrm{x}$ coordinate of the spike in box $(\mathrm{X}, \mathrm{Y}$, and $\mathrm{Z})$.

The $y$ coordinate of the spike in box (X, Y, and $Z)$

The $z$ coordinate of the spike in box (X, Y, and Z). 


\begin{abstract}
If NTYPST $=4 \quad$ (parameter 20, card 2) Enter the box type in which the neutrons will be started at the point $(x, y$, and $z$ )

NBOXST

TFX

TFY

TFZ

if $\mathrm{NTYPST}=5$

NBOXST

if NTYPST $=6$

LFIN

NBXS

NBYS

NBZS

TFX

THY

TFZ

The box type in which the neutrons will be started

The $x$ coordinate of the point at which the neutrons will be started in box type NBOXST

The $y$ coordinate of the point at which the neutrons will be started in box type NBOXST

The $z$ coordinate of the point at which the neutrons will be started in box type NBOXST

(parameter 20, card 2) Enter the box type in which the neutrons will be started The box type in which the neutrons will be started

(parameter 20, card 2)

The final neutron to be started at this point The first LFIN must be $\geqslant 1$ (The first neutron at this point is the one following the previous LFIN ) Points are read untıl LFIN = NPB (parameter 3, card 2), the number of neutrons per batch

The $X$ index of the box

The $Y$ index of the box

The $Z$ index of the box

The $x$ coordinate of the point

The $y$ coordinate of the point

The $z$ coordinate of the point

For example, dssume there are 50 neutrons in a generation, and you wish to start the first five neutrons in box $(1,1,1)$ at $x=10, y=00, z=00$, the next 25 neutrons in box $(1,2,1)$ at $x=10$, $y=00, z=20$, and the remaining neutrons in box $(1,2,2)$ at $x=15, y=15, z=15$ Then the input card could be entered as follows
\end{abstract}

51111000003012110002050122151515

Card(s) 14 Search Constants Enter onl if $N S C H=1,2$, or 3

The physical significance of a search constant may best be described as a proportiondity constant For a dimension search, the search constant (CONS) is proportional to the relative change in dimension $\left(\mathrm{XX}_{n \in \mathrm{n}}-\mathrm{XX} / 1\right) / \mathrm{XX} / /$ divided by the change in k-effective $\left(\mathrm{k}_{n,}-\mathrm{k} / l\right)$ where $\mathrm{XX}_{o l}$ is the dimension that yielded a $\mathrm{k}$-effective of $\mathrm{k} i d$ and $\mathrm{XX}_{n i n}$ is the dimension that yielded a $k$-effective of $k_{n \in w}$ The search constant is positive if $k$-effective increases as the dimension increases and negative if $\mathrm{k}$-effective decreases as the dimension increases

If $\mathrm{NSCH}=1$ or 3 (parameter 17, card 2) Enter one set for each geometry region, and in corresponding order There will be one entry on a card for a sphere or hemisphere, three entries for a cylınder, xyclınder, or ycylınder, and six entries for a cube, cuboid or general region 
Each entry corresponds to a dimension and tells how that

dımensıon will be altered A value of zero means that dımension will be unchanged

NOTE Zeros should ALWAYS be entered for a general

region because a search cannot be made for a general region

CONS(1) Search constant for the radius of a sphere, hemisphere, cylinder, xcylinder, ycylınder, hemicylinder, $+x$ dimension of cube or cuboid

CONS(2) Search constant for $+z$ of cylinder, $+x$ of $x c y l i n d e r,+y$ of ycylinder, $+\mathrm{x}$ of $\mathrm{xhemicylinder,}+\mathrm{y}$ of yhemicylinder, $+\mathrm{z}$ of zhemicylinder, $-x$ dimension of cube or cuboid

CONS(3) Search constant for $-z$ of cylinder, $-x$ of xcylınder, $-y$ of ycylinder, -x of xhemicylinder, $-y$ of yhemicylinder, $-z$ of zhemicylinder, $+y$ dimension of cube or cubold

CONS(4) Search constant for $-\mathrm{y}$ dimension of cube or cubord

$\operatorname{CONS}(5) \quad$ Search constant for $+z$ dimension of cube or cubold

CONS(6) Search constant for $-\mathrm{z}$ dimension of cube or cuboid NOTE If $N S C H=1$ or 3 and the problem contains a reflector that is to maintain its thickness even if the unit spacing changes, simpl enter zeros for all six search constant for each of the core boundary and reflector regions The code will automatkally calculate the nen core boundar and maintain proper reflector thickness and weightings

If $\mathrm{NSCH}=2$ (parameter 17, card 2) Enter only one set There will be three entries, one for each coordinate direction of the array The number of units in a given direction will be changed by an integer multiple of the search constant specified For any array search, the search constant for a given direction represents the minımum number of units by which the array size can be changed in that direction The change in the number of units in each direction maintains the proportionality of the search constants stated for those directions The search constant is positive if k-effective increases as the array size increases and negative if $k$-effectıve decreases as the array size incredses

CONS(1) Search constant for changing the number of units in the $\mathrm{X}$ direction CONS(2) Search constant for changing the number of units in the Y direction CONS(3) Search constant for changing the number of units in the $\mathrm{Z}$ direction

Card 15 END CASE This card is optional It enables KENO to read to the end of a case that contains an error and to start on a new case

Card 16 END KENO This card is optional and comes after the last card of the last case No more data will be read after this card has been encountered 
4. Determination of KENO Core Requirements

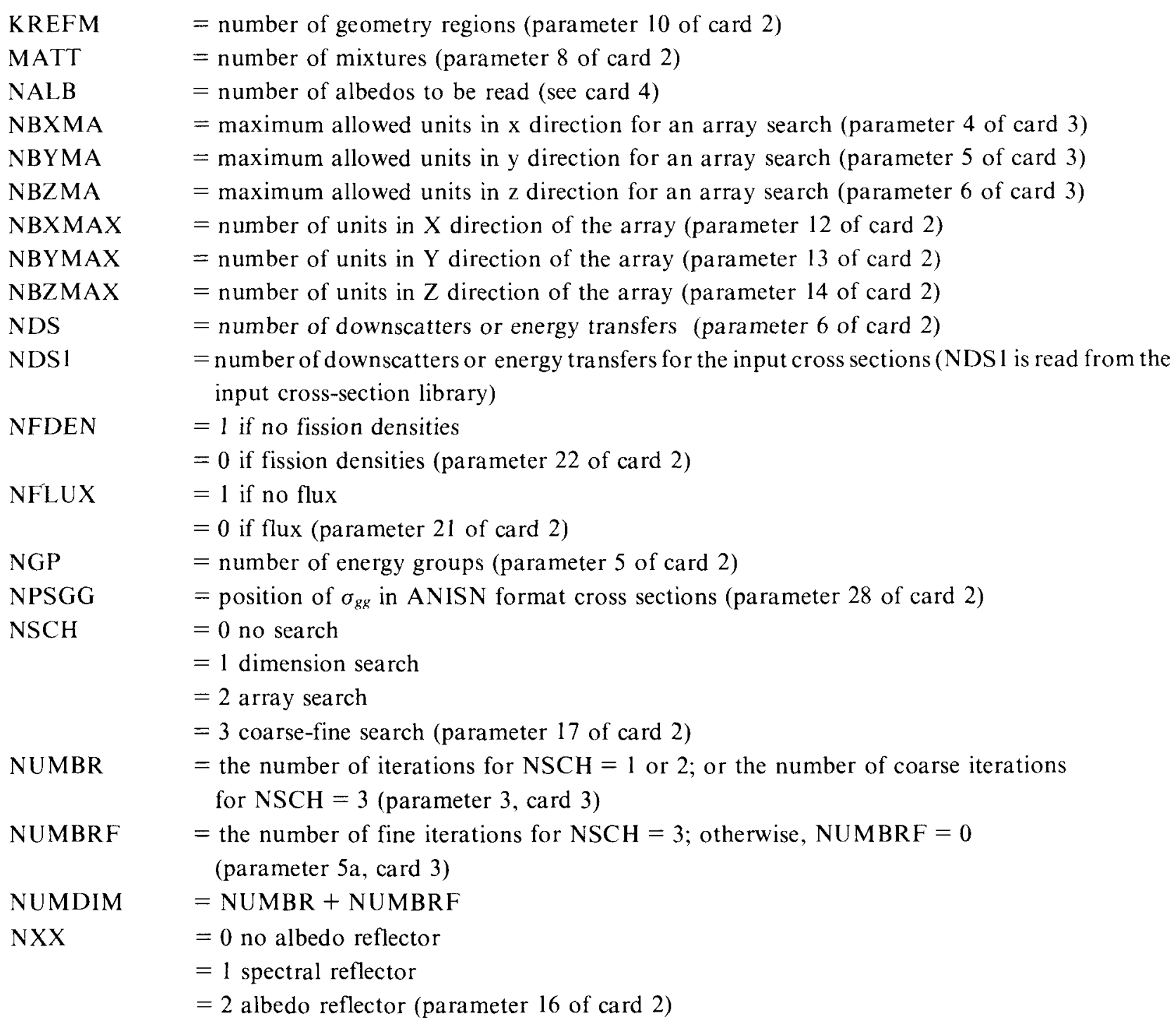

MATDIM $=$ NBXMAX*NBYMAX*NBZMAX

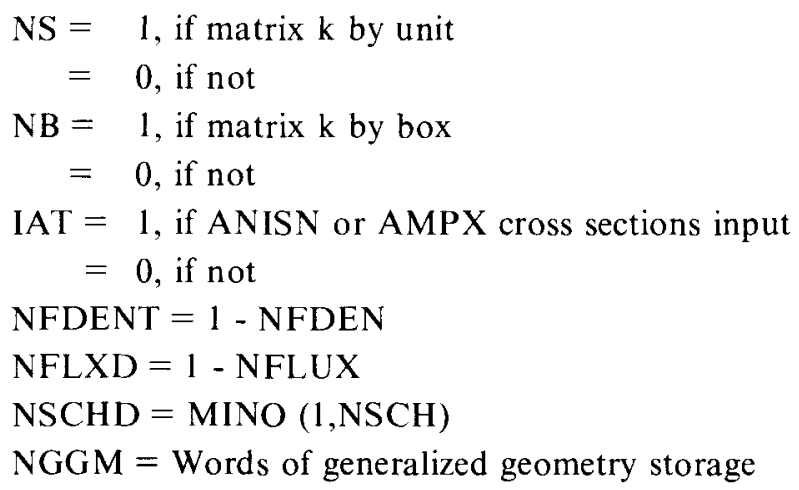




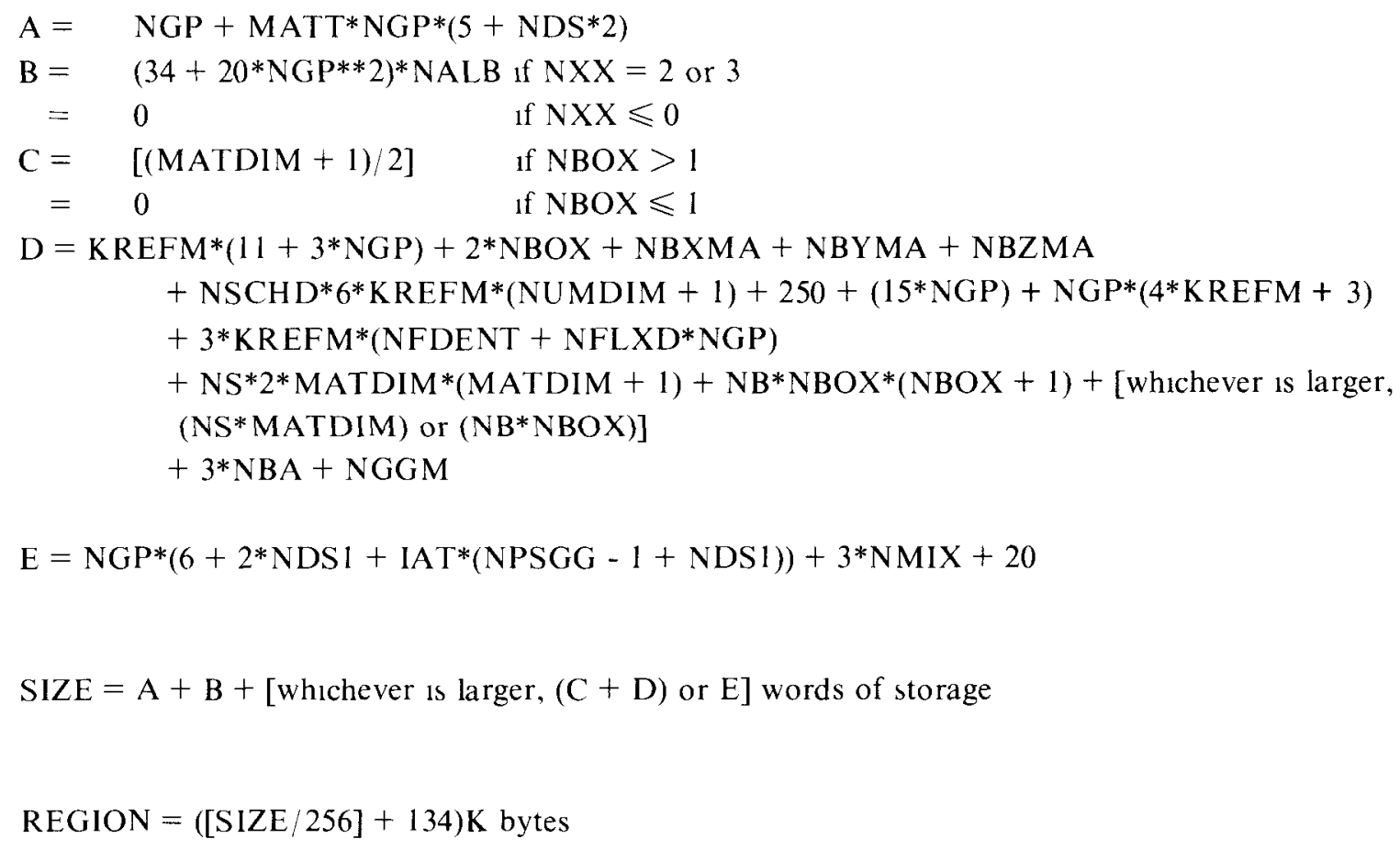




\section{ACKNOWLEDGMENTS}

Special recognition is given to G E Whitesides of the Computer Sciences Division of Oak Ridge National Laboratory He was responsible for the conception and development of the original KENO code and has contributed significantly to some of the techniques utilized in KENO IV

Financial support for this work was provided through the Transportation Branch of the Nuclear Regulatory Commission, the Oak Ridge Experiments Facility, and the Y-12 Technical Division 


\section{APPENDIX I ANISN Cross-Section Input}

ANISN $^{7,9}$ expects a table of cross sections for each group, g, of each materidl in the following format

Table I 1 ANISN cross section format

\begin{tabular}{|c|c|c|}
\hline Position & Cross Section Type & \\
\hline \multirow[t]{2}{*}{1} & detıvity & \\
\hline & dctivity & \\
\hline - & activity & \\
\hline & & \\
\hline NPST-2 & absorption & \\
\hline NPST-1 & nu fission & \\
\hline NPST & total & \\
\hline \multirow[t]{2}{*}{ NPST+1 } & $\sigma_{\mathrm{g}+\mathrm{N} U S \rightarrow \mathrm{g}}$ & \\
\hline & & upscatter 5 \\
\hline NPSGG-1 & $\sigma_{g+1 \rightarrow g}$ & \\
\hline NPSGG & $\sigma_{\mathrm{g} \rightarrow \mathrm{g}}$ & \\
\hline \multirow[t]{2}{*}{ NPSGG+1 } & $\sigma_{g-1 \rightarrow g}$ & \\
\hline & & downscatter 5 \\
\hline IHM & $\sigma_{\mathrm{g}-\mathrm{NDS} \rightarrow \mathrm{g}}$ & \\
\hline
\end{tabular}

${ }^{5}$ NUS is the NPSGG NPST

NDS is the number of groups of downscatter

NPST is the position of $\sigma_{\text {Total }}$

NPSGG is the position of $\sigma_{\mathrm{g} \rightarrow \mathrm{g}}$

IHM is NPSGG + NDS 1

Thus the parameters NPST, NPSGG, and IHM completely describe the format of the cross sections If there are no activity cross sections, NPST $=3$ If there is no upscatter NPSGG $=$ NPST +1 If there is no downscatter, IHM = NPSGG (1 e a one-group problem) It there $1 \mathrm{~s}$ upscatter, ANISN will compute a total upscatter cross section for edch group of each materidl and place that cross section in position IHM +1 The activity cross sections are ignored by KENO

The $\mathrm{P}_{L}$ cross-section tables must correspond in format to the $\mathrm{P}$ tables even though the transfer coefficients are the only numbers used Note that the $P_{L}$ cross sections must contan a $(2 L+1)$ term Some previous $\mathrm{S}$, codes supplied this term internally (e $\mathrm{g}$, DTF-II multiplied the $\mathrm{P}_{1}$ cross sections by 30$)$ 


\section{APPENDIX II Generalized Geometry Input}

If a GENERAL card is present in the input, then generalized GEOM data must be entered The following GEOM input description is essentially the same as that found in ORNL-3622

The outstanding feature of GEOM is its ability to describe multiple medid bounded by essentially arbitrary shapes As many as 33 distinct media may be included, while the permissible boundaries may be of any shape which can be described by quadric surfaces used singly or in combination

The initial step in the geometric description of a system for GEOM is to enclose the entire system in a cuboid whose faces are parallel with the $\mathrm{xy}, \mathrm{yx}$, and $\mathrm{xz}$ coordinate planes This cuboid is then divided into several smaller cuboids, called zones, by planes parallel to the coordinate planes and extending entirely across the system

The zones, in turn, are then divided into smaller cubolds, called blocks, by planes again parallel to the coordinate axes but extending only across individual zones The planes used as zone and block boundaries need not necessarily be boundaries between medid, however, if a boundary between two media is a plane parallel to a coordinate plane, it is advantageous to make it a block or zone boundary The use of the zone-block scheme allows complicated parts of the system under study to be divided into smaller blocks than may be needed for simpler regions If the whole system is relatively simple or requires a similar description throughout, the system should be composed of one zone divided into many blocks rather than many zones of one block each

Boundaries between media which are not also block boundaries may be any quadric surface A quadric surface is defined by the zeros of a quadratic function, and divides all space into two regions In one region, the function defining the surface will be positive, in the other it will be negative Each block may contain a maximum of 32 such surfaces as medium boundaries The surfaces will divide the block into sectors A sector is defined as a volume positive to one set of quadric surfaces but negative to another set Each sector must contain only one medium which may be the same as the medium in another sector Spatial volumes containing a single medium which cannot be described by a single sector definition must be divided into two or more sectors It is not necessary to mention every surface in the block in definıng a sector It is, in fact, more efficient to include in a sector definition only those surfaces which actually form the boundary of the sector In addition sectors containing the same medium may overlap without error

Care must be taken in the use of cones as quadric surfaces, since the quadratic equation describes a surface of two nappes If, as is usual, the described surface is but one nappe of the cone, a block boundary through the vertex must be used to cut off the surface

Input to GEOM (All alphabetıc input must be left-adjusted )

\section{Card A Format (15)}

a An index which is not used in KENO but must be specified as a 2

\section{Card B Format [A11,5(E10 5,A1)]}

This card lists the zone boundaries in increasing order along the $\mathrm{X}$ axis, including the boundaries of the parallelepiped enclosing the entıre system Since the number of boundaries depends upon the problem, commas in the Al fields separating the boundaries are used to indicate that the list continues, while the absence of a comma following the last boundary indicates that the list has ended The All field is for the programmer's convenience and will be ignored by the code 
Card(s) B' Format [6(E10 5,A1)]

If the number of boundaries exceeds the five allowed by the format of card $B$, the list is contınued on as many cards $\mathrm{B}^{\prime}$ as are required

Card C Format $[\mathrm{A} 11,5(\mathrm{E} 105, \mathrm{Al})]$

Identical with card B except that the listing is of the zone boundaries in order along the $Y$ axis

Card $\mathrm{C}^{\prime}$. Format [6(E10 5,A11)]

Identical with card $\mathrm{B}^{\prime}$ but continues the $\mathrm{Y}$ axis zone boundaries

Card D Format $[\mathrm{A} 11,5(\mathrm{E} 10$ 5,A1) $]$

Identical with card B except that the histing is of the zone boundaries in order along the $\mathrm{Z}$ axis

Card D' Format [6(E10 5,Al)]

Identical with card $\mathrm{B}^{\prime}$ but continues the $\mathrm{Z}$ axis zone boundaries

Cards $E$ through $P$ Constitute a complete zone description This set of cards must be included once tor each zone

$$
\text { a } l \mathrm{~m} \mathrm{n}
$$

Card E. Format $(A 6,15,15,15)$

a The word ZONE.

$l, \mathrm{~m}, \mathrm{n}$ Each zone is located in the system by three integers $l, \mathrm{~m}$, and $\mathrm{n}$. These specify the zone as being the / th in the $\mathrm{X}$ direction, the $\mathrm{mth}$ in the $\mathrm{Y}$ direction, and the $\mathrm{nth}$ in the $\mathrm{Z}$ direction The integers $l, \mathrm{~m}$, and $\mathrm{n}$ run from 1 to the maximum number of zones in each direction

\section{Card F: Format $[\mathrm{A} 11,5(\mathrm{E} 10.5, \mathrm{Al})]$}

This card lists the block boundaries in this zone in increasing order along the $\mathrm{X}$ axis, including the boundaries of the zone

Card(s) $F^{\prime}$. Format $[6($ E $10.5, \mathrm{Al})]$

This is a block list contınuation card sımılar to card $\mathrm{B}^{\prime}$ of the zone listıng

Cards $G, G^{\prime}$

The same as cards $F$ and $F^{\prime}$ except that the block boundaries along the $\mathrm{Y}$ axis are listed.

\section{Cards $\mathrm{H}, \mathrm{H}^{\prime}$.}

The same as cards $F$ and $F^{\prime}$ except that the block boundaries along the $Z$ axis are listed

Cards $\mathbf{J}$ through $\mathbf{P}$. Constitute a complete block description. This set of cards must be included once for each block in the zone. 
a $l \mathrm{~m} \mathrm{n}$

Card J. Format (A6,I5, I5, I5)

a. The word BLOCK.

$l, \mathrm{~m}, \mathrm{n}$ : Each block is located in the zone by three integers. $l, \mathrm{~m}$, and $\mathrm{n}$ These specify the block as being the $l$ th in the $\mathrm{X}$ direction, the mth in the $\mathrm{Y}$ direction, and the nth in the $\mathrm{Z}$ direction, within the given zone. The integers $l, m$, and $n$ run from 1 to the maximum number of blocks in each direction

Card K Format $[\mathrm{Al} 2,10(15, \mathrm{Al})]$

d The word MEDIA

b A list of the media, sector by sector, in the block As with other lists, a comma in the Al field indicates that the list continues; its termination is indicated by the absence of the comma A media number of 1000 signifies an internal void, while a media number of 0 signifies an external void

Card(s) K' Format [12(15, Al)]

The continuation, if required, of the medium list

\section{Card L Format $[\mathrm{A} 12,10(15, \mathrm{Al})]$}

a. The word SURFACES.

b A list of the quadric surfaces appearing in the block Commas in the Al field indicate that the list continues, a blank indicates the end of the list The numbers appearing in this list derive from the order in which the surfaces are mathematically described on card $\mathrm{R}$, which will be described later in the input

Card L' Format [8(15,Al)]

The continuation, if needed, of the list begun on card L

\section{Card M Format $(\mathrm{A} 6,18 \mathrm{I} 3)$}

a The word SECTOR

b The designation of each sector with reference to its position relative to the quadric surfaces. For every sector in the block there must be a card $\mathrm{M}$, which will have as many references as there are surfaces in the block. The status of the sector is listed according to the following key

+1 The sector is on the positive side of the surface

-1 The sector is on the negative side of the surface.

0 The surface is not needed in the definition of the sector The order in which each reference to a quadric surface appears on each card $\mathrm{M}$ must correspond to the order in which the quadric surfaces are listed on card $\mathrm{L}$

If there is only one sector in a block, cards $\mathrm{L}$ and $\mathrm{M}$ should be omitted 
Card Q Format (15,11A6)

a The total number of quadric surfaces in the entire si stem The alphabetic data in the A6 fields is ignored by the code

\section{Card R Format [4(E10 5, A5,A1)]}

Each quadric surface is described by writing the quadratic function whose zeros define the surface, in a fixed field format resembling the normal manner of writıng functions Each term in the function is specified by

a The coefticient of the term

b May be XSQ, YSQ, ZSQ (used for $\mathrm{x}, \mathrm{y}$, and $z$ ), $X Z, Y X, Y Z, X Y, Z X, Y Z, X, Y, Z$, or blank

$c$ A nonblank chardeter in this field indicates the end of the function The next function must start on a new card 
APPENDIX III Standard KFNO Libraries

Table III-1 Differential albedo ID's for differential albedo option

\begin{tabular}{llcr}
\hline 12 in water & Differential albedo, 4 incident angles & DP $_{0}(3048 \mathrm{~cm})$ & 1112 \\
12 in water & Differential albedo, 4 incident angles & $(3048 \mathrm{~cm})$ & 1012 \\
12 in paraffin & Differential albedo, 4 incident angles & $(3048 \mathrm{~cm})$ & 2012 \\
7874 in carbon & Differential dibedo, 4 incident angles & $(20000 \mathrm{~cm})$ & 3080 \\
12 in polyethylene & Differential albedo, 4 incident angles & $(3048 \mathrm{~cm})$ & 4012 \\
4 in concrete & Differential albedo, 4 incident angles & $(1016 \mathrm{~cm})$ & 5004 \\
8 in concrete & Differential albedo, 4 incident angles & $(2032 \mathrm{~cm})$ & 5008 \\
12 in concrete & Differential albedo, 4 incident angles & $(3048 \mathrm{~cm})$ & 5012 \\
16 in concrete & Differential albedo, 4 incident angles & $(4064 \mathrm{~cm})$ & 5016 \\
24 in concrete & Differential albedo, 4 incident angles & $(6096 \mathrm{~cm})$ & 5024 \\
\hline
\end{tabular}

Table III 2 Weightıng ID's for automatic reflector option

\begin{tabular}{lcccc}
\hline Refl Matl & ID & Groups & Thickness & Increments \\
\hline Concrete & 301 & 16 & $5 \mathrm{~cm}$ & 20 \\
& & 123 & $5 \mathrm{~cm}$ & 20 \\
Pardffın & 400 & 16 & $3 \mathrm{~cm}$ & 10 \\
& & 123 & $5 \mathrm{~cm}$ & 10 \\
Water & 500 & 16 & $3 \mathrm{~cm}$ & 10 \\
& & 123 & $3 \mathrm{~cm}$ & 10 \\
Graphite & 6100 & 16 & $20 \mathrm{~cm}$ & 6 \\
& & 123 & $20 \mathrm{~cm}$ & 6 \\
\hline
\end{tabular}


The following mixtures are premixed on the KENO 16 group cross-section library They are materials that are frequently used in KENO calculations at Oak Ridge National Laboratory it is recommended that, rather than using the premixed concrete and vermiculite on this data set, their number densities be recalculated by the user because the composition of these materials varies widely, depending upon the geographical location and the application for which they are intended

Table III 3 Mixtures on KENO xsec tape

\begin{tabular}{|c|c|c|c|}
\hline Mixture & Density & $\begin{array}{l}\text { Number Density } \\
\text { (atoms/barn-cm) }\end{array}$ & ID Number \\
\hline Carbon Steel & $782 \mathrm{~g} / \mathrm{cc}$ & $C=003921, F e=083491$ & 00100 \\
\hline 304 Stainless Steel & $79 \mathrm{~g} / \mathrm{cc}$ & $\begin{array}{l}C=3 \quad 1691-4, \mathrm{Cr}=16471-2, \\
M n=1 \quad 7321-3, \Gamma \mathrm{e}=60362 \\
N_{1}=64834-3, \mathrm{Sl}=1694-3\end{array}$ & 00200 \\
\hline Oak Ridge Concrete & $23 \mathrm{~g} / \mathrm{cc}$ & $\begin{array}{l}\mathrm{H}=0085, \mathrm{C}=0202 \\
\mathrm{O}=0355, \mathrm{Ca}=0111 \\
\mathrm{Sl}=0017, \mathrm{Mg}=00186 \\
\mathrm{He}=193-4, \mathrm{Al}=556-4 \\
\mathrm{~K}=403, \mathrm{Nd}=1635\end{array}$ & 00300 \\
\hline Ordinary Concrete & $237 \mathrm{~g} / \mathrm{cc}$ & $\begin{array}{l}\mathrm{H}=014868, \mathrm{C}=003814 \\
\mathrm{O}=041519, \mathrm{Ca}=011588, \\
\mathrm{~S}_{1}=006037, \mathrm{Mg}=000587 \\
\mathrm{Fe}=0001968, \mathrm{Al}=000735 \\
\mathrm{Nd}_{\mathrm{d}}=000304\end{array}$ & 00301 \\
\hline Magnuson Concrete & $215 \mathrm{~g} / \mathrm{cc}$ & $\begin{array}{l}\mathrm{H}=004240, \mathrm{C}=011300 \\
\mathrm{O}=040200, \mathrm{Ca}=007270 \\
\mathrm{~S}=001930, \mathrm{Mg}=004990 \\
\mathrm{Fe}=000129, \mathrm{Al}=000375 \\
\mathrm{~K}=00311, \mathrm{Na}=000079 \\
\mathrm{~S}=000100, \mathrm{Cl}=000019 \\
\mathrm{Tl}=000040, \mathrm{Zn}=000089 \\
\mathrm{Mn}=000012\end{array}$ & 00302 \\
\hline$x(L)$ Polyethylene & $092 \mathrm{~g} / \mathrm{cc}$ & $\mathrm{H}=079433, \mathrm{C}=039716$ & 00401 \\
\hline $\mathrm{dE} / \mathrm{E}$ Polyethylene & $092 \mathrm{~g} / \mathrm{cc}$ & $\mathrm{H}=079433, \mathrm{C}=039716$ & 00402 \\
\hline$x(\mathrm{~L})$ Polyethylene & $9982 \mathrm{~g} / \mathrm{cc}$ & $\mathrm{H}=066743, \mathrm{O}=033372$ & 00501 \\
\hline dE/E Water & $9982 \mathrm{~g} / \mathrm{cc}$ & $\mathrm{H}=066743, \mathrm{O}=033372$ & 00502 \\
\hline$x(E)$ Plexıglas & $1182 \mathrm{~g} / \mathrm{cc}$ & $\begin{array}{l}H=056884, C=035552 \\
O=014221\end{array}$ & 00601 \\
\hline $\mathrm{dE} / \mathrm{L}$ Plexiglas & $1182 \mathrm{~g} / \mathrm{cc}$ & $\begin{array}{l}\mathrm{H}=056884, \mathrm{C}=035552 \\
\mathrm{O}=014221\end{array}$ & 00602 \\
\hline Magnuson Vermıculite & & 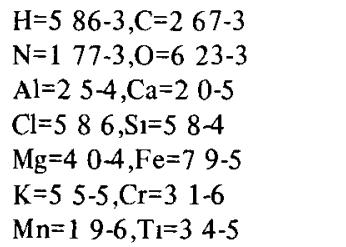 & 00701 \\
\hline
\end{tabular}


Table III-4 KENO 16 group cross-section library

\begin{tabular}{|c|c|c|}
\hline \multicolumn{2}{|c|}{ Mixture Title } & ID \\
\hline \multicolumn{2}{|c|}{ CARBON STEEL $7.82 \mathrm{~g} / \mathrm{cc} C=003921, \mathrm{FE}=.083491$} & 100 \\
\hline \multicolumn{2}{|c|}{ TYPE 304 STAINLESS STEEL $7.9 \mathrm{~g} / \mathrm{cc}$ CONTAINS C, CR, MN, FE, NI, SI } & 200 \\
\hline \multicolumn{2}{|c|}{ OAK RIDGE CONCRETE $2.3 \mathrm{~g} / \mathrm{cc}$} & 300 \\
\hline \multicolumn{2}{|c|}{ ORDINARY CONCRETE $2.37 \mathrm{~g} / \mathrm{cc}$} & 301 \\
\hline \multicolumn{2}{|c|}{ MAGNUSUN CONCRETE $2.15 \mathrm{~g} / \mathrm{cc}$} & 302 \\
\hline \multicolumn{2}{|c|}{$\chi$ (E)POLYETHYLENE $092 \mathrm{~g} / \mathrm{cc} \mathrm{H}=.079433, \mathrm{C}=039716$} & 401 \\
\hline \multicolumn{2}{|c|}{ DE $/$ E POLYETHYLENE $0.92 \mathrm{~g} / \mathrm{cc} \mathrm{H}=.079433, \mathrm{C}=.039716$} & 402 \\
\hline \multicolumn{2}{|c|}{$\chi($ E)WATER $0.9982 \mathrm{~g} / \mathrm{cc} \mathrm{H}=.066742, \mathrm{O}=.033371$} & 501 \\
\hline \multicolumn{2}{|c|}{ DE/E WATER $0.9982 \mathrm{~g} / \mathrm{cc} \mathrm{H}=.066742, \mathrm{O}=.033371$} & 502 \\
\hline \multicolumn{2}{|c|}{$\chi($ E)PLEXIGLAS $1182 \mathrm{~g} / \mathrm{cc} \mathrm{H}=.056884, \mathrm{C}=.035552, \mathrm{O}=014221$} & 601 \\
\hline \multicolumn{2}{|c|}{ DE/E PLEXIGLAS $1182 \mathrm{~g} / \mathrm{cc} \mathrm{H}=.056884, \mathrm{C}=035552, \mathrm{O}=014221$} & 602 \\
\hline \multicolumn{2}{|c|}{ MAGNUSON VERMICULITE } & 701 \\
\hline Element Title & Source & ID \\
\hline HYDROGEN X(E) & Hansen Roach & 1101 \\
\hline HYDROGEN DE/E & Hansen Roach & 1102 \\
\hline DEUTERIUM $x(\mathrm{E})$ & Hansen Rodch & 1201 \\
\hline LITHIUM-6 & Hansen, Roach & 3100 \\
\hline LITHIUM-7 & Hansen Rodch & 3200 \\
\hline BERYLLIUM & Hansen Roach & 4100 \\
\hline BORON & Hansen Rodch & 5100 \\
\hline CARBON & Hansen Rodch & 6100 \\
\hline NJTROGEN & Hansen Rodch & 7100 \\
\hline OXYGEN & Hansen Rodch & 8100 \\
\hline FLUORINE & Hansen Roach & 9100 \\
\hline SODIUM & Hansen Rodch & 11100 \\
\hline MAGNESIUM & XSDRN & 12100 \\
\hline ALUMINUM & Hansen Rodch & 13100 \\
\hline SILICON & XSDRN & 14100 \\
\hline SULFUR & XSDRN & 16100 \\
\hline CHLORINE & Hansen Rodch & 17100 \\
\hline POTASSIUM & Hansen Rodch & 19100 \\
\hline CALCIUM & GAM-2 & 20100 \\
\hline TITANIUM & GAM-2 & 22100 \\
\hline VANADIUM & GAM-2 & 23100 \\
\hline CHROMIUM & AEROJET & 24100 \\
\hline MAGNANESE & XSDRN & 25100 \\
\hline IRON & Hansen Rodch & 26100 \\
\hline COBALT & Hansen Rodch & 27100 \\
\hline NICKEL & Hansen Roach & 28100 \\
\hline COPPER & XSDRN & 29100 \\
\hline ZINC & GAM-2 & 30100 \\
\hline ZIRCONIUM & Hansen Roach & 40100 \\
\hline NIOBIUM & Hansen Roach & 41100 \\
\hline MOLYBDENUM & Hansen Rodch & 42100 \\
\hline CADMIUM & GAM-2 & 48100 \\
\hline INDIUM & GAM-2 & 49100 \\
\hline CERIUM & Hansen Roach & 58100 \\
\hline SAMARIUM & GAM-2 & 62100 \\
\hline EUROPIUM & GAM-2 & 63100 \\
\hline GADOLINIUM & GAM-2 & 64100 \\
\hline TANTALUM & Hansen Rodch & 73100 \\
\hline TUNGSTEN & GAM-2 & 74100 \\
\hline LEAD & XSDRN & 82100 \\
\hline TH-232 SIG $\mathrm{P}=50$ & Hansen Roach & 90104 \\
\hline TH-232 SIG $P=1000$ & Hansen Rodch & 90108 \\
\hline TH-232 SIG $P=1250$ & Hansen Rodch & 90109 \\
\hline TH-232 SIG $P=1500$ & Hansen Rodch & 90110 \\
\hline
\end{tabular}


Table III-4 (contınued)

\begin{tabular}{|c|c|c|c|}
\hline \multicolumn{2}{|r|}{ Element Title } & Source & ID \\
\hline TH-232 S & SIG $P=1750$ & Hansen Roach & 90111 \\
\hline TH-232 S & SIG $P=2000$ & Hansen Rodch & 90112 \\
\hline TH-232 S & SIG P $=2500$ & Hansen Roach & 90113 \\
\hline TH-232 S & SIG P $=3000$ & Hansen Rodch & 90114 \\
\hline TH-232 S & SIG $\mathbf{P}=3500$ & Hansen Roach & 90115 \\
\hline TH-232 II & INFINITE DILUTION & Hansen Roach & 90200 \\
\hline TH-232 S & SIG $\mathrm{P}=20$ & Hansen Roach & 90202 \\
\hline TH-232 S & SIG $P=40$ & Hansen Roach & 90204 \\
\hline TH-232 S & SIG $P=60$ & Hansen Roach & 90206 \\
\hline TH-232 S & SIG $P=80$ & Hansen Roach & 90208 \\
\hline TH-232 S & SIG $P=100$ & Hansen Roach & 90210 \\
\hline TH-232 S & SIG $P=150$ & Hansen Roach & 90212 \\
\hline $\mathrm{TH}-232 \mathrm{~S}$ & SIG $P=200$ & Hansen Roach & 90214 \\
\hline TH-232 S & SIG $P=300$ & Hansen Roach & 90216 \\
\hline TH-232 S & SIG $P=400$ & Hansen Roach & 90218 \\
\hline TH-232 S & SIG P $=600$ & Hansen Roach & 90220 \\
\hline TH-232 S & SIG P $=800$ & Hansen Roach & 90222 \\
\hline TH-232 S & SIG $P=1000$ & Hansen Roach & 90224 \\
\hline TH-232 S & SIG $P=1500$ & Hansen Roach & 90226 \\
\hline TH-232 S & SIG P $=2000$ & Hansen Roach & 90228 \\
\hline TH-232 S & SIG P $=3000$ & Hansen Roach & 90230 \\
\hline TH-232 S & SIG $P=4000$ & Hansen Roach & 90232 \\
\hline TH-232 S & SIG $\mathrm{P}=6000$ & Hansen Roach & 90234 \\
\hline TH-232 S & SIG P $=10 \mathrm{~K}$ & Hansen Roach & 90236 \\
\hline TH $-232 \quad \mathrm{~S}$ & SIG P $=20 \mathrm{~K}$ & Hansen Roach & 90238 \\
\hline $\mathrm{U}-233$ & & Hansen Roach & 92300 \\
\hline $\mathrm{U}-233-1$ & SIG $P=20$ & Hansen Roach & 92301 \\
\hline U-233-2 & SIG $P=40$ & Hansen Roach & 92302 \\
\hline U-233-3 & SIG P $=60$ & Hansen Roach & 92303 \\
\hline U-233-4 & SIG $P=100$ & Hansen Roach & 92304 \\
\hline U-233-5 & SIG $P=200$ & Hansen Roach & 92305 \\
\hline U-233-6 & SIG $P=400$ & Hansen Roach & 92306 \\
\hline $\mathrm{U}-233-7$ & SIG $P=600$ & Hansen Roach & 92307 \\
\hline U-233-8 & SIG P $=1000$ & Hansen Roach & 92308 \\
\hline U 233-9 & SIG P $=2000$ & Hansen Rodch & 92309 \\
\hline U-233-10 & SIG P $=4000$ & Hansen Roach & 92310 \\
\hline U-233-11 & SIG $P=6000$ & Hansen Rodch & 92311 \\
\hline $\mathrm{U}-233-12$ & SIG $P=10000$ & Hansen Rodch & 92312 \\
\hline $\mathrm{U}-234$ & & Mihalczo Mod of H-R U-238 & 92400 \\
\hline $\mathrm{U}-235 \mathrm{YR}$ & & Hansen Roach & 92500 \\
\hline $\mathrm{U}-235-1 \mathrm{R}$ & SIG $P=20$ & Hansen Roach & 92501 \\
\hline $\mathrm{U}-235-2 \mathrm{R}$ & SIG $P=40$ & Hansen Roach & 92502 \\
\hline $\mathrm{U}-235-3 \mathrm{R}$ & SIG P $=60$ & Hansen Roach & 92503 \\
\hline $\mathrm{U}-235-4 \mathrm{R}$ & SIG $P=100$ & Hansen Roach & 92504 \\
\hline $\mathrm{U}-235-5 \mathrm{R}$ & SIG P $=200$ & Hansen Roach & 92505 \\
\hline $\mathrm{U}-235-6 \mathrm{R}$ & SIG P $=400$ & Hansen Roach & 92506 \\
\hline $\mathrm{U}-235-7 \mathrm{R}$ & SIG P $=600$ & Hansen Roach & 92507 \\
\hline $\mathrm{U}-235-8 \mathrm{R}$ & $\operatorname{SIG} P=1000$ & Hansen Roach & 92508 \\
\hline $\mathrm{U}-235-9 \mathrm{R}$ & SIG $P=2000$ & Hansen Rodch & 92509 \\
\hline $\mathrm{U}-235-10 \mathrm{R}$ & R $\quad$ SIG P $=4000$ & Hansen Rodch & 92510 \\
\hline $\mathrm{U}-235-11 \mathrm{R}$ & R SIG P $=6000$ & Hansen Roach & 92511 \\
\hline $\mathrm{U}-235-12 \mathrm{R}$ & R $\quad$ SIG P $=10000$ & Hansen Rodch & 92512 \\
\hline $\mathrm{U}-236$ & & Mihalczo Mod of H-R U-238 & 92600 \\
\hline $\mathrm{U}-238 \mathrm{Y}$ & & Hansen Roach & 92800 \\
\hline $\mathrm{U}-238 \quad \mathrm{~S}$ & SIG $P=12$ & Hansen Roach JRK Mod & 92801 \\
\hline $\mathrm{U}-238$ & SIG $P=15$ & Hansen Rodch JRK Mod & 92802 \\
\hline $\mathrm{U}-238$ & SIG $P=20$ & Hansen Roach JRK Mod & 92803 \\
\hline $\mathrm{U}-238$ & SIG $P=25$ & Hansen Roach JRK Mod & 92804 \\
\hline
\end{tabular}


Table III-4 (contınued)

\begin{tabular}{|c|c|c|c|}
\hline \multicolumn{2}{|r|}{ Element Title } & Source & ID \\
\hline $\mathrm{U}-238$ & SIG $P=30$ & Hansen Roach JRK Mod & 92805 \\
\hline U-238 & SIG $P=35$ & Hansen Roach JRK Mod & 92806 \\
\hline U 238 & SIG $P=40$ & Hansen Roach JRK Mod & 92807 \\
\hline $\mathrm{U}-238$ & SIG $P=45$ & Hansen Roach JRK Mod & 92808 \\
\hline U-238 & SIG $P=50$ & Hansen Roach JRK Mod & 92809 \\
\hline U-238 & SIG $P=55$ & Hansen Roach JRK Mod & 92810 \\
\hline $\mathrm{U}-238$ & SIG $P=60$ & Hansen Roach JRK Mod & 92811 \\
\hline $\mathrm{U}-238$ & SIG $P=65$ & Hansen Rodch JRK Mod & 92812 \\
\hline $\mathrm{U}-238$ & $\operatorname{SIG} P=70$ & Hansen Roach JRK Mod & 92813 \\
\hline $\mathrm{U}-238$ & SIG $P=75$ & Hansen Roach JRK Mod & 92814 \\
\hline $\mathrm{U}-238$ & SIG $P=80$ & Hansen Roach JRK Mod & 92815 \\
\hline U-238 & SIG $P=85$ & Hansen Roach JRK Mod & 92816 \\
\hline U 238 & SIG $P=90$ & Hansen Rodch JRK Mod & 92817 \\
\hline $\mathrm{U}-238$ & SIG $P=95$ & Hansen Roach JRK Mod & 92818 \\
\hline $\mathrm{U}-238$ & SIG $P=100$ & Hansen Roach JRK Mod & 92819 \\
\hline U-238 & SIG $P=110$ & Hansen Roach JRK Mod & 92820 \\
\hline $\mathrm{U}-238$ & $\operatorname{SIG} P=120$ & Hansen Roach JRK Mod & 92821 \\
\hline $\mathrm{U}-238$ & SIG $P=130$ & Hansen Roach JRK Mod & 92822 \\
\hline $\mathrm{U}-238$ & SIG $P=140$ & Hansen Rodch JRK Mod & 92823 \\
\hline U-238 & SIG P $=160$ & Hansen Roach JRK Mod & 92824 \\
\hline $\mathrm{U}-238$ & SIG P $=180$ & Hansen Roach JRK Mod & 92825 \\
\hline$U-238$ & $\operatorname{SIGP}=200$ & Hansen Roach JRK Mod & 92826 \\
\hline $\mathrm{U}-238$ & SIG $P=220$ & Hansen Roach JRK Mod & 92827 \\
\hline U 238 & SIG $P=240$ & Hansen Roach JRK Mod & 92828 \\
\hline U-238 & SIG P $=260$ & Hansen Roach JRK Mod & 92829 \\
\hline U-238 & SIG P $=280$ & Hansen Roach JRK Mod & 92830 \\
\hline $\mathrm{U}-238$ & SIG P $=300$ & Hansen Roach JRK Mod & 92831 \\
\hline $\mathrm{U}-238$ & SIG P $=330$ & Hansen Roach JRK Mod & 92832 \\
\hline $\mathrm{U}-238$ & SIG $P=360$ & Hansen Roach & 92833 \\
\hline $\mathrm{U}-238$ & SIG $P=400$ & Hansen Roach & 92834 \\
\hline U-238 & SIG $P=450$ & Hansen Roach & 92835 \\
\hline U-238 & SIG $P=500$ & Hansen Roach & 92836 \\
\hline $\mathrm{U}-238$ & SIG $P=550$ & Hansen Roach & 92837 \\
\hline U-238 & SIG P $=600$ & Hansen Rodch & 92838 \\
\hline $\mathrm{U}-238$ & SIG $P=650$ & Hansen Roach & 92839 \\
\hline $\mathrm{U}-238$ & SIG $P=700$ & Hansen Roach & 92840 \\
\hline $\mathrm{U}-238$ & SIG P $=800$ & Hansen Roach & 92841 \\
\hline $\mathrm{U}-238$ & SIG $P=900$ & Hansen Roach & 92842 \\
\hline $\mathrm{U}-238$ & SIG $P=1000$ & Hansen Roach & 92843 \\
\hline $\mathrm{U}-238$ & SIG $P=1500$ & Hansen Roach & 92844 \\
\hline $\mathrm{U}-238$ & SIG $P=2000$ & Hansen Roach & 92845 \\
\hline U-238 & SIG $P=3000$ & Hansen Roach & 92846 \\
\hline $\mathrm{U}-238$ & SIG $P=4000$ & Hansen Roach & 92847 \\
\hline $\mathrm{U}-238$ & SIG P $=5000$ & Hansen Roach & 92848 \\
\hline $\mathrm{U}-238$ & SIG $P=6000$ & Hansen Roach & 92849 \\
\hline $\mathrm{U}-238$ & SIG $P=8000$ & Hansen Roach & 92850 \\
\hline U-238 & SIG $P=10000$ & Hansen Roach & 92851 \\
\hline $\mathrm{U}-238$ & SIG $P=20000$ & Hansen Roach & 92852 \\
\hline U-238 & SIG $P=40000$ & Hansen Roach & 92853 \\
\hline $\mathrm{U}-238$ & SIG $P=60000$ & Hansen Roach & 92854 \\
\hline $\mathrm{U}-238$ & SIG $P=100000$ & Hansen Roach & 92855 \\
\hline $\mathrm{U}-238-1 \mathrm{R}$ & R SIG $P=20$ & Hansen Roach & 92856 \\
\hline $\mathrm{U}-238-2 \mathrm{R}$ & SIG $\mathrm{P}=40$ & Hansen Roach & 92857 \\
\hline $\mathrm{U}-238-3 \mathrm{R}$ & SIG $P=60$ & Hansen Roach & 92858 \\
\hline$U-238-4 R$ & SIG $P=100$ & Hansen Roach & 92859 \\
\hline$U-238-5 R$ & SIG $P=200$ & Hansen Roach & 92860 \\
\hline $\mathrm{U}-238-6 \mathrm{R}$ & SIG $P=400$ & Hansen Roach & 92861 \\
\hline $\mathrm{U}-238-7 \mathrm{R}$ & SIG $P=600$ & Hansen Roach & 92862 \\
\hline
\end{tabular}


Table III 4 (contınued)

\begin{tabular}{|c|c|c|c|}
\hline \multicolumn{2}{|c|}{ Element Title } & Source & \multirow{2}{*}{$\frac{\text { ID }}{94000}$} \\
\hline PU-240 & & Hansen Roach & \\
\hline PU-240-1 & SIG $P=50$ & Hansen Roach & 94001 \\
\hline PU-240-2 & SIG $P=100$ & Hansen Roach & 94002 \\
\hline PU-240-3 & SIG P $=200$ & Hansen Roach & 94003 \\
\hline PU-240-4 & SIG $P=400$ & Hansen Roach & 94004 \\
\hline PU-240-5 & SIG P $=600$ & Hansen Roach & 94005 \\
\hline PU-240-6 & SIG $P=1000$ & Hansen Roach & 94006 \\
\hline PU-240-7 & SIG P $=2000$ & Hansen Roach & 94007 \\
\hline PU-240-8 & SIG $P=4000$ & Hansen Roach & 94008 \\
\hline PU-240-9 & SIG P -6000 & Hansen Roach & 94009 \\
\hline PU-240-10 & SIG P $=10000$ & Hansen Roach & 94010 \\
\hline PU-240-11 & SIG $P=20000$ & Hansen Roach & 94011 \\
\hline PU-240-12 & SIG $P=40000$ & Hansen Roach & 94012 \\
\hline PU-240-13 & SIG $P=60000$ & Hansen Roach & 94013 \\
\hline PU-240-14 & SIG $P=100000$ & Hansen Roach & 94014 \\
\hline PU-240-15 & SIG $P=200000$ & Hansen Roach & 94015 \\
\hline PU-240-16 & SIG $P=400000$ & Hansen Roach & 94016 \\
\hline PU-240-17 & SIG $P=600000$ & Hansen Roach & 94017 \\
\hline PU-240-18 & SIG $P=1000000$ & Hansen Roach & 94018 \\
\hline PU-241 & & GAM-2 & 94100 \\
\hline PU-242 & & GAM-2 & 94200 \\
\hline PU-238 & & Hansen Roach & 94800 \\
\hline PU-238-1 & SIG $P=100$ & Persimmon & 94801 \\
\hline PU-238-2 & SIG P $=1000$ & Persimmon & 94802 \\
\hline PU-238-3 & SIG $P=10000$ & Persimmon & 94803 \\
\hline PU-238 Y & & Persimmon & 94804 \\
\hline PU-239 & & Hansen Roach & 94900 \\
\hline PU-239-1 & SIG $P=20$ & Hansen Roach & 94901 \\
\hline PU-239-2 & $\operatorname{SIG} P=40$ & Hansen Roach & 94902 \\
\hline PU-239-3 & SIG $P=60$ & Hansen Roach & 94903 \\
\hline PU-239-4 & $S I G P=100$ & Hansen Roach & 94904 \\
\hline PU-239-5 & SIG $P=200$ & Hansen Roach & 94905 \\
\hline PU-239-6 & SIG $P=400$ & Hansen Roach & 94906 \\
\hline PU-239-7 & SIG $P=600$ & Hansen Roach & 94907 \\
\hline PU-239-8 & SIG P $=1000$ & Hansen Roach & 94908 \\
\hline PU-239-9 & SIG P $=2000$ & Hansen Roach & 94909 \\
\hline PU-239-10 & SIG $P=4000$ & Hansen Roach & 94910 \\
\hline PU-239-11 & SIG P $=6000$ & Hansen Roach & 94911 \\
\hline PU-239-12 & SIG $P=10000$ & Hansen Roach & 94912 \\
\hline PU-239-13 & SIG $P=20000$ & Hansen Roach & 94913 \\
\hline PU-239-14 & SIG P $=40000$ & Hansen Roach & 94914 \\
\hline PU-239-15 & SIG $P=60000$ & Hansen Roach & 94915 \\
\hline PU-239-16 & SIG $P=100000$ & Hansen Roach & 94916 \\
\hline
\end{tabular}




\section{Random Sequence}

The random number package utılized in KENO IV always starts at the same place when a problem is run Therefore, if the same problem is run as the first problem, it will give identical results each time The random sequence can be changed by increasing or decreasing the number of neutrons per generation by at least one, or by changing a problem's position if stacked cases were run For example, if a problem is the third problem in a set of stacked problems, it will have a different random sequence than if it were the first or second problem in the stack

RNDOUT is an entry point in the random number package that loads the current random number in a double-precision argument as a right-adjusted, six-byte integer

RNDIN is an entry point in the random number package that uses its double-precision argument (a right-adjusted six byte integer) to set the current random number

RNDIN and RNDOUT are not utllized by KENO IV but are avalable to be used as desired

\section{Matrix K-effective}

Matrix k calculations in KENO IV provide an alternate method of estimating k-effective in addition to providing such information as cofactor k-effective, source vector, and fission probability matrix Subroutme MATK solves for the principal eigenvalue and eigenvector of a matrix by using an iterative technique If a matrix calculation has been specified, the necessary source and fission weight data is collected in subroutıne BEGIN during the regular neutron tracking procedure Matrix information can be collected by box type, by array unit, or both The fission weights are summed in a fission weight matrix as they are generated Their location in the matrix is determined by the position where the neutron was born and the position where it caused a fission A source vector is generated by summing the weight, WT, when a fission neutron is born in an array unit At the end of each generation, the fission weight matrix by array unit is normalized by the source vector by array unit This normalized matrix, $T(1, \mathrm{j})$ is called the "FISSION PROBABILITY MATRIX BY UNIT" and gives the probability that a neutron born in unit $I$ will cause a fission in unit $J$ The principal eigenvalue of this matrix is determined by subroutine MATK and is printed as the "MATRIX K-EFF" for each generation

The fission probability matrix information by box type is collected in the same manner but is not normalized by the source vector until the entire tracking procedure has been completed This normalized matrix STMAT $(1,1)$ gives the probability that a neutron born in box type 1 will cause a fission in box type $\mathrm{J}$

The information that can be obtained from a matrix calculation includes the following

I The average value of the matrix k-effective by array unit This is the largest eigenvalue of the "FISSION PROBABILITY MATRIX BY UNIT" The result is printed in subroutine BEGIN for each generation

The remaining matrix information is printed in subroutine FINALE except the source vectors, which are printed in subroutıne LABL

2 COFACTOR K-EFFECTIVE by unit This is the eigenvalue of the "FISSION PROBABILITY MATRIX BY UNIT", reduced by the row and column that references that unit The difference between the k-effective of the system and the cofactor k-effective of a unit is a 
measure of the in situ k-effective of that unit or the contribution that unit makes to the k-effective of the system It should be noted that the cofactor k-effective of units composed entirely of nonfissionable material should be the same as the k-effective of the system The cofactor k-effectives printed for such units in KENO IV may not be identical to the k-effective of the system but may be different by some small amount due to roundoff

3 FISSION PROBABILITY MATRIX BY UNIT This square matrix is composed of the probability that a neutron born in unit 1 causes a fission in unit $\mathrm{J}$ The principal eigenvalue of this matrix is the k-effective of the system The print flag LIST makes it possible to avoid printing this matrix

4 SOURCE VECTOR BY UNIT This is the elgenvector of the "FISSION PROBABIIITY MATRIX BY UNIT" The sum of the components of this vector should be near 1

5 AVERAGE UNIT SELF MULTIPLICATION This is the probability that a neutron born in a unit produces a fission in that same unit

6 BOX TYPE K-EFFECTIVE This is the largest eigenvalue of the "FISSION PROBABILITY MATRIX BY BOX TYPE" This calculation is done only once in the solution of a problem and then only if matrix k-effective by box type was specified in the parameters

7 FISSION PROBABILITY MATRIX BY BOX TYPE This is the matrix that is solved to determine the BOX TYPE K-EFFECTIVE It gives the probability that a neutron born in box ty pe 1 causes a fission in box type $\mathrm{J}$

8 SOURCE VECTOR BY BOX TYPE is the elgenvector of the "FISSION PROBABII ITY MATRIX BY BOX TYPE" The components of this vector should sum to 1000

9 COFACTOR K-EFFECTIVE BY BOX TYPE The cofactor k-effective for edch box type is found by solving the FISSION PROBABILITY MATRIX by box type, stıkıng out the row and column that pertain to that box type This gives an estumate of the $k$-effective of the array, neglectung the contribution of that box type The cofactor k-effective of box types without fissionable material is very near the k-effective by box type

\section{L ifetıme and Generation Time}

In KENO IV the velocity data can be read in from cards or calculated from the energy and lethargy intormation stored on the cross-section librarv If velocities are expected from cards, the velocities must be entered in units of $\mathrm{cm} / \mathrm{sec}$ If velocities are to be calculated from the energy and lethargy information on the library tape, the following relationships are used

$$
V=\sqrt{\frac{2 \bar{E}}{M}}
$$

where

$V$ is velocity in $\mathrm{cm}$ sec

$\bar{E}$ is the average energy in electron volts at the midpoint of the lethargy interval

$M$ is the mass of a neutron in grams $=16710^{+} \mathrm{g}$ 
There are $1602 \times 10^{12} \mathrm{erg} / \mathrm{ev}$ or $1602 \times 10^{12} \mathrm{~g} \mathrm{~cm}^{2} / \mathrm{sec}^{2} / \mathrm{ev}$

therefore $v=13859 \times 10^{6} \sqrt{ } E$

where $\quad \overline{\mathrm{E}}=\sqrt{\left(\mathrm{E}_{l+1}\right)\left(\mathrm{E}_{l}\right)}$

$E_{l+1}$ and $E_{l}$ are in units of ev and are the energies at the

bounds of the group interval

Lifetıme and generatıon tıme calculations utılize an elapsed tıme, TME, defined as distance traveled multiplied by $1 /$ velocity This time is collected at boundary crossings and utilized whenever a collısıon occurs The generation tıme, TIMG, is defined as follows

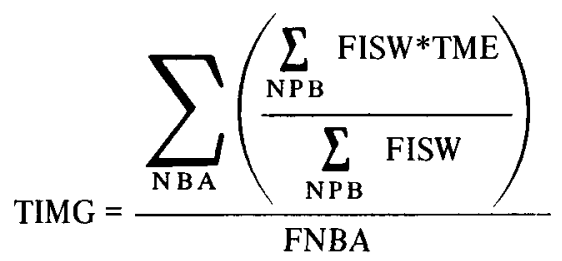

where

FISW is the fission weight,

TME is elapsed time as defined above,

$\mathrm{FNBA}=\mathrm{NBA}=$ the number of generations that were run, and

NPB is the number of neutrons per generation

Thus generation time is the average time between successive neutron generations in the system The neutron lifetıme, TIML, is defined as follows

$$
\mathrm{TIML}=\frac{\sum_{\mathrm{NBA}}\left(\frac{\sum_{\mathrm{NPB}}(\mathrm{AB} * \mathrm{TME}+\mathrm{WT} * \mathrm{TME})}{\mathrm{FNPB}}\right)}{\text { FNBA }}
$$

where

$A B$ is the absorption weight,

WT is the weight associated with a neutron that leaks from the system,

TME is the elapsed time,

FNFB $=$ NPB $=$ number of neutrons per generation, and

$\mathrm{FNBA}=\mathrm{NBA}=$ number of generatıons

Thus the lifetıme is the average life span of a neutron in the system ( $1 \mathrm{e}$, untıl it escapes from the system or is absorbed) 


\section{Albedo}

The major advantage of using the albedo reflector option as opposed to actual tracking in the reflector is a significant decrease in the computing time For criticality calculations, it should be noted that for small arrays (small edge or face size), the result should tend to be conservative due to corner effects For large arrays (large edge or face size) the k-effective should agree better with actual tracking results as the face size of the array approaches an infinite slab

To generate a set of albedos for a given reflector material, the ANISN code is used to generate the angular flux for a source inserted at a given angle and energy This angular flux must be generated for all input polar angles and energy groups The presently used albedos use four polar angles, corresponding to a $\mathrm{S}_{8}$ quadrature set in ANISN

Subroutine ALBIN integrates and normalızes the angular current to form the probability distribution tables Entry point ALBEDO utilizes these probability tables to determıne from the input angle and energy of a neutron, its probability of return, and if the neutron is returned, its returning angle and energy

\section{$5 \sigma_{p}$ or Resonance Corrected Cross Sections for Homogeneous Systems}

" $\sigma_{p}$ " is a resonance correction that is made to compensate for the self-shielding of incident neutrons due to the nature of the material

A $\sigma_{p}$ correction is generally used for resonance nuclides The $\sigma_{p}$ correction is usually much more important for U-238 than for U-235 If a $\sigma_{p}$ should have been used for U-238 but infinite dilution cross sections were used instead, the k-effective calculated by KENO may be too low

The $\sigma_{p}$ of a resonance nuclide in a homogeneous system is calculdted according to the following equation

$$
\sigma_{\mathrm{p}_{\mathrm{D}}}=\frac{\sum_{i=1}^{\mathrm{M}} \sigma_{\text {scatt }_{1}} \mathrm{~N}_{1}}{\mathrm{~N}_{\mathrm{D}}}
$$

where

$\sigma_{\varsigma a t}$ is the scattering cross section in the resonance energy range for the $1 t h$ component of the mixture, itn component of the mixture,

$N_{t}$ is the number density of the th component of the mixture in atoms/barn-cm, $M$ is the number of components in the mixture, and

$\mathbf{N}_{D}$ is the number density of the isotope for which $\sigma_{p_{D}}$ is being calculated 
A table of approximate $\sigma_{\text {scat }}$ for several nuclides is given below

Table IV-1 Approximate scattering cross section for frequently used elements

\begin{tabular}{|c|c|}
\hline Element & $\sigma_{\text {scatt }}$ \\
\hline Al & 14 \\
\hline B & 40 \\
\hline C & 46 \\
\hline F & 34 \\
\hline $\mathrm{I} \mathrm{e}$ & 114 \\
\hline $\mathrm{H}$ & 210 \\
\hline $\mathbf{K}$ & 22 \\
\hline Mo & 60 \\
\hline $\mathrm{N}$ & 100 \\
\hline $\mathrm{Na}$ & 31 \\
\hline O & 37 \\
\hline Sı & 22 \\
\hline Th & 120 \\
\hline All U & 120 \\
\hline $\mathrm{Cl}$ & 60 \\
\hline $\mathrm{Pu}$ & 120 \\
\hline $\mathrm{Cu}$ & 75 \\
\hline L1 7 & 10 \\
\hline $\mathrm{Nb}$ & 63 \\
\hline $\mathrm{N}_{1}$ & 175 \\
\hline $\mathrm{Zr}$ & 62 \\
\hline $\mathrm{Cr}$ & 43 \\
\hline $\mathbf{M}$ & 65 \\
\hline
\end{tabular}




\section{APPENDIX V Interpretation of KENO IV Results}

Results printed by KENO IV generation-by-generdtion as they are calculated, include GENERATION, K-EFFECTIVE, ELAPSED TIME (MIN), AVG K-EFF, DEVIATION, and MATRIX K-EFF The k-effective is calculated and printed for each generation The elapsed time is the amount of time spent in executing the program to the end of that generation The AVG K-EFF, AKBAR, is the running average of the k-effectives (note that it is set to 10 for the first two batches) The devidtion is the deviation associated with the average k-effective if matrix $k$ calculations by unit were specified, the result is printed under the heading MAIRIX K-EFF This result is the principal eigenvalue of the "FISSION PROBABILIIY MATRIX BY UNI $\Gamma$ " and should tend to converge as more and more generdtions are run If matrix $k$ calculations were not specified, reros will be printed The printout associated with the matrix $k$ options is described in the matrix k-effective section of TIPS FOR USING KENO

The individual k-effectives and the running dierage k-effectives are printed to provide information about how rapidly the code is running and how stable k-effective is When interpreting KENO IV results, it is suggested that the k-effective of the problem be determined from the page or pages where the lifetime and generation times are printed These k-effectives, printed under the heading AVERAGE K-EFFECTIVE is simply the average of the individual k-etfectives when the $k$-effectives of the first $\mathrm{N}$ generations have been excluded from the averaging process $\mathrm{N}$ is printed under the heading NO OF INITIAI GENERAIIONS SKIPPED 1 he devidtion from the mean is printed under the hedding DEVIATION for convenience, the 67,95 , and $99 / /$ confidence interval are printed for each average k-effective The NUMBER OF HIS IORIES is the number of neutron histories that were utilized in determining the average k-effective it is worthwhile to verity that the average k-effectives do not drift significantly as more and more generations are skipped Iaturalls the last few average k-effectives should be excluded from this condition because so few histories are involved in averaging them If a drift in the average $\mathrm{k}$-effectives is apparent, it could indicate a poorly converged source A more accurate representation of the source through a different starting distribution may correct the problem It is usually advisable to run at least 50 generations in order to be sure the problem has converged

The leakage, absorptions, and tissions are printed by energy group and may be further divided by geometry region The fissions by energy group give an indication of where the fission actinity has occurred A well-moderdted or thermal system should have a "soft spectrum" with most of the fissions occurring in the thermal energy groups A "fast" system should have most of the fission occurring in the upper energy groups The sum of the total leakage and absorption should be ver close to $10 \mathrm{lt}$ albedos are not utilized and severe weighting is not imposed The total fissions should be very nearly equal to the average k-effective for skıping NSKIP generdtions

The fission density, percent devidion and total fissions are printed for each region in the problem I he summation of the total fissions over all geometri regions is equal to the total fissions (1 e, the one printed with the leakdges and absorptions), which in turn is the k-eflective of the system The tission density for a given region is simply the total fissions for that region divided by the volume of that region and is in units of fissions per cubic centimeter

KENO IV calculates a volume averaged track length flux in units of neutrons per square centimeter pei source neutron These fluxes are printed with their associated deviations for each geometry region and energy group 
The frequency distributions are printed last These are plots of the frequency with which the individual generation k-effectives fall within a certain range in k-effective The range is scaled such that the plots do not exceed the width of a page One asterisk is printed for each k-effective that is calculated This does exclude the first NSKIP (number of generations to be skipped) generations for the first plot A total of four plots is made, (1) All generations, (2) the last three-quarters of the generations, (3) the last one-half of the generations and (4) the last one-fourth of the generations These plots can be used to estimate the normality of the distribution of the $k$-effectives and can sometimes show a trend indicative of source convergence difficulties 


\section{APPENDIX VI}

\section{Sample Problem Input}

This appendix contains a set of 19 sample problems that demonstrate some of the options avalable in KENO IV Included for each sample problem is a brief problem description followed by the card input data necessary to execute the problem Selected printouts are included in Section 2 of this appendix

\section{SAMPLE PROBLEM 1 2C8 BARE}

This problem is a simple $2 \times 2 \times 2$ array of uranium metal cylinders as described in the article, "Critical Three-Dimensional Arrays of U(93 2)-Metal Cylinders"(1), by J T Thomas This critical experiment is designated in Table II of that artıcle as cylinder index 11 and reflector index 1

\section{CARD INPUT}

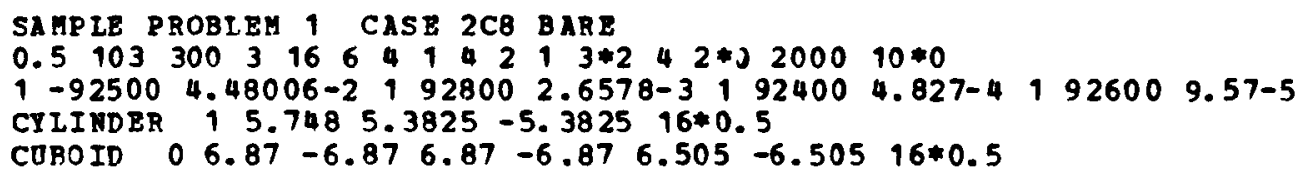

\section{SAMPLE PROBLEM 2 2C8 BARE WITH 8 BOX TYPES MATRIX CALCULATION}

This problem is the same as sample problem 1 except it is set up as a mixed box problem with each unit of the arrdy defined as a different box type Matrix k-effective will be calculated for this problem by both unit and box type The print flag is set to print all cross section data A cosine start is used

\section{CARD INPUT}

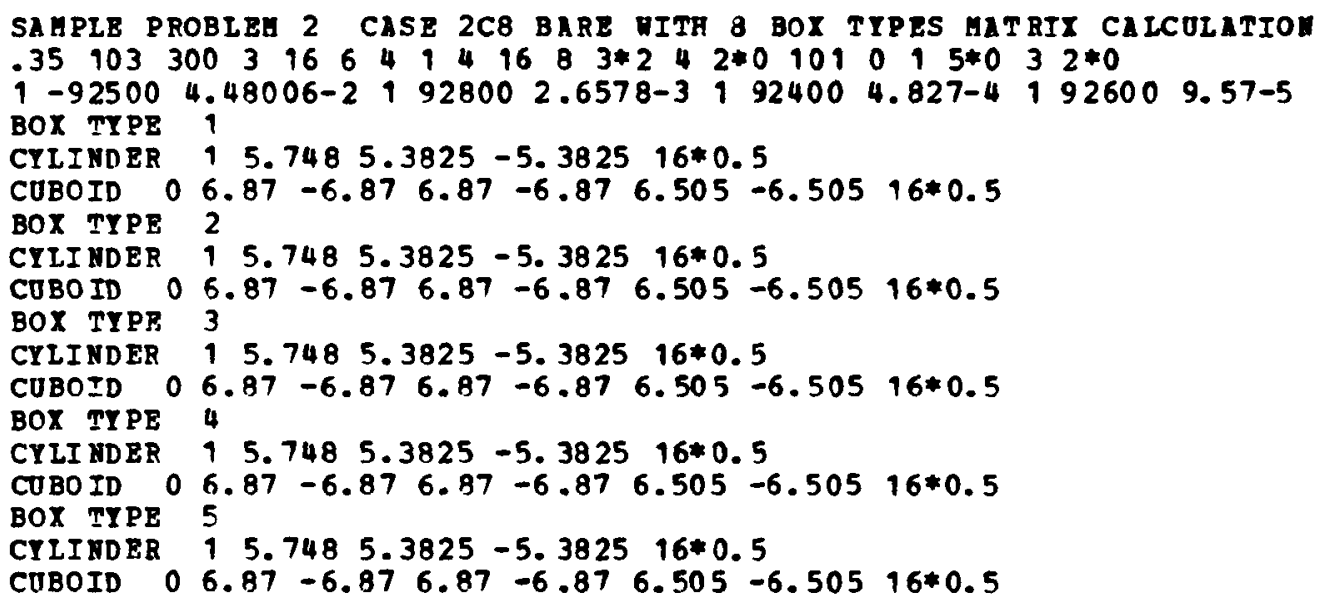




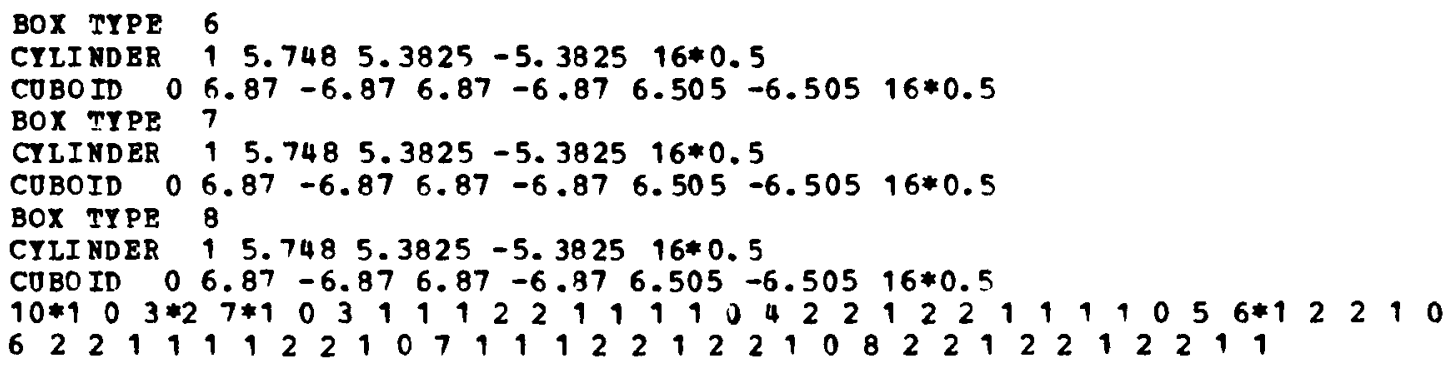

SAMPLE PROBLEM 3 2C8 BARE MIXED BOX WITH 2 BOX TYPES (XSECS FROM PRIOR CASE)

Same as sample problem 2 except (1) use cross sections from case 2 (the preceding case), (2) set up as 2 box types with the bottom layer being box type 1 and the top layer being box type 2

\section{CARD INPUT}

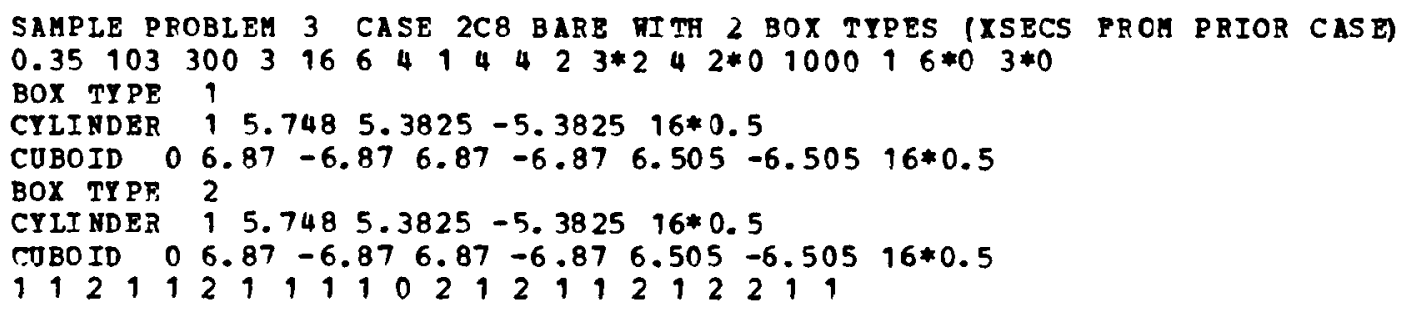

SAMPLE PROBLEM 4 2C8 BARE, MIXED BOX, SEARCH, XSEC, GEOMETRY FROM PRIOR CASE

Use cross sections and geometry from problem 3 (precedıng case) It will do a search on the radius of the cylinders, maintaining the initial height, until it is within I standard deviation of a k-effective of 0975 , or until three passes have been made Search constants of 1.0 were entered for the radius of the cylinders and search constants of 0.0 were entered for the cylinder height and the cuboid dimensions

\section{CARD INPUT}

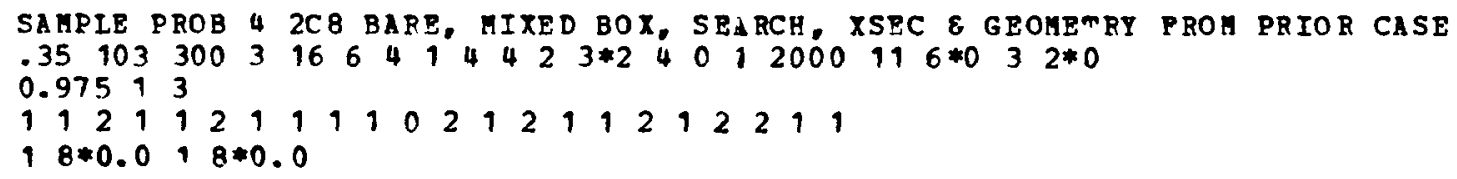




\section{SAMPLE PROBLEM 5 2C8 15.24 CM PARAFFIN REFL}

A $2 \times 2 \times 2$ array of uranium metal cylinders reflected by six inches of paraffin on all faces. This critical experiment ${ }^{10}$ is designated as cylinder index 11 and reflector index 5 in Table II of reference 10

\section{CARD INPUT}

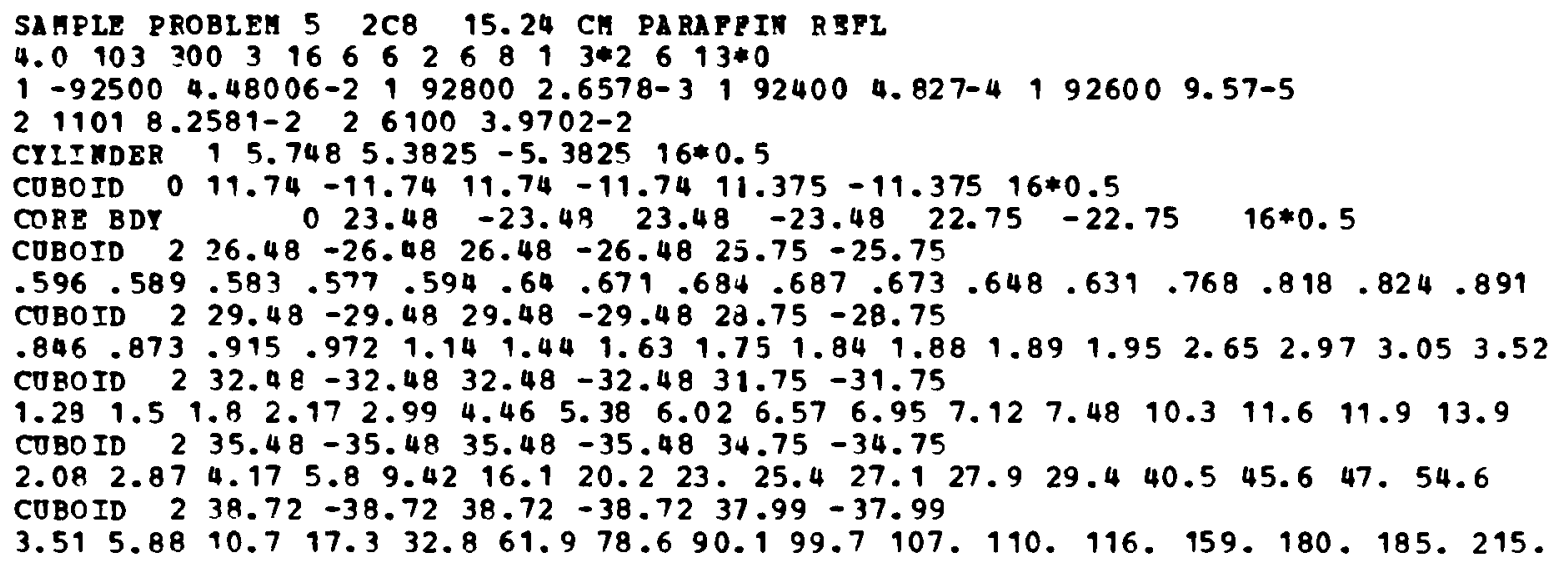

SAMPLE PROBLEM 6 2C8 15.24 CM PARAFFIN REFL AUTOMATIC REFL

This problem is the same as sample problem 5 except it is set up using the automatic reflector option instead of describing the reflector manually. Computer output for this problem is included in Section 2 of this appendix

\section{CARD INPUT}

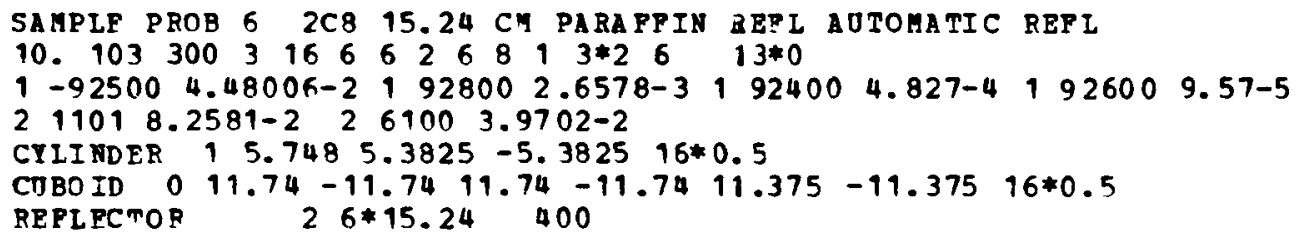




\section{SAMPLE PROBLEM 7 2C8 12 INCH PARAFFIN ALBEDO REFLECTOR}

This problem is the same as sample problems 5 and 6 except the reflector 15 represented by a 12-inch paraffin albedo Note the decrease in execution time when using albedo reflector instead of doing actual tracking Note also that k-effective is somewhat higher for this system, probably due to the small edge size of the system ${ }^{11}$

\section{CARD INPUT}

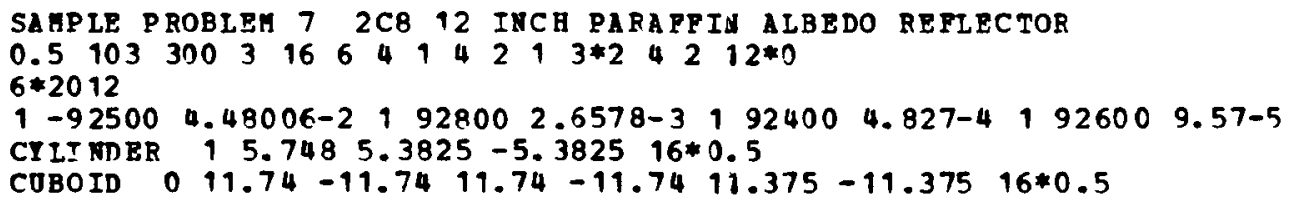

\section{SAMPLE PROBLEM 8 2C8 SPACING SEARCH}

This problem is set up with an initial spacing of $\pm 7557 \mathrm{~cm}$ in the $\mathrm{x}$ and $\mathrm{y}$ directions and $\pm 71555 \mathrm{~cm}$ in the $\mathrm{z}$ direction The search option is activated to search for a k-effective within two standard deviations of 1000 The experimentally correct result ${ }^{10}$ is $\pm 687 \mathrm{~cm}$ in the $x$ and $y$ directions and $\pm 6505 \mathrm{~cm}$ in the $z$ direction Computer printout for this problem is included in Section 2 of this appendix

\section{CARD INPUT}

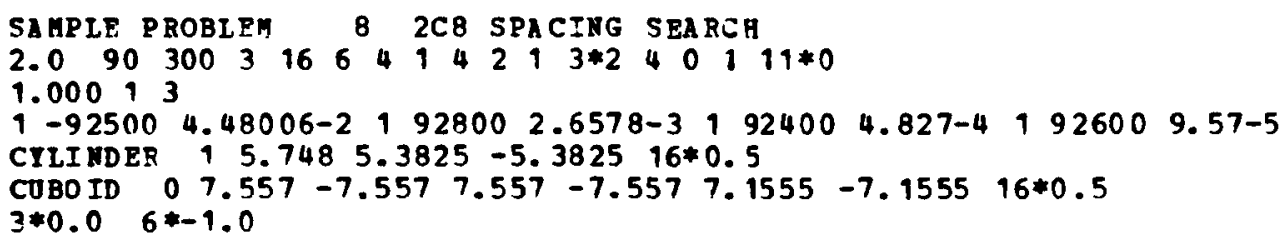

\section{SAMPLE PROBLEM 9 2C8 REFLECTOR THICKNESS SEARCH}

This problem is initially described with a $05 \mathrm{~cm}$ thick paraffin reflector $A$ search will be made for the reflector thickness of paraffin that is necessary to make the system critical This occurs experimentally at a reflector thickness of $13 \mathrm{~cm}^{10}$

\section{CARD INPUT}

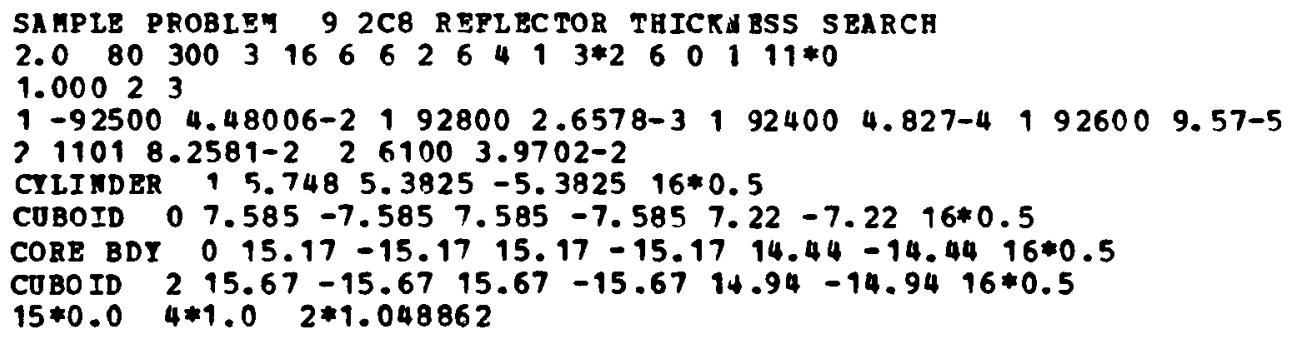


SAMPLE PROBLEM 10 ONE 2C8 UNIT (SINGLE UNIT)

One of the $2 \mathrm{C}$ units is described and run as a single-unit problem $(\mathrm{NBOX}=0)$ and its $\mathrm{k}$-effective is calculated

\section{CARD INPUT}

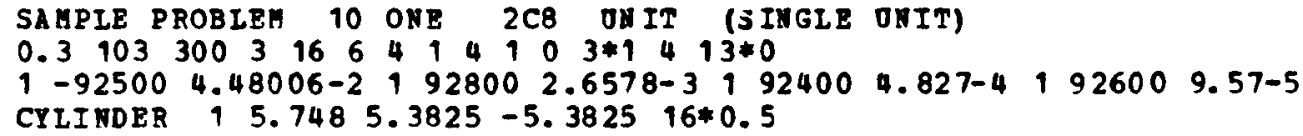

\section{SAMPLE PROBLEM 11 BARE 2C8 USING SPECULAR REFLECTION}

One of the $2 \mathrm{C} 8$ units is described and the $2 \times 2 \times 2$ array is simulated by using specular reflection on the positive $x, y$, and $z$ faces of the unit This is a simulation of sample problem 1

\section{CARD INPUT}

SAMPIE PROBLEM 11 BARE 2C8 OSIYG SPECOLAR REPLECTION

$0.3103 \quad 300 \quad 3 \quad 16 \quad 6 \quad 4 \quad 142513 * 144112 * 0$

$-1.00 .0-1.00 .0-1.00 .0$

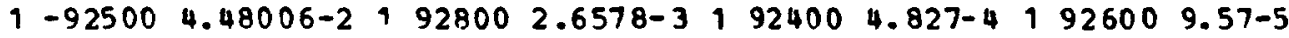

CYIINDER $15.748 \quad 5.3825 \quad-5.3825 \quad 16 * 0.5$

COBCID $06.87 \quad-6.87 \quad 6.87-6.87 \quad 6.505-6.505 \quad 16 * 0.5$

\section{SAMPLE PROBLEM 12 INFINITELY LONG CYLINDER FROM 2 C8 UNIT}

The fuel and cylinder radius from sample problem 1 is used The length of the cylinder is arbitrarily chosen to be $20 \mathrm{~cm}$ and the unit is specularly reflected on the top and bottom to create an infınıtely long cylınder

\section{CARD INPUT}

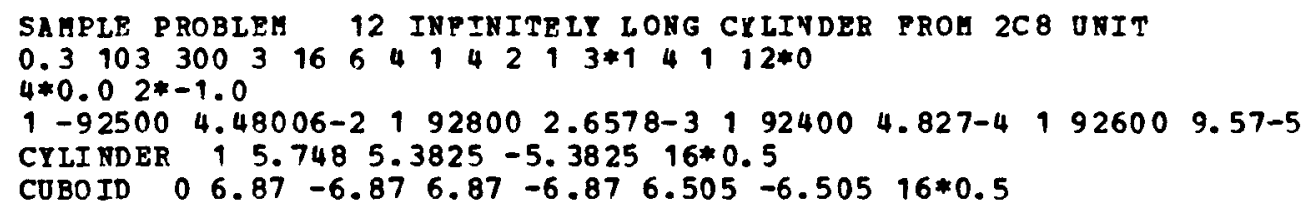




\section{SAMPLE PROBLEM 13 INFINITE ARRAY OF 2C8 UNITS}

The geometry description from sample problem 1 is used and the cuboid is specularly reflected on all faces to create an infinite array of units having an edge spacing of $2.244 \mathrm{~cm}$ in the $\mathrm{x}$ and $\mathrm{y}$ directions and $2.245 \mathrm{~cm}$ in the $\mathrm{z}$ direction.

\section{CARD INPUT}

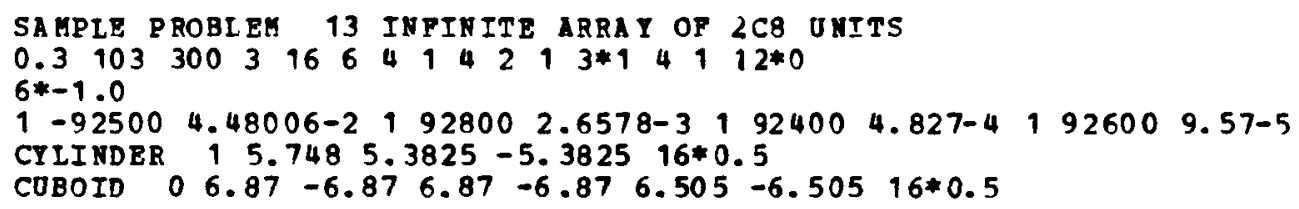

\section{SAMPLE PROBLEM $14 \quad 93 \%$ UO $_{2} \mathrm{~F}_{2}$ SOLUTION SPHERE FORWARD CALCULATION}

A single uranyl fluoride sphere is described as a single unit and run as a forward (regular k-effective) problem

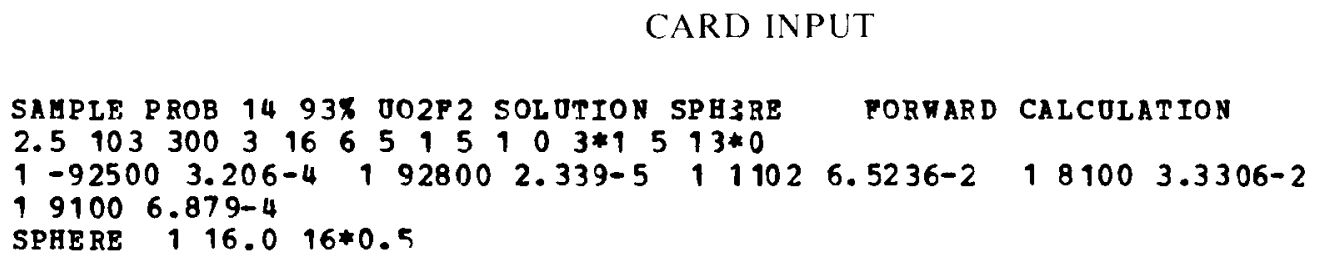

The uranyl fluoride sphere from sample problem 14 is described and run as an adjoint calculation Note that the forward and adjoint k-effectives should be the same within statistical error when a problem is run both ways

\section{CARD INPUT}

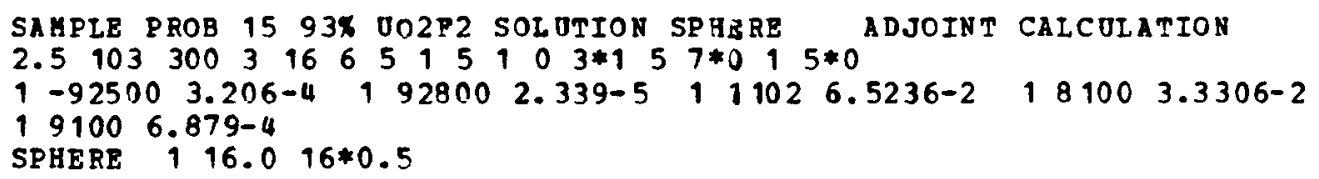




\section{SAMPLE PROBLEM 16 GENERALIZED GEOMETRY GROTESQUE}

This is a generalized geometry description of a critical assembly ${ }^{12,13}$ of eight enriched uranium units placed on a diaphragm, with an irregularly shaped centerpiece positioned in the center hole of the diaphragm. The assembly and centerpiece are shown in Figure 4. The eight units consist of an approximate parallelepiped with an irregular top, a parallelepiped, and six cylinders of assorted sizes. The centerpiece, which penetrated the hole in the support diaphragm consists of a cylinder topped by a parallelepiped topped by a hemisphere. The computer printout for this problem is included in Section 2 of this appendix.

\section{CARD INPUT}

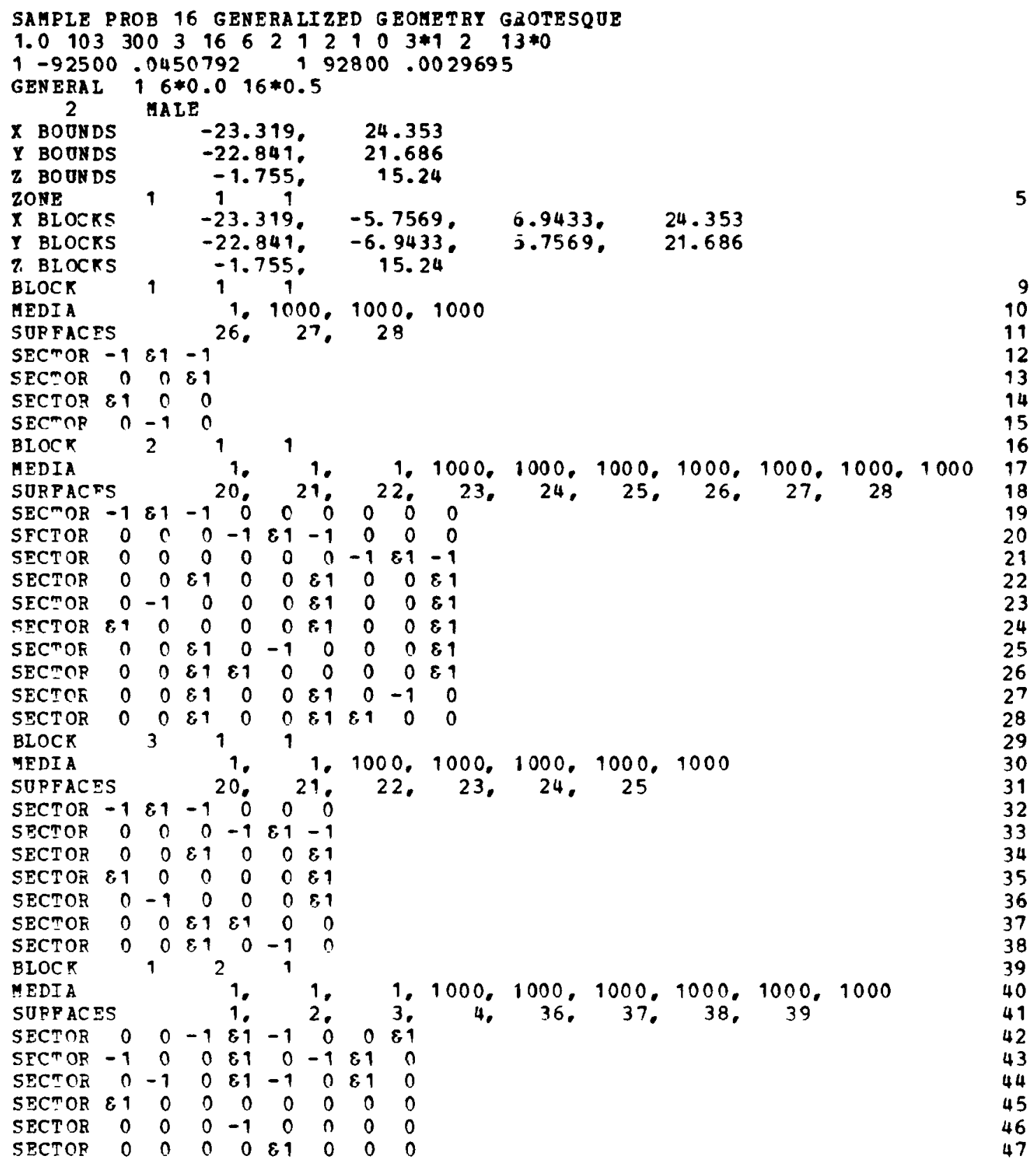




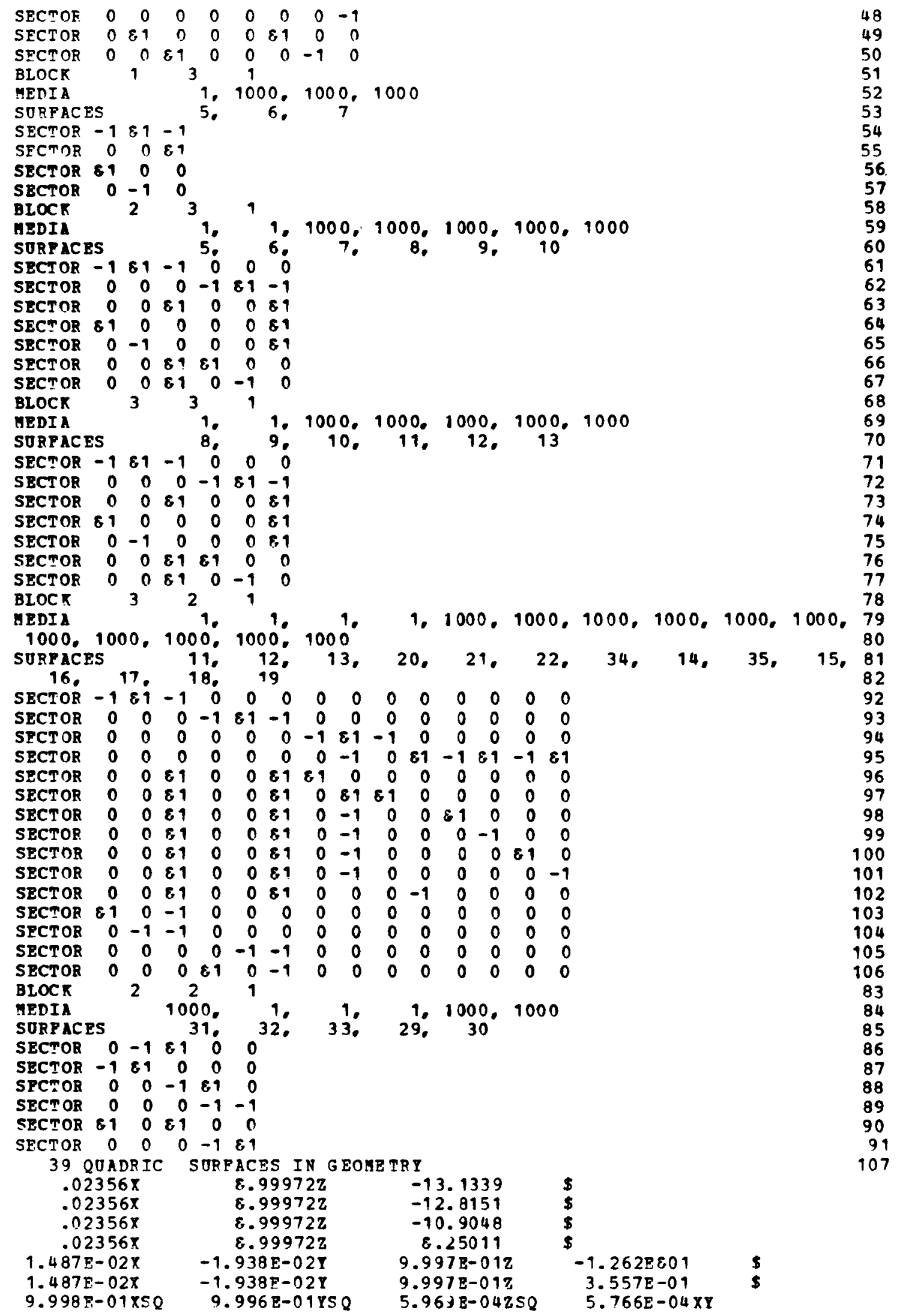




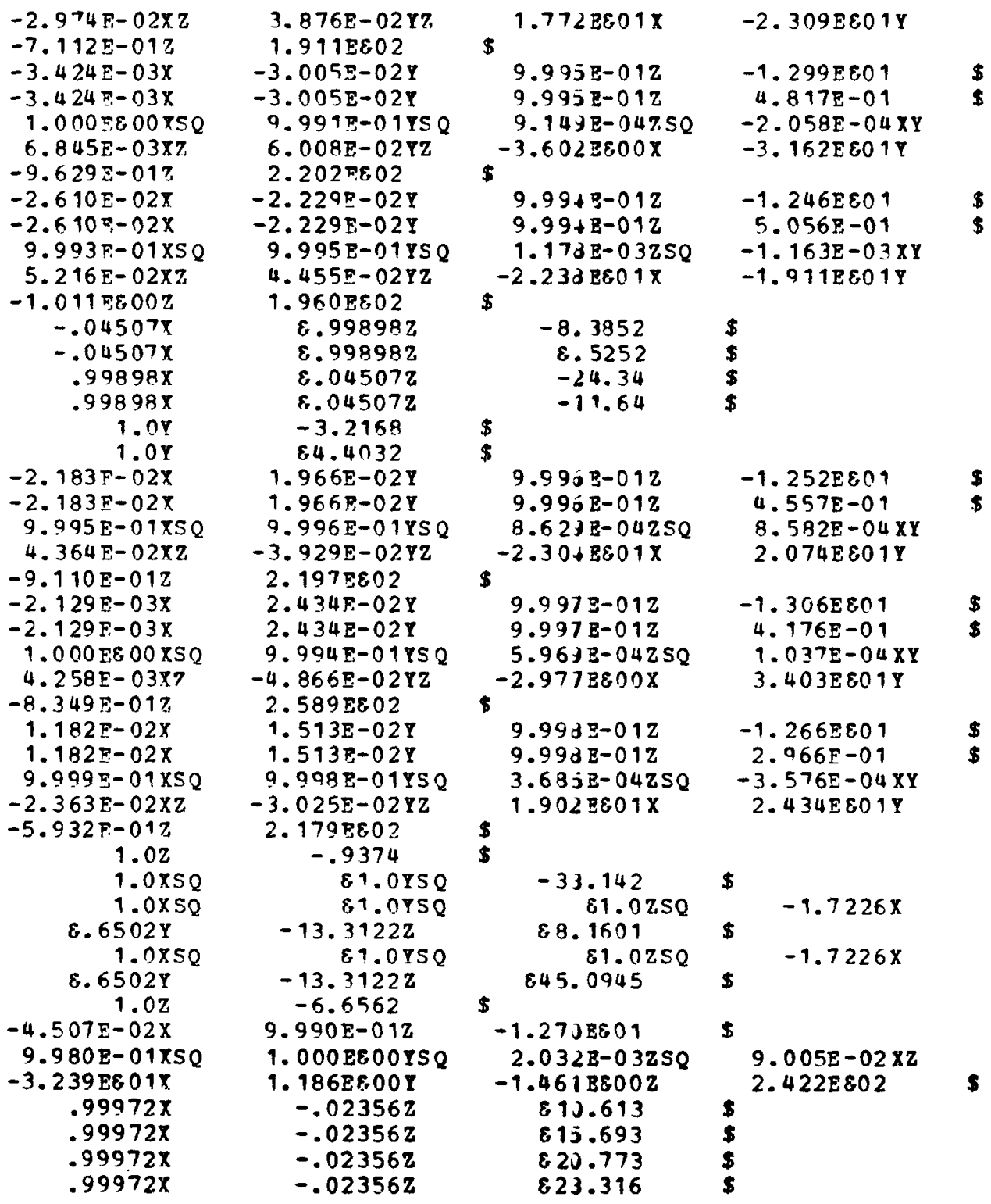




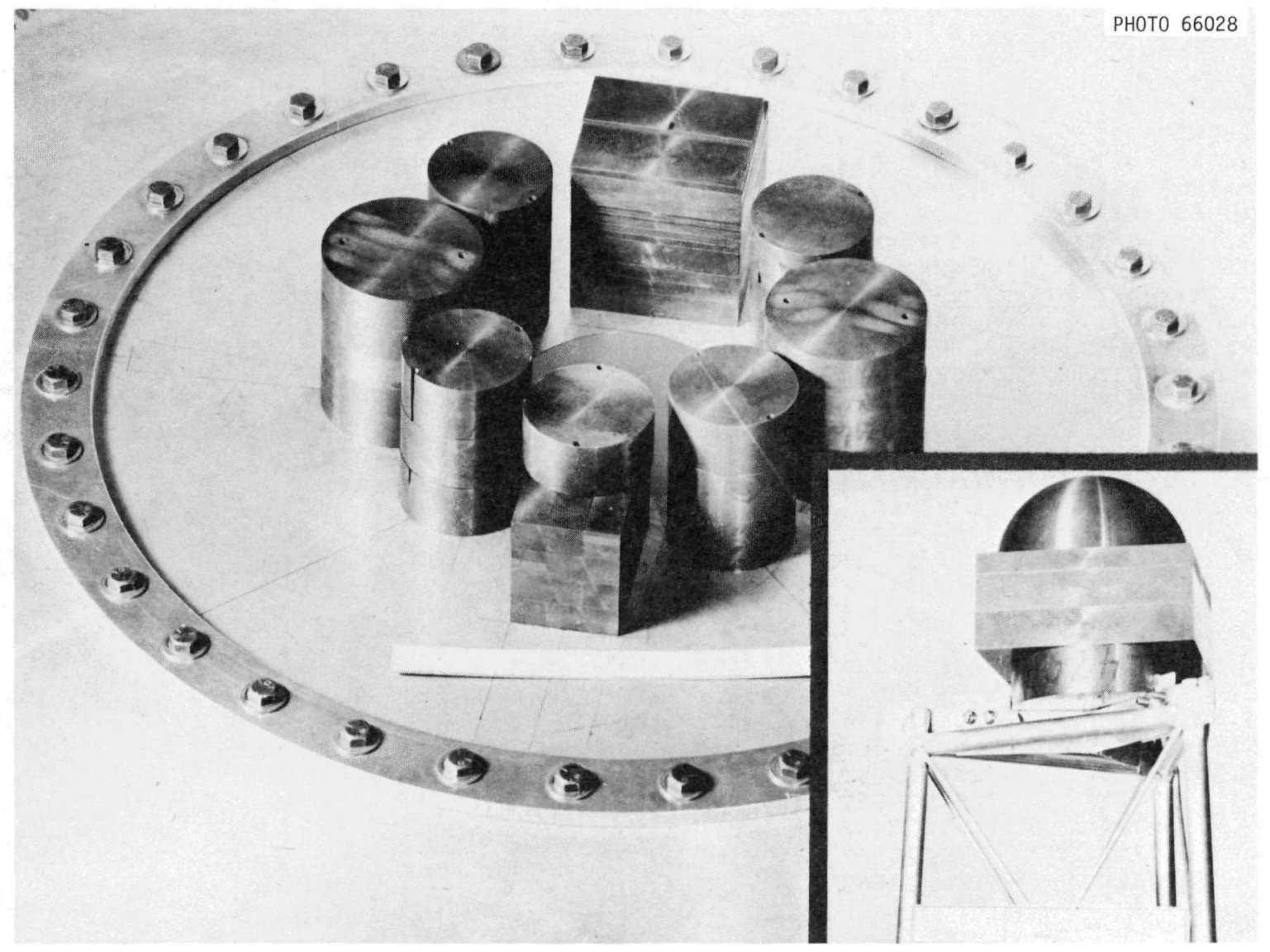

Figure 4 . 


\section{SAMPLE PROBLEM 17 2C8 BARE WRITE RESTART}

This problem is the same as sample problem 1, a $2 \times 2 \times 2$ array of metal cylinders. Restart information is written out after the completion of every fifth generation The computer printout for this problem is included in Section 2 of this appendix

\section{CARD INPUT}

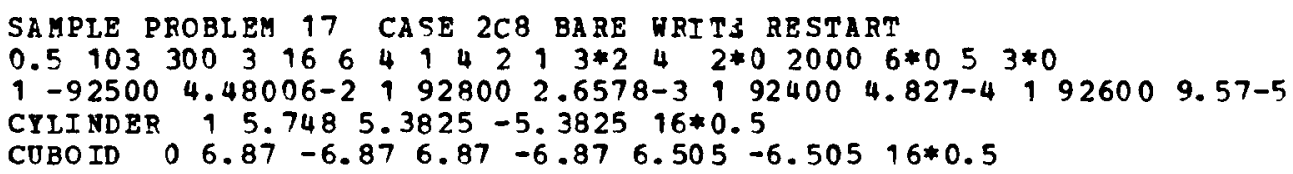

\section{SAMPLE PROBLEM 18 2C8 BARE READ RESTART DATA}

This problem is a restart of sample problem 17 The problem is restarted from the tenth set of restart data that was written by sample problem 17 The computer printout for this problem is included in Section 2 of this appendix

\section{CARD INPUT}

SAMPLE PROBLEM 18 CASE 2C8 BARE READ RESTART DATA

$0.5103300 \quad 3166414213 * 242 * 020000-10 \quad 8 * 0$

\section{SAMPLE PROBLEM 194 AQUEOUS 4 METAL MIXED BOX MATRIX CALCULATION}

This problem is a critical experiment consisting of a composite array ${ }^{16,14}$ of four highly enriched uranium metal cylinders and four cylindrical plexiglas containers filled with uranyl nitrate solution The metal units in this experiment are designated in Table II of ref 10 as cylinder index 11 and reflector index 1 This system is illustrated in Fig. 5. The computer printout for this problem is included in Section 2 of this appendix.

\section{CARD INPUT}

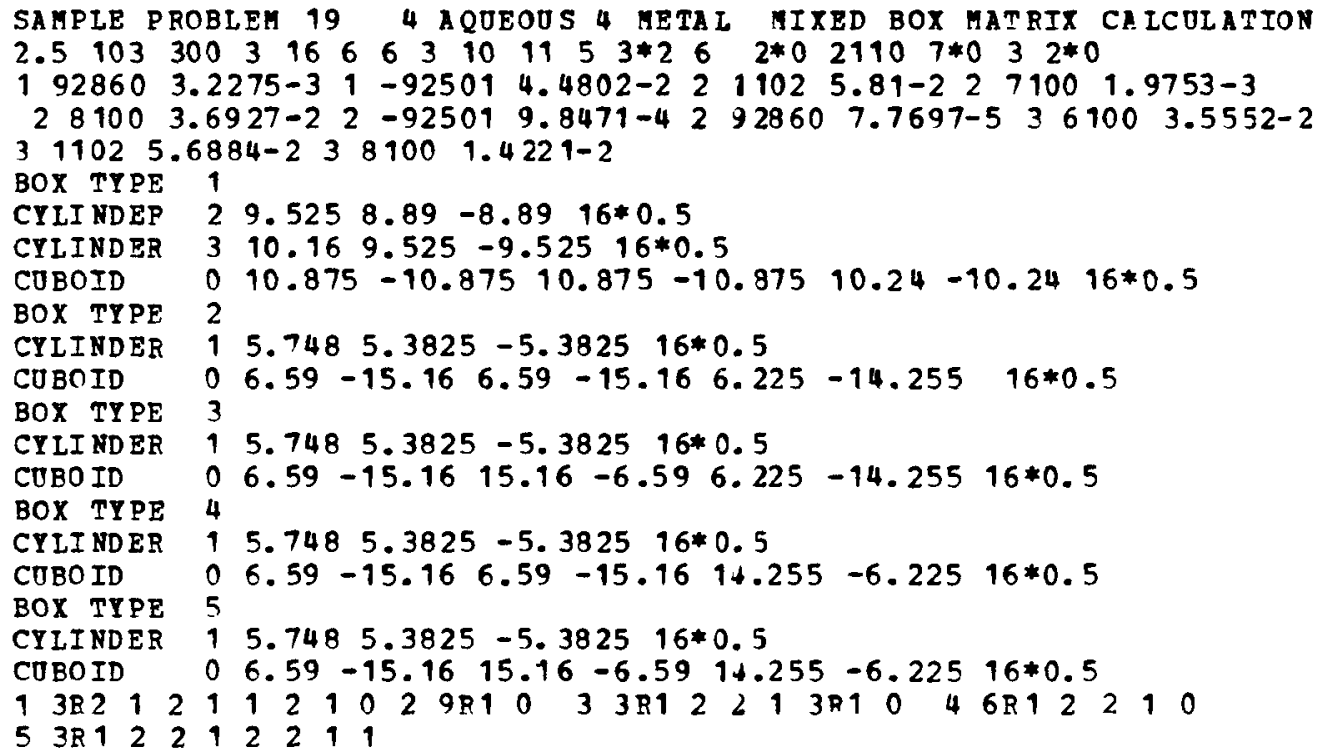


The metal units in this experiment are designated in Table II of reference 10 as cylinder index 11 and reflector index 1 .

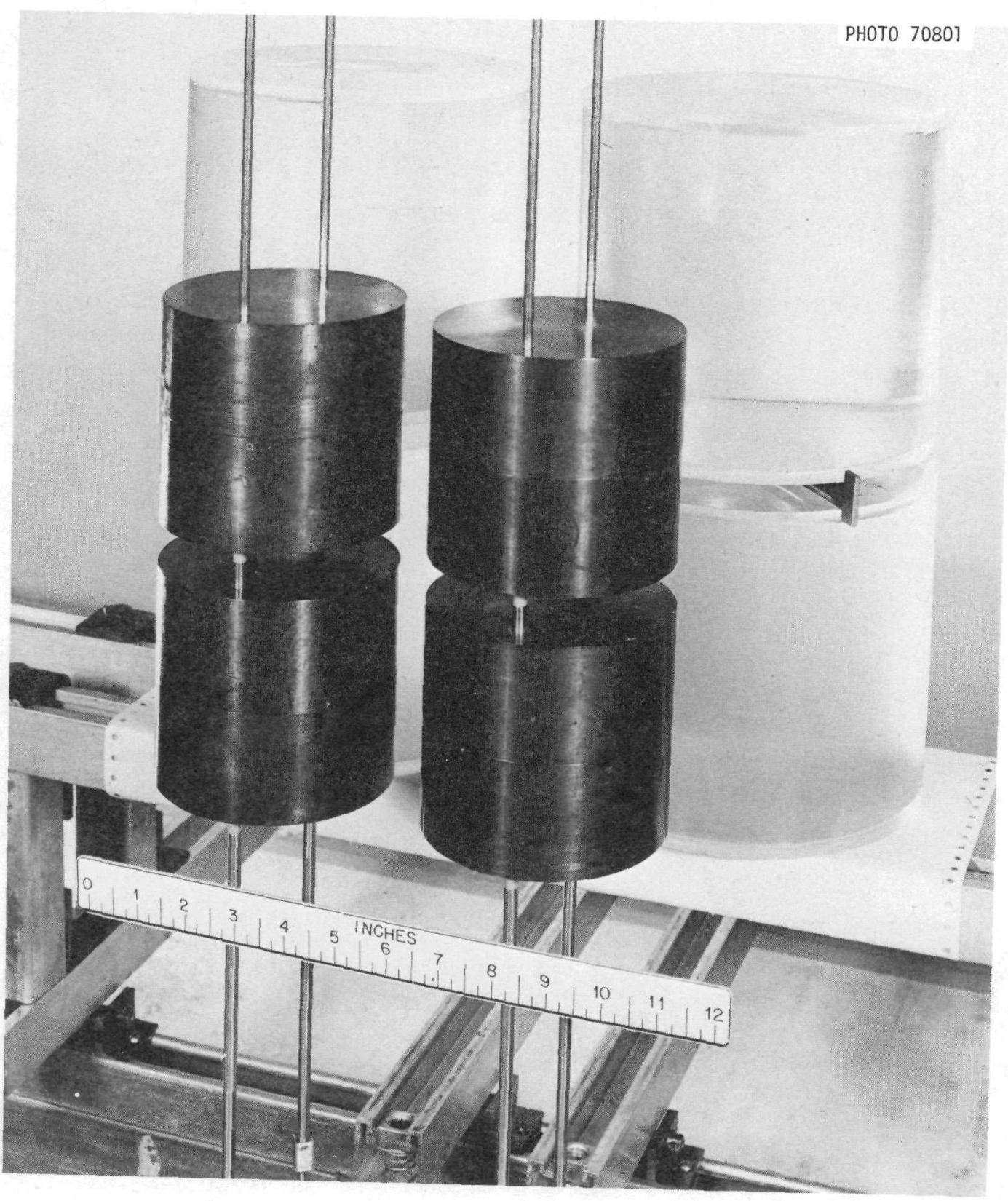

Figure 5.

\section{Sample Problem Output}

The computer printout for sample problems $6,8,16,17,18$, and 19 are included in this section. 
SAMPLE PROB $6 \quad 268 \quad 15.24$ CM PARAFFIN REFL AUTOMATIC REFL

NUMBER OF GENERATIONS 103

NUMBER PER GENERATION

300

NUMBER TF GENERATIONS TO BE SKIPPED 3

NUMBER OF ENERGY GROUPS

MAX. NUMBER OF ENERGY TRANSFERS

NUMBER OF INPUT NUCLIDES

NUMBER OF MIXTURES

NUMBER OF MIXING TABLE ENTRIES

NUMBER DF GEOMETRY CARDS

NUMBER OF BOX TYPES

NUMBER OF UNITS IN $X$ OIRECTION

NUMBER OF UNITS IN $Y$ OIRECTION

NUMBER OF UNITS IN $Z$ DIRECTION

NUMBER OF NUCLIDES READ FROM TAPE

ALBEDO TYPE

SEARCH TYPE

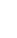

MAXIMUM TIME $=10.0000$ M INUTES

STORAGE LOCAT IONS REOU IRED FOR THIS JOB REMAINING AVA ILABLE LOCATIONS= 27982

\section{START TYPE}

GENERATIONS BETWEEN CHECKPOINTS

LIST INPUT X-SECTIONS READ FROM TAPE

LIST 1-D MIXTURE X SECTIONS

LIST 2-D MIXTURE $X$-SECTIONS

LIST FISS. AND ABS. BY REGION

USE X-SECTIONS FROM PREVIOUS CASE

USE GEOMETRY FROM PREVIOUS CASE

USE VELOCITIES FROM PREVIOUS CASE

COMPUTE MATRIX K-EFFECTIVE BY UNIT

COMPUTE MATRIX K-EFFECT IVE BY BOX TYPE NO

LIST FISS FROB MATRIX BY UNIT

ADJOINT CALCULATION NO

USE EXPONENTIAL TRANSFORM NO

CALCULATE FLUX YES

CALCULATE FISSION DENSITIES YES

6834 
SAMPLE PROB 62 C8 15.24 CM PARAFFIN REFL AUTOMATIC REFL

$$
\begin{array}{ccc}
\text { MIXTURE } & \text { NUCLIDE } & \text { DENSITY } \\
1 & -92500 & 4.48006 E-02 \\
1 & 92800 & 2.65780 E-03 \\
1 & 92400 & 4.82700 E-04 \\
1 & 92600 & 9.5700 C E-05 \\
2 & 1101 & 8.25810 E-02 \\
2 & 6100 & 3.57020 E-02
\end{array}
$$

CROSS SECTIONS READ FROM TAPE

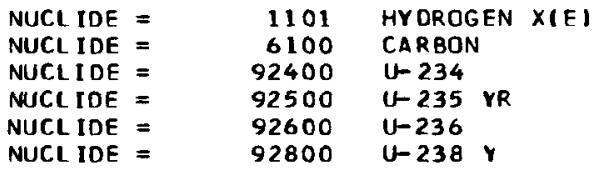

HANSEN ROACH

HANSEN ROACH

MIHALCZO MOO

MIHALCZO MOO OF H-R U-238

HANSEN ROACH 
SAMPLE PROB 6 2C8 15.24 CM PARAFFIN REFL AUTOMATIC REFL

MIXTURE $=1$

\begin{tabular}{|c|c|c|c|c|c|}
\hline P. & $\begin{array}{l}\text { BSORPTION } \\
\text { ROBABILITY }\end{array}$ & $\begin{array}{l}\text { NUF ISS ION } \\
\text { PROBABILITY }\end{array}$ & $\begin{array}{l}\text { NON-ABSOR PTI } \\
\text { PROBABILIITY }\end{array}$ & $\begin{array}{l}\text { ON TOTAL } \\
\text { CROSS-SECTION }\end{array}$ & FISS ION \\
\hline & $2.88282 \mathrm{E}-01$ & $8.16362 \mathrm{E}-01$ & $7.11718 E-01$ & $2.03826 \mathrm{E}-01$ & $2.04000 E-01$ \\
\hline & $2.79495 \mathrm{~F}-01$ & $6.86119 E-01$ & $7.20504 \mathrm{E}-01$ & & \\
\hline & $2.71457 \mathrm{E}-01$ & $6.27380 E-01$ & $28542 E-01$ & $23507 \mathrm{E}-01$ & $0 E-01$ \\
\hline & & & -01 & & \\
\hline & & 4. & $D E-01$ & $3.8 C$ & \\
\hline & $2.39931 E-01$ & $4.61768 E-01$ & $7.60215 E-01$ & $5.94246 E-01$ & 1. \\
\hline 7 & $3.44514 E-01$ & $682 E-01$ & $E-01$ & $7.21796 \mathrm{E}-01$ & \\
\hline 8 & $5.06884 E-01$ & $8.72719 E-01$ & $4.93116 E-01$ & $9.93835 E-01$ & OOOE 00 \\
\hline & 7.217108 & $113 E 00$ & $E-O \mathbf{l}$ & 73 & \\
\hline & & $837 E 00$ & 01 & $37 \mathrm{E}$ & \\
\hline 1 & $8.86332 E-01$ & $1.14093 \mathrm{EOO}$ & $1.13668 \mathrm{E}-01$ & $4.19760 E 00$ & OOE 00 \\
\hline & & $8.92047 E-01$ & & & \\
\hline & & $7950 E \quad 00$ & -01 & $2565 E$ & 00 \\
\hline & $8.82566 F-01$ & $1.89106 \mathrm{E} 00$ & 1.174 & $4.06296 \mathrm{E} 00$ & $1.00000 E 00$ \\
\hline & & $93100 E 00$ & $33 E-02$ & $35157 \mathrm{E} \quad 01$ & OOE 00 \\
\hline & $3 E-01$ & $2.03304 E$ & $72 E-02$ & 5828 & 0 \\
\hline
\end{tabular}

CUMULATIVE TRANSFER PROBABILITIES

\begin{tabular}{|c|c|c|c|c|c|c|}
\hline$M$ & 0 & & & $1+$ & I+ & $I+$ \\
\hline 1 & $3.9857 E-01$ & $4.8931 E-01$ & $6.1384 E-01$ & $8.3220 E-01$ & $991 \mathrm{E}-01$ & $0000 E$ \\
\hline 2 & $5.4663 E-01$ & $6.2288 \mathrm{~F}-01$ & & & & \\
\hline 3 & $6.9055 E-01$ & $8.5777 E-C l$ & $5 E-01$ & $1.0000 E$ & $O E$ & OOE $O O$ \\
\hline 4 & 8. $8815 E-01$ & 9.7967E-01 & $1.0000 E 00$ & $1.0000 E 00$ & $O E O O$ & OOE 00 \\
\hline 5 & $9.8742 \mathrm{~F}-01$ & 1.00 & $1.0000 E 00$ & 1.0 & 1 & $10 E$ \\
\hline 6 & $9.9433 E-01$ & $1.0000 E 00$ & $1.0000 E 00$ & $1.0000 E$ & OE 00 & JOE 00 \\
\hline 7 & $9.9486 \mathrm{E}-01$ & $1.0000 E \quad 00$ & $1.0000 E 00$ & $1.0000 E$ & $O E$ & OE \\
\hline 8 & $3 E-01$ & $1.0000 E \quad 00$ & $1.0000 E 00$ & $1.0000 E$ & OE OO & OEE \\
\hline 9 & $9.9503 E-01$ & $1.0000 E \quad 00$ & $1.0000 E 00$ & $1.0000 \mathrm{E}$ & $O E O O$ & OE 00 \\
\hline 10 & $9.9490 F-01$ & $1.0000 E \quad 00$ & $1.0000 E 00$ & $1.0000 E 00$ & DOE OO & OOOE \\
\hline$=$ & & - & & & & \\
\hline 15 & $9.9591 \mathrm{~F}-01$ & $1.0000 \mathrm{OF} \quad 00$ & $1.0 \mathrm{COOE} 00$ & 1. & 1. & $O E$ \\
\hline 16 & $1.0000 E 00$ & $1.0000 E 00$ & $1.0000 E 00$ & $1.0000 E$ & 00 & $1.0000 \mathrm{E}$ \\
\hline
\end{tabular}

MUBAR
FROM
$+1$
I+ 2
$1+3$
$1+4$
I+ 5
$I=\frac{0.0}{2}$ THRU I $=\begin{aligned} & 0.0 \\ & 16\end{aligned}$ SAME AS ABOV
0.0
0.0
0.0 
SAMPLE PROB 6 2C8 15.24 CM PARAFFin REFL AUTOMATIC REFL

MIXTURE $=2$

\begin{tabular}{|c|c|c|c|c|c|}
\hline GP. & $\begin{array}{l}\text { ABSORPTION } \\
\text { PROBABIL ITY }\end{array}$ & $\begin{array}{l}\text { NU*F ISS ION } \\
\text { PROBABILITY }\end{array}$ & $\begin{array}{l}\text { NOA-ABSOR PTI } \\
\text { PROBABIL I TI }\end{array}$ & $\begin{array}{l}\text { ON TOTAL } \\
\text { CROSS-SECTION }\end{array}$ & $\begin{array}{l}\text { FISSION } \\
\text { SPECTRUM }\end{array}$ \\
\hline 1 & 0.0 & 0.0 & $1.00000 E 00$ & $1.67254 E-01$ & 0.0 \\
\hline 2 & 0.0 & 0.0 & $9.99999 E-01$ & $2.33100 E-01$ & 0.0 \\
\hline 3 & 0.0 & 0.0 & $9.99999 E-01$ & $3.68355 E-01$ & 0.0 \\
\hline 4 & 0.0 & 0.0 & $1.00000 E O C$ & 4.551 & 0.0 \\
\hline 5 & 0.0 & 0.0 & $1.00000 E O 0$ & $6.85995 E-01$ & 0.0 \\
\hline 6 & 0.0 & 0.0 & $1.00003 \mathrm{E} \quad 00$ & $1.13493 E \quad 00$ & 0.0 \\
\hline 7 & 0.0 & 0. & $9.99999 E-01$ & $1.35306 E 00$ & 0.0 \\
\hline 8 & $5.85257 E-05$ & 0.0 & $9.99941 E-01$ & $1.41102 E 00$ & 0.0 \\
\hline 9 & $2.34103 E-04$ & 0.0 & $9.99764 E-01$ & $1.41102 \mathrm{E} 00$ & 0.0 \\
\hline 10 & $4.68205 F-04$ & 0.0 & $9.99531 E-01$ & $1.41102 E 00$ & 0.0 \\
\hline 11 & $B .19360 E-04$ & 0.0 & $9.99179 E-01$ & $1.41102 E 00$ & 0.0 \\
\hline 12 & $1.45904 E-03$ & 0.0 & $9.98541 \mathrm{E}-01$ & $1.41499 E \quad 00$ & 0.0 \\
\hline 13 & $2.62627 \mathrm{~F}-03$ & 0.0 & $97373 E-01$ & $.41499 E \quad 00$ & 0.0 \\
\hline 14 & $3.47661 E-03$ & 0.0 & $9.96523 E-01$ & $1.66273 \mathrm{EOO}$ & 0.0 \\
\hline 15 & $4.80345 E-03$ & 0. & $95197 E-01$ & $2.24075 E 00$ & 0.0 \\
\hline & $.18326 E-03$ & 0.0 & $93817 E-01$ & $3.89238 E \quad 00$ & 0.0 \\
\hline
\end{tabular}

CUMULATIVF TRANSFER PROBABILITIES

\begin{tabular}{|c|c|c|c|c|c|c|}
\hline $\begin{array}{l}\text { FROM } \\
\text { I }\end{array}$ & Tn $1+$ & It & $1+2$ & $1+3$ & It & $1+$ \\
\hline 1 & $.9342 E-01$ & $6.8055 E-C 1$ & $7.9460 E-01$ & $9.0866 \mathrm{E}-01$ & $9.7729 E-C$ & 1.0 \\
\hline 2 & $2.2132 \mathrm{~F}-01$ & $5.3378 \mathrm{E}-\mathrm{Cl}$ & $7.9275 \mathrm{E}-01$ & $9.4828 \mathrm{E}-01$ & $9.9114 \mathrm{E}-01$ & $O F$ \\
\hline $\begin{array}{l}3 \\
4\end{array}$ & $\begin{array}{l}1.9459 \mathrm{E}-01 \\
2.8980 \mathrm{E}-01\end{array}$ & $\begin{array}{l}6.8300 \mathrm{E}-01 \\
8.3562 \mathrm{E}-01\end{array}$ & $\begin{array}{l}9.2064 E-01 \\
9.7206 E-01\end{array}$ & $\begin{array}{l}9.8655 \mathrm{E} \\
9.9510 \mathrm{E}\end{array}$ & $\begin{array}{l}9.9753 \mathrm{E} \\
9.9909 \mathrm{E}\end{array}$ & $\begin{array}{l}\text { DOE OO } \\
\text { DOE OO }\end{array}$ \\
\hline 5 & $4.8378 E-01$ & $9.1658 \mathrm{E}-\mathrm{Cl}$ & $5.8531 \mathrm{E}-01$ & 9. & $2 E$ & DOE OO \\
\hline 6 & $4.5508 E-01$ & $9.0727 E-01$ & S. $8330 E-01$ & $9.9691 \mathrm{E}-$ & $909 \mathrm{E}-$ & OEE \\
\hline 7 & $4.3686 F-01$ & $8.9936 E-01$ & S.8169E-01 & $9.9445 E-$ & $7 E$ & $O E$ \\
\hline 8 & $4.2409 E-01$ & $8.5734 E-01$ & & 9.85 & & \\
\hline 0 & $4.2557 \mathrm{E}-01$ & $8.3094 E-01$ & $9.4 \geq 34 E-01$ & $9.8314 E-01$ & $8 E-01$ & OOE \\
\hline 10 & $3.0123 E-01$ & $7.7240 \mathrm{E}-01$ & $161 E-01$ & 9.7 & $7 E$ & $O E$ \\
\hline 11 & 2.7 & $7.8814 E-01$ & $7 E-01$ & $9.7188 \mathrm{E}-01$ & 9.92 & \\
\hline 12 & $4 E-01$ & $7.7013 \mathrm{~F}-\mathrm{Cl}$ & $D E-02$ & $8 E-01$ & $10 E$ & OEE \\
\hline 13 & & $7.1175 \mathrm{E}-01$ & s. & $1.0000 E$ & $1.0000 \mathrm{E}$ & 1.0 \\
\hline 14 & $3.2264 F-01$ & $8.3553 F-01$ & $1.0000 E 00$ & $1.0000 E 00$ & $1.0000 E$ & $O E$ \\
\hline 15 & $E-01$ & 1.0 & OE 00 & $1.0000 \mathrm{E} 00$ & 1. & 1. \\
\hline 16 & $1.0000 E 00$ & $1.0000 E 00$ & $1.0000 E 00$ & $1.0000 E 00$ & $0000 \mathrm{E} 00$ & $.0000 E$ \\
\hline
\end{tabular}

MUBAR

\begin{tabular}{|c|c|c|c|c|c|c|}
\hline $\begin{array}{l}\text { RחM } \\
\text { I }\end{array}$ & It & It & $1+$ & It & 4 & + \\
\hline 1 & $\begin{array}{l}1.0211 E-02 \\
2.4011 E-02\end{array}$ & $\begin{array}{l}5.6558 E-01 \\
6.4515 E-C 1\end{array}$ & $\begin{array}{l}5.4578 E-01 \\
5.8276 E-01\end{array}$ & $\begin{array}{l}4.1126 E-01 \\
3.5763 E-01\end{array}$ & $\begin{array}{l}2.5180 E-01 \\
1.7355 E-01\end{array}$ & $\begin{array}{l}1.0870 E-01 \\
8.0000 E-02\end{array}$ \\
\hline 3 & 1.612 & 6.1 & $E-01$ & 2.2 & & \\
\hline & 1.746 & 5. & 1 & 1. & 4. & 0 \\
\hline 5 & 4.21 & 5. & & 9. & & \\
\hline 6 & & & $E-01$ & 1. & $3.3333 \mathrm{E}$ & \\
\hline 7 & 01 & & $E-01$ & $005 E-01$ & $.5574 \mathrm{E}-02$ & 3.33331 \\
\hline
\end{tabular}


$8 \quad 4.8539 E-01 \quad 5.4961 E-01 \quad 2.5410 E-01 \quad 1.4167 E-01 \quad 8.1967 E-02 \quad 3.8462 E-02$

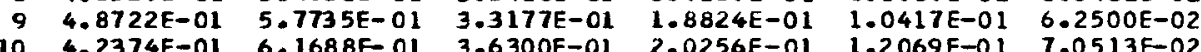

$\begin{array}{cccccccc}10 & 4.2374 E-01 & 6.1688 E-01 & 3.6300 E-01 & 2.0256 E-01 & 1.2069 E-01 & 7.0513 E-02 \\ 11 & 3.9067 E-01 & 6.1789 E-01 & 3.5691 E-01 & 2.1140 E-01 & 1.2500 E-01 & 4.1667 E-02\end{array}$

$12 \quad 3.8497 E-01 \quad 6.1886 E-C 1 \quad 3.7502 E-01 \quad 2.2673 E-01 \quad 7.2351 E-02 \quad 0.0$

$\begin{array}{lllllll}13 & 3.5989 \mathrm{E}-01 & 6.3896 \mathrm{E}-01 & 4.0 \mathrm{OC1} 1 \mathrm{E}-01 & 1.2882 \mathrm{E}-01 & 0.0 & 0.0\end{array}$

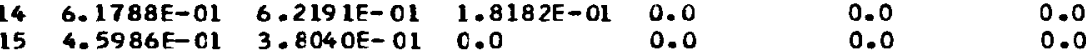

16 2.5618E-01 $0 . \mathrm{C} \quad 0.0 \quad 0.0 \quad 0.000$ 
SAMPLE PROB 6 2C 8 15.24 CM PARAFFin REFL AUTOMATIC REFL GEOMETRY DESCRIPTION

REGION
1 CYL INDER
2 Cuboid

REFLECTOR

1 CORE BDY 0

2 CUBOID 2

3 CUBO ID 2

4 Cubo 102

5 CUBOID 2

6 CUBOID

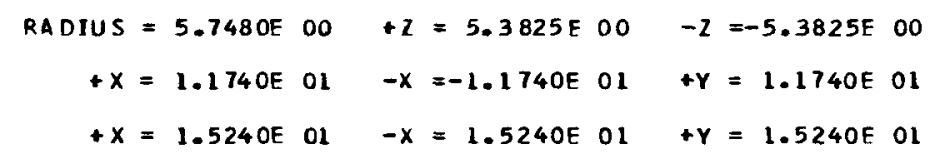


SAMPLE PROB $6228 \quad 15.24$ CM PARAFFIN REFL AUTOMATIC REFL

\section{WEIGHTING FUNCTION}

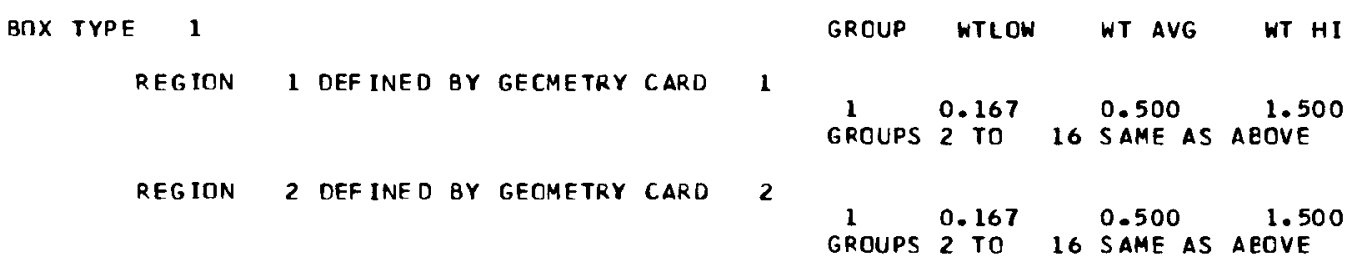

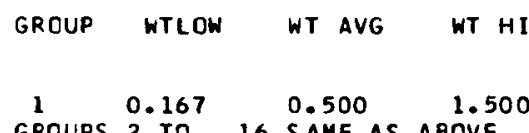

$\begin{array}{lll}0.282 & 0.846 & 2.538 \\ 0.291 & 0.873 & 2.619 \\ 0.305 & 0.915 & 2.745 \\ 0.324 & 0.972 & 2.916 \\ 0.380 & 1.140 & 3.420 \\ 0.480 & 1.440 & 4.320 \\ 0.543 & 1.630 & 4.890 \\ 0.583 & 1.750 & 5.250 \\ 0.613 & 1.840 & 5.520 \\ 0.627 & 1.880 & 5.640\end{array}$




\begin{tabular}{|c|c|c|c|c|c|}
\hline & & $\begin{array}{l}11 \\
12 \\
13 \\
14 \\
15 \\
16\end{array}$ & $\begin{array}{l}0.630 \\
0.650 \\
0.883 \\
0.990 \\
1.017 \\
1.173\end{array}$ & $\begin{array}{l}1.890 \\
1.950 \\
2.650 \\
2.970 \\
3.050 \\
3.520\end{array}$ & $\begin{array}{r}5.670 \\
5.850 \\
7.950 \\
8.910 \\
9.150 \\
10.560\end{array}$ \\
\hline REGION & 4 DEF INED BY GEOMETRY CARD & $\begin{array}{r}1 \\
2 \\
3 \\
4 \\
5 \\
6 \\
7 \\
8 \\
9 \\
10 \\
11 \\
12 \\
13 \\
14 \\
15 \\
16\end{array}$ & $\begin{array}{l}0.427 \\
0.500 \\
0.600 \\
0.7223 \\
0.997 \\
1.487 \\
1.793 \\
2.007 \\
2.190 \\
2.317 \\
2.373 \\
2.493 \\
3.433 \\
3.867 \\
3.967 \\
4.633\end{array}$ & $\begin{array}{l}1.280 \\
1.500 \\
1.800 \\
2.170 \\
2.990 \\
4.460 \\
5.380 \\
6.020 \\
6.570 \\
6.950 \\
7.120 \\
7.480 \\
10.300 \\
11.6000 \\
11.900 \\
13.900\end{array}$ & $\begin{array}{r}3.840 \\
4.500 \\
5.400 \\
6.510 \\
8.970 \\
13.380 \\
16.140 \\
18.060 \\
19.710 \\
20.850 \\
21.360 \\
22.440 \\
30.900 \\
34.800 \\
35.700 \\
41.700\end{array}$ \\
\hline REGION & 5 DEF INED BY GEOMETRY CARD & $\begin{array}{r}1 \\
2 \\
3 \\
4 \\
5 \\
6 \\
7 \\
8 \\
9 \\
10 \\
11 \\
12 \\
13 \\
14 \\
15 \\
16\end{array}$ & $\begin{array}{l}0.693 \\
0.957 \\
1.390 \\
1.933 \\
3.140 \\
5.367 \\
6.733 \\
7.667 \\
8.467 \\
9.033 \\
9.300 \\
9.800 \\
13.500 \\
15.200 \\
15.667 \\
18.200\end{array}$ & $\begin{array}{r}2.080 \\
2.870 \\
4.170 \\
5.800 \\
9.420 \\
16.100 \\
20.200 \\
23.000 \\
25.400 \\
27.100 \\
27.900 \\
29.400 \\
40.500 \\
45.600 \\
47.000 \\
54.600\end{array}$ & $\begin{array}{r}6.240 \\
8.610 \\
12.510 \\
17.400 \\
28.260 \\
48.300 \\
60.600 \\
69.000 \\
76.200 \\
81.300 \\
83.700 \\
88.200 \\
121.500 \\
136.800 \\
141.000 \\
163.800\end{array}$ \\
\hline REGION & 6 DEF INE D BY GEOMETRY CARD & $\begin{array}{r}1 \\
2 \\
3 \\
4 \\
5 \\
6 \\
7 \\
8 \\
9 \\
10 \\
11 \\
12 \\
13 \\
14 \\
15 \\
16\end{array}$ & $\begin{array}{r}1.170 \\
1.960 \\
3.567 \\
5.767 \\
10.933 \\
20.633 \\
26.200 \\
30.033 \\
33.233 \\
35.667 \\
36.667 \\
38.667 \\
53.000 \\
60.000 \\
61.667 \\
71.667\end{array}$ & $\begin{array}{r}3.510 \\
5.880 \\
10.700 \\
17.300 \\
32.800 \\
61.900 \\
78.600 \\
90.100 \\
99.700 \\
107.000 \\
110.000 \\
116.000 \\
159.000 \\
180.000 \\
185.000 \\
215.000\end{array}$ & $\begin{array}{l}10.530 \\
17.640 \\
32.100 \\
511.900 \\
58.400 \\
185.700 \\
235.800 \\
270.300 \\
255.100 \\
31.000 \\
330.000 \\
348.000 \\
477.000 \\
540.000 \\
555.000 \\
645.000\end{array}$ \\
\hline
\end{tabular}


SAMPLE PROB 6 2C8 15.24 CM PARAFFin REFL AUTOMATIC REFL

VOLUMES

BOX TYPE

REGION DEFINED BY GEOMETRY CARD REGION DEFINED BY GEOMETRY CARD

REFLECTOR

VOLLMES - GEOMETRY CARO

REG ION DEFINED BY GEOMETRY CARD

REGION DEFINED BY GEOMETRY CARD

REGION DEFINED BY GEOMETRY CARO

IS

IS

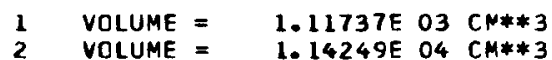

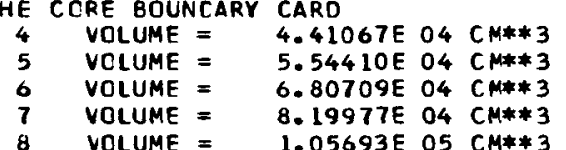

TOT AL VOL UMES

$1 \quad 8.93896 E 03$

VLUME FRACTION OF THE CORE CCNTAINING FISSILE MATERIAL $=0.89088 E-01$

START TYPE $=0$

THE NEUTRONS WERE STARTEO IN THE ARRAY WITH A FLAT DISTRIEUTION.

300 NEUTRONS WERE INITIALLY STARTED

O DO917 MINUTES HERE REOUIRED FOR STARTING。
CUMULATIVE VOLUME $=1.11737 \mathrm{E} 03 \mathrm{CM} * 3$
CUMULATIVE VOLUME $=1.25423 \mathrm{C}$ O4 CM*33

CUMULATIVE VOLUME

CUMULATIVE VOLUME

CUMULATIVE VOLUME

CUMULATIVE VOLUME

CUMULATIVE VOLUME $=$
1. 44445E O5 CM**3

1. $99886 E$ O5 CM**3

.67957E OS CM**3 
SAMPLE PROB 6 2C 8 15.24 CM PARAFFIN REFL AUTOMATIC REFL

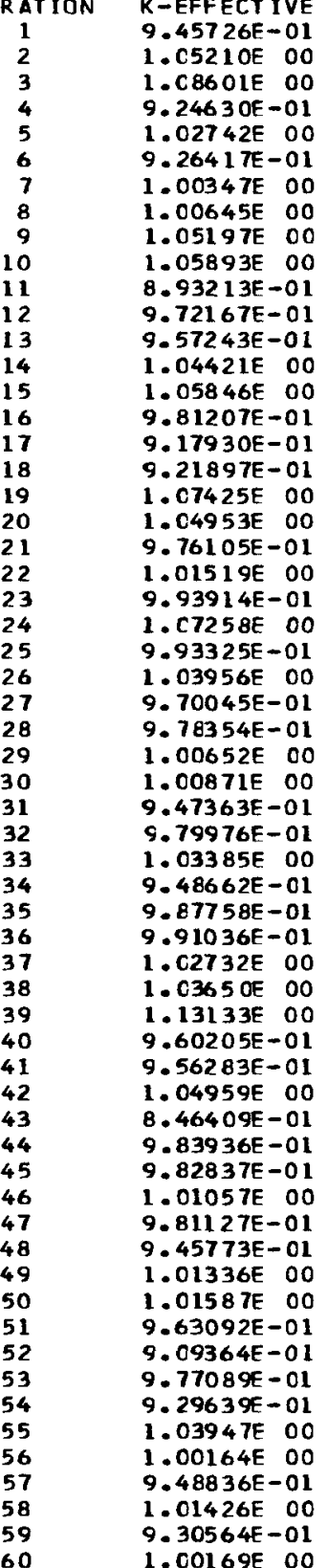

ELAPSED TIMERMINI

6.250009

$1.18833 E-01$

$1.86333 E-01$

$3.23000 E-01$

$3.95833 E-01$

$4.61667 E-01$

$18000 E-01$

$5.90833 E-02$

$6.53000 E-01$

$7.25833 \mathrm{E}-\mathrm{O}$

$7.83000 E-01$

$6.47667 E-01$

$9.08833 \mathrm{BE}-01$

$9.75500 E-01$

$1.04133 E 00$

$1.10217 E 00$

$1.17100 E$ OO

$1.22767 E$ OO

$1.29550 E$ OO

$1.35050 E$ OO

$1.41550 E$ OO

$1.47000 E$ OO

.54050E OO

$1.59100 E$ OO

$1.65850 E$ OO

$1.78833 E 00$

$1.78833 E 00$

$1.83967 E$ OO

$1.90350 E$ OO

$2.02967 E 00$

$2.08750 E$ DO

$2.15217 E 0 O$

$2.21850 E$ OO

$2.28083 E$ OO

$2.34550 E O O$

$2.41933 E 00$

$2.49717 E \quad 00$

$2.55883 E \quad 00$

$2.61517 E \quad 00$

$2.70100 E 00$

$2.75933 E$ DO

$2.82217 E$ OO

$2.88833 \mathrm{E} O O$

2.95467E $O O$

$3.02550 E$ OO

$3.09300 E$ OO

$\begin{array}{lll}3.15917 E & 00 \\ 3.21550 E & 00\end{array}$

$3.21550 E$ OO

$3.27350 E$ EO

3.35267E 00

$3.43050 E$ OO

$3.50183 E 00$

3.56350E OO

$3.63267 E 00$

$3.75433 E$ OO

$3.81083 E$ OO

3.8725 OE 00
AVG. K-EFF

$1.00000 E$ OO

$1.00000 E$ OO

$.00532 E 00$

$1.01269 E 00$

9. $91119 E-01$

$9.93589 \mathrm{E}-01$

$9.95732 E-01$

$1.00377 E$ OO

1.01066 E 00

$9.97612 E-01$

$9.95068 E-0$

$9.91629 E-01$

$9.96011 E-01$

$1.00081 E 00$

$9.99414 E-01$

$9.93982 \mathrm{E}-01$

S. $89477 E-01$

$9.94463 E-01$

$9.97521 E-01$

$9.96393 \mathrm{E}-01$

$9.97333 \mathrm{E}-0$

1. 000 OE OD

.

..00028E 00

$1.00192 \mathrm{E} 00$

.

$1.00003 E 00$

$1.00034 E 00$

$9.98516 \mathrm{E}-01$

$9.97897 E-01$

$9.99057 E-01$

$9.97482 E-01$

9.97187E-01

9. $97006 E-01$

$9.97872 \mathrm{E}-01$

9. $98945 E-01$

$1.00252 \mathrm{E} 00$

$1.00141 \mathrm{E} 00$

.00025E 00

$1.00148 \mathrm{E} \mathrm{OO}$

9. $97703 E-0$

$9.97375 \mathrm{E}-0$

$9.97037 E-01$

$9.97344 E-01$

$9.96983 E-01$

9. $95870 E-01$

$9.96242 E-01$

9.9665 LE-O 1

$9.95966 \mathrm{E}-01$

$9.94234 E-O 1$

$9.93898 \mathrm{E}-0$

$9.92662 \mathrm{E}-01$

$936 \mathrm{E}-\mathrm{O}$

. $93694 \mathrm{E}-01$

$93260 E-O 1$

$92160 \mathrm{E}-01$

$9.92325 E-01$
DEVIAT ICN

0.0

$8.06950 E-02$

. $71741 E-02$

3. $97155 E-02$

$3.08621 E-02$

.52897E-02

.28364E-02

.09482 E-02

$2.26143 \mathrm{E}-02$

$2.03860 E-02$

$.87577 E-02$

$.76750 \mathrm{E}-02$

$1.69544 \mathrm{E}-02$

$1.57563 \mathrm{E}-02$

1. $56438 \mathrm{E}-02$

$1.53112 \mathrm{E}-02$

$1.52229 \mathrm{E}-02$

$1.46768 E-02$

$1.39311 E-02$

$126031 E-02$

$1.26031 E-02$

.

.19459E-02

$11595 \mathrm{E}-02$

$.07528 \mathrm{E}-02$

$1.07528 \mathrm{E}-02$

$9.98028 \mathrm{E}-03$

$9.80207 E-03$

$9.49035 E-03$

$9.25075 E-03$

$9.09588 \mathrm{E}-03$

$8.82206 E-03$

$8.56107 E-03$

B. $35866 \mathrm{E}-03$

$8.19257 E-03$

$8.73616 E-03$

.

政 $C 3$

.

(4)

. 73531 E- 03

.

$.34600 E-03$

. $16620 E-03$

$8.06395 E-03$

$7.89950-03$

$7.74369 E-03$

$7.65926 \mathrm{E}-0 \mathrm{~B}$

.

.

$7.38384 \mathrm{E}-03$

$7.04332 E-03$

$6.88563 E-03$
MATR IX K-EFF

0.0

0.0

0.0

0.0

0.0

0.0

0.0

0.0

0.0

0,0

0.0

0.0

0.0

0.0

0.0

0.0

0.0

0.0

0.0

0.0

0.0

0.0

0.0

0.0

0.0

0.0

0.0

0.0

0.0

0.0

0.0

0.0

0.0

0.0

0.0

0.0

0.0

0.0

0.0
0.0
0.0

0.0

0.0 


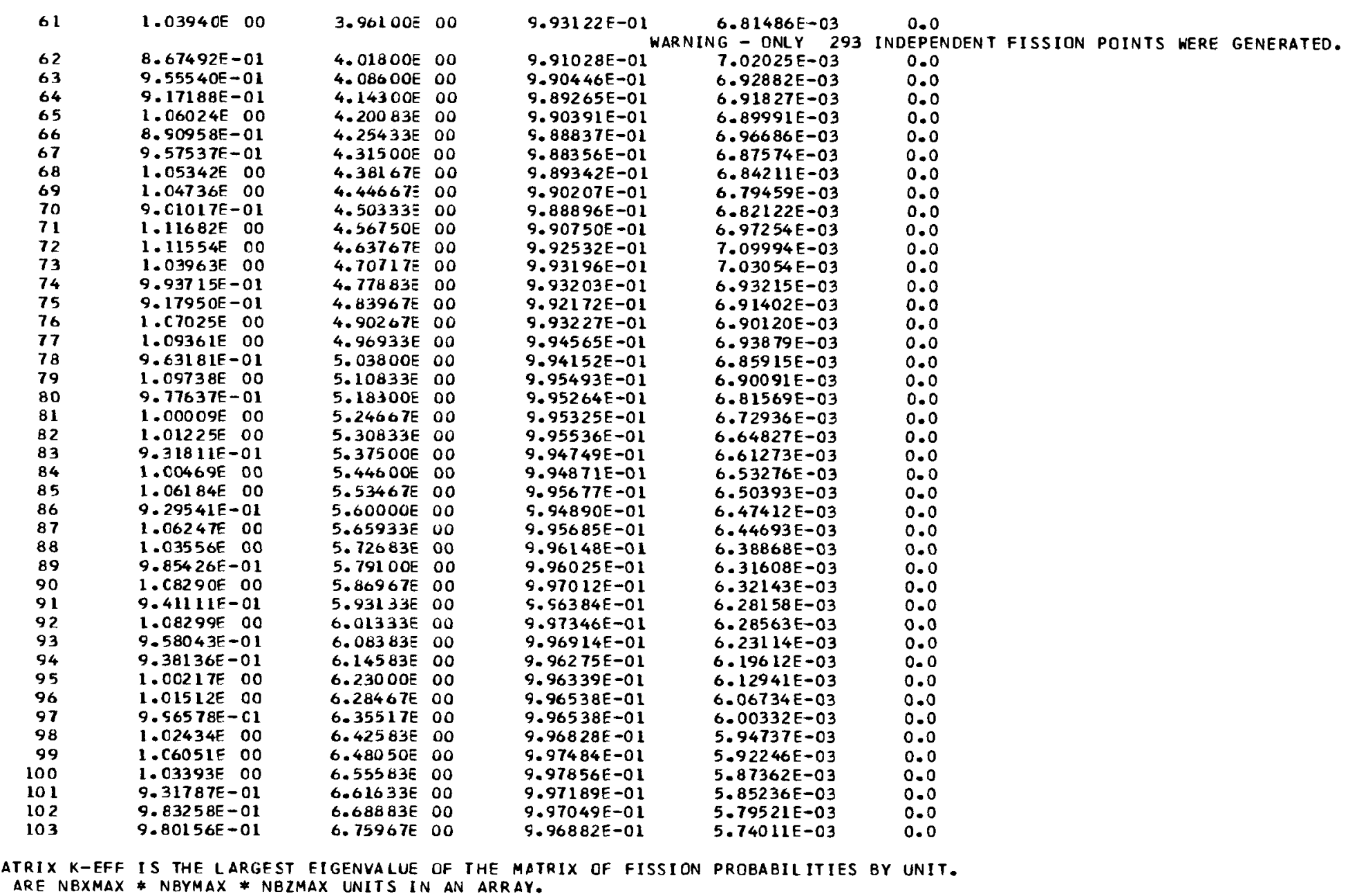


SAMPLE PROB $62 C 815.24$ CM PARAFFIN REFL AUTOMATIC REFL

\begin{tabular}{|c|c|c|c|c|c|c|c|c|c|c|c|c|}
\hline $\begin{array}{l}\text { NO. NF INITIAL } \\
\text { GENERATIONS } \\
\text { SK IPPED }\end{array}$ & $\begin{array}{l}\text { AVER AGE } \\
\text { K-EFFECTIVE }\end{array}$ & & DEVIATION & $\begin{array}{c}67 \\
\text { CONFIDEN }\end{array}$ & $\begin{array}{l}\text { PER } \\
\text { NCE }\end{array}$ & $\begin{array}{l}\text { CENT } \\
\text { INTERVAL }\end{array}$ & $\begin{array}{r}95 \\
\text { CONFIDEA }\end{array}$ & $\begin{array}{l}\text { PER } \\
\text { NCE }\end{array}$ & $\begin{array}{l}\text { CENT } \\
\text { INTERVAL }\end{array}$ & $\begin{array}{r}99 \text { PER } \\
\text { CONFIOENCEE }\end{array}$ & $\begin{array}{l}\text { CENT } \\
\text { INTER VAL }\end{array}$ & $\begin{array}{l}\text { NUMBER OF } \\
\text { HI STOR IES }\end{array}$ \\
\hline 3 & 0.99599 & $+O R$ & -0.00572 & 0.99027 & то & 1.00171 & 0.98455 & To & 1.00744 & 0.97882 TO & 1.01316 & 30000 \\
\hline 4 & 0.99671 & $+O R$ & -0.00573 & 0.99098 & to & 1.00245 & 0.98524 & TO & 1.00818 & 0.57951 T0 & 1.01392 & 29700 \\
\hline 5 & 0.99640 & $+O R$ & -0.00579 & 0.99061 & TO & 1.00218 & 0.98483 & TO & 1.00797 & 0.97904 TO & 1.01375 & 29400 \\
\hline 6 & 0.99712 & $+D R$ & -0.00580 & 0.99132 & TO & 1.00292 & 0.98552 & 10 & 1.00872 & 0.97972 то & 1.01452 & 29100 \\
\hline 7 & 0.99705 & $+\mathrm{GR}$ & -0.00586 & 0.99119 & To & 1.00291 & 0.98533 & TO & 1.00877 & 0.97948 T & 1.01463 & 28800 \\
\hline 8 & 0.99696 & $+\mathrm{OR}$ & -0.00592 & 0.99103 & TO & 1.00288 & 0.98511 & TO & 1.00880 & 0.97919 TO & 1.01472 & 28500 \\
\hline 9 & 0.59637 & $+\mathrm{OR}$ & -0.00595 & 0.99042 & TO & 1.00232 & 0.98446 & To & 1.00828 & 0.57851 Tо & 1.01423 & 28200 \\
\hline 10 & 0.99570 & $+O R$ & -0.00598 & 0.98972 & To & 1.00168 & 0.98374 & TO & 1.00766 & 0.97776 Tо & 1.01364 & 27900 \\
\hline 11 & 0.59681 & $+O R$ & -0.00594 & 0.99087 & Tо & 1.00275 & 0.98493 & TO & 1.00869 & 0.97899 TO & 1.01463 & 27600 \\
\hline 12 & 0.99708 & $+O R$ & -0.00600 & 0.99108 & TO & 1.00308 & 0.98508 & TO & 1.00908 & 0.97908 TO & 1.01508 & 27300 \\
\hline 17 & 0.99739 & $+\mathrm{OR}$ & -0.00620 & 0.99119 & TO & 1.00359 & 0.98500 & TO & 1.00978 & 0.97880 Tо & 1.01598 & 25800 \\
\hline 22 & 0.59677 & $+O R$ & -0.00640 & 0.99037 & TO & 1.00317 & 0.98397 & 10 & 1.00958 & $0.97757 \mathrm{ro}$ & 1.01598 & 24300 \\
\hline 27 & 0.99565 & $+\mathrm{OR}$ & -0.00672 & 0.98893 & TO & 1.00236 & 0.98221 & TO & 1.00908 & 0.97550 TO & 1.01580 & 22800 \\
\hline 32 & 0.99645 & $+O R$ & -0.00715 & 0.98931 & TO & 1.00360 & 0.98216 & TO & 1.01075 & 0.97501 TO & 1.01790 & 21300 \\
\hline 37 & 0.99636 & + OR & -0.00762 & 0.98874 & To & 1.00398 & 0.98111 & TO & 1.01160 & 0.97349 TO & 1.01922 & 19800 \\
\hline 42 & 0.99387 & $+\mathrm{OR}$ & -0.00781 & 0.98606 & TO & 1.00168 & 0.97824 & TO & 1.00949 & 0.97043 To & 1.01730 & 18300 \\
\hline 47 & 0.99680 & $+D R$ & -0.00807 & 0.98874 & ro & 1.00487 & 0.98067 & 10 & 1.01293 & $0.97260 \mathrm{TO}$ & 1.02100 & 16800 \\
\hline 52 & 0.99948 & $+O R$ & -0.00859 & 0.99089 & TO & 1.00807 & 0.98231 & TO & 1.01665 & 0.97372 TO & 1.02524 & 15300 \\
\hline 57 & 1.00167 & $+O R$ & -0.00928 & 0.99239 & To & 1.01095 & 0.98311 & TO & 1.02023 & 0.97383 TO & 1.02951 & 13800 \\
\hline 62 & 1.00545 & $+O R$ & -0.00966 & 0.99579 & ro & 1.01511 & 0.98613 & TO & 1.02477 & 0.57647 TO & 1.03442 & 12300 \\
\hline 67 & 1.01228 & $+Q R$ & -0.00986 & 1.00241 & ro & 1.02214 & 0.99255 & TO & 1.03201 & $0.98268 \mathrm{TO}$ & 1.04187 & 10800 \\
\hline 72 & 1.00671 & $+\mathrm{OR}$ & -0.00955 & 0.99716 & TO & 1.01625 & 0.98761 & TO & 1.02580 & 0.97807 TO & 1.03535 & 9300 \\
\hline 77 & 1.00357 & $+O R$ & -0.00991 & 0.99366 & To & 1.01347 & 0.98376 & TO & 1.02338 & 0.97385 TO & 1.03329 & 7800 \\
\hline 82 & 1.00201 & $+O R$ & -0.01119 & 0.99083 & TO & 1.01320 & 0.97964 & 10 & 1.02438 & 0.96846 TO & 1.03557 & 6300 \\
\hline 87 & 1.00325 & $+O R$ & -0.01209 & 0.99116 & TO & 1.01534 & 0.97906 & TC & 1.02744 & $0.96697 \mathrm{rO}$ & 1.03953 & 4800 \\
\hline 92 & 0.99309 & $+\mathrm{OR}$ & -0.01208 & 0.98102 & TO & 1.00517 & 0.96894 & TO & 1.01724 & $0.95687 \mathrm{TO}$ & 1.02932 & 3300 \\
\hline
\end{tabular}


SAMPLE PROB 62 2C8 15.24 CM PARAFFIN REFL AUTOMATIC REFL

\section{NO. OF INITIAL \\ SKIPPED}

97

AVERAGE

K-EFFECTIVE DEVIATION

1.00233

$+C R-0.01889$
67 PER CENT CONFIDENCE INTERVAL 0.98344 TO 1.02122
95 PER CENT

95 PER CENT
CONFI DENCE INTERVAL

$0.96456 \quad 101.04010$

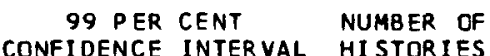

0.94567 T0 1.05899 
SAMPLE PROB $6 \quad 2 C 815.24$ CM PARAFFIN REFL AUTOMATIC REFL

\begin{tabular}{|c|c|c|c|c|}
\hline GROUP & REGION & LEAKAGE & ABSORPTIONS & FISSIONS \\
\hline 1 & & $4.893090-03$ & $3.843880-02$ & $1.08852 D-01$ \\
\hline 2 & & $6.494030-03$ & $7.322990-02$ & $1.797690-01$ \\
\hline 3 & & $2.385730-03$ & $4.39184 \mathrm{D}-02$ & $1.015020-01$ \\
\hline 4 & & $3.847960-03$ & $7.012510-02$ & $1.541920-01$ \\
\hline 5 & & $2.036500-03$ & $6.302740-02$ & $1.32663 \mathrm{C}-01$ \\
\hline 6 & & $1.866000-03$ & $2.233750-02$ & $4.299030-02$ \\
\hline 7 & & $3.156700-03$ & $6.503250-03$ & $1.20562 D-02$ \\
\hline 8 & & 0.0 & $6.530010-03$ & $1.115220-02$ \\
\hline 9 & & $2.186790-03$ & $8.24198 D-03$ & $1.314770-02$ \\
\hline 10 & & 0.0 & $5.796730-03$ & $8.31976 \mathrm{C}-03$ \\
\hline 11 & & 0.0 & $5.684010-03$ & $6.720370-03$ \\
\hline 12 & & $3.318650-03$ & $5.642270-03$ & $4.78832[-03$ \\
\hline 13 & & 0.0 & $5.39888 D-03$ & $7.36918 D-03$ \\
\hline 14 & & 0.0 & $4.967810-03$ & $6.53905 \mathrm{c}-03$ \\
\hline 15 & & 0.0 & $2.03058 D-02$ & $1.83930 \mathrm{C}-02$ \\
\hline 16 & & $7.548840-03$ & $5.315910-01$ & $1.875430-01$ \\
\hline TOTAL $=$ & & $3.773430-02$ & $9.117390-01$ & $9.959970-01$ \\
\hline
\end{tabular}


SAMPLE PROB 62 2C 15.24 CM PARAFFIN REFL AUTOMATIC REFL **** FISSION DENSITIES ****

\begin{tabular}{|c|c|c|c|c|}
\hline & REG I ON & $\begin{array}{l}\text { FIS S ION } \\
\text { DEN SI TYY }\end{array}$ & $\begin{array}{l}\text { PERCENT } \\
\text { DEVIATI ON }\end{array}$ & $\begin{array}{c}\text { TOTAL } \\
\text { FISSICNS }\end{array}$ \\
\hline$B O X$ TYPF & $\begin{array}{l}1 \\
2\end{array}$ & $\begin{array}{l}1.114 E-C 4 \\
0.0\end{array}$ & $\begin{array}{l}0.58 \\
0.0\end{array}$ & $\begin{array}{l}9.959 E-01 \\
0.0\end{array}$ \\
\hline REFLFCTOR & $\begin{array}{l}1 \\
2 \\
3 \\
4 \\
5 \\
6\end{array}$ & $\begin{array}{l}0.0 \\
0.0 \\
0.0 \\
0.0 \\
0.0 \\
0.0\end{array}$ & $\begin{array}{l}0.0 \\
0.0 \\
0.0 \\
0.0 \\
0.0 \\
0.0\end{array}$ & $\begin{array}{l}0.0 \\
0.0 \\
0.0 \\
0.0 \\
0.0 \\
0.0\end{array}$ \\
\hline
\end{tabular}


SAMPLF PROB $6 \simeq 8 \quad 25.24$ CM PARAFFIN REFL AUTOMATIC REFL

\begin{tabular}{|c|c|c|c|c|}
\hline \multirow{2}{*}{$\begin{array}{l}\text { FLUXFS } \\
\text { GROUP }\end{array}$} & \multicolumn{2}{|c|}{$\begin{array}{l}\text { FOR BOX TYPE } \\
\text { REGION }\end{array}$} & REG ION & 2 \\
\hline & FL UX & $\begin{array}{l}\text { PERCENT } \\
\text { DEVIATION }\end{array}$ & FLUX & $\begin{array}{c}\text { PERCENT } \\
\text { OE VIATI ON }\end{array}$ \\
\hline 1 & $7.511 \mathrm{E}-05$ & 1.66 & $2.337 E-05$ & $5 \quad 1.98$ \\
\hline 2 & $1.350 E-04$ & 1.20 & $4.257 E-05$ & 1.48 \\
\hline 3 & $8.161 F-05$ & 1.73 & $2.458 E-05$ & 2.06 \\
\hline 4 & $1.287 E-04$ & 1.27 & $4.063 E-05$ & 1.32 \\
\hline 5 & $9.180 E-05$ & 1.53 & $3.164 E-05$ & 1.43 \\
\hline 6 & $1.824 E-05$ & 3.08 & $1.184 E-05$ & 2.93 \\
\hline 7 & $2.914 E-06$ & 7.26 & $7.571 E-06$ & 3.96 \\
\hline 8 & 1. $536 E-06$ & 7.83 & $6.965 E-06$ & 4.21 \\
\hline & $7.040 \mathrm{E}$ & 7.46 & $6.294 E$ & 3.58 \\
\hline 10 & $2.414 E-07$ & 10.34 & $3.883 E-06$ & 5.05 \\
\hline 11 & $1.600 E-07$ & 10.51 & $3.545 E-06$ & 5.30 \\
\hline 12 & $1.609 E-07$ & 10.93 & $3.655 E-06$ & 4.82 \\
\hline 13 & $2.473 E-07$ & 10.99 & $3.037 E-06$ & 5.72 \\
\hline 14 & $8.903 E-08$ & 11.78 & $2.744 E-06$ & 0.48 \\
\hline 15 & $9.004 E-08$ & 7.23 & $6.839 E-06$ & 3.95 \\
\hline 16 & $3.758 E-07$ & 2.98 & $6.740 E-05$ & 2.13 \\
\hline
\end{tabular}


SAMPLE PROB 622815.24 CM PARAFFIN REFL AUTOMATIC REFL

\begin{tabular}{|c|c|c|c|c|c|c|c|c|c|c|c|c|}
\hline \multirow{2}{*}{$\begin{array}{l}\text { FLUXES } \\
\text { GROUP }\end{array}$} & \multicolumn{2}{|c|}{ FOR REFL ECTOR } & REGION & 2 & REGION & 3 & REGION & 4 & REGION & 5 & REGION & 6 \\
\hline & FLUX & $\begin{array}{l}\text { PERCENT } \\
\text { DEVIATI ION }\end{array}$ & FLUX & $\begin{array}{l}\text { PERCENT } \\
\text { DE VIATIION }\end{array}$ & FLUX & $\begin{array}{l}\text { PERCENT } \\
\text { DEVIATI ON }\end{array}$ & FLUX & $\begin{array}{l}\text { PERCENT } \\
\text { DEV IATION }\end{array}$ & FLUX & $\begin{array}{l}\text { PERCENT } \\
\text { DEVIATION }\end{array}$ & FLUX & $\begin{array}{l}\text { PERCENT } \\
\text { DEVIATI }\end{array}$ \\
\hline 1 & 0.0 & 0.0 & 9. $054 E-06$ & 2.01 & $3.631 E-06$ & 2.83 & $1.574 E-06$ & 4.33 & $6.889 E-07$ & 5.86 & $3.006 E-07$ & $\begin{array}{l}8.59 \\
8.59\end{array}$ \\
\hline 2 & 0.0 & 0.0 & $1.638 \mathrm{E}-05$ & 1.38 & $6.206 E-06$ & 2.08 & $2.511 E-06$ & 2.79 & $1.114 E-06$ & 4.43 & $4.378 E-07$ & 8.67 \\
\hline 3 & 0.0 & 0.0 & $9.675 E-06$ & 1.63 & $3.236 \mathrm{E}-06$ & 2.54 & $1.314 E-06$ & 4.25 & $5.699 E-07$ & 9.21 & $1.747 \mathrm{E}-07$ & 13.76 \\
\hline 4 & 0.0 & 0.0 & $1.599 E-05$ & 1.08 & $5.289 E-06$ & 1.66 & $1.886 \mathrm{E}-06$ & 3.56 & $7.437 E-07$ & 6.71 & $2.893 \mathrm{E}-07$ & 14.01 \\
\hline 5 & 0.0 & 0.0 & 1.83 OE- 05 & 0.96 & $6.898 \mathrm{E}-06$ & 1.78 & $2.571 E-06$ & 2.85 & $8.413 E-07$ & 9.34 & $3.225 E-07$ & 19.41 \\
\hline 6 & 0.0 & 0.0 & 1. C56E-05 & 1.22 & $4.442 E-06$ & 1.73 & $1.707 E-06$ & 4.91 & $6.778 E-07$ & 11.00 & $2.046 E-07$ & 24.79 \\
\hline 7 & 0.0 & 0.0 & $7.586 E-06$ & 1.17 & $3.565 \mathrm{~F}-06$ & 1.95 & $1.390 \mathrm{E}-06$ & 5.04 & $4.685 E-07$ & 15.18 & $9.757 E-08$ & 48.94 \\
\hline 8 & 0.0 & 0.0 & $6.577 E-06$ & 1.13 & $3.473 E-06$ & 2.13 & $1.411 E-06$ & 6.20 & $4.273 E-07$ & 16.47 & $5.704 E-08$ & 43.32 \\
\hline 9 & 0.0 & 0.0 & $6.605 E-06$ & 1.25 & $3.563 E-06$ & 2.21 & $1.429 \mathrm{E}-06$ & 5.61 & $3.892 E-07$ & 15.11 & $1.333 E-07$ & 52.07 \\
\hline 10 & 0.0 & 0.0 & $4.434 E-06$ & 1.41 & $2.592 E-06$ & 2. & $1.042 \mathrm{E}$ & & $3.374 E-07$ & & $5.081 E-08$ & 54.73 \\
\hline 11 & 0.0 & 0.0 & $3.936 E-06$ & 1.55 & $2.327 E-06$ & 2.79 & $9.315 \mathrm{E}$ & 7.28 & $3.970 E-07$ & 17. & $2.687 E-08$ & 73.66 \\
\hline 12 & 0.0 & 0.0 & $4.174 E-06$ & 1.70 & $2.510 E-06$ & 2.61 & $9.500 E-07$ & 6.84 & $4.779 E-07$ & 17.53 & $5.275 \mathrm{E}-08$ & 81.71 \\
\hline 13 & 0.0 & 0.0 & $3.586 \mathrm{E}-06$ & 1.52 & $2.279 E-06$ & 2.72 & $1.025 \mathrm{E}-06$ & 8.49 & $3.561 E-07$ & 20.41 & $1.066 \mathrm{E}-07$ & 78.94 \\
\hline 14 & 0.0 & 0.0 & $2.991 E-06$ & 1.06 & $1.910 E-06$ & 3.31 & $8.212 E-07$ & 7.59 & $3.196 E-07$ & 22.78 & $4.223 E-08$ & 55.78 \\
\hline 15 & 0.0 & 0.0 & $8.726 E-06$ & 1.60 & $6.187 E-06$ & 3.45 & $2.840 E-C 6$ & 7.82 & $1.068 E-06$ & 18.14 & $1.451 \mathrm{E}-07$ & 46.97 \\
\hline 16 & 0.0 & 0.0 & $1.217 E-04$ & 1.76 & $1.147 \mathrm{E}-04$ & 2.91 & $6.109 E-05$ & 6.41 & $2.601 E-05$ & 15.62 & $2.036 \mathrm{E}-06$ & 46.99 \\
\hline
\end{tabular}


0.8459 TO 0.8690 0.8690 TO 0.892 0.8921 TO 0.9152 0.9152 to 0.9383 0.9383 T0 0.9613 0.9613 ro 0.9844 0.9844 ro 1.0075 1.0075 TO 1.0306 1.0306 ro 1.0537 1.0537 TO 1.0768 1.0768 To 1.0999 1.0999 TO 1.1230 ** ***** $* * * * * * * * * * * *$

\section{$* * * * * * * * * * *$}

$* * * * * * \neq * \neq * * * * * * *$ $* * * * * * * * * * * * * * 4$ $4+4+444$

$* * * *$

$* *$

0.8459 TO 0.8690

0.8690 To 0.8921

0.9152 Tा 0.9383

0.9383 TO 0.9613

0.9613 TO 0.9844

0.9844 TO 1.0075

1.0075 TO 1.0306

1.0306 in 1.0537

1.0537 TO 1.0768

1.0768 to 1.0999

1.0999 TO 1.1230

1.1230 TO 1.246

$*$

$* *$

$* * * * * * * * * *$

$* * * * * * * * * * *$

$* * * * * * * * *$

$* * * * *$

$* * * *$

$*$

FREOUENCY FOR GENERATICNS

29 TO 103

0.8690

0.8690 TO 0.8921

0.8921 To 0.9152

0.9152 TO 0.9383

0.9383 To 0.9613

0.9613 TO 0.9844

0.9844 Tत 1.0075

1.0075 TO 1.0306

1.0306 to 1.0537

1.0537 ro 1.0768

1.0768 ro 1.0999

1.0999 To 1.1230

FEOUENCY FOR GENERATICNS

4 TO 103

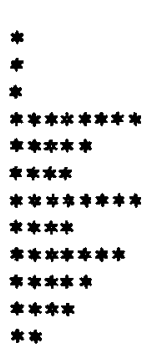

FRE OUENCY FOR GENERATICNS

54 TO 103

0.8459 TO 0.8690

0.8690 T0 0.8921

0.9152 T0 0.9383

0.9383 To 0.9613

0.9613 TO 0.9844

0.9844 TO 1.0075

1.0075 th 1.0306

1.0306 To 1.0537

1.0537 T0 1.0768

1.0768 TO 1.0999

1.0999 TO 1.1230

1.1230 TO 1.1461

FREOUENCY FOR GENERATICNS

79 TO 103

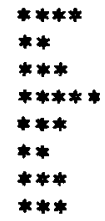

********* END OF FILE ON UNIT

$5 * * * * * * * * * *$ 
MAX. NUMBER OF ENERGY TRANSFERS

NUMBER OF INPUT NUCL IDES

NUMBER OF MIXTURES

NUMBER OF MIXING TABLE ENTRIFS

NUMBER OF GEOMETRY CARDS

NUMBER NF BOX TYPFS

NUMBER DF UNITS IN $X$ DIRECTION

NUMBER DF UNITS IN Y DIRECTION

NUMBER OF UNITS IN 2 DIRECTICN

NUMBER OF NUCLIDES READ FROM TAPE

ALBEDO TYPE

SEARCH TYPF

MAXIMUM TIME $=2.0000$ MINLTES

START TYPE

GENERATIONS BETWEEN CHECKPOINTS

LIST INPUT X-SECTIONS READ FROM TAPE NO

LIST 1-D MIXTURE $X$ SECTIONS YES

LIST 2-D MIXTURE X-SECTIONS YES

LIST FISS. AND ABS. BY REGION NC

USE X-SECTICNS FROM PREVIOUS CASE NO

USE GEOMETFY FROM PREVIOUS CASE NO

USE VELOCITIES FROM PREVIOUS CASE NO

COMPUTE MATRIX K-EFFECTIVE BY UNIT NC

COMPUTE MATRIX K-EFFECTIVE BY BOX TYPE NO

LIST FISS PROB MATRIX BY UNIT NO

ADJOINT CALCULATION

USE EXPONEATIAL TRANSFORM NO

CALCULATE FLUX YES

calculate fission densities yes 
SAMPLE PROBLEM 8 2C8 SPACING SEARCH

MIXTURE NUCLIDE

$\begin{aligned} & 1 \\ & 1\end{aligned}-92500$

4.8270 CE-OC

92600 9.570CCE-C5

CROSS SECTIONS READ FROM TAPE

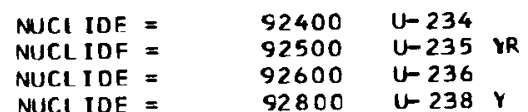

MIHALCZO MOD OF H-R U-238

HAASEN ROACH

MIHALCZC MOD OF H-R U-238

HANS EN ROACH 
MIXTURE $=$

\begin{tabular}{|c|c|c|c|c|c|}
\hline GP. & $\begin{array}{l}\text { ABSORPTION } \\
\text { PROBABILITY }\end{array}$ & $\begin{array}{l}\text { NU*F I SS ION } \\
\text { PROBAB I L I TY }\end{array}$ & $\begin{array}{l}\text { NON-ABSOR P TI } \\
\text { PROBABILI IT }\end{array}$ & $\begin{array}{l}\text { N TOTAL } \\
\text { CROSS-SECT }\end{array}$ & $\begin{array}{l}\text { FISSION } \\
\text { SPECTRUM }\end{array}$ \\
\hline $\mathbf{1}$ & $2.88282 E-01$ & $8.16362 E-01$ & $7.11718 \mathrm{E}-01$ & $2.03826 \mathrm{E}-$ & $2.04000 E-01$ \\
\hline & $05 E-01$ & $195-01$ & $504 E-01$ & & \\
\hline 3 & $2.71457 \mathrm{E}-01$ & $E-01$ & $E-02$ & $7 E-01$ & -01 \\
\hline & 2.4500 & $E-01$ & -01 & 2. & \\
\hline & $930 E-01$ & $B E-01$ & -01 & $8 E-01$ & -01 \\
\hline 6 & 2.3 & $E-01$ & & 5.94 & \\
\hline 7 & 3.44 & $E-01$ & -01 & 7.21 & DOE $0 O$ \\
\hline 8 & $5.06884 E-01$ & $8.72719 E-01$ & $16 E-01$ & $E-01$ & OOE 00 \\
\hline & 7.217 & $3 E 00$ & & 1.73 & \\
\hline & & $3837 E$ & & 3. & \\
\hline 11 & $8.86332 \mathrm{E}$ & $1.14093 E 00$ & 1.1 & 4.19 & OOE OO \\
\hline & 8.845 & $8.92047 E-01$ & 1 & 14 $14+2$ & \\
\hline & & & & & \\
\hline & $8.82566 E-01$ & $1.89106 \mathrm{E} 00$ & $1.17435 E-01$ & $6 E$ & $1.00000 E 00$ \\
\hline & & $1.93100 E$ & $4.53733 E-02$ & $1.05157 \mathrm{E}$ & OOOOE OO \\
\hline & & & $1.71272 E-02$ & $78582 \mathrm{E}$ & OOOOOE 00 \\
\hline
\end{tabular}

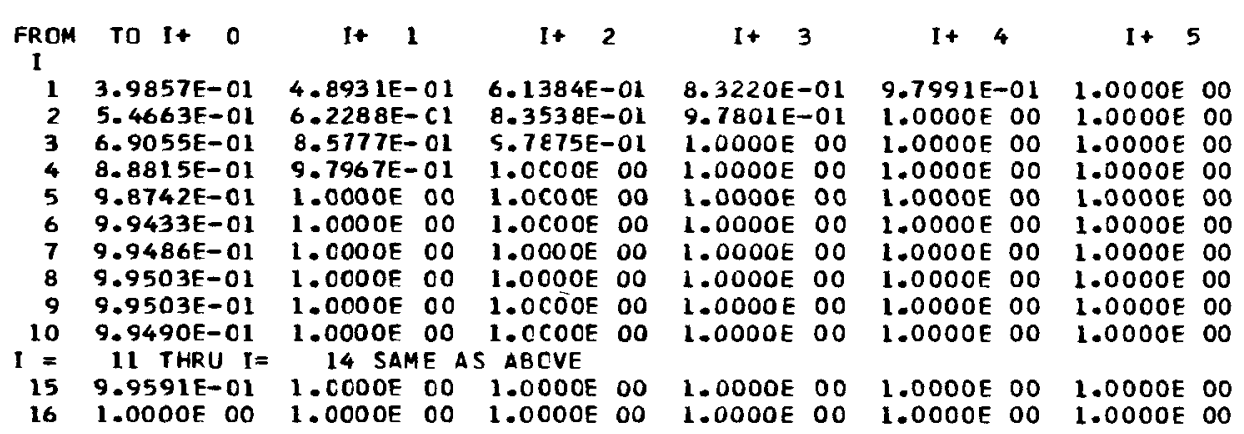

MUBAR

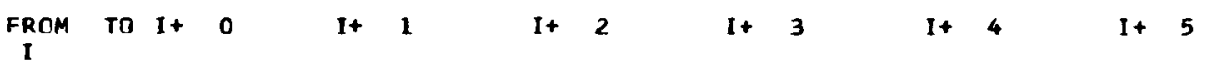
10.0
0.0 0.0
0.0
0.0
0.0 
SAMPLE PROBLEM 8 2C8 SPACING SEARCH

GEOMETRY DESCRIPTION

REGION

1 Cylinder 1 RADIUS $=5.7480 E 00$

2 CUBO 10 $+x=7.5570 E$ OO

$+z=5.3825 E$ OO

$-x=-7.5570 E 00$
$-2=-5.3825 \mathrm{E} 00$

$+Y=7.5570 E$ OO
$-Y=-7.5570 E \quad 00$
$-Z=-7.1555 \mathrm{E} 00$ 
SAMPLF PROBLEM 8 2C8 SPACING SEARCH

WEIGHTING FUNCTION

BOX TYPE

GROUP WTLOW WT AVG WT HI

REGION I DEF INED BY GECME TRY CARD

$\begin{array}{llll}1 & 0.167 & 0.500 & 1.500\end{array}$

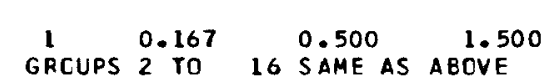

REG ION 2 DEF INE D BY GEOMETRY CARD 
VOLUMES

BOX TYPE

I REGION DEFINED BY GECMETRY CARD

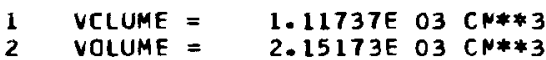

CUMULATIVE VOLUME $=1.11737 E$ O3 CM**3 CUMULATIVE VOLUME $=3.2691$ OE O3 CM**3 TOTAL VOLUMES

$\begin{array}{lll}1 & 8.93896 E & 03 \\ 2 & 1.72139 E & 04\end{array}$

VILUME FRACTION OF THE CORE CCNTAINING FISSILE MATERIAL $=0.34180$ OO

START TYPE $=0$

THF NEUTRONS WERE STARTED IN THE ARRAY WITH A FLAT OISTRIBUTION.

300 NEUTRONS WERE INITIALLY STAR TED

RFAD SEARCH CATA
O.0O217 MINUTES WERE REOUIRED FOR STARTING. 
SAMPLE PROBLEM GENER ATION
$82 C 8$ SPACING SEARCH

$\begin{array}{ll} & \\ 8.25274 E-01 & 6.83333 E-03 \\ 9.03134 E-01 & 1.21667 E-02 \\ 8.59577 E-01 & 1.75000 E-02 \\ 9.66195 E-01 & 2.60000 E-02 \\ 9.49888 E-01 & 3.41667 E-02 \\ 9.68434 E-01 & 4.13333 E-02 \\ 9.49882 E-01 & 4.80000 E-02 \\ 9.26781 E-01 & 5.55000 E-02 \\ 9.25062 E-01 & 6.21667 E-02 \\ 8.73986 E-01 & 6.76666 E-02 \\ 9.78998 E-01 & 7.60000 E-02 \\ 9.96002 E-01 & 8.38333 E-02 \\ 8.88199 E-01 & 9.01666 E-02 \\ 1.02059 E-00 & 9.80000 E-02 \\ 9.03838 E-01 & 1.04333 E-01 \\ 9.54782 E-01 & 1.12500 E-01 \\ 9.84242 E-01 & 1.20500 E-01 \\ 9.39344 E-01 & 1.27167 E-01 \\ 8.77059 E-01 & 1.32667 E-01 \\ 8.8753 E-01 & 1.38500 E-01 \\ 8.57903 E-01 & 1.45167 E-01 \\ 9.42993 E-01 & 1.51833 E-01 \\ 9.53350 E-01 & 1.59167 E-01 \\ 9.42191 E-01 & 1.66333 E-01 \\ 9.40668 E-01 & 1.73500 E-01 \\ 9.27922 E-01 & 1.80833 E-01 \\ 9.440616 E-01 & 1.88500 E-01 \\ 9.70689 E-01 & 1.95167 E-01 \\ 9.92884 E-01 & 2.01000 E-01 \\ 9.10282 E-01 & 2.08000 E-01 \\ 9.20734 E-01 & 2.14667 E-01 \\ 9.70186 E-01 & 2.21833 E-01 \\ 9.77310 E-01 & 2.29167 E-01 \\ 9.18911 E-01 & 2.35167 E-01 \\ 9.79603 E-01 & 2.43000 E-01 \\ 9.55138 E-01 & 2.50167 E-01 \\ 9.16220 E-01 & 2.56667 E-01 \\ 9.96674 E-01 & 2.64333 E-01 \\ 9.29095 E-01 & 2.70833 E-01 \\ 9.43160 E-01 & 2.77167 E-01 \\ 9.70202 E-01 & 2.84667 E-01 \\ 8.37832 E-01 & 2.90500 E-01 \\ 8.95768 E-01 & 2.96667 E-01 \\ 8.87213 E-01 & 3.03833 E-01 \\ 9.87986 E-01 & 3.11833 E-01 \\ 9.57082 E-01 & 3.20000 E-01 \\ 9.21852 E-01 & 3.25500 E-01 \\ 9.41177 E-01 & 3.32167 E-01 \\ 8.67363 E-01 & 3.38000 E-01 \\ 9.51818 E-01 & 3.45000 E-01 \\ 9.28585 E-01 & 3.51833 E-01 \\ 9.73013 E-01 & 3.59667 E-01 \\ 9.05999 E-01 & 3.65500 E-01 \\ 9.37279 E-01 & 3.73000 E-01 \\ 8.94740 E-01 & 3.79167 E-01 \\ 9.19820 E-01 & 3.85500 E-01 \\ 9.62928 E-01 & 3.93333 E-01 \\ 1.60385 E-00 & 4.00833 E-01 \\ 9.23351 E-01 & 4.06667 E-01 \\ 9\end{array}$

AVG. K-EFF $1.00000 E 00$ $1.00000 E 00$ $1.00000 E$ OO $8.59577 E-01$ 9. $12886 E-01$ 9.252 20E-OI . $36023 E-01$ .38795E-01 9.36792E-OL .. $3517 E-01$ . $27475 E-01$ . 32 OOE 01 $9.39480 E-O 1$ 941066 E 01 $9.4963 E-01$ $9.40158 E-01$ $9.40158 E-01$ $9.43097 E-01$ $9.38991 \mathrm{E}-01$ $9.36111 E-01$ $9.34099 E-01$ $9.34543 E-01$ 9. $35438 \mathrm{~B}-01$ $9.35745 \mathrm{E}-01$ $9.35958 E-01$ $9.35623 \mathrm{E}-01$ $9.35823 \mathrm{E}-01$ $9.37164 \mathrm{E}-01$ $9.35524 E-01$ 9.34622E-01 $9.34143 \mathrm{E}-01$ $9.35344 E-01$ $9.36698 \mathrm{E}-01$ $9.36142 \mathrm{E}-01$ 9. $37459 E-01$ 9. $37357 E-01$ $9.39004 \mathrm{E}-01$ $9.38736 \mathrm{E}-01$ 9. $38852 E-01$ $9.39656 \mathrm{E}-01$ $9.37110 E-01$ $9.36102 \mathrm{E}-01$ 9. $34938 E-01$ 9. $36171 E-01$ $9.37555 \mathrm{E}-01$ 9. $37206 E-O 1$ . $37293 E-01$ $9.35805 E-01$ . $36138 E-01$ $9.35984 E-O 1$ $9.36724 E-01$ $9.36122 E-01$ $9.35362 E-01$ $9.35074 E-01$ 9.35581E-01 . $36800 \mathrm{E}-01$ s. $36564 E-01$
CEVIATICN
MATR IX K-EFF
ONLY 293 INDEPENDENT FISSION POINTS WERE GENERATED. $0.0 \quad 0.0$

0.0

$5.33055 \mathrm{E}-02$

2.01871E-02

$1.66044 E-02$

$1.41342 E-02$

1.44

$1.39545 \mathrm{E}-02$

$1.39728 \mathrm{E}-02$

$1.37239 \mathrm{E}-02$

$1.34089 \mathrm{E}-02$

1. $24652 \mathrm{E}-02$

$1.19707 E-02$

1.12000 E-02

1.12102E-02

$1.09577 \mathrm{E}-02$

$1.09577 E-02$

$1.00315 \mathrm{E}-02$

$9.58637 E-03$

$9.14515 E-03$

$8.74162 E-03$

8. 37677 E-03

8.03720 E-03

$7.83672 \mathrm{E}-03$

$7.71729 E-03$

7.49037 E-O3

7.24341 E-03

7. $10008 E-03$

$6.99851 E-03$

$6.80012 E-03$

$6.72080 E-03$

$6.54187 E-03$

$6.38250 E-03$

$6.41703 E-03$

$6.24669 E-03$

$6.08223 E-03$

$5.97823 E-03$

6. $35824 E-03$

$6.28277 E-03$

$6.24095 E-03$

6.21800 E- 03

$6.23184 E-03$

$6.10196 E-03$

$5.96812 E-C 3$

$6.02639 E-03$

S.

$5.72061 E-03$

S.72061E-03

5.64002E-03

$5.48168 \mathrm{E}-03$

5. $38667 \mathrm{E}-03$

5.31210E-03

$5.35685 E-03$

$5.26775 \mathrm{E}-03$

0.0

0.0

0.0

0.0

0.0

0.0

0.0

0.0
0.0

0.0

0.0

0.0

0.0

0.0

0.0
0.0
0.0

0.0
0.0

0.0

0.0

0.0

0.0

0.0

0.0

0.0

0.0

0.0

0.0

0.0

0.0

0.0
0.0

0.0

0.0
0.0

0.0

0.0

0.0

0.0

0.0
0.0

0.0
0.0

0.0
0.0

0.0 


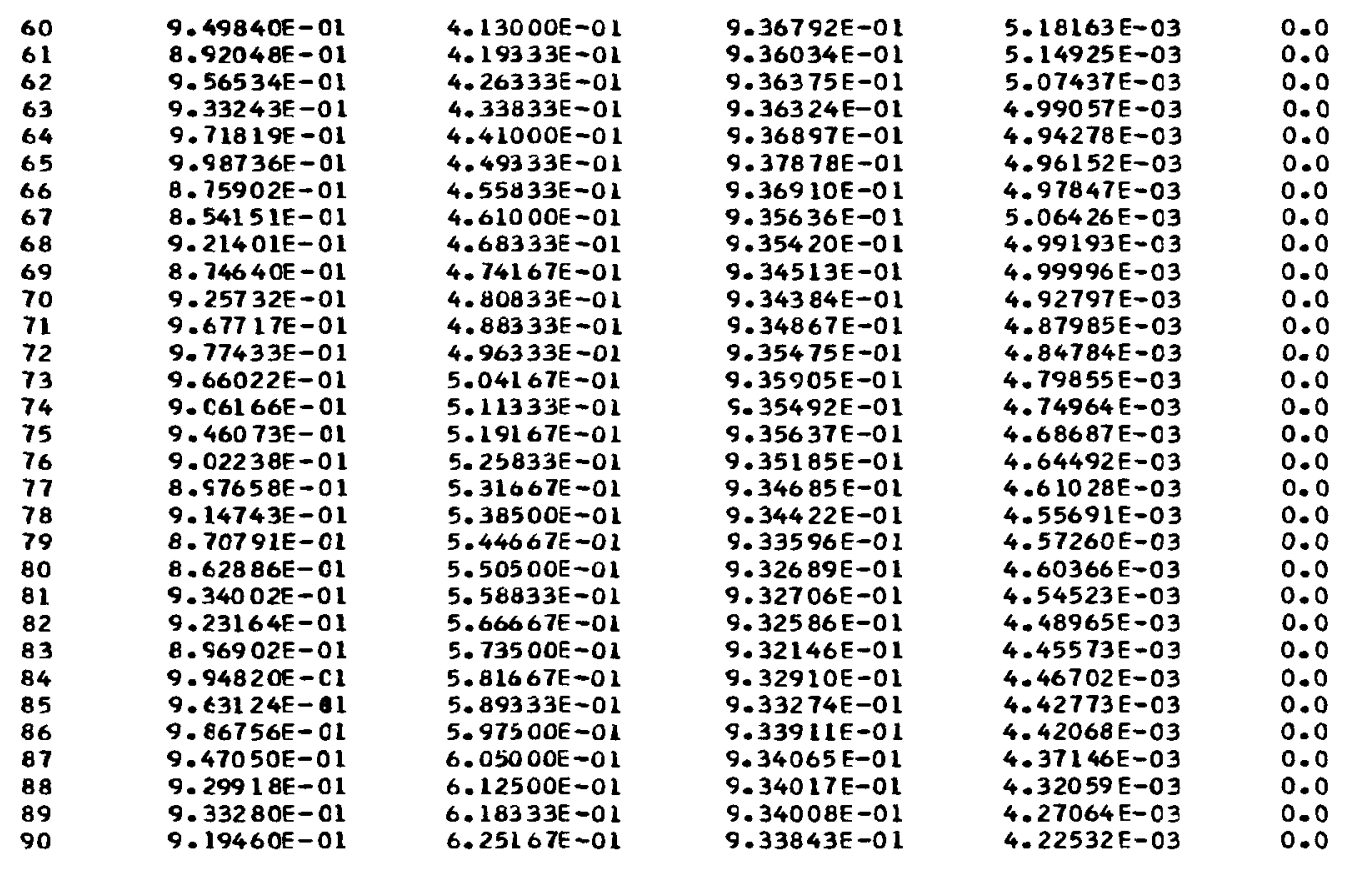

0.0
0.0
0.0
0.0
0.0
0.0
0.0
0.0
0.0
0.0
0.0
0.0
0.0
0.0
0.0
0.0
0.0
0.0
0.0
0.0
0.0
0.0
0.0
0.0
0.0
0.0
0.0
0.0
0.0
0.0
0.0

THE MATRIX K-EFF IS THE LARGEST EIGENVALUE OF THE MATRIX OF FISSION PROBABILITIES BY UNIT. THERE ARE NBXMAX * NBYMAX * NBZMAX UNITS IN AN ARRAY. 
SAMPLE PROBLFM 8 2CB SPACING SEARCH

LIFETIME $=1.09773 \mathrm{~F}-08+0 R-6.59320$ E-11

GENERATION TIME $=7.01510 E-09+$ OR $-7.94819 E-11$

\begin{tabular}{|c|c|c|c|}
\hline $\begin{array}{l}\text { GENERATIONS } \\
\text { SKIPPED }\end{array}$ & $\begin{array}{c}\text { AVER AGE } \\
\text { K-EFFECTIV }\end{array}$ & & DE VI AT I ON \\
\hline 3 & 0.93470 & $+O R$ & -0.00418 \\
\hline 4 & 0.93433 & $+O R$ & -0.00421 \\
\hline 5 & 0.93415 & $+Q R$ & -0.00426 \\
\hline 6 & 0.93374 & $+C R$ & -0.00429 \\
\hline 7 & 0.93355 & $+O R$ & -0.00434 \\
\hline 8 & 0.93363 & $+\mathrm{OR}$ & -0.00439 \\
\hline 9 & 0.53373 & $+O R$ & -0.00444 \\
\hline 10 & 0.93448 & $+O R$ & -0.00444 \\
\hline 11 & 0.93392 & $+O R$ & -0.00446 \\
\hline 12 & 0.93312 & $+O R$ & -0.00444 \\
\hline 17 & 0.93194 & $+\mathrm{OR}$ & -0.00446 \\
\hline 22 & 0.93364 & $+O R$ & -0.00464 \\
\hline 27 & 0.93306 & $+\mathrm{CR}$ & -0.00500 \\
\hline 32 & 0.93307 & $+\mathrm{OR}$ & -0.00529 \\
\hline 37 & 0.93152 & $+C R$ & -0.00563 \\
\hline 42 & 0.93112 & + OR & -0.00567 \\
\hline 47 & 0.93033 & + $O R$ & -0.00585 \\
\hline 52 & 0.93005 & + OR & -0.00628 \\
\hline 57 & 0.93095 & + OR & -0.00704 \\
\hline 62 & 0.92842 & $+O R$ & -0.00765 \\
\hline 67 & 0.52878 & $+O R$ & -0.00158 \\
\hline 72 & 0.52750 & $+\mathrm{OR}$ & -0.00851 \\
\hline 77 & 0.92899 & $+O R$ & -0.01084 \\
\hline 82 & 0.94641 & $+C R$ & -0.01186 \\
\hline 87 & 0.52755 & $O R$ & -0.00416 \\
\hline
\end{tabular}

$\begin{aligned} 67 & \text { PER CENT } \\ \text { CONFIOENCE } & \text { INTERV }\end{aligned}$

0.93052 TO 0.93888

0.93012 TO 0.93854

0.92989 TO 0.93841

0.92945 TO 0.93803

0.92921 TO 0.93788

0.92924 TO 0.93802

0.92929 To 0.93818

0.93004 TO 0.93892

0.92946 TO 0.93837

0.92868 TO 0.93756

0.92748 TO 0.93641

0.92900 TO 0.93828

0.92806 TC 0.93806

0.92778 то 0.93836

0.92590 TO 0.93715

0.92545 To 0.93680

0.92448 TO 0.93617

0.92378 To 0.93633

0.92391 TO 0.93799

0.92077 To 0.93607

0.92120 TO 0.93636

0.91899 TO 0.93601

0.91815 To 0.93983

0.93456 To 0.95827

0.92339 TO 0.93171

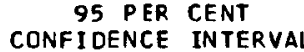

0.92633 TO 0.94306

0.92590 TC 0.94276

0.92563 TO 0.94267

0.92516 To 0.94232

0.92487 TO 0.94222

0.92485 TO 0.94241

0.92485 10 0.94262

0.92561 TO 0.94335

0.92501 TO 0.94283

0.92424 TO 0.94200

0.92301 TO 0.94087

0.92435 TC 0.94292

0.92306 TO 0.94305

0.92249 TO 0.94365

0.92027 T0 0.94278

0.91978 TO 0.94247

0.91863 TO 0.94202

0.91750 TO 0.94260

0.91688 TO 0.94502

0.91313 10 0.94371

0.91362 T0 0.94394

0.91048 TO 0.94452

0.90732 To 0.95067

0.92270 To 0.97013

0.91923 TC 0.93587

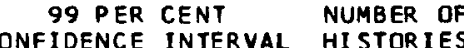
0.92215 TO $0.94724 \quad 26100$ 0.92169 TO $0.94697 \quad 25800$ 0.92137 To $0.94693 \quad 25500$ 0.92087 T0 $0.94661 \quad 25200$ 0.92053 To $0.94656 \quad 24900$ 0.92046 TO $0.94680 \quad 24600$ 0.92040 To $0.94707 \quad 24300$ 0.92117 TO C. 9477924000 $\begin{array}{lll}0.92055 \text { TO } 0.94728 & 23700\end{array}$ 0.91980 TO $0.94644 \quad 23400$ $\begin{array}{lll}0.91855 \text { TO } 0.94533 & 21900\end{array}$ 0.91971 TO $0.94757 \quad 20400$ $\begin{array}{llll}0.91806 & \text { TO } 0.94805 \quad 18900\end{array}$ $\begin{array}{llll}0.91720 & \text { To } 0.94894 \quad 17400\end{array}$ 0.91464 TO $0.94841 \quad 15900$ 0.91410 TO $0.94814 \quad 14400$ 0.91279 TO $0.94787 \quad 12900$ $\begin{array}{llll}0.91123 & \text { T0 } 0.94888 & 11400\end{array}$ 0.90984 TO $0.9520 t \quad 9900$ 0.90548 To $0.95136 \quad 8400$ 0.90604 TO $0.95152 \quad 6900$ 0.90197 TO $0.95303 \quad 5400$ 0.89648 TO $0.96150 \quad 3900$ 0.91084 To $0.98198 \quad 2400$ 0.91507 TO $0.94004 \quad 900$ 
SAMPLE PROBLEM $B$ 2C 8 SPACING SEARCH

THE MINIMUM DEVIATION OF 0.00418 OCCURS AFTER SKIPPING

THE DESIREO VALUE OF K-EFFECTIVE IS 1.00000 + CR -

3 GENERATIONS. THE CORRESPONDING K-EFFECTIVE IS 0.93470

\section{ITERATION NI.}

I DF a MAXIMUM of

3 I TERATICAS.

REGION NUMBER

*** CYLINDER
SEARCH CONSTANTS

1 WILL NOT BE ALTERED.

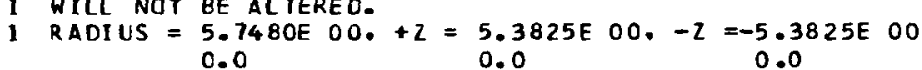

$$
\begin{aligned}
& 5.7480 \\
& 0.0
\end{aligned}
$$

REGION NUMBER 2 WILL BE ALTERED.

*** CUBOID

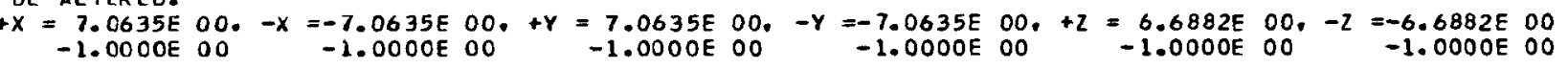


SAMPLE PROBLEM

$82 C 8$ SPACING SEARCH

AFTER SKIPPING

3 GENERATIONS. THE TOTAL LEAKAGE $=5.952760-01$

TOTAL ABSCRPTIONS $=4.037600-01$

TOTAL FISSIONS $=9.347020-01$

ELAPSED TIME $0.62517 M I N L T E S$ 
0.8224 TO 0.8455 0.8455 to 0.8686 0.8686 To 0.8917 0.9148 To 0.9379 0.9370 T0 0.9610 0.9610 TO 0.9841

0.9610 ro 0.9841

1.0072 To 1.0303 $*$

$* * *$

$* * * * * * * *$

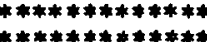

$* * * * * * * * * * * * * * *$

$* * * * * * * * * * * * * *$

$* * * * * * * * *$

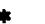

0.8224 TO 0.8455 0.8455 TO 0.8686 0.8686 TO 0.8917 0.8917 TO 0.9148 0.9148 TO 0.9379 0.9379 TO 0.961 0.9610 T0 0.984 0.9841 To 1.007 1.0072 TO 1.0303 $*$

FREQUENCY FOR GENERATICNS

0.8224 to 0.8455 0.8455 TO 0.8686 0.8686 To 0.8917 0.8917 TO 0.9148 0.9148 TO 0.9379 0.9379 TO 0.9610 0.9610 TO 0.9841 1.0072 to 1.0303

$* * *$

$* * * * * * * * * * *$

$* * * * * * * * * * * * * * *$

$* * * * * * * * * *$

$* * * * * * *$

FRE OUENCY FOR GENERATICNS 46 TO 87

***

$* * * * * * * *$

*******

$4 * 4 * 4 *$

0.8224 T0 0.8455

0.822470 .0455

0.8686 T0 0.8986

0.8917 TO 0.9148

0.9148 TO 0.9379

0.9379 TO 0.9610

0.961 TO .9841

0.9841 TO 1.0072

1.0072 To 1.0303

$* *$
$* *$
$* * * * *$
$* * * *$
$* *$
$* * * *$
$* *$

FRE OUENCY FOR GENERATICNS

67 TO 87 
VOLUMES

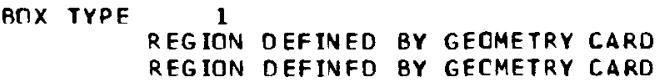

TOTAL. VOL UMES

$\begin{array}{lll}1 & 8.93896 \mathrm{E} & 03 \\ 2 & 1.24176 \mathrm{E} & 04\end{array}$

VOLUME FRACTION OF THE CORE CCNTAINING FISSILE MATERIAL= 0.41856 D O0

START TYPE $=0$

300 NEUTRONS WERE INITIALLY STARTED

0.00200 MINUTES WERE REOUIRED FOR STARTING. 
K-EFFECTIVE ELAPSED TIME(MIN)

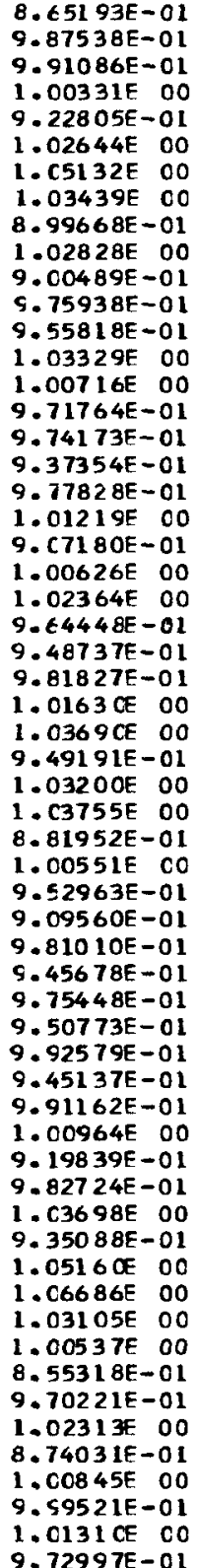

$7.50000 E-03$

$1.36667 E-02$

$2.11667 E-02$

$2.78333 E-02$
$3.41667 E-02$

4.250 OOE -02

$5.23333 E-02$

6.000 OOE -02

$6.58333 E-02$

$7.41667 E-02$

$8.86666 E-02$

$9.58333 \mathrm{E}-02$

$1.03333 \mathrm{E}-01$

$1.11500 E-01$

$1.18167 E-01$

$1.24833 E-01$

$1.31167 E-01$

$1.37833 \mathrm{E}-01$

$1.44167 E-01$

$1.49500 E-01$

$1.56667 E-01$

$1.64833 E-01$
$1.70833 E-01$

$1.70833 E-01$

$1.84500 E-01$

$1.92333 E-01$

$2.00667 E-01$

$2.07833 E-01$

$2.15833 E-01$

$2.37333 E-01$

$2.44167 E-01$

$2.50000 E-O 1$

$2.57333 E-01$

$2.63667 E-01$

2.71167E-01

2. $78167 E-01$

2. $85667 E-O L$

$2.92333 E-01$
$3.00333 E-01$

3.08667E-01

$3.15000 E-01$

$3.22833 \mathrm{E}-01$

3. $32333 E-01$

3.

$3.46667 E-01$

3.56167E-O

$3.041672-01$

3.77000E-01

$3.84167 E-01$

$3.84167 E-01$

$3.92333 E-01$

$3.98167 E-01$
$4.05833 E-01$

$4.13667 E-01$

$4.21667 E-01$
AVG. $K-E F F$

MATR IX K-EFF

$1.00000 E 00$

1.00000 E 00

$9.91086 E-01$

$9.97198 E-01$

$9.72400 E-01$

$5.85909 E-01$

$1.00489 E$ OO

$9.89858 E-01$

$9.94661 E-01$

5. 841 S8E- 01

$9.83372 E-01$

$9.80867 E-01$

$9.85235 E-01$

$9.86922 E-01$

9.85062 E-O

. 85062 E 01

$9.82080 E-01$

$9.83515 E-01$

$9.79497 E-01$

$9.80835 \mathrm{E}-01$

$9.82873 E-01$

$9.82036 E-01$

$9.82036 E-01$

$9.80639 \mathrm{E}-01$

$9.82065 E-01$

S. $84174 E-01$

9.84174E-O1

$9.84632 \mathrm{E}-0 \mathrm{I}$

$9.86456 E-0 \mathrm{l}$

$9.82972 E-01$

9.83699E-01

9.82738E-01

9. 80520 E-01

9. $80535 \mathrm{E}-01$

9. $79538 \mathrm{E}-01$

$9.79424 E-01$

$9.78650 E-01$

$9.79016 E-01$

9. $78147 E-01$

$9.78472 \mathrm{E}-01$

9.79232E-01

$9.77818 E-01$

$9.77931 \mathrm{E}-01$

$9.79273 E-01$

$9.78291 E-01$

$9.79885 E-01$

$9.82762 E-01$

$9.82762 E-01$

S. $80665 E-01$

9.80460E-01

$9.80460 E-01$

$9.81280 E-01$

$9.79257 E-01$
$9.79797 E-01$

$9.80156 E-01$

$9.80744 E-O 1$

0.0

0.0

$6.16183 E-03$

2.50539E-02

$2.22766 E-02$

2.16533E-02

1.86470 E-02

$2.17735 E-02$

$1.94579 E-02$

$2.00992 E=02$

$1.79964 E-02$

$1.64700 \mathrm{E}=02$

$1.56567 \mathrm{E}-02$

$1.45005 E-02$

$1.34683 E-02$

.

$1.13915 \mathrm{E}-02$

$08745 E-02$

$10458 E-02$

$.05646 E-02$

$1.02526 \mathrm{E}-02$

$9.80999 \mathrm{E}-03$

$9.48614 E-03$

$9.08427 E-03$
$8.82896 E-03$

$8.74187 E-03$

$8.51078 E-03$

$8.38769 E-03$

$8.29821 E-03$

$8.74158 E-03$

$8.48624 E-03$

$8.27270 E-03$

$8.31994 E-03$

$8.07187 E-03$

$7.90197 E-03$

7.68137E-03

$7.51192 \mathrm{E}-03$

$7.32092 \mathrm{E}-\mathrm{C} 3$

$7.18410 E-03$

$7.01023 E-03$

$6.87983 E-03$

$6.86183 E-03$

$6.70239 E-03$

$6.68451 E-03$

$6.77185 \mathrm{E}-03$

$6.7088 E-03$

$6.58718 E-03$

$6.58718 E-03$

$6.80815 E-03$

$6.80815 E-03$
$6.72650 E-03$

$6.72650 E-03$

$6.90185 E-03$
$6.79477 E-03$

$6.68012 \mathrm{E}-03$

$6.68012 E-03$

6.47137E-03
MEPENDENT FISSION POINTS MERE GENERATED. 0.0

0.0

0.0

0.0

0.0

0.0

0.0

0.0

0.0

0.0

0.0

0.0

0.0

0.0

0.0

0.0

0.0

0.0

0.0

0.0

0.0

0.0

0.0

0.0

0.0

0.0

0.0

0.0
0.0

0.0

0.0

0.0

0.0
0.0

0.0

0.0

0.0
0.0
0.0

0.0

0.0 


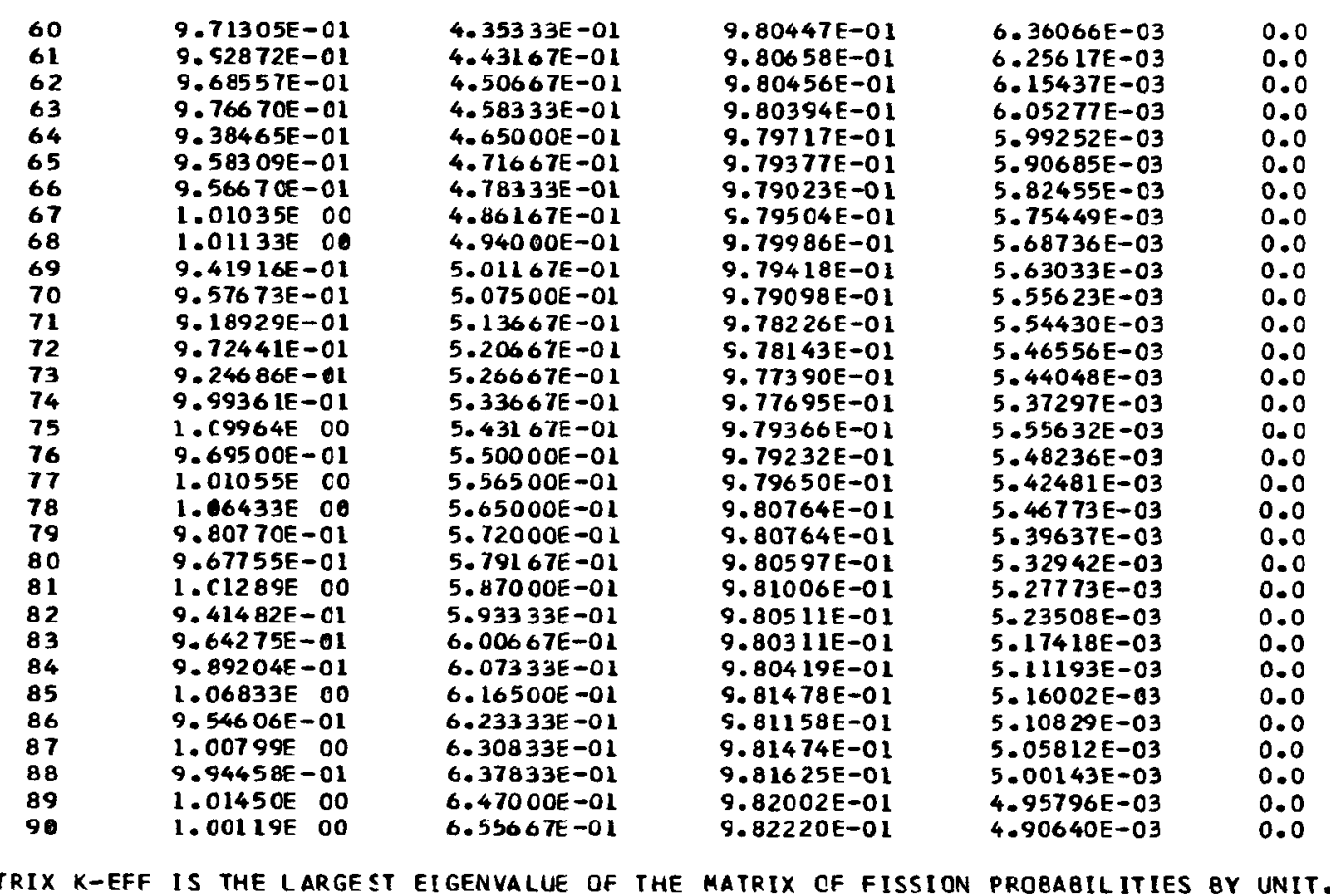

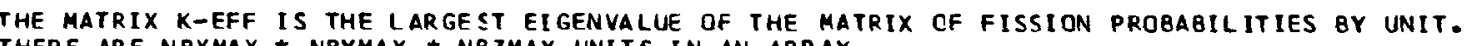
THERE ARE NBXMAX * NBYMAX * NBZMAX UNITS IN AN ARRAY. 
SAMPLE PROBLEM 8 2C8 SPACING SEARCH

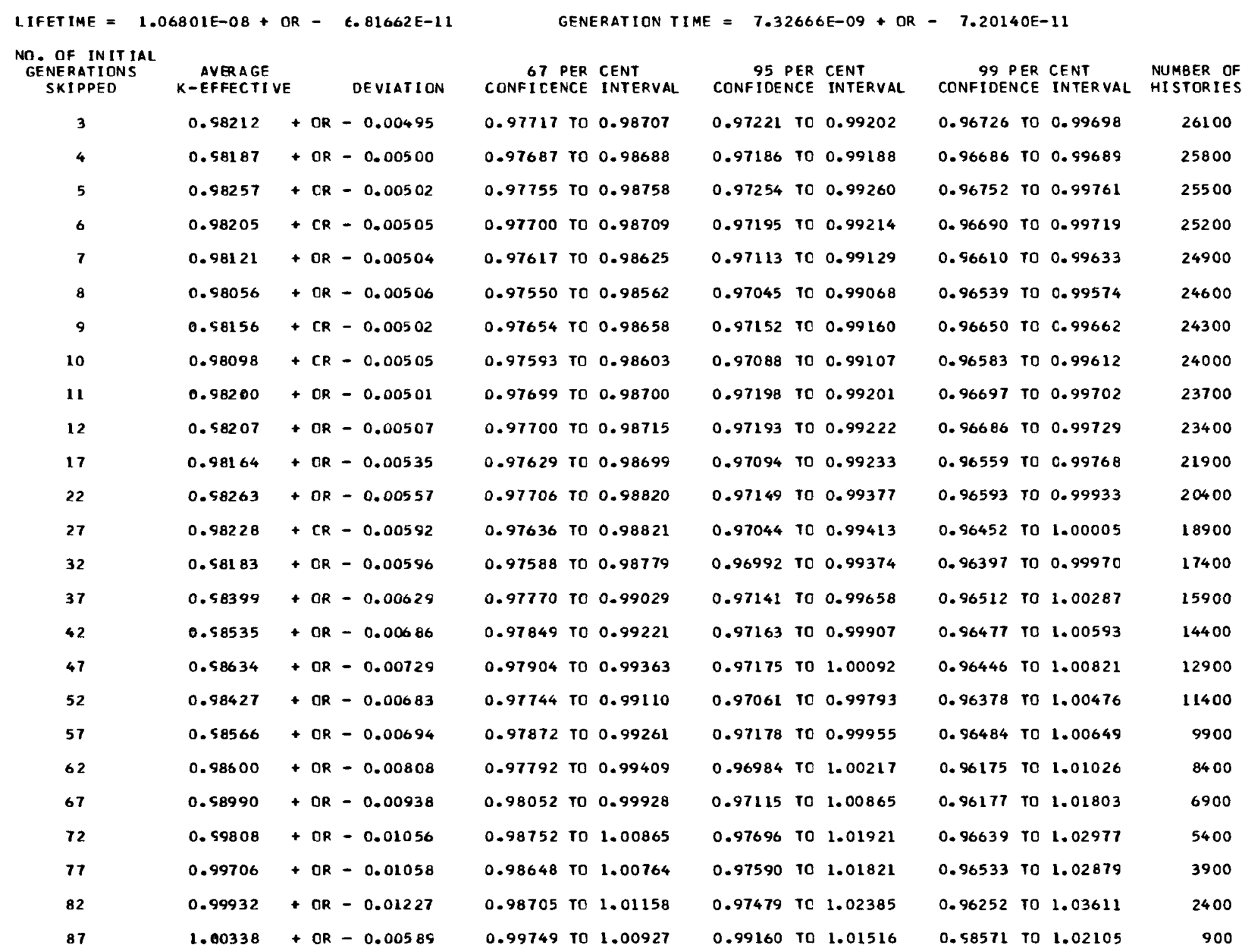


SAMPLE PROBLEM E 2 C8 SPACING SEARCH

THE MINIMUM DEVIATION OF 0.00495 OCCURS AFTER SKIPPING 3 GENERATIONS. THE CORRESPONOING K-EFFECTIVE IS O.98212

THE DESTRED VALUE OF K-EFFECTIVE IS $1.00000+$ CR - 1 STANDARD DEVIATIONS

ITFRATION NO. 2 OF A MAXIMUM OF 3 ITERATICAS.

REGION NUMBER 1 WILL NOT BE ALTERED.

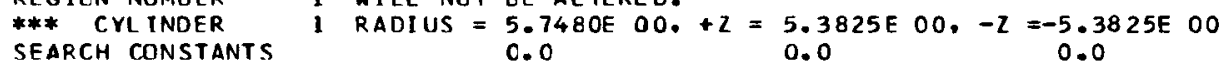

REGION NUMBER 2 WILL BE ALTERED.

$+X=6.8774 E$ OO. $-X=-6.8774 \mathrm{E} 00,+Y=6.8774 \mathrm{E} 00,-\gamma=-6.8774 \mathrm{E} 00,+Z=6.5120 \mathrm{E} \quad 00,-2=-6.5120 \mathrm{E} 00$ 
SAMPLE PROBLEM 2 C 2 SPACING SEARCH

AFTER SKIPPING 3 GENERATIONS. THE TOTAL LEAKAGE $=5.751470-01$ TOTAL ABSCRPTIONS = 4.24941D-01 TOTAL FISSIONS = 9.82126D-01 ELAPSED TIMF $0.65567 M I N U T E S$ 
SAMPLE PROBLEM

0.8346 TO 0.8577 0.8577 To 0.8808 8808 to 0.9039 0.9039 TO 0.9270 .9270 TO 0.950 0.9732 TO 0.9563 $0.9963 \mathrm{TO} .0194$ 1.0194 TO 1.0425 1.0425 TO 1.0656 1.0425 To 1.0656 1.0887 to 1.1118

0.8346 TO 0.8577 0.8577 TO 0.8808 0.8808 TO 0.9039 0.9039 T0 0.9270 0.9270 TO 0.9501 0.9501 TO 0.5732 0.9732 TO 0.9563 0.9963 To 1.0194 .0194 TO 1.0425 .0656 TO 1.088 1.0887 to 1.1118

0.8346 TO 0.8577 0.8577 TO 0.8808 0.8808 TO 0.9039 0.9039 to 0.9270 0.9270 ro 0.9501 0.9501 TO 0.9732 0.9732 ro 0.5563 0.9963 TO 1.0194 1.0425 to 1.0656 1.0425 ro 1.0656 1.0656 To 1.0887

0.8346 TO 0.8577

0.8346 To 0.8577 0.8808 in 0.8639 0.9039 TO 0.9270 0.9270 ro 0.9501 0.9501 TO 0.9732 0.9732 to 0.9963 0.9963 Tn 1.0194 1.0194 TO 1.0425 1.0425 TO 1.0656 1.0656 TO 1.0887 1.0887 To 1.1118
82 C 8 SPAC ING SEARCH

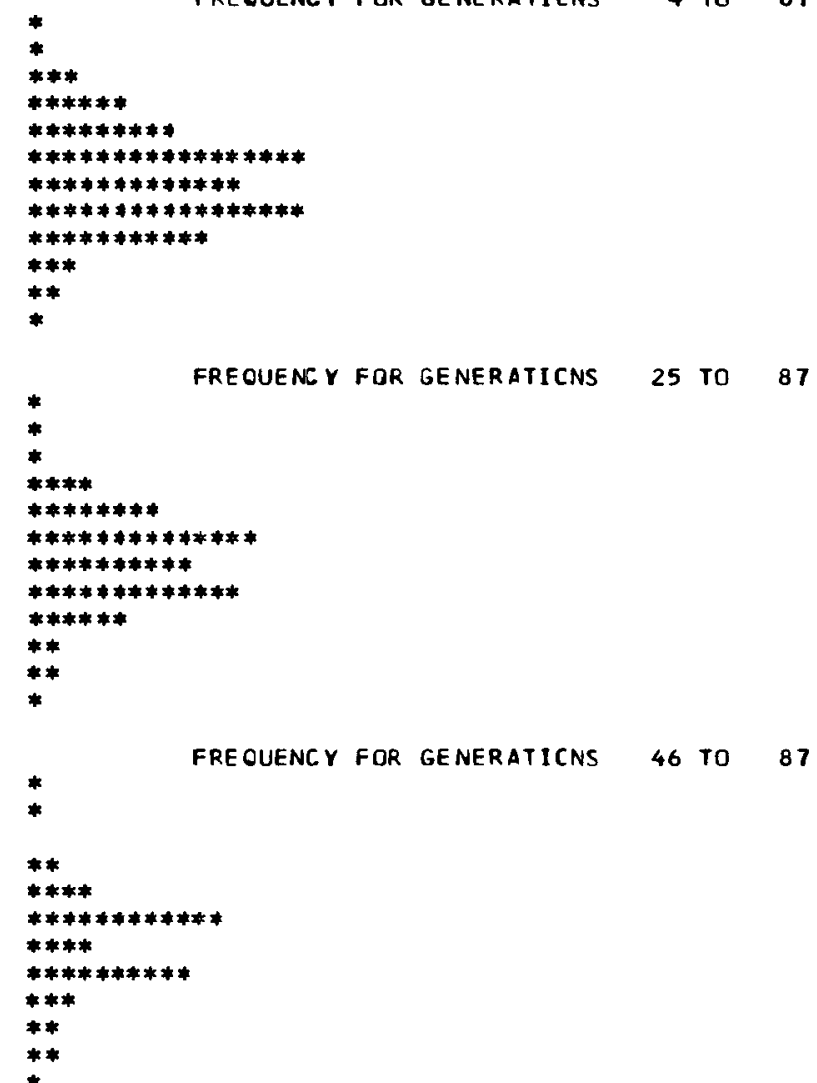




\section{VOLUMES}

BOX TYPE REGION DEFINED BY GECMETRY CARD REGION DEFINED BY GECMETRY CARD
REGION DEFINED BY GEOMETRY CARD

1 VCLUME $=1.11737 \mathrm{E} 03 \mathrm{CM} * 3$ VOLUME $=1.34672 \mathrm{E} 03 \mathrm{CM}$ C*3
CUMULATIVE VOLUME CUMULATIVE VOLUME
1. $11737 E \quad 03 C M * * 3$ $2.46409 E$ O3 CM**3

TOTAL VOLUMES

1 VOLUMES

VOLUME FRACTION OF THE CORE CONTAINING FISSILE MATERIAL $=0.45346$ E 00

START TYPE $=0$

300 NEUTRONS WERE INITIALLY STARTED
0.00217 MINUTES WERE REOUIRED FOR STARTING. 
SAMPLE PROBLEM

GENFRATION
82 C8 SPAC ING SEARCH $9.49329 E-01$ $9.67207 E-01$ $1 . C 9156 E$ OO 1.06761E 00 $.02057 E$ CO $1.03386 E$ CO $1.04634 \mathrm{E} \mathrm{OO}$ 9.80797E-OI $8.88414 E-01$ $1.08887 E$ DO $9.47517 E-01$ 9. $54675 E-01$ 1. $02844 E$ OO $9.44549 E-C 1$ $9.68742 E-01$ $1.04425 E$ OO $1.02068 E$ OO $1.06448 E$ OO 1.0555 OE CO $1.08462 E 00$ $9.66366 E-01$ $1.01564 \mathrm{E} 00$ 9. $46838 \mathrm{E}-0$ $9.46838 \mathrm{E}-01$ $9.55788 E-01$ $9.40199 E-01$ $1.03401 E$ OO $9.92529 \mathrm{E}-\mathrm{C} 1$ $1.04455 \mathrm{EE} 00$ $9.80443 E-01$ $1.10413 E$ OO $1.04526 \mathrm{E}$ CO $1.00929 E$ OO $1.03164 E \quad 00$ $9.42140 E-01$ $8.93321 E-01$ $1.00453 E \quad 00$ $9.74946 E-0$ $1.01529 E \quad 00$ $1.01436 E$ OO $9.14951 E-0$ $1.03582 E \quad 00$ $1.05308 E$ OO $9.91416 E-01$ 1.C1183E 00 1.C1786E 00 $1.05996 \mathrm{E}$ OO $1.06174 E$ CO $1.02320 E$ OO 1. C8488E 00 $9.75512 E-0$ $8.78216 E-01$ $9.68784 E-01$ $1.02252 E 00$ $9.20273 E-01$ 9. $90819 E-O 1$ $9.88417 E-01$ $9.81806 E-01$
ELAP SED TIME(MIN) 8.500 ODE -03 $1.50000 E-02$ 2.41667E-02 $3.21667 E-02$ $3.96667 \mathrm{E}-02$ $4.63333 E-02$ $5.35000 E-02$ 6. $00000 E-02$ $6.58333 \mathrm{E}-02$ $7.38333 E-02$ $7.88333 \mathrm{E}-02$ $8.54999 E-02$ $9.26666 \mathrm{E}-02$ $1.00000 E-01$ $1.06833 \mathrm{E}-01$ $1.15000 E-01$ $1.21833 E-01$ $1.31000-O$ $1.38833 \mathrm{E}-01$ 1. $53333 \mathrm{E} O \mathrm{~L}$ $1.59367 E-01$ $1.59167 E-01$

$1.73333 \mathrm{E}-01$

$1.80833 E-01$

$1.80833 E-01$

$1.85833 E-01$

$1.95167 E-01$

$2.03833 E-01$

$2.18333 E-01$ $2.183500 E-01$ $2.32667 E-01$ $2.40833 E-01$ $2.48000 E-01$ $2.55167 E-O$ $2.61333 \mathrm{E}-01$ $2.66833 E-01$ .74167E-0 2.81000E-OL $2.88000 E-0$ $2.96000 E-01$ $3.01833 E-0$ $3.09667 E-01$ 3.18000E-OL 3.251 $67 E-01$ 3. $31667 E-01$ 3.400 OOE -01 $3.48000 E-01$ $3.56333 E-01$ $3.63000 E-01$ 3.71000E-OL 3.775 $67 E-O L$ $3.82500 E-O L$ 3. $97500 E-O L$ . 4.05O OOE -OL $4.18833 E-01$ $4.26333 E-01$ 4. $33500 E-01$
AVG. K-EFF . $00000 E$ OO $1.00000 E$ DO $1.09156 \mathrm{E} \mathrm{OO}$ $1.07959 E 00$ $1.05992 \mathrm{E} \mathrm{OO}$ $1.05340 E$ OO $1.05199 E$ OO $1.04012 \mathrm{E} O 0$
$1.01845 \mathrm{E} 00$ $1.01845 E$ EO $1.02725 E 00$ $1.01839 E$ OO $1.01602 \mathrm{E} 00$ $1.01715 E 00$ $1.01110 E 00$ $1.00784 E$ OO $1.01044 E$ OO $1.01112 E$ OO $1.01446 E$ OO $1.01687 E$ OD T 1.01778E 00 $1.01414 E 00$ 1.01108E 00 $1.01108 E 00$ $1.00583 \mathrm{E} O 0$ $1.00583 E$ OO $1.00928 E 00$ 1.00957 E 00 $1.01082 E 0 O$ $1.00977 E$ OO $1.01292 \mathrm{E} 00$ $1.01396 E$ OO 1.01381 E 00 $1.01435 \mathrm{E} 00$ $1.01223 E$ OO $1.00883 E 00$ $1.00871 E 00$ .00780E 00 $.00800 E 00$ $1.00816 E \quad 00$ $1.00583 E 00$ 1. $00656 \mathrm{E} \mathrm{OO}$ $1.00767 E 00$ $1.00729 E 00$ $1.00739 E$ DO $1.00763 E$ OO 1.00876 E OO $1.00989 E$
$1.001017 E$ $1.01017 E$ OO $1.01169 E 00$ 1.00836 E $1.00836 E$ OD $1.00760 E$ OO 1.00780E 00 $1.00780 E 00$ $1.00593 \mathrm{E} \mathrm{OO}$ $1.00563 E$ OO $1.00522 E 00$

$\begin{array}{ll}\text { CEVIATICN } & \text { MATRIX K-EFF } \\ 0.0 & 0.0 \\ 0.0 & 0.0 \\ 0.0 & 0.0 \\ 1.20002 E-02 & 0.0 \\ 2.08422 E-02 & 0.0 \\ 1.6157 E-02 & 0.0 \\ 1.25632 E-02 & 0.0 \\ 1.56859 E-02 & 0.0 \\ 2.54094 E-02 & 0.0 \\ 2.37034 E-02 & 0.0 \\ 2.27038 E-02 & 0.0 \\ 2.04431 E-02 & 0.0 \\ 1.85290 E-02 & 0.0 \\ 1.79635 E-02 & 0.0 \\ 1.68392 E-02 & 0.0 \\ 1.58094 E-02 & 0.0 \\ 1.47342 E-02 & 0.0 \\ 1.41764 E-02 & 0.0 \\ 1.35338 E-02 & 0.0 \\ 1.33038 E-02 & 0.0 \\ 1.29064 E-02 & 0.0 \\ 1.27977 E-02 & 0.0 \\ 1.21718 E-02 & 0.0 \\ 1.20059 E-02 & 0.0 \\ 1.17206 E-02 & 0.0 \\ 1.15817 E-02 & 0.0 \\ 1.16303 E-02 & 0.0 \\ 1.12181 E-02 & 0.0 \\ 1.08120 E-02 & 0.0 \\ 1.04977 E-02 & 0.0 \\ 1.01789 E-02 & 0.0 \\ 1.03270 E-02 & 0.0 \\ 1.00433 E-02 & 0.0 \\ 9.72617 E-03 & 0.0 \\ 9.44291 E-03 & 0.0 \\ 9.40381 E-03 & 0.0 \\ 9.74550 E-03 & 0.0 \\ 9.46957 E-03 & 0.0 \\ 9.25447 E-03 & 0.0 \\ 9.01062 E-03 & 0.0 \\ 8.77906 E-03 & 0.0 \\ 8.86938 E-03 & 0.0 \\ 8.67988 E-03 & 0.0 \\ 8.54484 E-03 & 0.0 \\ 8.35055 E-03 & 0.0 \\ 8.15964 E-03 & 0.0 \\ 7.97994 E-03 & 0.0 \\ 7.88943 E-03 & 0.0 \\ 7.80055 E-03 & 0.0 \\ 7.64048 E-03 & 0.0 \\ 7.63891 E-03 & 0.0 \\ 7.51667 E-03 & 0.0 \\ 7.81616 E-03 & 0.0 \\ 7.70161 E-03 & 0.0 \\ 7.55714 E-03 & 0.0 \\ 7.41911 E-03 & 0.0 \\ 7.45507 E-03 & 0.0 \\ 7.32688 E-03 & 0.0 \\ 7.20348 E-03 & 0.0 \\ 7.09181 E-03 & 0.0 \\ 139 & \end{array}$




\begin{tabular}{|c|c|c|c|c|c|c|}
\hline $\begin{array}{l}61 \\
62\end{array}$ & $\begin{array}{l}1.04511 E 00 \\
1.00681 E 00\end{array}$ & $\begin{array}{l}4.41333 E-01 \\
4.48333 E-01\end{array}$ & $\begin{array}{l}1.00589 E \\
1.00591 E\end{array}$ & $\begin{array}{l}00 \\
00\end{array}$ & $\begin{array}{l}7.00229 E-C 3 \\
6.88541 E-03\end{array}$ & $\begin{array}{l}0.0 \\
0.0\end{array}$ \\
\hline 63 & $9.41917 E-01$ & $4.54333 E-01$ & $1.00486 E$ & 00 & $6.85219 \mathrm{E}-03$ & 0.0 \\
\hline 64 & $1.00340 E \quad 00$ & $4.61833 E-01$ & $1.00483 E$ & 00 & $6.74152 E-03$ & 0.0 \\
\hline 65 & $1.01583 E \quad 00$ & $4.69333 E-01$ & $1.00501 E$ & 00 & $6.63497 E-03$ & 0.0 \\
\hline 66 & $1.06365 \mathrm{E} \mathrm{OO}$ & $4.78000 E-01$ & $1.00593 \mathrm{E}$ & 00 & $6.59474 E-03$ & 0.0 \\
\hline 67 & $9.81059 E-01$ & $4.86000 E-01$ & $1.00554 \mathrm{E}$ & 00 & $6.50304 E-03$ & 0.0 \\
\hline 68 & $9.83415 E-01$ & $4.93500 E-01$ & $1.00521 \mathrm{E}$ & 00 & $6.41290 E-03$ & 0.0 \\
\hline 69 & $1.07946 E \quad 00$ & $5.01833 E-01$ & $1.00632 E$ & 00 & $6.41389 E-03$ & 0.0 \\
\hline 70 & $9.98253 \mathrm{E}-01$ & $5.10000 E-01$ & $1.00620 \mathrm{E}$ & 00 & $6.31872 E-03$ & 0.0 \\
\hline 71 & $1.03925 E \quad 00$ & $5.16833 E-01$ & $1.00668 \mathrm{E}$ & 00 & $6.24520 E-03$ & 0.0 \\
\hline 72 & S. $81228 E-01$ & $5.24167 E-01$ & $1.00631 \mathrm{E}$ & 00 & $6.16848 E-03$ & 0.0 \\
\hline 73 & $9.67029 E-01$ & $5.30500 E-01$ & $1.00576 E$ & 00 & $6.10533 E-03$ & 0.0 \\
\hline 74 & $9.65258 E-01$ & $5.36833 E-01$ & $1.00520 E$ & 00 & $6.04554 E-03$ & 0.0 \\
\hline 75 & $9.43908 E-01$ & $5.43333 E-01$ & $1.00436 \mathrm{E}$ & 00 & $6.02103 E-03$ & 0.0 \\
\hline 76 & $1.02167 E 00$ & $5.50000 E-01$ & $1.00459 \mathrm{E}$ & 00 & $5.94350 E-03$ & 0.0 \\
\hline 77 & $1.01699 E 00$ & $5.56833 E-01$ & $1.00476 \mathrm{E}$ & 00 & $5.86707 E-03$ & 0.0 \\
\hline 78 & $9.76686 E-01$ & $5.63333 \mathrm{E}-0 \mathrm{I}$ & $1.00439 E$ & 00 & $5.80049 E-03$ & 0.0 \\
\hline 79 & $1.06227 E \quad 00$ & $5.71000 E-01$ & $1.00514 \mathrm{E}$ & 00 & $5.77416 E-03$ & 0.0 \\
\hline 80 & $1.01561 E 00$ & $5.79667 E-01$ & $1.00527 E$ & 00 & $5.69972 E-03$ & 0.0 \\
\hline 81 & $9.47208 \mathrm{E}-01$ & $5.86000 E-01$ & $1.00454 \mathrm{E}$ & 00 & $5.67601 E-03$ & 0.0 \\
\hline 82 & $1.02682 E \quad 00$ & $5.93333 E-01$ & $1.00482 E$ & 00 & $5.61208 \mathrm{E}-03$ & 0.0 \\
\hline 83 & $1.02671 E 00$ & $6.01000 E-01$ & $1.00508 E$ & 00 & $5.54903 E-03$ & 0.0 \\
\hline 84 & $9.78720 E-01$ & $6.08333 E-01$ & $1.00476 \mathrm{E}$ & 00 & $5.49114 E-03$ & 0.0 \\
\hline 85 & $9.99624 E-01$ & $6.15500 E-01$ & $1.00470 E$ & 00 & $5.42442 E-03$ & 0.0 \\
\hline 86 & $1.01833 E 00$ & $6.22667 E-01$ & $1.00486 \mathrm{E}$ & 00 & $5.36280 E-03$ & 0.0 \\
\hline 87 & $1.04805 E \quad 00$ & $6.30000 E-01$ & $1.00537 \mathrm{E}$ & 00 & $5.32226 \mathrm{E}-03$ & 0.0 \\
\hline 88 & $1.01404 E \quad 00$ & $6.37500 E-01$ & $1.00547 \mathrm{E}$ & 00 & $5.26215 E-03$ & 0.0 \\
\hline 89 & $1.05724 E \quad 00$ & $6.45167 E-01$ & $1.00607 \mathrm{E}$ & 00 & $5.23570 E-03$ & 0.0 \\
\hline 90 & $9.74901 E-01$ & $6.52500 E-01$ & $1.00571 \mathrm{E}$ & 00 & $5.18654 E-03$ & 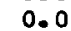 \\
\hline
\end{tabular}

THE MATRIX K-efF IS THE LARGEST EIgENVALUE OF THE MATRIX OF FISSION PROBABILITIES BY UNIT. THERE ARE NBXMAX * NOYMAX * NBZMAX UNITS IN AN ARRAY. 
SAMPLE PROBLEM 8 2C8 SPACING SEARCH

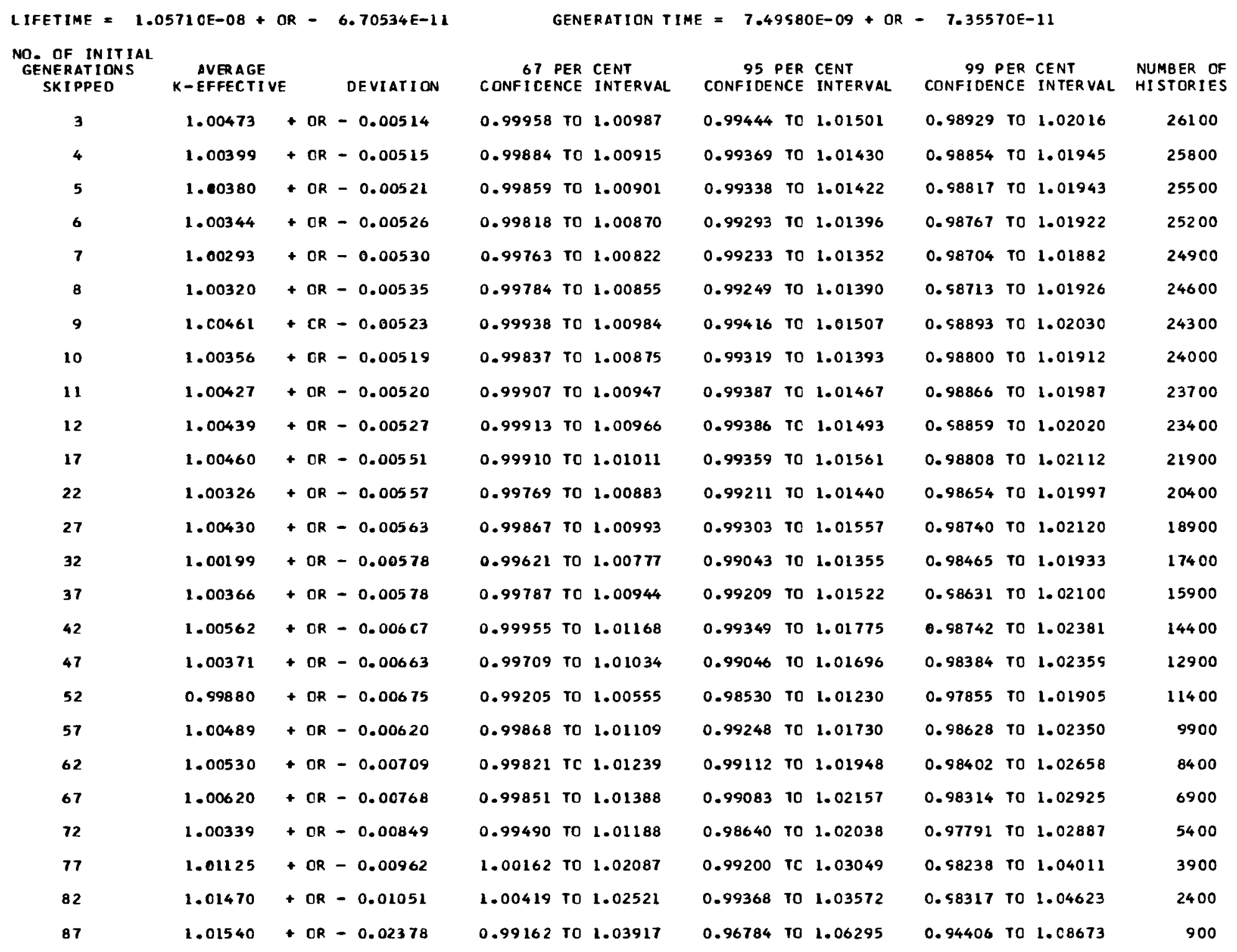


THE DES IRED VALUE OF K-EFFECTIVE IS

1.00000

$+C R-$

1 STANDARO DEVIATIONS

*** SEARCH COMPLETED 


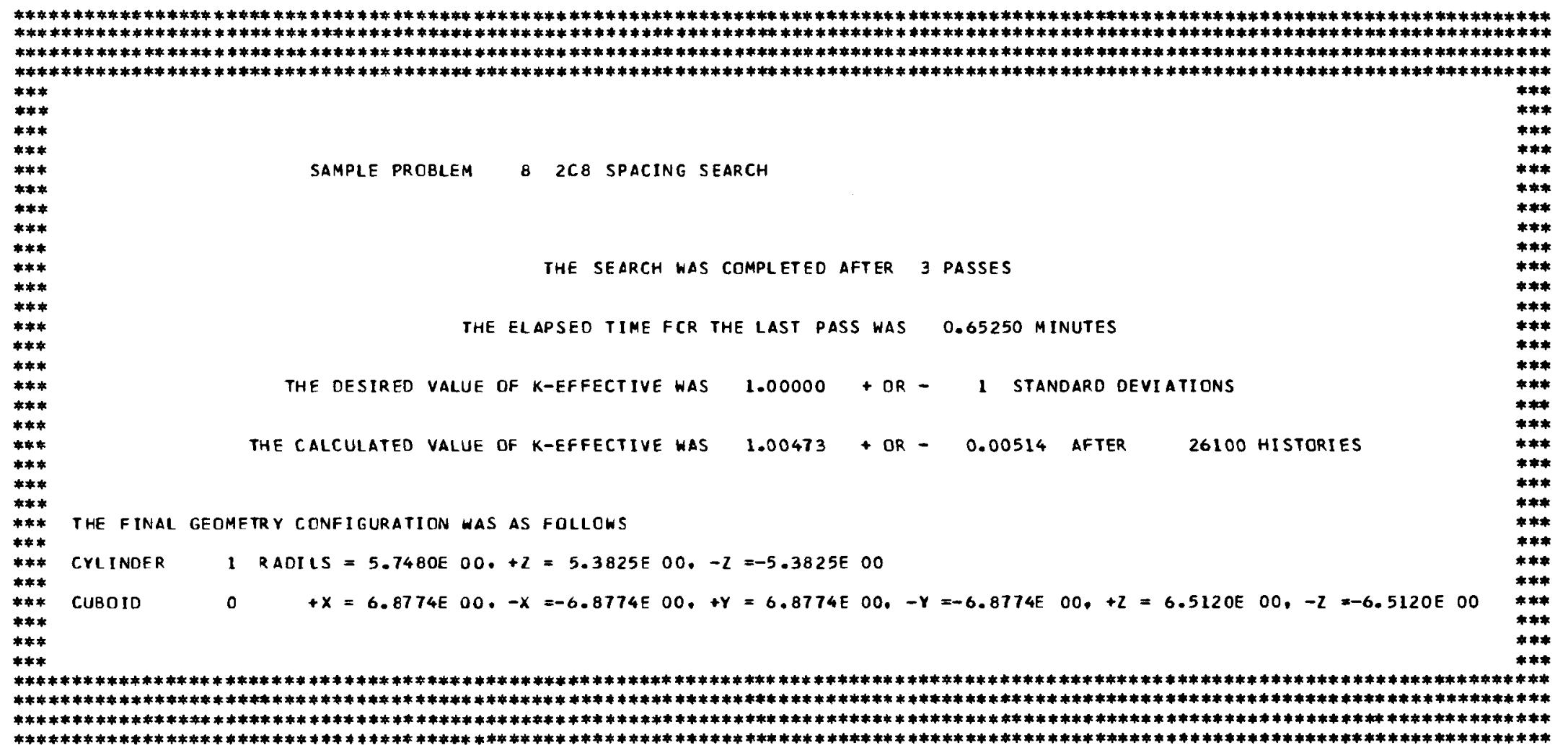




\begin{tabular}{|c|c|c|c|c|c|}
\hline GROUP & RFGION & LEAKAGE & ABSORP TIONS & FISSIONS & WITH 3 GENERATIONS \\
\hline 1 & & $7.767000-02$ & $5.027020-02$ & $1.42356 c-01$ & \\
\hline 2 & & $1.432260-01$ & $9.832770-02$ & $2.413800-01$ & \\
\hline 3 & & 8. $58883 D-02$ & $6.140600-02$ & $1.419190-01$ & \\
\hline 4 & & $1.451980-01$ & $1.049150-01$ & $2.306900-01$ & \\
\hline 5 & & $9.820180-02$ & $9.466820-02$ & $1.992620-01$ & \\
\hline 6 & & $1.100950-02$ & $2.504350-02$ & $4.819830-02$ & \\
\hline 7 & & $5.297380-05$ & $4.999730-04$ & $9.268830-04$ & \\
\hline 8 & & 0.0 & 0.0 & 0.0 & \\
\hline 9 & & 0.0 & 0.0 & 0.0 & \\
\hline 10 & & 0.0 & 0.0 & 0.0 & \\
\hline 11 & & 0.0 & 0.0 & 0.0 & \\
\hline 12 & & 0.0 & 0.0 & 0.0 & \\
\hline 13 & & 0.0 & 0.0 & 0.0 & \\
\hline 14 & & 0.0 & 0.0 & 0.0 & \\
\hline 15 & & 0.0 & 0.0 & 0.0 & \\
\hline 16 & & 0.0 & 0.0 & 0.0 & \\
\hline TOTAL $=$ & & $5.652470-01$ & $4.351310-01$ & 1.00473000 & \\
\hline
\end{tabular}

ELAPSEO TIMF $0.65250 M I N U T E S$ 
SAMPLE PROBLEM 8 2C8 SPACING SEARCH

**** FISS ION OENSITIES ****

$$
\begin{array}{llc}
\text { FISSION } & \text { PERCENT } & \text { TOTAL } \\
\text { DENSITY DEVIATION } & \text { FISSICNS }
\end{array}
$$

80X TYPE

REGION DENSITY DEVIATION

FISSICNS

$\begin{array}{llll}1 & 1.124 E-C 4 & 0.51 & 1.005 E 00 \\ 2 & 0.0 & 0.0 & 0.0\end{array}$




\begin{tabular}{|c|c|c|c|c|}
\hline SAMPLE & PROBL EM & $2 C 8$ & SPACING SEAR & $\mathrm{RCH}$ \\
\hline FLUXES & \multicolumn{3}{|c|}{$\begin{array}{c}\text { FOR BOX TYPE } \\
\text { REGION }\end{array}$} & \\
\hline GROUP & Flux & $\begin{array}{l}\text { PERCENT } \\
\text { DE VIATION }\end{array}$ & FLUX & PERCENT \\
\hline 1 & $9.431 E-05$ & 1.86 & $5.261 E-05$ & 2.30 \\
\hline 2 & $1.813 E-04$ & 1.00 & $1.021 E-04$ & 1.56 \\
\hline 3 & $1.12 B E-04$ & 1.75 & $6.344 E-05$ & 2.39 \\
\hline 4 & $1.901 E-04$ & 1.08 & $1.64 \mathrm{EE}-04$ & 1.29 \\
\hline 5 & $1.420 E-04$ & 1,32 & $7.531 \mathrm{~L}-05$ & 1.62 \\
\hline 6 & $1.918 E-05$ & 3.29 & $9.259 \mathrm{E}-06$ & 4.59 \\
\hline 7 & $1.971 E-07$ & 24.23 & $5.896 E-08$ & 59.95 \\
\hline 8 & 0.0 & 0.0 & 0.0 & 0.0 \\
\hline 9 & 0.0 & 0.0 & c.o & 0.0 \\
\hline 10 & 0.0 & 0.0 & 0.0 & 0.0 \\
\hline 11 & 0.0 & 0.0 & 0.0 & 0.0 \\
\hline 12 & 0.0 & 0.0 & 0.0 & 0.0 \\
\hline 13 & 0.0 & 0.0 & 0.0 & 0.0 \\
\hline 14 & 0.0 & 0.0 & 0.8 & 0.0 \\
\hline 15 & 0.0 & 0.0 & 0.0 & 0.0 \\
\hline 16 & 0.0 & 0.0 & 0.0 & 0.0 \\
\hline
\end{tabular}


SAMPLE PROBLEM

0.8777 To 0.9008 0.9008 to 0.9239 0.9239 TO 0.9470 0.9470 to 0.5701 0.9701 To 0.9932 0.9932 To 1.0163 1.0163 in 1.0394 1.0394 TO 1.0625 1.0625 To 1.0856 1.0856 TO 1.1086

0.8777 t 0.9008 0.9008 To 0.923 0.9239 Tn 0.9470 0.9470 To 0.9701 0.9701 in 0.9932 0.9932 TO 1.0163 1.0163 TD 1.0394 1.0394 ro 1.0625
1.0625 To 1.0856 $\begin{array}{ll}1.0625 & \text { To } 1.0856 \\ 1.0856 \text { TO } 1.1086\end{array}$

0.8777 to 0.9008 0.9008 Tn 0.9239 0.9239 TO 0.9470 0.9470 To 0.5701 0.9932 Tn 1.0163 1.0163 Tn 1.0394 1.0394 in 1.0625 1.0625 TO 1.0856 1.0856 TO 1.1086 0.8777 Tn 0.9008
0.9008 to 0.9239 0.9239 in 0.9470 0.9239 TO 0.9470
0.9470 TO 0.9701 0.9470 To 0.9701
0.9701 to 0.5532 0.9932 in 1.0163 1.0163 TO 1.0394 1.0394 in 1.0625 1.0625 TO 1.0856 1.0856 in 1.1086
$82 C 8$ SPAC ING SEARCH

FRE QUENC Y FOR GENERATICNS

4 T0 87

$* *$

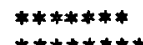

$* * * * * * * *$

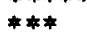

$* *$

FREOUENCY FOR GENERATICNS

25 TO 87

$* * * *$

$* * * * *$

$* * * * * * * * * *$

$* * * * * * * * * * * *$

$* * * * * * * * * * * *$

$* * * * * * *$

$* * *$

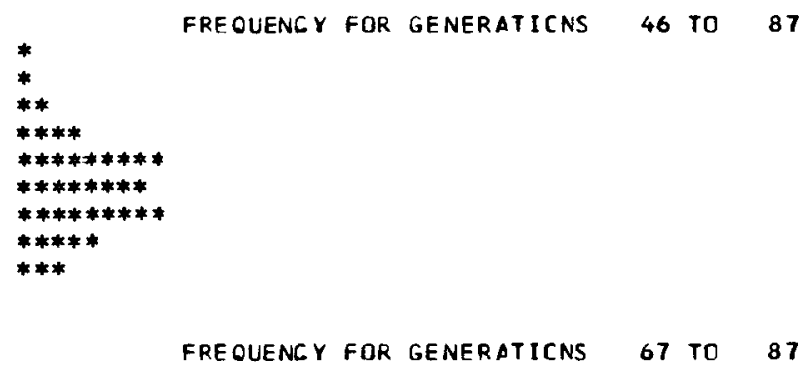

*

$* * * * *$

$* * *$

$* *$

$*$ 
SAMPLE PROB 16 GENERALIZED GECMETRY GROTESOUE

NUMBER OF GENERATIONS 103

NUMBER PFR GENERATION

300

NUMBER OF GENERATIONS TO BE SKIPPED

NUMBER OF ENFRGY GROUPS

3

MAX. NUMBER OF ENERGY TRANSFERS

NUMBER OF INPUT NUCL IDES

NUMBER OF MIXTURFS

NUMBER OF MIXING TABLE ENTRIES

NUMBER OF GECMETRY CARDS

NUMBER OF BOX TYPES

NUMBER OF UNITS IN X DIRECTION

NUMBER OF UNITS IN $Y$ DIRECTION

NUMBER OF UNITS IN $Z$ DIRECTION

NUMBER TF NUCLIDES READ FROM TAPE

AL BEDO TYPE

SEARCH TYPE

THIS PROBLEM WAS RUN AS A SINGLE UNIT.

MAXIMUM TIME $=1$. COOO MINUTES

STORAGE LOCATIONS REOUIRED FOR THIS JOB $=$
ST ART TYPE

GENERATIONS EETWEEN CHECKPOINTS O

LIST INPUT $X$-SECTIONS REAO FROM TAPE NC

LIST 1-D MIXTURE X SECTIONS YES

LIST 2-D MIXTURE X-SECTIONS YES

LIST FISS. AND ABS. BY REGION NO

USE X-SECTIONS FROM PREVIOUS CASE NO

USE GEOMETRY FROM PREVIOUS CASE NO

USE VELOCITIES FROM PREVIOUS CASE NO

COMPUTE MATRIX K-EFFECTIVE BY UNIT NO

COMPUTE MATRIX K-EFFECTIVE BY BOX TYPE NO

LIST FISS PROB MATRIX BY UNIT NO

ADJOINT CALCULATION NO

USE EXPONENTIAL TRANSFORM

CALCULATE FLUX YES

CALCULATE FISSION DENSITIES YES 
SAMPLE PROB 16 GENERAL I ZED GECMETRY GRO IESOUE

MIXTURE NUCLIDE DENSITY

$1 \quad-92500 \quad 4.50792 E-C 2$

CROSS SFCTIONS READ FROM TAPE

NUCLIDF $=\quad 92500 \quad U-235 \mathrm{YR}$ NUCL IDE $=\quad \$ 2800 \quad$ U $238 \mathrm{Y}$

HANSEN ROACH 


\begin{tabular}{|c|c|c|c|c|c|}
\hline & $\begin{array}{l}\text { ABSORPT ION } \\
\text { PROBAB IL ITY }\end{array}$ & $\begin{array}{l}\text { NU*F I SS ION } \\
\text { PROB AB I L ITY }\end{array}$ & $\begin{array}{l}\text { NON-AB SOR PII } \\
\text { PROBABIL I ITY }\end{array}$ & $\begin{array}{l}\text { TOTAL } \\
\text { CROSS-SECTION }\end{array}$ & $\begin{array}{r}\text { FISSION } \\
\text { SPECTRUM }\end{array}$ \\
\hline $\mathbf{I}$ & $2.87423 E-01$ & 8.13257E-01 & $7.12576 E-01$ & & $2.04000 \mathrm{E}-01$ \\
\hline 2 & $2.787655-01$ & $6.83927 \mathrm{E}-01$ & $7.21234 \mathrm{E}-01$ & $2.15922 E-01$ & $5.48000 F-01$ \\
\hline & & $25525 \mathrm{E}-\mathrm{Cl}$ & -01 & & \\
\hline & 2. & & & 50 & \\
\hline & $1.97927 \mathrm{E}-01$ & $E-01$ & $E-01$ & $5 E-01$ & $D E-01$ \\
\hline & 2.41056 & 4.6 & & & \\
\hline & 3.461 & 6.422 & -01 & $9 E-01$ & IOE 00 \\
\hline & 5.0849 & 8.764 & -01 & $E-01$ & OE OO \\
\hline & & & & & DE 00 \\
\hline 10 & 8.52644 & $1.29510 \mathrm{E} 00$ & 01 & 24 & SOE OO \\
\hline 11 & 8.86442 & 1.14 & 01 & $E$ & DOE 00 \\
\hline 12 & 8.8 & $1 E-01$ & $2 E-01$ & $02 E 00$ & DOE 00 \\
\hline 13 & 7.865 & $1.48128 \mathrm{E} \quad 00$ & $33 E-01$ & $2.23679 E \quad 00$ & JOE OO \\
\hline & 8.83119 & $1.89233 \mathrm{E} \quad 00$ & 1.1 & $49 E 00$ & DOOE 00 \\
\hline & & & & & 0 \\
\hline & - & $528 E$ & $\boldsymbol{J} 2$ & $028>>>$ & 50000 \\
\hline
\end{tabular}

CUMULATIVE TRANSFER PROBABILITIES

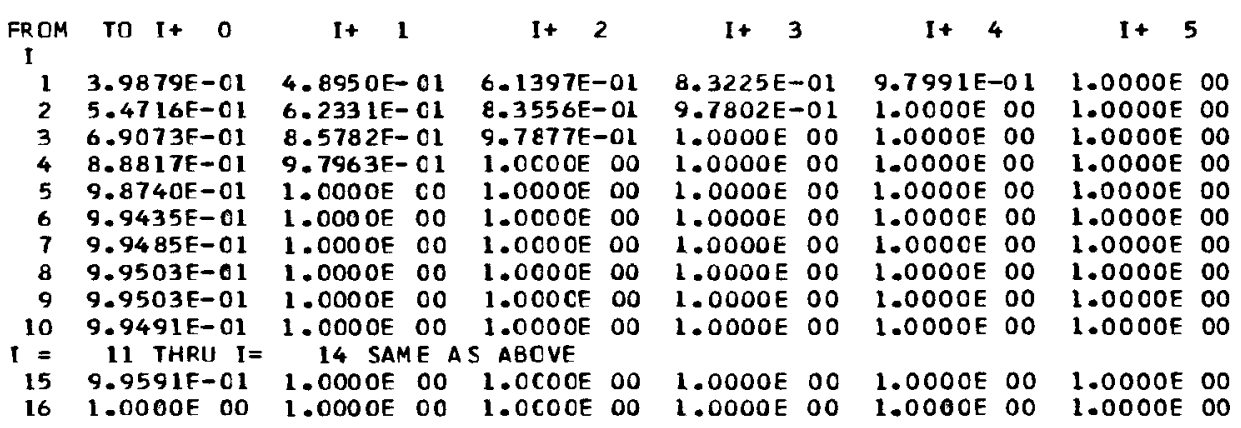

MUEAR
FROM TO It
I+ 1
I+ 2
I* 3
I 0.0
$0 . c$
C. 0
$S$ ABOV
0.0
0.0
0.0 
SAMPLE PROB 16 GENERAL IZED GECMETRY GRO TESOUE

GEOMETRY DE SCRIPTION

REG ION

$x=0.0$

$-x=0.0$

$+Y=0.0$

$-\gamma=0.0$

$+z=0.0$

$-2=0.0$ 
SAMPLE PROB 16 GENERAL IZED GECME TRY GROTESOUE

\section{WEIGHT ING FUNCT ION}

BOX TYPE

WLOW

WT AVG

WT HI

REGION I DEF INE D BY GECMETRY CARD

$$
\begin{aligned}
& 1 \\
& \text { GROUPS } \\
& 2 \text { TO } \\
& \text { TO }
\end{aligned}
$$


2
$X$ BNOSNOS MALE

$Y$ BOUNDS $-0.22841 E$ O2, 0.21686 , 02

$1-0.23319 E$ 02, $-0.57569 \mathrm{E}$ 01, $0.69433 \mathrm{E} 01,0.24353 \mathrm{E} \quad 02$

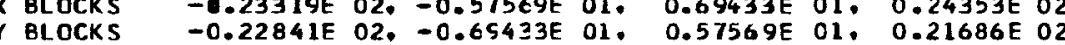

7 BLOCKS -0.17550 O1, $0.15240 \mathrm{E} 02$

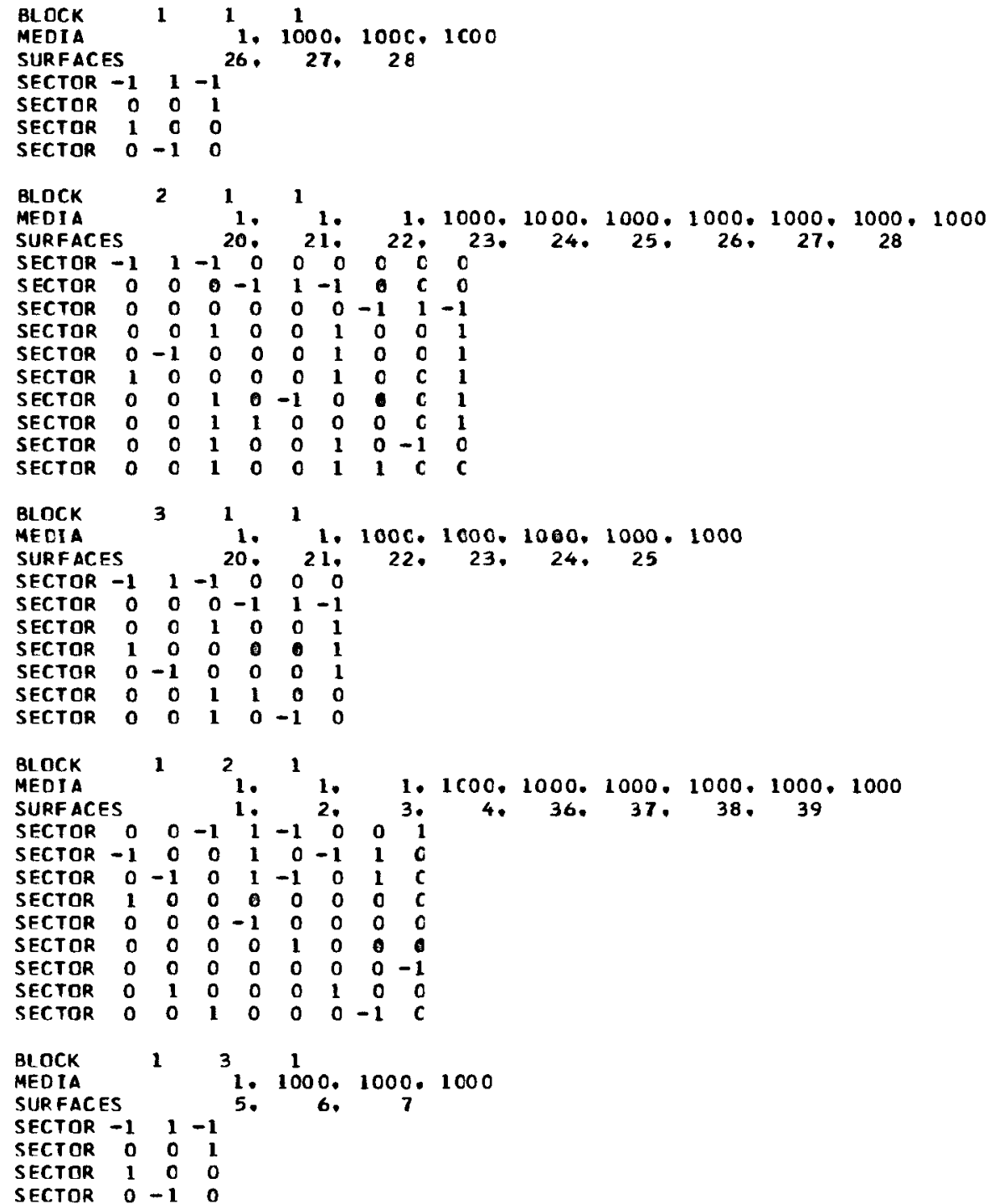




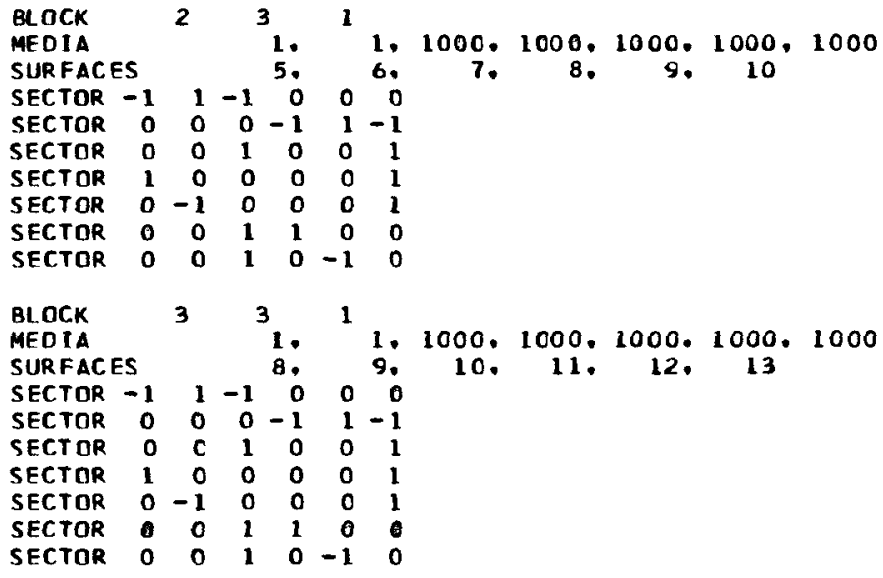

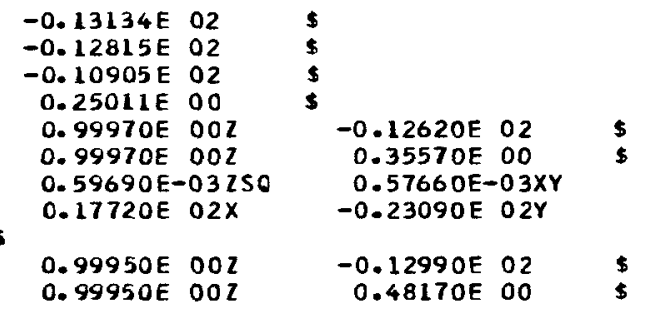


$0.10000 E$ O1XSO $0.68450 E-C 2 X$ $0.96290 \mathrm{DOZ}$ -0.26100E-01X $0.59930 \mathrm{~F} 00 \times 50$ 0.5930 E dOXSO $-0.10110 \mathrm{E} 012$ $-0.45070 \mathrm{E}-01 \mathrm{X}$ $-0.45070 E-01 X$ $0.99898 E$ OOX $0 . \$ 9898 \mathrm{~F}$ OOX 0.10000 E OLY 0.10000 OIY $-0.21830 \mathrm{E}-01 \mathrm{X}$ $-0.21830 E-01 x$ $0.99950 \mathrm{E}$ 0OXSO $0.43640 E-01 \times Z$ -0. $\$ 1100 E 002$ $-0.21290 E-02 x$ $-0.21290 E-02 X$ 0.10000 E O1XSO $0.42580 E-C 2 \times Z$ $-0.83490 \mathrm{E} 002$ $0.11820 \mathrm{~F}-01 \mathrm{X}$ 0.11820 E-O1X $0.99990 E$
$-0.23630 \mathrm{E}-01 \times \mathrm{X}$ -0.59320 E $00 Z$ 0.10000 E 012 0.10000 e O1XSO $0.10000 F$ O1XSO $0.65020 E$ OOY . 1 DOODE OIXSO 0.65020 E OOY 0.45070 -OIX $0.59800 \mathrm{~F}$ O0XSO $-0.32390 \mathrm{E}$ C2X $0.99972 E$ DOX $0.99972 E$ DOX $0.99972 E$ DOX $0.99972 F$ oOX
$0.99910 E$ OOYSO $0.60 \mathrm{C} 80 \mathrm{OE}-\mathrm{C} 1 \mathrm{YZ}$ $-0.22290 \mathrm{E}-01 \mathrm{Y}$ $0.99550 E$ OOYSO $0.44550 E-01 Y Z$ $0.19600 F 03$ $0.99858 E 00$ $0.99858 E$ COZ 0.45858 SCOZ $0.45070 \mathrm{E}-\mathrm{Cl}$ $-0.32168 E$ O1 $0.44032 \mathrm{E} \mathrm{Cl}$ $0.19660 E-01 Y$ $0.19660 E-01 Y$ $0.99960 E$ OOYSO $-0.39290 E-C 1 Y Z$ $0.21570 \mathrm{E} \mathrm{C3}$ $0.24340 E-C 1 Y$ $0.24340 E-C 1 Y$ $0.99940 E$ OOYSO

$-0.48660 \mathrm{E}-01 \mathrm{YZ}$ $0.25890 E \quad 03$ 0.1513 CE-C1Y $0.15130 E-01 Y$ $0.99980 E$ OOYSO $-0.30250 E-C 1 Y Z$ $0.21750 E$ C $-0.93740 E$ CO $0.100 C O E$ OIYSO $0.10000 E$ CIYS $-0.13312 E$ O2Z 0.10000E OIYSO $-0.13312 E$ O2Z $-0.66562 E$ O1 $0.999 \mathrm{CCE}$ COZ - 1000 E OIY 0.11860e OIY $-0.23560$ $-0.23560 \mathrm{E}-012$ $-0.23560 \mathrm{E}-012$
$0.91490 E-0325 C$ $0.99940 E$ OOZ 0.11780E-02250 $0.52520 E$ OO $-0.24340 E 02$

0.99960 E 002 $0.99960 E$ OOL $0.86290 E-032 S 6$

$s$

\section{$0.99970 E \quad 002$} $0.99970 E \quad 002$ $0.59690 \mathrm{E}-03$ $\$$ 0.99980 E 002 $0.99980 E 00 Z$ OOE 002 $0.19020 E$ O $2 X$

$s$ $-0.33142 E \quad 02$ 0.10000 E OLLSO 0.81601E OI $0.10000 \mathrm{E} 01256$ $s$

$0.20320 E-0225 C$ -0.14610E OL $0.10613 E$ E2 O. $0.20773 E$ O2
$0.23316 E$ O2
$-0.20580 E-03 X Y$

$-0.31620 E$ O2Y

-0.12460 E 02 $0.50560 E$ OO -0.11630 E-02XY $-0.19110 \mathrm{E} 02 \mathrm{Y}$

$$
\$
$$

\section{$\begin{array}{rl}-0.12520 E & 02 \\ 0.45570 E \text { \$ } & \text { \$ }\end{array}$ $0.85820 E-03 X Y$ 0.20740 E O2Y}

-0.13060 E 02 0.41760 E 00 $0.10370 E-03 X Y$ 0.34030 E O2Y

-0.12660 E 02 $0.29660 \mathrm{E} \mathrm{OO}$ $-0.35760 E-03 X Y$ $0.24340 E$ O2Y

\section{$\$$} $-0.17226 E 01 \mathrm{X}$
$-0.17226 E$ O1X

$0.90050 E-01 \times Z$ 
SAMPLE PROB 16 GENERAL IZED GECMETRY GRO TESOUE

VOLUMES

BOX TYPE REGION DEFINED BY GEOMETRY CARO

1 VOLUME $=3.60751 E 04 \mathrm{CM} * * 3$ TOTAL VOLUMES

$$
1 \quad 3.60751 E \text { O4 }
$$

VOLUME FRACTION OF THE CORE CCNTAINING FISSILE MATERIAL $=0.10000$ E 01

START TYPE $=0$

THE NEUTRONS WERE STARTED in the ARRAY WI TH A FLAT DISTRIRUTION.

300 NFUTRONS WERE INITIALLY STARTED

0.00883 MINUTES WFRE REOUIRED FOR STARTING. 
SAMPLE PROB 16 GENERAL IZED GECME TRY GRO TESOUE

GENER AT ION
1
2
3
4
5
5
6
7
8
9
10
11
12
13
14
15
16
17
18
19
20
21
22
23
24
25
26
27
28
29
30
31
32
33
34
35
36
37
38
39
40

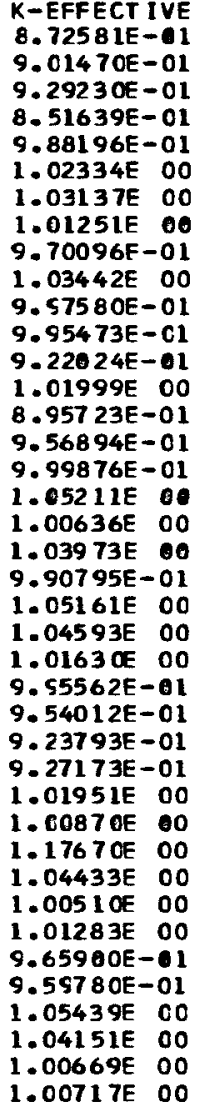

ELAPSED TIMEIMIN
$3.08333 E-02$
$5.33333 E-02$
$7.68333 E-02$
$9.85000 E-02$
$1.25500 E-01$
$1.53000 E-01$
$1.791677-01$
$2.05167 E-01$
$2.30000 E-01$
$2.55833 E-01$
$2.81000 E-01$
$3.05167 E-01$
$3.28500 E-01$
$3.546677-01$
$3.76833 E-01$
$4.01667 E-01$
$4.26833 E-01$
$4.53500 E-01$
$4.79167 E-01$
$5.04333 E-01$
$5.29167 E-01$
$5.55500 E-01$
$5.81000 E-01$
$6.04667 E-01$
$6.29333 E-01$
$6.51667 E-01$
$6.75000 E-01$
$6.98500 E-01$
$7.23833 E-01$
$7.48333 E-01$
$7.76833 E-01$
$8.01333 E-01$
$8.2767 E-01$
$8.53333 E-01$
$8.80000 E-01$
$9.05000 E-01$
$9.31833 E-01$
$9.57500 E-01$
$9.82500 E-01$
$1.00683 E 00$

AVG K-EFF
$1.00000 E$ O0
$1.00000 E$ O0
$9.29230 E-01$
$8.90434 E-01$
$9.23021 E-01$
$9.48100 E-01$
$9.64753 E-01$
$9.72713 E-01$
$9.72339 E-01$
$9.80100 E-01$
$9.82042 E-01$
$9.83385 E-01$
$9.77807 E-01$
$9.81322 E-01$
$9.74737 E-01$
$9.73463 E-01$
$9.75224 E-01$
$9.80029 E-01$
$9.81577 E-01$
$9.84807 E-01$
$9.85122 E-01$
$9.88446 E-01$
$9.91183 E-01$
$9.92325 E-01$
$9.92465 E-01$
$9.90863 E-01$
$9.88180 E-01$
$9.85833 E-01$
$9.87080 E-01$
$9.87852 E-01$
$9.94364 E-01$
$9.96030 E-01$
$9.96322 E-01$
$9.96838 E-01$
$9.95900 E-01$
$9.94838 E-01$
$9.96539 E-01$
$9.97788 E-01$
$9.98028 E-01$
$9.98268 E-01$

DEVIATICN
0.0
0.0
0.0
$3.88022 \mathrm{E}-02$
$3.95444 \mathrm{E}-02$
$3.75609 \mathrm{E}-02$
$3.35231 \mathrm{E}-02$
$2.85053 \mathrm{E}-02$
$2.40942 \mathrm{E}-02$
$2.22622 \mathrm{E}-02$
$1.97296 \mathrm{E}-02$
$1.76981 \mathrm{E}-02$
$1.69524 \mathrm{E}-02$
$1.58695 \mathrm{E}-02$
$1.60142 \mathrm{E}-02$
$1.48810 \mathrm{E}-02$
$1.39649 \mathrm{E}-02$
$1.39187 \mathrm{E}-02$
$1.31659 \mathrm{E}-02$
$1.28275 \mathrm{E}-02$
$1.21404 \mathrm{E}-02$
$1.19883 \mathrm{E}-02$
$1.17266 \mathrm{E}-02$
$1.12398 \mathrm{E}-02$
$1.07407 \mathrm{E}-02$
$1.04067 \mathrm{E}-02$
$1.03363 \mathrm{E}-02$
$1.02037 \mathrm{E}-02$
$9.89749 \mathrm{E}-03$
$9.56867 \mathrm{E}-03$
$1.12981 \mathrm{E}-02$
$1.10407 \mathrm{E}-02$
$1.06822 \mathrm{E}-02$
$1.03566 \mathrm{E}-02$
$1.00814 \mathrm{E}-02$
$9.83786 \mathrm{E}-03$
$9.70395 \mathrm{E}-03$
$9.51272 \mathrm{E}-03$
$9.25536 \mathrm{E}-03$
$9.01267 \mathrm{E}-03$
9

MATR IX K-EFF
0.0
0.0
0.0
0.0
0.0
0.0
0.0
0.0
0.0
0.0
0.0
0.0
0.0
0.0
0.0
0.0
0.0
0.0
0.0
0.0
0.0
0.0
0.0
0.0
0.0
0.0
0.0
0.0
0.0
0.0
0.0
0.0
0.0
0.0
0.0
0.0
0.0
0.0
0.0
0.0
0
THE MATRIX K-EFF IS THE LARGEST EIGENVALUE OF THE MATRIX OF FISSION PROBABILITIES BY UNIT.
THERE ARE NBXMAX * NBYMAX * NEZMAX UNITS IN AN ARRAY. 
SAMPLE PROB 16 GENERAL IZED GECMEIRY GROTESOUE

LIFET IME $=6.48759 \mathrm{E}-09+$ OR $-8.42788 \mathrm{E}-11$

\section{NO. OF INITIAL}

GENERATIONS
SKIPPEO

AVER AGE
K- EFFECTIVE

DEVIATION

3

4

5

6

7

8

9
GENERATION TIME $=5.71515 E-09+$ OR $-8.71827 E-11$

67 PER CENT
CONFICENCE INTERVAL 95 PER CENT CONFIOENCE INTER VAL 99 PER CENT CONFIOENCE INTERVAL NUMBER OF CONFICENCE INTERVAL CONFIOENCE INTERVAL CONFIDE 0.99108 TO 1.00919 0.99597 TO 1.01255 0.99620 To 1.01324 0.99542 TO 1.01292 0.99437 TO 1.01233 0.99380 To 1.01232 0.99462 TO 1.01363 0.99334 To 1.01288 0.99319 To 1.01342 0.99311 To 1.01406 1.00241 To 1.02419 0.99572 TO 1.02265 1.00114 TO 1.03421 0.99518 TO 1.01816 1.00693 TO 1.02998
0.98202 TO 1.01825 0.98768 10 1.02084 0.98769 ro 1.02175 0.98667 TO 1.02168 0.98538 TO 1.02131 0.98454 TO 1.02159 0.98512 To 1.02313 0.98357 TO 1.02265 0.98308 TO 1.02353 0.98264 TO 1.02454 0.99152 TO 1.03508 0.98225 TO 1.03612 0.98461 TO 1.05074 0.98369 TO 1.02965 0.99540 TO 1.04151
0.97296 TO 1.02730

11100

0.97939 TO $1.02913 \quad 10800$ 0.97917 TO $1.03027 \quad 10500$ 0.97791 To $1.03043 \quad 10200$ 0.97640 TO $1.03029 \quad 9900$ 0.97527 To $1.03085 \quad 9600$ 0.97561 TO 1.032639300 0.97380 TO 1.032429000 0.97297 ro $1.03364 \quad 8700$ 0.57216 TO $1.03501 \quad 8400$ 0.98062 TO 1.045976900 0.96879 To $1.04959 \quad 5400$ 0.96808 To $1.06727 \quad 3900$ 0.97220 To $1.04114 \quad 2400$ 0.98387 TO $1.05304 \quad 900$ 
SAMPLE PROB 16 GENERAL IZED GECMETRY GROTESOUE

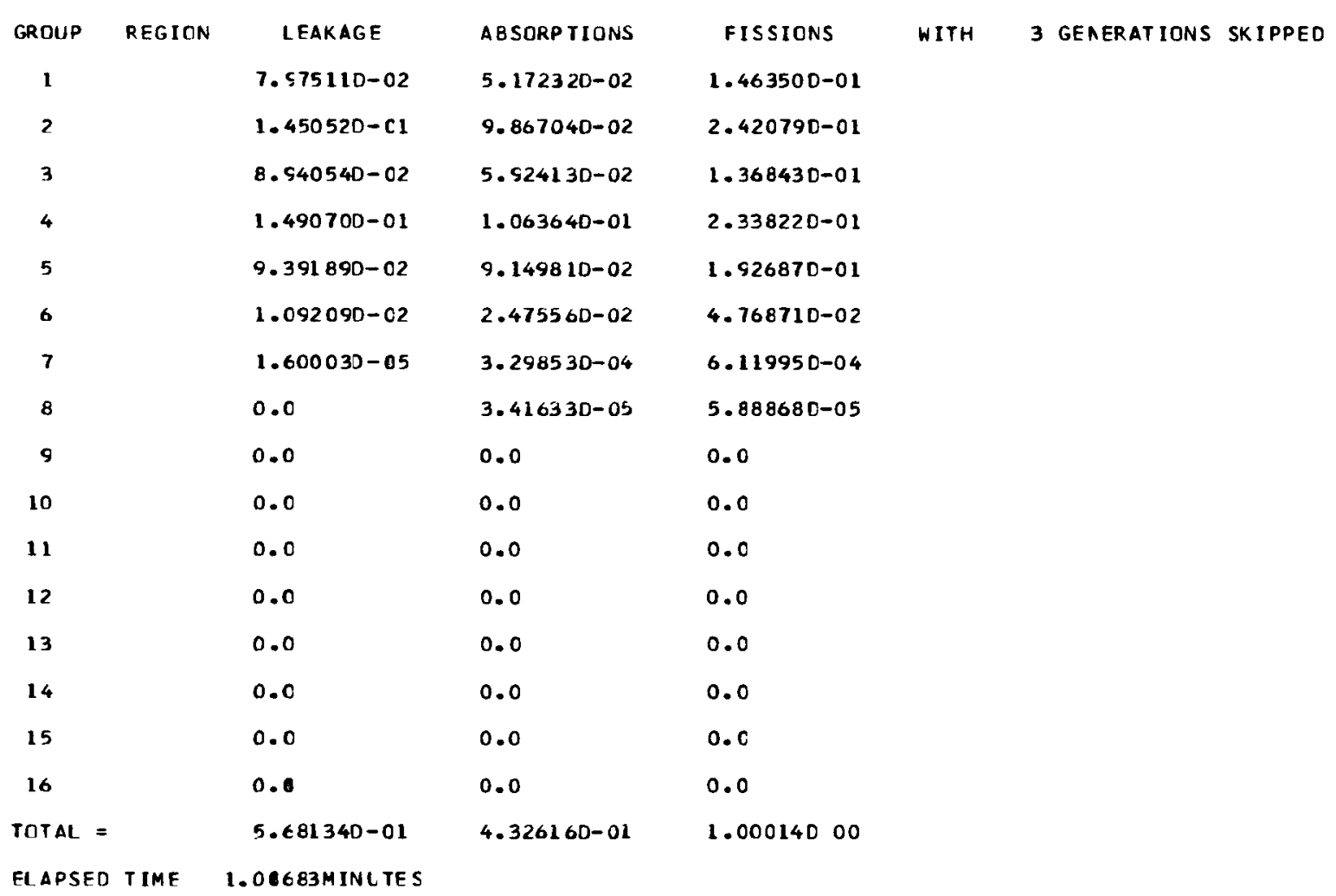


SAMPLE PROB 16 GENERALIZED GECMETRY GROTESOUE

**** FISSION DENSITIFS ****

$$
\begin{array}{ll}
\text { FISSION } & \text { PERCENT } \\
\text { DENSITY DOTAL } \\
\text { DEVIATION }
\end{array}
$$

BOX TYPE

1

$2.772 E-05 \quad C .91$

$1.000 E 00$

******** WARNING ************* WARNING **********

THE FISSION DENSITY AND FLUX WERE COMPUTED USING ARBITRARY VOLUMES ILISTED UNDER - TOTAL VOL UMES - I IN THE REgIONS DE SCRI BED BY GFNERALIZFD GEOM. THEY MUST BE MLLTIPLIED BY THE TRLE VOLUME OVER THE ARBITRARY VOLUME TO OBTAIN THE CORRECT VALUES. 
SAMPLE PROB 16 GENERAL ILED GECMETRY GROTESOUE

FLUXES FOR BOX TYPE

\begin{tabular}{clc} 
GROUP & FLUX & \multicolumn{1}{c}{$\begin{array}{r}\text { PERCENT } \\
\text { DEVIATION }\end{array}$} \\
1 & $2.395 E-05$ & 2.13 \\
2 & $4.535 E-05$ & 1.19 \\
3 & $2.818 E-05$ & 2.48 \\
4 & $4.789 E-05$ & 1.26 \\
5 & $3.446 E-05$ & 2.49 \\
6 & $4.755 E-06$ & 5.71 \\
7 & $2.958 E-08$ & 43.00 \\
8 & $4.043 E-10$ & 100.00 \\
9 & 0.0 & 0.0 \\
10 & 0.0 & 0.0 \\
11 & 0.0 & 0.0 \\
12 & 0.0 & 0.0 \\
13 & 0.0 & 0.0 \\
14 & 0.0 & 0.0 \\
15 & 0.0 & 0.0 \\
16 & 0.0 & 0.0
\end{tabular}


0.8500 To 0.8731

0.8731 To 0.8962

0.9193 TO 0.9424

0.9193 T0 0.9424

0.9655 T0 0.9886

0.9886 T0 1.0117

1.0117 T0 1.0348

1.0348 TO 1.0579

1.0579 TO 1.0810

1.0810 TO 1.1041

1.1041 TO 1.1271

1.1271 TO 1.1502

1.1502 TO 1.1733

1.1733 T0 1.1964

0.8500 TO 0.8731

0.8731 T0 0.8562

0.8962 TO 0.9193

0.9193 To 0.9424

0.9424 ro 0.9655

0.9655 TO 0.5886

0.9886 to 1.011

1.0117 TO 1.0348

1.0348 To 1.0579

1.0810 T0 1.1041

$1.081041 \mathrm{TO} 1.127$

1.1041 10 1.1271

1.1502 TO 1.1733

1.1502 ro 1.1733

4 TO

40

$* *$

$* * *$

$* * * * * * * * * * *$

********4

FRE OUENCY FOR GENERATICNS

13 TO

$* * *$

$* * * * * * * *$

$* * * *$

$* * * * * * *$

FREOUENCY FOR GENERATICNS 22 TO 40

0.8500 TO 0.8731
0.8731 To 0.8962

0.8962 TO 0.9193

0.9193 TO 0.9424

0.9424 To 0.965

0.5655 To 0.5886

0.9886 TO 1.0117

1.0117 TO 1.034

1.0348 TO 1.0579

1.0579 TO 1.0810

1.0810 TO 1.104

1.1041 ro 1.127

1.1271 TO 1.1502

1.1502 TO 1.173

1.1733 TO 1.1964
$*$

$* * * * *$

$* * *$

****** 
SAMPLE PROB 16 GENERAL IZED GECMETRY GROTESOUE

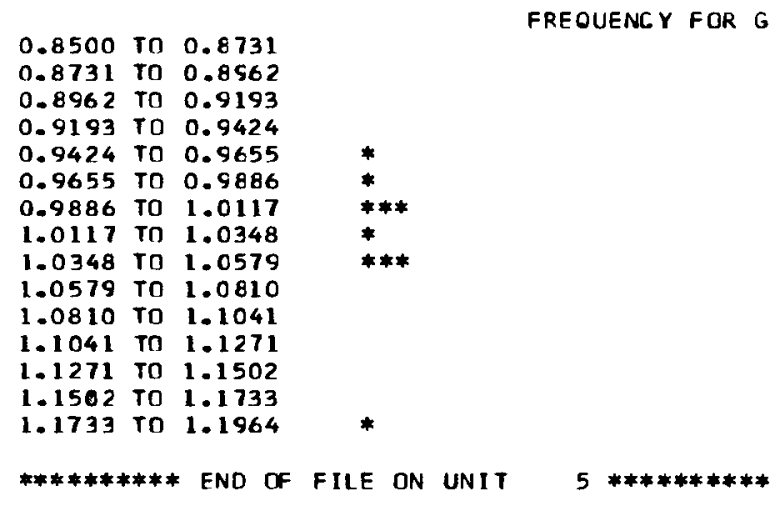


SAMPLE PROBLEM 17 CASE 2 CQ EARE RRITL RESTART

NUMBER OF GENERATIONS 103

NUMBER PER GENERATION

NOMBER OP GENEBATIONS TO BE SKIPEED

NOMBER OF ENERGY GROOPS

MAX. NUMBER OF ENERGY T RANSFERS

NUMBER OP INPOT NOCLIDES

NUMBER OP MIXIURES

NOMBER OP HIXING TABIE ENTEIES

NUMBPR OF GEOMETRY CARDS

NUMBER OF BOX TYPES

NOHBER OF ONITS IN $X$ DIRECTICN

NUMBER OF ONITS IN I DIRECTION

NOMBER OP ONITS IN 2 DIRECTICN

NOMBER OF NOCLIDES READ PROM TAPE

ALBEDO TYPE

SEARCH TYFE

3

MAXIMUM TIME $=0.5000$ MINUTES
START TYPE

GENERATIONS BETHEEN CHECRPOINTS LIST INPUT X-SECTIONS READ PROM TAPE

IIST 1-D MIXTORE X SECTIONS

LIST 2-D MIXTOEE I-SECTIONS

LIST FISS. AND ABS. BY REGION

OSE X-SECTIONS PROM PREVIOUS CASE

OSE GEOMETEY PFOH PREVIOUS CASE

USE VELOCITIES FROM PREVIOUS CASE

COMPOTE MATRIX R-EFPECTIVE BY ONIT

CONPOTE HATRIR T-EFFECTIVE BY BOT IYPE

LIST FISS PROB MATRIX BY ONIT

ADJOINT CALCULATION

OSE EXPONENTIAI TRANSFORM

CAICOLATE FLOX

CA ICOLATE FISSION DENSITIES
No

No

STORAGE LOCATIONS REQOIRED FOR THIS JOB REMAINING AVAILAELE IOCATIONS $=27250$ 
SAHPLE PROBLEM 17 CASE 2CA BABE RFITB RESTART

$$
\begin{array}{ccc}
\text { MIXTURE } & \text { NOCLIDE } & \text { DENSITI } \\
1 & -92500 & 4.48006 \mathrm{~B}-02 \\
1 & 92800 & 2.65780 \mathrm{~B}-\mathrm{C3} \\
1 & 92400 & 4.82700 \mathrm{~B}-\mathrm{C4} \\
1 & 92600 & 9.57000 \mathrm{~B}-05
\end{array}
$$

CROSS SECTIONS READ PROM TAPE

$\begin{array}{llll}\text { NOCIIDE }= & 92400 & 0-234 \\ \text { NOCLIDE }= & 92500 & 0-235 \\ \text { NUCLIDE }= & 92600 & 0-236 \\ \text { NOCLIDE }= & 92800 & 0-238\end{array}$

MIHALCZC MOD OP $\mathrm{B}-\mathrm{R} \quad \mathrm{O}-238$

HAN SEN BCACH
UIHALCZC MOD OP $H-R \quad 0-238$ 
SAMPLE PROBLEM 17 CASE 2CB EABE RRITE RESTART

GEOMETRY DESCRIETION

REGION

1 CYLINDER 1 RADIOS $=5.7480 E 00+z=5.3825 E 00 \quad-z=-5.3825 E 00$

2 CUBOID $0 \quad T X=6.8700 E 00 \quad-X=-6.8700 E 00 \quad+Y=6.8700 E 00$

$-\mathrm{Z}=-6.8700 \mathrm{E} 00 \quad+Z=6.5050 \mathrm{E} \quad 00 \quad-Z=-6.505 \mathrm{CE} \quad 00$ 
SAMPLE PROBLEM 17 CASE 2CA EARE RRIT3 RESTART

WEIGHTING PJNCTION

BOX TYPE

GROOP NTION TI AVG WI HI

BEGION 1 DEFINED BY GECMETRY CARD

$$
\begin{array}{llll}
1 & 0.167 & 0.500 & 1.500 \\
\text { GRCOPS } & 2 & \text { TC } & 16 \text { SAME AS ABOVE }
\end{array}
$$

REGION 2 DEFINED BY GECHETRY CARD

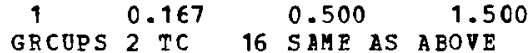


SAMPLE PFOBLEM 17 CASE 2 C8 BARE MRITE RESTART

VOLUMES

BOX TYP E

1
1

TOTAI VOLUMES

$\begin{array}{lll}1 & 8.93896 \mathrm{E} & 03 \\ 2 & 1.07100 \mathrm{E} & 04\end{array}$

VOLUME FRACTION CF THE CORE CONTAINING PISSILE MATERIAL $=0.45493 \mathrm{E}$ 00

START TYPE $=0$

THE NETTRONS DERE STARTED IN THE ARRA $Y$ TITH A FLAT DISTRIBUTICN.

300 NEDTRONS RERE INITIALL Y STARTED

0.00183 MINOTES TERE REQOTREI FOE STARTING. 
SAMPLE PROBLEM 17 CASE 2 C8 EARE NHITE RESTART

\begin{tabular}{|c|c|c|c|c|c|}
\hline $\begin{array}{c}\text { GENB RATI ON } \\
1 \\
2 \\
3 \\
4 \\
5\end{array}$ & $\begin{array}{l}\text { K-EF FECTIVE } \\
9.48664 \mathrm{E}-01 \\
9.26448 \mathrm{E}-01 \\
9.32275 \mathrm{E}-01 \\
1.00046 \mathrm{E} 00 \\
1.03192 \mathrm{E} 00\end{array}$ & $\begin{array}{c}\text { ELAESBD TIME (MIN) } \\
8.33333 \mathrm{E}-03 \\
1.55000 \mathrm{E}-02 \\
2.10000 \mathrm{~B}-02 \\
2.93333 \mathrm{~B}-02 \\
3.90000 \mathrm{E}-02\end{array}$ & $\begin{array}{r}\text { AVG . K-EFF } \\
1.00000 \mathrm{~F} 00 \\
1.00000 \mathrm{E} 00 \\
9.32275 \mathrm{E}-\mathrm{Cl} \\
9.66366 \mathrm{E}-01 \\
9.88216 \mathrm{E}-\mathrm{Cl}\end{array}$ & $\begin{array}{l}\text { DEVIATION } \\
0.0 \\
0.0 \\
0.0 \\
3.40933 \text { E-02 } \\
2.94086 \text { E-02 } \\
\text { BESTART NOMEER }\end{array}$ & $\begin{array}{l}\text { MATEIX K-EFP } \\
0.0 \\
0.0 \\
0.0 \\
0.0 \\
0.0 \\
1 \text { RRITTEN }\end{array}$ \\
\hline $\begin{array}{r}6 \\
7 \\
8 \\
9 \\
10\end{array}$ & 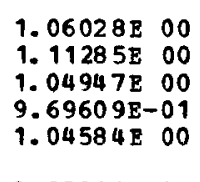 & $\begin{array}{l}4.80000 \mathrm{E}-02 \\
5.63333 \mathrm{E}-02 \\
6.51667 \mathrm{E}-02 \\
7.25 \mathrm{C00 \textrm {B }}-02 \\
7.96666 \mathrm{~B}-02\end{array}$ & $\begin{array}{l}1.00623 E \\
1.02756 E\end{array}$ & $\begin{array}{l}2.75176 \mathrm{E}-02 \\
3.01511 \mathrm{E}-02 \\
2.48861 \mathrm{E}-02 \\
2.27981 \mathrm{E}-02 \\
1.99590 \mathrm{E}-02 \\
\text { RESTART NOMEER }\end{array}$ & $\begin{array}{l}0.0 \\
0.0 \\
0.0 \\
0.0 \\
0.0 \\
2 \text { MRITTEN }\end{array}$ \\
\hline $\begin{array}{l}11 \\
12 \\
13 \\
14 \\
15\end{array}$ & $\begin{array}{l}9.65813 \mathrm{E}-01 \\
1.05368 \mathrm{E} 00 \\
1.03684 \mathrm{E} 00 \\
9.47292 \mathrm{E}-01 \\
9.89856 \mathrm{E}-01\end{array}$ & $\begin{array}{l}8.60000 \mathrm{E}-02 \\
9.43333 \mathrm{E}-02 \\
1.02500 \mathrm{E}-01 \\
1.08000 \mathrm{E}-01 \\
1.16000 \mathrm{~B}-01\end{array}$ & $\begin{array}{ll}1.01872 \mathrm{E} & C O \\
1.02222 \mathrm{~F} & C O \\
1.02355 \mathrm{E} & C O \\
1.01719 \mathrm{E} & C O \\
1.01509 \mathrm{E} & C O\end{array}$ & $\begin{array}{l}1.88099 \mathrm{E}-02 \\
1.71818 \mathrm{E}-02 \\
1.56006 \mathrm{E}-02 \\
1.55945 \mathrm{E}-02 \\
1.44985 \mathrm{E}-02 \\
\text { RESTART NUM EER }\end{array}$ & $\begin{array}{l}0.0 \\
0.0 \\
0.0 \\
0.0 \\
0.0 \\
3 \text { RRITTEN }\end{array}$ \\
\hline $\begin{array}{l}16 \\
17 \\
18 \\
19 \\
20\end{array}$ & 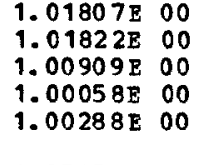 & $\begin{array}{l}1.25000 \mathrm{E}-01 \\
1.32500 \mathrm{E}-01 \\
1.39667 \mathrm{E}-01 \\
1.46000 \mathrm{E}-01 \\
1.53000 \mathrm{E}-01\end{array}$ & 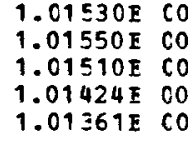 & $\begin{array}{l}1.34255 \mathrm{E}-02 \\
1.25007 \mathrm{E}-02 \\
1.17025 \mathrm{E}-02 \\
1.10269 \mathrm{E}-02 \\
1.04161 \mathrm{E}-02 \\
\text { RESTART NOMEER }\end{array}$ & $\begin{array}{l}0.0 \\
0.0 \\
0.0 \\
0.0 \\
0.0 \\
4 \text { WRITTEN }\end{array}$ \\
\hline $\begin{array}{l}21 \\
22 \\
23 \\
24 \\
25\end{array}$ & $\begin{array}{l}1.07051 \mathrm{E} 00 \\
9.60427 \mathrm{E}-01 \\
9.56329 \mathrm{E}-01 \\
1.00177 \mathrm{E} 00 \\
1.04658 \mathrm{E} 00\end{array}$ & $\begin{array}{l}1.60833 \mathrm{E}-01 \\
1.67667 \mathrm{E}-01 \\
1.75000 \mathrm{E}-01 \\
1.82667 \mathrm{E}-01 \\
1.91333 \mathrm{E}-01\end{array}$ & 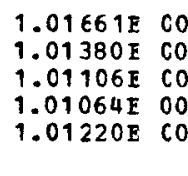 & $\begin{array}{l}1.02913 \mathrm{E}-02 \\
1.01636 \mathrm{E}-02 \\
1.00520 \mathrm{E}-02 \\
9.59202 \mathrm{E}-03 \\
9.29951 \mathrm{E}-03 \\
\text { RESTART NUMEER }\end{array}$ & $\begin{array}{l}0.0 \\
0.0 \\
0.0 \\
0.0 \\
0.0 \\
5 \text { DR ITTEN }\end{array}$ \\
\hline $\begin{array}{l}26 \\
27 \\
28 \\
29 \\
30\end{array}$ & $\begin{array}{l}9.92254 \mathrm{E}-01 \\
1.05239 \mathrm{E} 00 \\
9.68244 \mathrm{E}-01 \\
9.69718 \mathrm{E}-01 \\
9.96146 \mathrm{~B}-01\end{array}$ & $\begin{array}{l}1.98000 \mathrm{E}-01 \\
2.06333 \mathrm{E}-01 \\
2.13000 \mathrm{E}-01 \\
2.20000 \mathrm{E}-01 \\
2.27500 \mathrm{E}-01\end{array}$ & 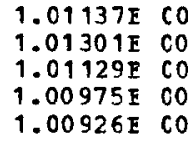 & $\begin{array}{l}8.94107 \mathrm{E}-03 \\
8.73464 \mathrm{E}-03 \\
8.56930 \mathrm{E}-03 \\
8.38979 \mathrm{E}-03 \\
8.09668 \mathrm{E}-03\end{array}$ & $\begin{array}{l}0.0 \\
0.0 \\
0.0 \\
0.0 \\
0.0\end{array}$ \\
\hline $\begin{array}{l}31 \\
32 \\
33 \\
34 \\
35\end{array}$ & $\begin{array}{l}9.94557 \mathrm{E}-01 \\
9.56272 \mathrm{E}-01 \\
1.00044 \mathrm{E} \quad 00 \\
1.02966 \mathrm{E} \quad 00 \\
9.83747 \mathrm{E}-01\end{array}$ & $\begin{array}{l}2.34333 \mathrm{E}-01 \\
2.41000 \mathrm{E}-01 \\
2.48333 \mathrm{E}-01 \\
2.56833 \mathrm{E}-01 \\
2.63000 \mathrm{E}-01\end{array}$ & 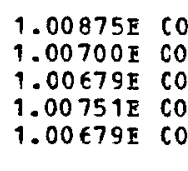 & $\begin{array}{l}7.82992 \mathrm{E}-03 \\
7.76182 \mathrm{E}-03 \\
7.51382 \mathrm{E}-03 \\
7.30582 \mathrm{E}-03 \\
7.12205 \mathrm{E}-03 \\
\text { RESTART NOM EER }\end{array}$ & $\begin{array}{l}0.0 \\
0.0 \\
0.0 \\
0.0 \\
0.0 \\
7 \text { BR ITTEN }\end{array}$ \\
\hline $\begin{array}{l}36 \\
37 \\
38 \\
39 \\
40\end{array}$ & $\begin{array}{l}9.53114 \mathrm{~B}-01 \\
9.39802 \mathrm{E}-01 \\
8.8382 \mathrm{~B}-01 \\
9.63702 \mathrm{E}-01 \\
1.00218 \mathrm{E} \quad 00\end{array}$ & $\begin{array}{l}2.69333 \mathrm{E}-01 \\
2.74333 \mathrm{E}-01 \\
2.81000 \mathrm{E}-01 \\
2.87667 \mathrm{E}-01 \\
2.96333 \mathrm{E}-01\end{array}$ & $\begin{array}{l}1.00521 \mathrm{E} C O \\
1.00334 \mathrm{E} C O \\
1.00002 \mathrm{E} C O \\
9.99037 \mathrm{E}-\mathrm{C1} \\
9.99119 \mathrm{E}-\mathrm{CI}\end{array}$ & $\begin{array}{l}7.08709 \mathrm{E}-03 \\
7.13312 \mathrm{E}-03 \\
7.68414 \mathrm{E}-03 \\
7.53712 \mathrm{E}-03 \\
7.33598 \mathrm{E}-03 \\
\text { RESTART NOM EER }\end{array}$ & $\begin{array}{l}0.0 \\
0.0 \\
0.0 \\
0.0 \\
0.0 \\
8 \text { VR IT TEN }\end{array}$ \\
\hline $\begin{array}{l}41 \\
42 \\
43 \\
44 \\
45\end{array}$ & $\begin{array}{l}1.05249 \mathrm{E} 00 \\
9.94617 \mathrm{E}-01 \\
9.64916 \mathrm{E}-01 \\
1.01404 \mathrm{E} 00 \\
1.00956 \mathrm{~B} 00\end{array}$ & $\begin{array}{l}3.05 \in 33 \mathrm{E}-01 \\
3.12 \in 67 \mathrm{E}-01 \\
3.20 \leq 00 \mathrm{E}-01 \\
3.27167 \mathrm{E}-01 \\
3.34 \in 67 \mathrm{E}-01\end{array}$ & $\begin{array}{l}1.00049 \mathrm{E} C O \\
1.00034 \mathrm{E} C O \\
9.99476 \mathrm{E}-\mathrm{C} 1 \\
9.99823 \mathrm{E}-01 \\
1.00005 \mathrm{E} C O\end{array}$ & $\begin{array}{l}7.27695 \mathrm{E}-03 \\
7.09399 \mathrm{E}-03 \\
6.97405 \mathrm{E}-03 \\
6.81400 \mathrm{E}-03 \\
6.65927 \mathrm{E}-03 \\
\text { RESTART NUM EER }\end{array}$ & $\begin{array}{l}0.0 \\
0.0 \\
0.0 \\
0.0 \\
0.0 \\
9 \text { GR ITTEN }\end{array}$ \\
\hline $\begin{array}{l}46 \\
47 \\
48 \\
49 \\
50\end{array}$ & $\begin{array}{l}1.05045 \mathrm{E} \quad 00 \\
9.96764 \mathrm{E}-01 \\
9.39462 \mathrm{E}-01 \\
1.03453 \mathrm{E} 00 \\
1.00944 \mathrm{E} 00\end{array}$ & $\begin{array}{l}3.45000 \mathrm{E}-01 \\
3.51833 \mathrm{E}-01 \\
3.58333 \mathrm{E}-01 \\
3.65 \varepsilon 33 \mathrm{E}-01 \\
3.72667 \mathrm{E}-01\end{array}$ & $\begin{array}{l}1.00119 \mathrm{E} \quad \mathrm{CO} \\
1.00110 \mathrm{E} \quad 00 \\
9.99756 \mathrm{E}-\mathrm{C1} \\
1.00049 \mathrm{E} \quad 00 \\
1.00 C 68 \mathrm{E} \quad \mathrm{CO}\end{array}$ & $\begin{array}{l}6.60829 \mathrm{E}-03 \\
6.45936 \mathrm{E}-03 \\
6.45638 \mathrm{E}-03 \\
6.36315 \mathrm{E}-03 \\
6.23355 \mathrm{E}-03 \\
\text { RESTART NOM NER }\end{array}$ & $\begin{array}{l}0.0 \\
0.0 \\
0.0 \\
0.0 \\
0.0 \\
10 \text { HRIT TEN }\end{array}$ \\
\hline
\end{tabular}




\begin{tabular}{|c|c|c|c|c|c|c|}
\hline $\begin{array}{l}51 \\
52 \\
53 \\
54 \\
55\end{array}$ & $\begin{array}{l}1.11304 \mathrm{E} 00 \\
9.26212 \mathrm{E}-01 \\
1.02864 \mathrm{E} 00 \\
9.51587 \mathrm{E}-01 \\
1.03430 \mathrm{E} 00\end{array}$ & $\begin{array}{l}3.83000 \mathrm{~B}-01 \\
3.88500 \mathrm{E}-01 \\
3.96833 \mathrm{E}-01 \\
4.02667 \mathrm{~B}-01 \\
4.10833 \mathrm{~B}-01\end{array}$ & $\begin{array}{l}1.00297 \mathrm{E} \\
1.00144 \mathrm{E} \\
1.00197 \mathrm{E} \\
1.00100 \mathrm{E} \\
1.00163 \mathrm{E}\end{array}$ & $\begin{array}{l}\text { Co } \\
\text { Co } \\
\text { CO } \\
\text { CO } \\
00\end{array}$ & $\begin{array}{l}6.52210 \mathrm{~B}-03 \\
6.57323 \mathrm{E}-03 \\
6.46304 \mathrm{E}-03 \\
6.40959 \mathrm{E}-03 \\
6.32160 \mathrm{~B}-03\end{array}$ & $\begin{array}{l}0.0 \\
0.0 \\
0.0 \\
0.0 \\
0.0\end{array}$ \\
\hline $\begin{array}{l}56 \\
57 \\
58 \\
59 \\
60\end{array}$ & 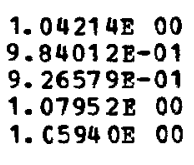 & $\begin{array}{l}4.18833 \mathrm{E}-01 \\
4.26000 \mathrm{E}-01 \\
4.32500 \mathrm{E}-01 \\
4.43000 \mathrm{E}-01 \\
4.51667 \mathrm{E}-01\end{array}$ & $\begin{array}{l}1.00238 \mathrm{E} \\
1.00205 \mathrm{E} \\
1.00070 \mathrm{E} \\
1.00208 \mathrm{E} \\
1.00307 \mathrm{E}\end{array}$ & $\begin{array}{l}\text { CO } \\
\text { CO } \\
\text { OO } \\
\text { CO } \\
\text { CO }\end{array}$ & $\begin{array}{l}\text { R.25TART } \\
6.25161 \mathrm{E}-03 \\
6.14479 \mathrm{E}-03 \\
6.18194 \mathrm{E}-03 \\
6.22712 \mathrm{E}-03 \\
6.19930 \mathrm{E}-03\end{array}$ & $\begin{array}{l}11 \\
0.0 \\
0.0 \\
0.0 \\
0.0 \\
0.0\end{array}$ \\
\hline $\begin{array}{l}61 \\
62 \\
63 \\
64 \\
65\end{array}$ & $\begin{array}{l}1.02553 \mathrm{E} \quad 00 \\
1.06355 \mathrm{E} \quad 00 \\
9.80649 \mathrm{E}-01 \\
1.00790 \mathrm{E} 00 \\
9.59801 \mathrm{E}-01\end{array}$ & $\begin{array}{l}4.60833 \mathrm{E}-01 \\
4.69167 \mathrm{E}-01 \\
4.76833 \mathrm{E}-01 \\
4.25500 \mathrm{E}-01 \\
4.92667 \mathrm{E}-01\end{array}$ & $\begin{array}{l}1.00345 \mathrm{E} \\
1.00445 \mathrm{E} \\
1.00406 \mathrm{E} \\
1.00412 \mathrm{E} \\
1.00342 \mathrm{E}\end{array}$ & $\begin{array}{l}00 \\
C 0 \\
00 \\
00 \\
00\end{array}$ & $\begin{array}{l}6.10402 \mathrm{E}-03 \\
6.08669 \mathrm{E}-03 \\
5.99745 \mathrm{E}-03 \\
5.90324 \mathrm{E}-03 \\
5.84755 \mathrm{E}-03 \\
\text { RESTART NOMBER }\end{array}$ & $\begin{array}{l}0.0 \\
0.0 \\
0.0 \\
0.0 \\
0.0 \\
13\end{array}$ \\
\hline 66 & 9. $82424 \mathrm{E}-01$ & $5.00500 \mathrm{E}-01$ & $1.00309 \mathrm{E}$ & 00 & $5.76431 \mathrm{E}-03$ & 0.0 \\
\hline
\end{tabular}

THE MATRIX K-EPF IS TAE IARGIST EIGENV RIOE OF THF MATRIX OF FISSION FROBABIIITIES BY ONIT. THERE ARE NBXMAX * NBYHAX * NBZHAX ONI IS IN AN AFRAY. 
SAMPLE PROBLEM 17 CASE 2 C8 BAER REITE RESTART IIFETIME $=1.03417 \mathrm{E}-08+\mathrm{OR}-7.73495 \mathrm{E}-11$

\begin{tabular}{|c|c|c|c|}
\hline $\begin{array}{l}\text { GENER AT IONS } \\
\text { SKI PPED }\end{array}$ & $\begin{array}{r}\text { A V FRAG } \\
K-\text { EFF FCT }\end{array}$ & & DEVIAIION \\
\hline 3 & 1.00422 & $+O R$ & $-0.00 \leq 74$ \\
\hline 4 & 1.00428 & $+O B$ & -0.00583 \\
\hline 5 & 1.00382 & $+O R$ & $-0.00 \leq 91$ \\
\hline 6 & 1.00288 & $+O R$ & -0.00593 \\
\hline 7 & 1.00102 & $+O R$ & -0.00573 \\
\hline 8 & 1.00018 & $+O R$ & -0.00576 \\
\hline 9 & 1.00072 & $+O R$ & $-0.00 \leq 84$ \\
\hline 10 & 0.99991 & $+O R$ & -0.00589 \\
\hline 11 & 1.00054 & $+\mathrm{OH}$ & -0.00596 \\
\hline 12 & 0.99955 & $+O R$ & -0.00599 \\
\hline 17 & 0.99930 & $+O B$ & -0.00645 \\
\hline 22 & 0.99823 & $+O R$ & -0.00694 \\
\hline 27 & 0.99674 & $+O R$ & -0.00753 \\
\hline 32 & 0.99964 & $+O R$ & -0.00847 \\
\hline 37 & 1.00280 & $+O R$ & $-0.00 \$ 50$ \\
\hline 42 & 1.00768 & $+O R$ & $-0.00 \varsigma 94$ \\
\hline 47 & 1.00782 & OB & 0.01217 \\
\hline 52 & 1.00900 & + & -0.01230 \\
\hline 57 & 1.00948 & $+0 \mathrm{~B}$ & -0.01727 \\
\hline 62 & 0.98269 & $+O R$ & -0.00985 \\
\hline
\end{tabular}

67 FEF CENT
CONFIDENCE INTERA
0.9984 E TO $1.0 C 955$
0.99845 TC 1.01011
0.99791 TO 1.00973
0.99695 TO $1.0 C 881$
0.99529 TC $1.0 C 675$
0.99442 TO 1.06595
0.99488 TC $1.0 C 656$
0.99403 TC 1.00580
0.99457 TO $1.0 C 650$
0.99356 TC 1.00554
0.99285 TC 1.00575
0.99129 TO 1.00517
0.98921 TO 1.00426
0.99117 TC $1.0 C 811$
0.99330 TO $1.0123 C$
0.99775 TC 1.01762
0.99565 TO 1.02000
0.99670 TO $1.0213 C$
0.99221 TO 1.02676
0.97285 TO 0.99254

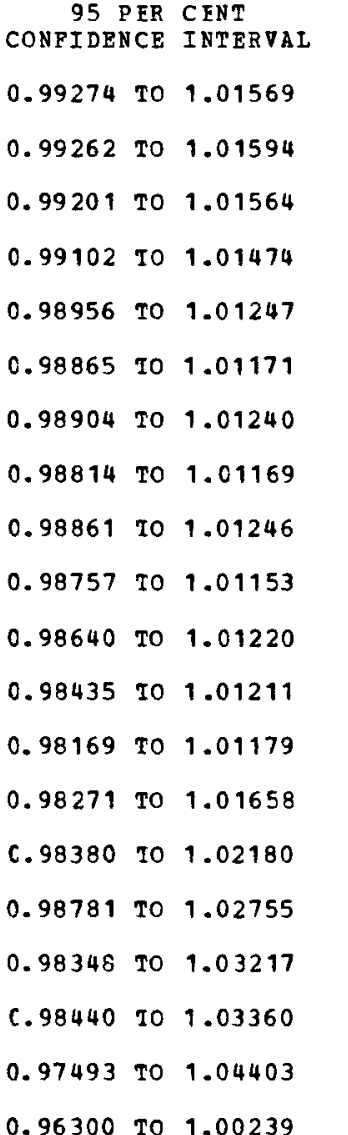

99 PER CENT

NOMBER OF CONFIDENCE INTERVAL HISTORIES

18900

0.98679 TO 1.02177

18600

0.98610 TO 1.02155

18300

0.98509 TO $1.02067 \quad 18000$

0.98384 TO $1.01820 \quad 17700$

0.98289 TO $1.01748 \quad 17400$

0.98320 TO $1.01824 \quad 17100$

0.98225 TO $1.01758 \quad 16800$

0.98264 TO $1.01843 \quad 16500$

0.98158 TO $1.01753 \quad 16200$

0.97995 TO $1.01865 \quad 14700$

0.97741 TO $1.01905 \quad 13200$

0.97416 To $1.01932 \quad 11700$

0.97424 TO $1.02505 \quad 10200$

0.97430 TO $1.03130 \quad 8700$

0.97788 T0 $1.03749 \quad 7200$

0.97131 то $1.04434 \quad 5700$

0.97210 To $1.04590 \quad 4200$

0.95766 TO $1.06130 \quad 2700$

0.95315 To $1.01223 \quad 1200$ 
SAMPLE PROBLEY 17 CASE 2C8 PARE VEITE RESTART

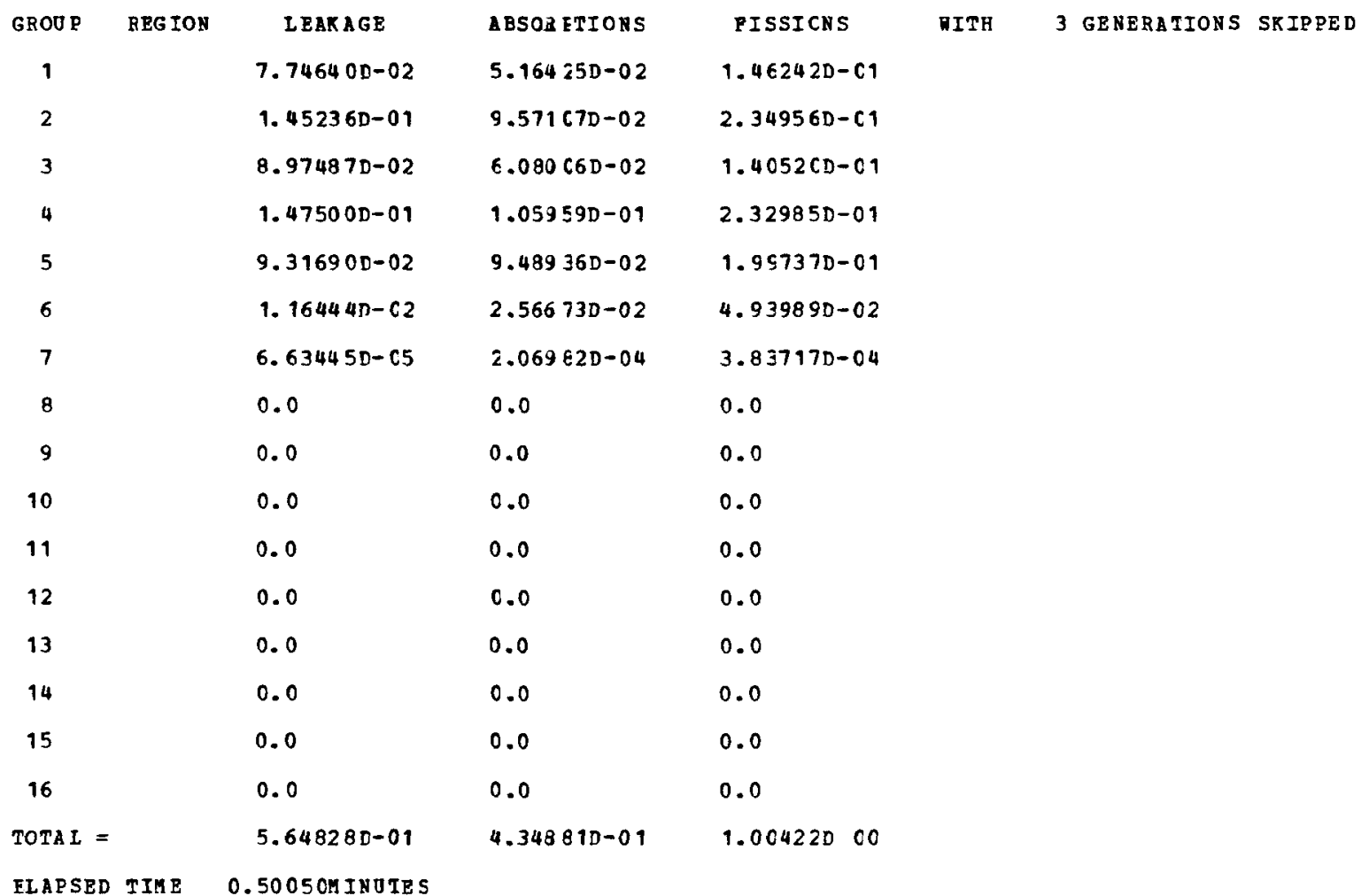

ELAPSED IIME 0.5005 OMINUTES 
SAaPLE PEOBLEM 17 CASE 2 C8 BARE RRITE RESTART **** PISSION DEMSITIES ****

$$
\begin{array}{lll}
\text { PISSION } & \text { FERCENT } & \text { TOTAL } \\
\text { DERSITY } & \text { CBVIATION } & \text { FISSICNS }
\end{array}
$$

BOX TYPE

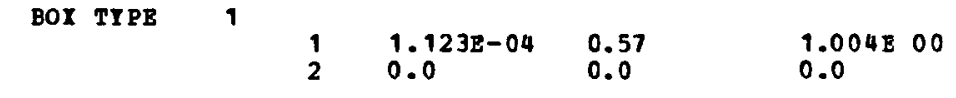


SAMPLE PROBLEM 17 CASE 2 CQ EABE DRITB RESTART

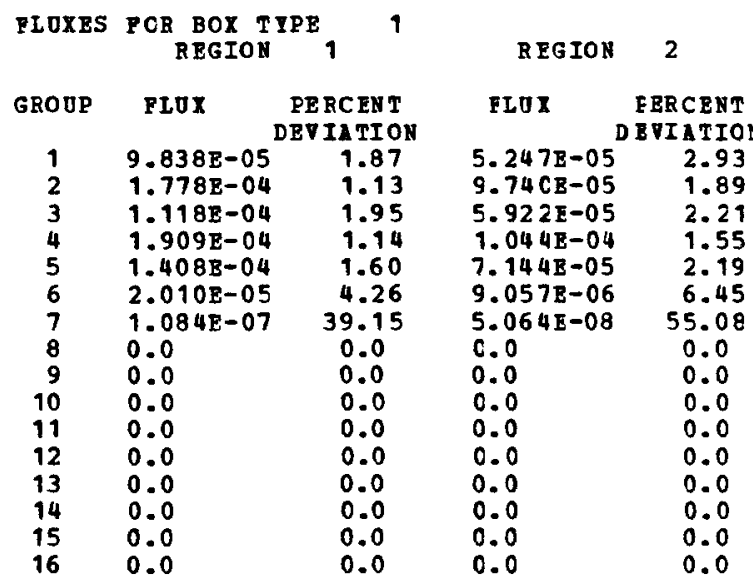


SAMPLE PROBLEM 17 CASE 2C8 BARE RRITE BESTART

0.8772 TO 0.9003

0.9003
0.9234 TO 0.9234
0.9465

0.9465 TC 0.9696

0.9696 TO 0.9927

0.9927 TO 1.0158

1.0158 To 1.0389

1.0389 TO 1.0619

1.0619 To 1.0850

1.0850 TO 1.1089

$* * * *$

$* * * * * * * * * * *$

$* * * * * * * * * 4$

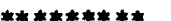

$\neq * * * * * * * * *$

***

**

0.8772 то 0.9003 C. 9003 TO 0.9234

0.9234 T0 0.9465

0.9465 TO 0.9696

0.9696 To 0.9927

0.9927 TO 9.0958

1.0158 TO 1.0389

1.0389 TO 1.0619

9.0619 TO 1.0850

1.0850 To 1.1081

1.1081 To 1.1312

0.8772 TO 0.9003

0.9003 To 0.9234

0.9234 To 0.9465

0.9465 TO 0.9696

0.9696 TO 0.9927

0.9927 To 1.0158

1.0158 10 1.0389

1.0619 T0 1.0850

1.0619 To 1.0850

1.1081 TO 1.1312

FEQUENCY FOR GENERATIONS

\section{****}

$* * * * * * * * *$

$* * * * * *$

$* * * * * * * * * * * *$

$* * *$

PEEQUENCY FOR GENERATIONS 3E IO 66

******

$* * * * * * *$

$4+4+4 *$

$* * * *$

***

0.8772 To 0.9003

0.8772 T0 0.9003

0.9234 To 0.9234

0.9234 TO 0.9465

0.9465 To 0.9696

0.9927 TO 1.0158

0.9927 TO
1.0158 TO
1.0389

1.0389 TO 1.0619

1.0619 TO 1.0850

1.0850 To 1.1081
1.1081 To 1.1312

PFECUENCX POR GENERATION

$2 C \quad 30 \quad 66$

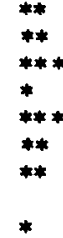

FEECOENCT POR GENERATIOHS

51 IC 66 
SAMPLE PROBLEL 18 CASE 2 C8 BARE READ RESTART DATA

NUMBER OF GENERATIONS 103

NUHBER PER GENEEATION 300

NUMBER OF GENERATIONS TO BE SRIPEED

NOBBER OF ENERGY GROOPS

MAX. NUHBER OF ENERGY TRANSFEAS

NOMBER OP INPOT NOCIIDES

NOMBBR OP MIXTURES

NOHBER OF MIXING IABLE BNTRIES

NOMBER OF GEOMETRY CARDS

NUABER OP BOX TYPES

NOABER OF ONITS IN $X$ DIRECTION

NOMBER OF ONITS IN Y DIRECTION

NOHBER OF ONITS IN 2 DIRECTICH

NOHBER OF NOCLIDES READ FROH TAPE

ALBEDO TYPE

SEARCH TYPE

MAXIHOH TIME $=0.5000$ MINOTES

STORAGE LOCATIONS REQUT RED FOR TEIS JOE = REMAINING AVAILABLE IOCATIONS= 27250
ST ART TYPE

$-10$

GENERATIONS BETHEEN CHECRPOINTS

LIST INPUT X-SECTIONS READ PROR TAFE

LIST 1-D MIXTOFE X SECTIONS

LIST 2-D UIXTOEE X-SBCTIONS

IIST PISS. AND ABS. BY REGION

OSE $X$-SECTIONS PROH PREVIOOS CASE

OSE GEOHETRY FFOH PREVIOOS CASE

OSE VELOCITIES FROA PRBVIOUS CASE

COMPOTE HATRIX R-EPPECTIVE BY ONIT

COMPUTE MATRIX R-EPFECTIVE BY BOX TYPE NO

IIST PISS PROB MATRIX BY ONIT

ADJOINT CAICULATIOH

USE EXPONENTIAL TRANSFORM

Ca ICULATE PLOX

CALCOLATE FISSION DENSTTIES YES 
SAHPLE PROBLEM 18 CASE 2 C8 GARE READ RESTART DATA

VOLUHES

BOX TIPE

REGION DEFINED BY GEONETEY CARD BEGION DEFINBD BY GBOHETEY CABD

$1 \quad$ VOLUHE $=1.11737 \mathrm{E} 03 \mathrm{CH} * * 3$

CUMULATIVE VOLOME $=1.11737 E 03$ CM**3 $2.45613 E 03 \quad C M * * 3$

TOTAL VOLOHES

$\begin{array}{lll}1 & 8.93896 \mathrm{~B} 03 \\ 2 & 1.07100 \mathrm{~B} & 04\end{array}$

VOLUGE PRACTION OP THB CORB CONTAINING PISSILE MATERIAL $=0.45493 \mathrm{E} 00$

START TYPE $=-10$

0.0 HINOIES UER REQUIRED POE STARIING. 
SAGPLE PROBLEM 18 CASE 2C8 EARB EBAD RESTART DATA

\begin{tabular}{|c|c|c|c|c|c|}
\hline 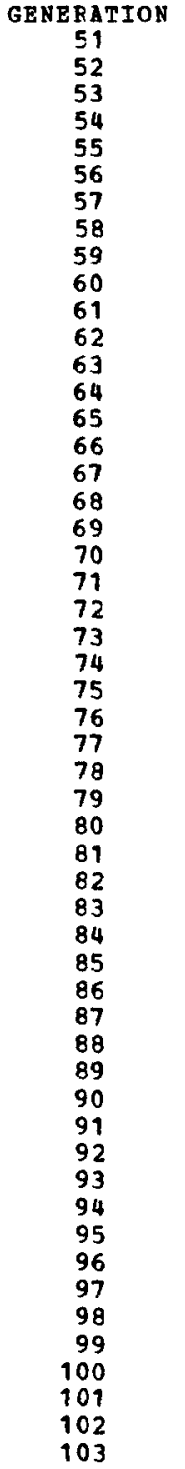 & 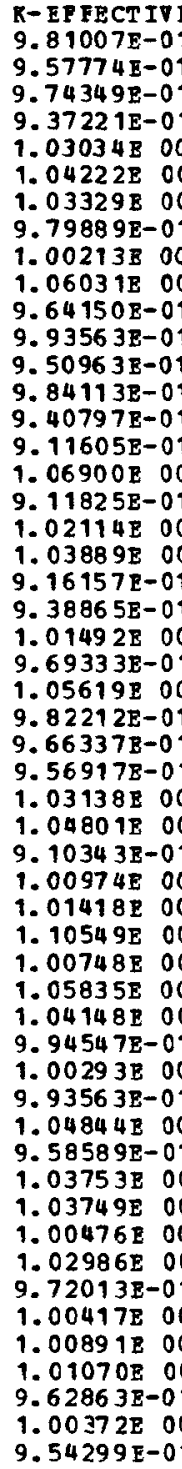 & 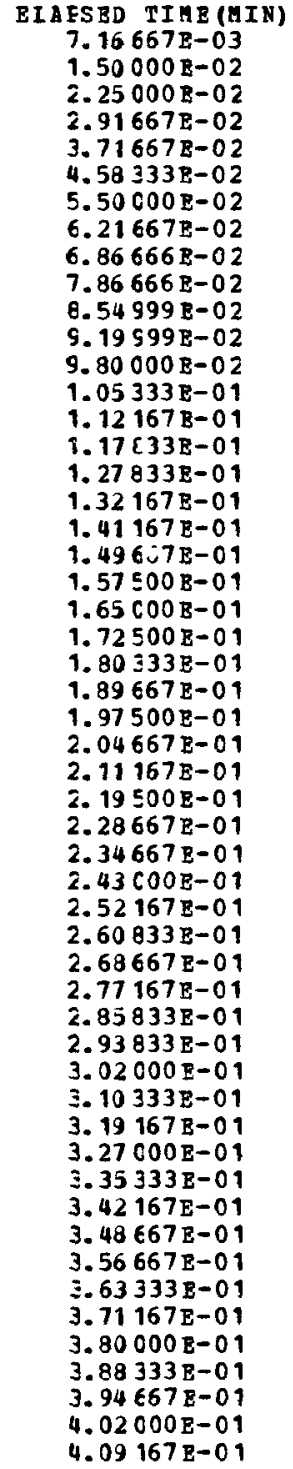 & 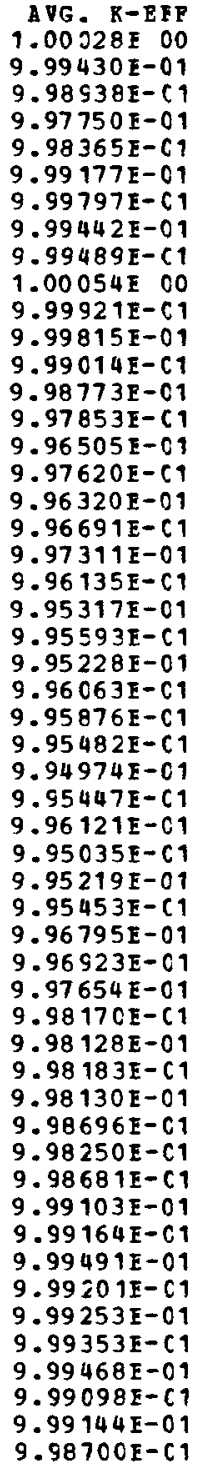 & $\begin{array}{l}\text { DEVIATION } \\
6.11814 \mathrm{E}-03 \\
6.05369 \mathrm{E}-03 \\
5.95463 \mathrm{E}-03 \\
5.95876 \mathrm{E}-03 \\
5.97725 \mathrm{E}-03 \\
5.82308 \mathrm{E}-03 \\
5.74946 \mathrm{E}-03 \\
5.65773 \mathrm{E}-03 \\
5.55731 \mathrm{E}-03 \\
5.56350 \mathrm{E}-03 \\
5.50134 \mathrm{E}-03 \\
5.40877 \mathrm{E}-03 \\
5.38061 \mathrm{E}-03 \\
5.29921 \mathrm{E}-03 \\
5.29466 \mathrm{E}-03 \\
5.38341 \mathrm{E}-03 \\
5.41608 \mathrm{E}-03 \\
5.48955 \mathrm{E}-03 \\
5.41972 \mathrm{E}-03 \\
5.37523 \mathrm{E}-03 \\
5.42597 \mathrm{E}-03 \\
5.41019 \mathrm{E}-03 \\
5.34081 \mathrm{E}-03 \\
5.27887 \mathrm{E}-03 \\
5.27263 \mathrm{E}-03 \\
5.20432 \mathrm{E}-03 \\
5.15007 \mathrm{E}-03 \\
5.10723 \mathrm{E}-03 \\
5.06261 \mathrm{E}-03 \\
5.04284 \mathrm{E}-03 \\
5.09563 \mathrm{E}-03 \\
5.03481 \mathrm{E}-03 \\
4.97786 \mathrm{E}-03 \\
5.09665 \mathrm{E}-03 \\
5.03663 \mathrm{E}-03 \\
5.02966 \mathrm{E}-03 \\
4.99701 \mathrm{E}-03 \\
4.93907 \mathrm{E}-03 \\
4.88217 \mathrm{E}-03 \\
4.82650 \mathrm{E}-03 \\
4.80535 \mathrm{E}-03 \\
4.77245 \mathrm{E}-03 \\
4.73937 \mathrm{E}-03 \\
4.70568 \mathrm{E}-03 \\
4.65505 \mathrm{E}-03 \\
4.61741 \mathrm{E}-03 \\
4.57771 \mathrm{E}-03 \\
4.53001 \mathrm{E}-03 \\
4.48453 \mathrm{E}-03 \\
4.44016 \mathrm{E}-03 \\
4.41076 \mathrm{E}-03 \\
4.36677 \mathrm{E}-03 \\
4.34653 \mathrm{E}-03\end{array}$ & $\begin{array}{l}\text { PAT RIX } \\
0.0 \\
0.0 \\
0.0 \\
0.0 \\
0.0 \\
0.0 \\
0.0 \\
0.0 \\
0.0 \\
0.0 \\
0.0 \\
0.0 \\
0.0 \\
0.0 \\
0.0 \\
0.0 \\
0.0 \\
0.0 \\
0.0 \\
0.0 \\
0.0 \\
0.0 \\
0.0 \\
0.0 \\
0.0 \\
0.0 \\
0.0 \\
0.0 \\
0.0 \\
0.0 \\
0.0 \\
0.0 \\
0.0 \\
0.0 \\
0.0 \\
0.0 \\
0.0 \\
0.0 \\
0.0 \\
0.0 \\
0.0 \\
0.0 \\
0.0 \\
0.0 \\
0.0 \\
0.0 \\
0.0 \\
0.0 \\
0.0 \\
0.0 \\
0.0 \\
0.0 \\
0.0\end{array}$ \\
\hline
\end{tabular}

THE MATRIX R-EFF IS THE LARGEST EIGENVALUE OF THE MATRIX OF FISSION FROBABILITIES BY ONIT. THBRE ARE NBXMAX * NEYMAX * BBZMAX UNIIS IN AN ARRAY. 
SAMPLE PROBLEM 18 CASE 2 C8 EARE READ RESTAFT DATA

IIFETIME $=1.04263 \mathrm{E}-08+$ OR $-6.29764 \mathrm{E}-11$

GENERATION TIME $=7.41373 E-09+O R-6.66802 E-11$

\begin{tabular}{|c|c|c|c|}
\hline $\begin{array}{l}\text { GEN ERAT IONS } \\
\text { SKI PPED }\end{array}$ & $\begin{array}{c}\text { AVFRAGE } \\
\text { K-EFFETIV }\end{array}$ & & DEV IA T ION \\
\hline 3 & 0.99936 & $+O R$ & -0.00433 \\
\hline 4 & 0.99935 & $+O R$ & -0.00438 \\
\hline 5 & 0.99902 & $+O B$ & -0.00441 \\
\hline 6 & 0.99839 & $+\mathrm{OR}$ & -0.00441 \\
\hline 7 & 0.99720 & $+O R$ & -0.00429 \\
\hline 8 & 0.99665 & $+O R$ & -0.00430 \\
\hline 9 & 0.99694 & $+\mathrm{OR}$ & -0.00433 \\
\hline 10 & 0.99641 & $+O R$ & -0.00435 \\
\hline 11 & 0.99674 & $+O B$ & -0.00438 \\
\hline 12 & 0.99612 & +08 & $-C .00439$ \\
\hline 17 & 0.99577 & $+O E$ & -0.00457 \\
\hline 22 & 0.99497 & $+O E$ & -0.00474 \\
\hline 27 & 0.99400 & $+\mathrm{OR}$ & -0.00492 \\
\hline 32 & 0.99519 & $+O R$ & -0.00521 \\
\hline 37 & 0.99624 & $+O R$ & $-0.00 \leq 48$ \\
\hline 42 & 0.99763 & $+O B$ & -0.00553 \\
\hline 47 & 0.99678 & $+O B$ & -0.00591 \\
\hline 52 & 0.99799 & $+0 \mathrm{~B}$ & -0.00628 \\
\hline 57 & 0.99739 & $+O R$ & -0.00667 \\
\hline 62 & 0.99707 & $+0 \mathrm{OB}$ & -0.00727 \\
\hline 67 & 1.00065 & $+O R$ & -0.00737 \\
\hline 72 & 1.00634 & $+O R$ & -0.00708 \\
\hline 77 & 1.00799 & $+O R$ & -0.00789 \\
\hline 82 & 1.01197 & $+\mathrm{OR}$ & -0.00784 \\
\hline 87 & 1.00152 & $+O B$ & -0.00716 \\
\hline 92 & 1.00239 & $+O \mathrm{OR}$ & -0.00860 \\
\hline
\end{tabular}

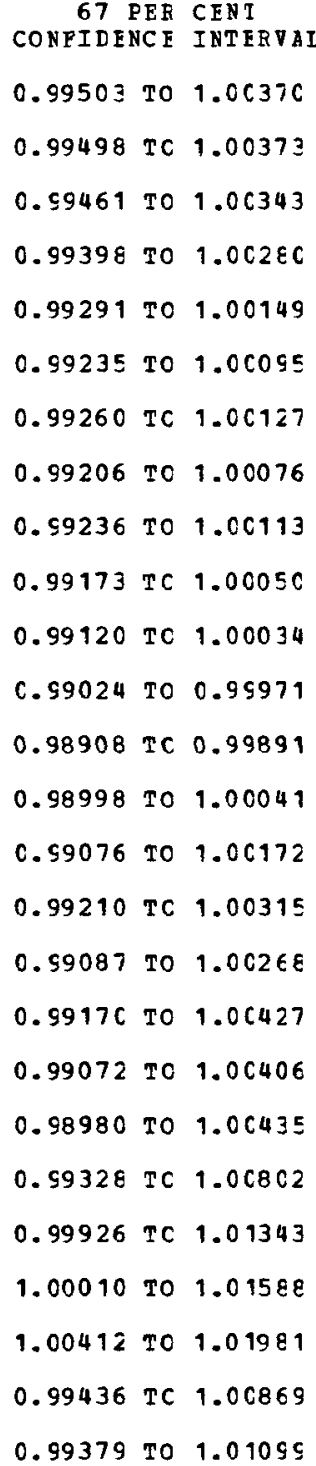

$\begin{aligned} & 95 \text { PER } \\ & \text { CENT } \\ & \text { CONFIDENCE INTERVAL }\end{aligned}$

$\begin{aligned} 99 & \text { PER CENT } \\ \text { CONFIDENCE } & \text { INTER }\end{aligned}$

NOMBER OF

0.99070 10 1.00803

0.98637 TO 1.01236

AISTORIES

0.99060 TO 1.00811

0.98622 Tо 1.01248

30000

0.99020 To 1.00784

0.98580 TO 1.01225

29700

0.98957 10 1.00721

0.98517 TO 1.01161

29400

0.98862 Tо 1.00577

0.98433 To 1.01006

29100

0.98805 To 1.00524

0.98375 TO 1.00954

28800

C. 98827 T0 1.00560

0.98393 TO 1.00994

28500

0.98771 To 1.00511

0.98336 TO 1.00946

28200

0.98798 то 1.00551

0.98359 TO 1.00989

27900

0.98734 T0 1.00489

0.98296 To 1.00928

27600

0.98664 To 1.00491

0.98207 To 1.00947

27300

0.98550 TO 1.00445

0.98076 To 1.00918

25800

0.98416 TO 1.00383

0.97924 To 1.00875

24300

22800

0.98477 To 1.00562

0.97956 Tо 1.01083

21300

0.98529 To 1.00720

0.97981 то 1.01268

19800

0.98658 To 1.00868

0.98105 TO 1.01420

18300

0.98496 TO 1.00859

0.97906 TO 1.01449

16800

0.98542 To 1.01056

0.97913 TO 1.01684

15300

0.98404 To 1.01074

0.97737 To 1.01741

13800

0.98252 To 1.01162

0.97525 To 1.01890

12300

0.98592 то 1.01539

0.97855 то 1.02275

10800

0.99218 To 1.02051

0.98509 TO 1.02759

9300

0.99220 I0 1.02377

0.98431 TO 1.03166

7800

0.99628 TO 1.02766

0.98843 To 1.03550

6300

0.98720 To 1.01585

0.98004 TO 1.02301

4800

c. 98519 T0 1.01960

0.97658 то 1.02820 
SAMPLE PROBLEM 18 CASE 2C8 BARE READ RESTAFT DATA

NO. OP INITIAL

SKIPPED

97

AVFRA GE

R-EFFECTIVB DEVIAIION

0.99078

67 PER CENT CONPIDENCE INTERVAI

0.98048 TO 1.00108

95 PER CENT

CONPIDENCE INTERVAL

0.97018 TO 1.01138

99 PER CENT NUMEFR OF

$0.95988 \quad 10 \quad 1.02168$

1800 
SAMPLE PROBLEM 18 CASE 2 C9 EARE READ RESTART DATA

\begin{tabular}{|c|c|c|c|c|c|c|c|}
\hline GROUP & REG ION & IEAR A GE & ABSORETIONS & FISSICNS & ตI TH & 3 GENERATIONS & SRIPPED \\
\hline 1 & & $7.91213 \mathrm{D}-02$ & $5.13373 D-02$ & $1.45378 D-C 1$ & & & \\
\hline 2 & & $1.46367 \mathrm{D}-01$ & $9.637990-02$ & $2.36599 D-01$ & & & \\
\hline 3 & & $8.99233 \mathrm{D}-02$ & $6.142 \approx 2 D-02$ & $1.41956 \mathrm{D}-\mathrm{C} 1$ & & & \\
\hline 4 & & $1.485350-01$ & $1.03456 \mathrm{D}-01$ & $2.274810-01$ & & & \\
\hline 5 & & $9.33108 D-02$ & $9.43695 \mathrm{D}-02$ & $1.98634 D-C 1$ & & & \\
\hline 6 & & $1.09062 \mathrm{D}-02$ & $2.527360-02$ & $4.86412 D-02$ & & & \\
\hline 7 & & $1.03079 D-04$ & $3.509 \Xi 9 D-04$ & $6.5 C 593 D-C 4$ & & & \\
\hline 8 & & 0.0 & $1.81515 D-05$ & $3.12521 D-05$ & & & \\
\hline 9 & & 0.0 & 0.0 & 0.0 & & & \\
\hline 10 & & 0.0 & 0.0 & 0.0 & & & \\
\hline 11 & & 0.0 & 0.0 & 0.0 & & & \\
\hline 12 & & 0.0 & 0.0 & 0.0 & & & \\
\hline 13 & & 0.0 & 0.0 & 0.0 & & & \\
\hline 14 & & 0.0 & 0.0 & 0.0 & & & \\
\hline 15 & & 0.0 & 0.0 & 0.0 & & & \\
\hline 16 & & 0.0 & 0.0 & 0.0 & & & \\
\hline TOTAL $=$ & & $5.68266 \mathrm{D}-01$ & $4.326 C 8 D-01$ & $9.993710-01$ & & & \\
\hline
\end{tabular}


SAMPLE PROBLEM 18 CASE 2 C8 BARE READ RESTART DATA

**** FISSION DENSITIES ****

$$
\text { FISSION EERCBNT TOTAI }
$$

REGION DENSITY FEVIATION FISTICNS

BOX TYPE

$\begin{array}{llll}1 & 1.1188-04 & 0.43 & 9.993 E-01 \\ 2 & 0.0 & 0.0 & 0.0\end{array}$


SAMPLE PROBLEM 18 CASE 2C8 EARE GEAD RESTART LATA

FLUXES FOR BOX TIPE

$$
\text { REGION } 1 \text { REGION }
$$

\begin{tabular}{|c|c|c|c|}
\hline Ux & PERCENT & FLUX & EERCENT \\
\hline & & & DEVIATIO \\
\hline & 1.44 & $5.424 \mathrm{~B}-05$ & 2.1 \\
\hline (4 & 0.99 & $\begin{array}{l}9.8804-03 \\
6\end{array}$ & 3.45 \\
\hline 4 & 0.92 & $1.052 E-04$ & 1.19 \\
\hline & 1.2 & $7.257 \mathrm{E}-05$ & 1.63 \\
\hline 05 & 3.31 & B.84 EE-06 & 4.64 \\
\hline 07 & 22.14 & $\epsilon .331 F-08$ & 40.67 \\
\hline 7 & 100.00 & 0. & 0 \\
\hline & 0.0 & 0. & 0.0 \\
\hline & 0.0 & $0 . \quad 2 \quad$ & 0.0 \\
\hline & 0.0 & 2 & $\begin{array}{l}0.0 \\
0.0\end{array}$ \\
\hline & 0.0 & & \\
\hline & 0.0 & 0. & \\
\hline & 0.0 & $c .0$ & 0.0 \\
\hline & 0.0 & 0.0 & 0.0 \\
\hline
\end{tabular}


SAMPLE PROBLEM 18 CASE 2 C8 EARE READ RESTART DATA

0.8723 TO 0.895

0.8954 To 0.918

0.9185 TC 0.9416

FEECUEMCY POR GENERATICNS

4 TC 103

0.9416 TO 0.9647

0.9878 TO 9.0109

1.0109 TC 1.0340

1.0340 TO 1.0571

1.0571 To 1.0802

1.0802 T0 1.1033

1.1033 TO 1.1264

0.8723 TO 0.8954

0.8954 TC 0.9185

0.9185 To 0.9416

0.9476 TO 0.9647

0.9647 To 0.9878

0.9878 io 1.0109

1.0709 ro 1.0340

1.0571 TO 1.0802

1.0802 TC 1.1033

1.1033 T0 1.1264

$* * * * *$

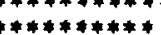

*

******

$* * * * * * * *$

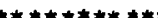

4.40

0.8723 то 0.8954

0.8954 TO 0.9185

0.9185 TO 0.9416

0.9416 TO 0.9647

0.9647 TO 0.9878

0.9878 TC 1.0109

1.0109 TO 1.0340

1.0340 TC 1.0571

1.0571 To 1.0802

1.0802 To 1.1033

1.1033 To 1.1264

0.8723 TO 0.8954

0.8954 TO 0.9185

0.9185 TO 0.9416

0.9416 TO 0.9647

0.9647 TO 0.9878

0.9878 TC 1.0109

1.0109 To 1.0340

1.0340 To 1.0571

1.0802 T0 1.1033

1.0802 To 1.1033

FFECUENCY FOR GENERATIONS

********** END OF PIIE ON ONIT

PFECUEMCY POR GENERATIONS 54 IC 103

$* * *$

PEECUENCY FOR GENERATIONS 7S IC 103

***

$* * * * * * * * * *$

$* * * * * * 4$

$5 * * * * * * * * * *$ 
SAMPLE PRBBLEM 194 AOUEOUS 4 METAL MIXED BOX MATRIX CALCULATION

NUMBER OF GENERATIONS

NUMBER PER GENERATION 300

NUMBER OF GENERATIONS TO BE SKIPPED 3

NUMBER OF ENERGY GROUPS 16

MAX. NUMBFR OF ENERGY TRANSFERS 6

NUMBER DF INPUT NUCLIDES

NUMBER TF MIXTURES 3

NUMBER OF MIXING TABLE ENTRIES 10

NUMBER OF GETMETRY CARDS 11

NUMBER OF BOX TYPES 5

NUMBER TF UNITS IN $X$ OIRECTION 2

NUMBER OF UNITS IN Y DIRECTION 2

NUMBER HF UNITS IN 2 DIRECTION 2

NUMBER OF NUCLIDES READ FROM TAPE 6

ALBEDO TYPE 0

SEARCH TYPE 0

MAXIMUM TIME $=2.5000$ MINUTES STORAGE LOCATIONS REQUIRED FOR THIS JOB =
REMAINING AVAIIABIE LOCATIONS =
9073

$\begin{array}{lr}\text { START TYPE } & 0 \\ \text { GENERATIONS BETWEFN CHECKPOINTS } & 0 \\ \text { LIST INPUT X-SECTIONS READ FROM TAPE } & \text { NC } \\ \text { LIST 1-D MIXTURE X SECTIONS } & \text { NO } \\ \text { LIST 2-O MIXTURE X-SECTIONS } & \text { NO } \\ \text { LIST FISS. AND ABS. BY REGION } & \text { YES } \\ \text { USE X-SECTIONS FROM PREVIOUS CASE } & \text { NO } \\ \text { USE GEOMETRY FROM PREVIOUS CASE } & \text { NO } \\ \text { USE VELOCITIES FROM PREVIOUS CASE } & \text { NO } \\ \text { COMPUTE MATRIX K-EFFECTIVE BY UNIT } & \text { YES } \\ \text { COMPUTE MATRIX K-EFFECTIVE BY BOX TYPE YES } \\ \text { LIST FISS PROB MATRIX BY UNIT } & \text { YES } \\ \text { ADJOINT CALCULATION } & \text { NC } \\ \text { USE EXPONENTIAL TRANSFORM } & \text { NO } \\ \text { CALCULATE FLUX } & \text { YES } \\ \text { CALCULATE FISSION DENSITIES } & \text { YES }\end{array}$


SAMPLE PRDBLEM 194 AQUEOUS 4 METAL MIXED BOX MATRIX CALCULATION

$\begin{array}{crr}\text { MIXTURE } & \text { NUCLIDF } & \text { DENSITY } \\ 1 & 92860 & 3.2275 C E-03 \\ 1 & -92501 & 4.48020 E-02 \\ 2 & 1102 & 5.81000 E-02 \\ 2 & 7100 & 1.97530 E-03 \\ 2 & 8100 & 3.69270 E-02 \\ 2 & -92501 & 9.8471 C E-04 \\ 2 & 92860 & 7.7657 C E-05 \\ 3 & 6100 & 3.5552 C E-02 \\ 3 & 1102 & 5.68840 E-02 \\ 3 & 8100 & 1.42210 E-02\end{array}$

\section{CRISS SFCTIONS READ FROM TAPE}

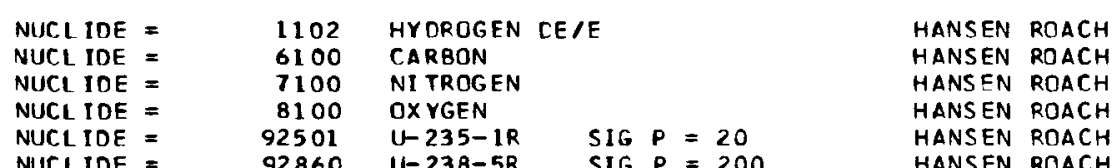

HANSEN ROACH 
MAPLF PRORLFM 194 AQUEOUS 4 NETAL MIXED 8OX MATRIX CALCULATION GFIMFTRY DESCRIPTION

BOX TYPF 1

RFGION

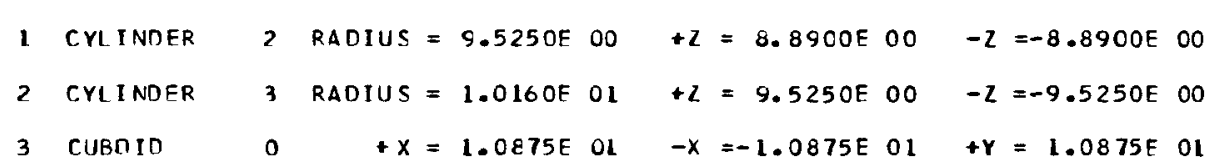

BOX TYPF 2

REGION

1 CYLINDER 1 RADIUS $=5.7480 E 00 \quad t z=5.3825 E 00 \quad-z=-5.3825 E 00$

, CUBOID $0+X=6.5900 F$ OO $-X=-1.5160 E 01+Y=6.5900 E 00$

BnX TYPF 3

RFGION

1 CYLINDFR 1 RADIUS $=5.7480 E 00$

2 CUBOID $O+X=6.5900 E$ OS

$+z=5.3825 E \quad 00 \quad-Z=-5.3825 E 00$

$-X=-1.5160 \mathrm{E} O 1+Y=1.5160 \mathrm{E} \mathrm{Ol}$

$-Y=-6.5900 E 00$

$+Z=6.2250 E O O$

$-z=-1.4255 E 01$

BNX TYPE 4

REGION

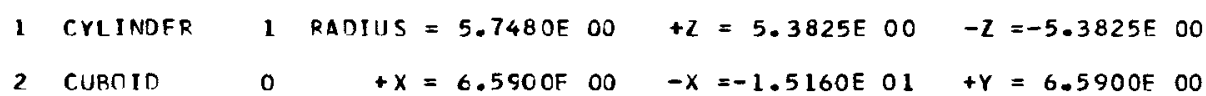

$+Y=6.5900 E$ E $00 \quad-Y=-1.5160 E 01 \quad+Z=1.4255 E$ O $01 \quad-Z=-6.2250 E 00$

BOX TYPF 5

RFGION

1 CYLINDER 1 RADIUS $=5.7480 E$ 00 $\quad Z=5.3825 E$ O0 $\quad-Z=-5.3825 E 00$

2 CUBOID $O \quad+X=6.5900 E 00 \quad-X=-1.5160 E 01 \quad$ tY $=1.5160 E 01$

$-Y=-6.5900 \mathrm{E} \quad 00 \quad+Z=1.4255 \mathrm{E} \mathrm{Cl} \quad-Z=-6.2250 \mathrm{E} 00$ 


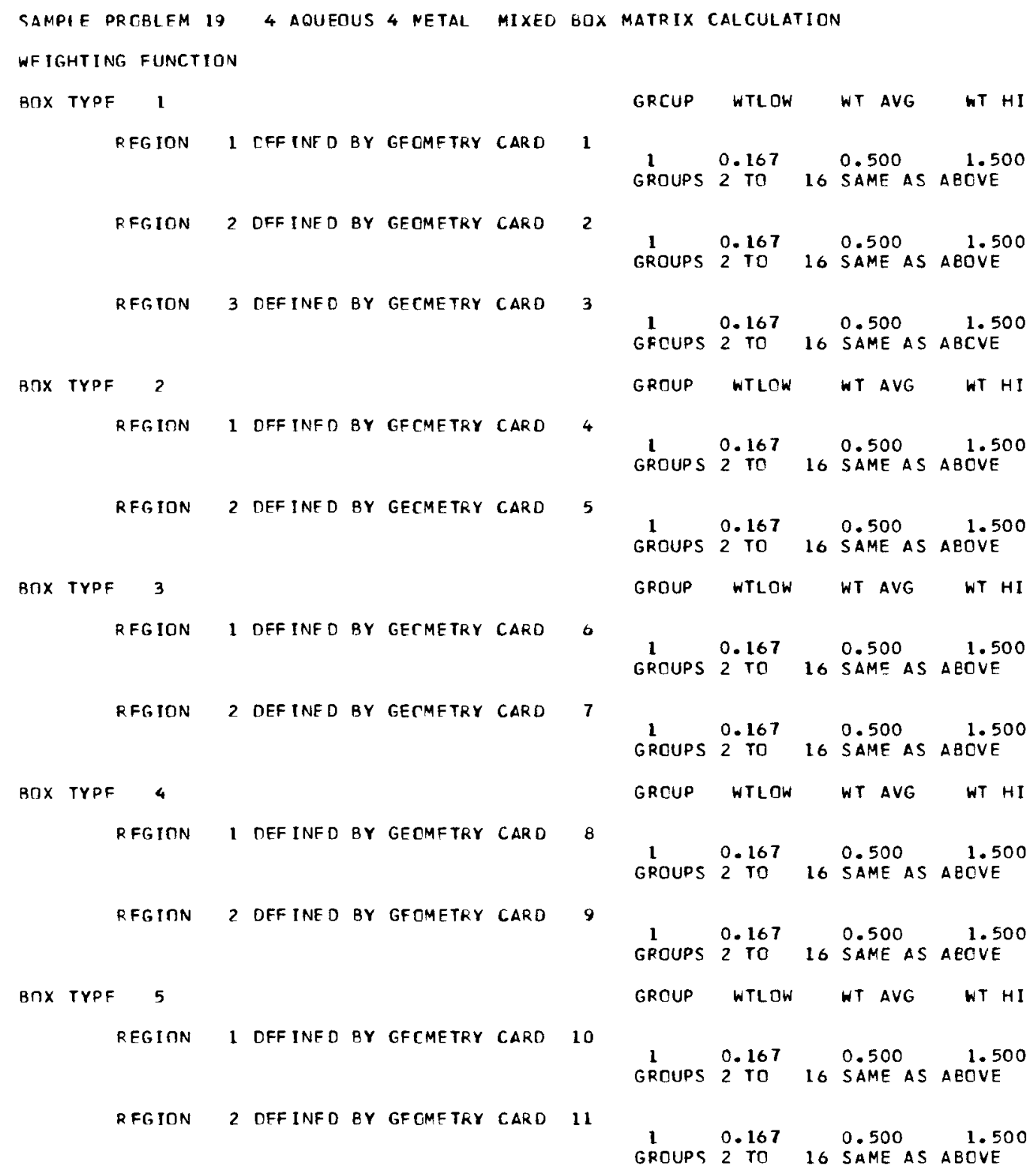




\title{
$\bullet$
}

SAMPLE PROBLEM 194 AOUEOUS 4 METAL MIXED BOX MATRIX CALCULATION

\begin{abstract}
ARRAY DESCR IPTION
\end{abstract}

$\begin{array}{ll}2= & 1 \\ 3 & 1 \\ 2 & 1 \\ 2= & 2 \\ 5 & 1 \\ 4 & 1\end{array}$


VOLUMFS BOX TYPF REGIDN DEFINED BY GEOMETRY CARD REGION DEFINED BY GECMETRY CARD

BOX TYPE

$\stackrel{2}{2}$ DEFINED BY GEOMETRY CARD REGION DEFINED BY GEOMETRY CARD

BOX TYPF

3
REG DEN DEFINED OY GEOMETRY CARO RFG ION DEFINED BY GEOMETRY CARD

BחX TYPE

EG ION DEFINED BY GECMETRY CARO REGION DEFINED BY GEOMETRY CARD

BOX TYPE 5
REGION DEFINED BY GEOMETRY CARD
RFGION DEFINED BY GECMEIRY CARD

TOTAL VOLUMES

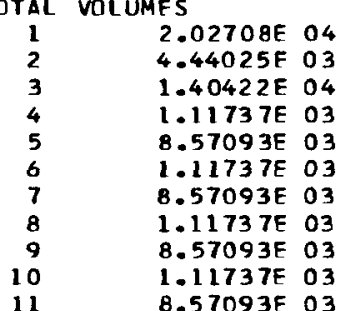

1 VOLUME $=5.06770 \mathrm{E} 03 \mathrm{CM} * * 3$ VOLUME $=1.11006$ E 03 CM**3

$4 \quad$ VOLUME $=1.11737 \mathrm{E} \mathrm{O3CM**3}$

6 VOLUME $=1.11737 E 03$ CN**3 7 VOLUME $=8.57093 \mathrm{E} 03 \mathrm{CM}$.*3

\section{VOLUME $=1.11737$ E 03 CM**3}

9 VOLUME $=8.57093 \mathrm{E} 03 \mathrm{CM}$ (N*3

10 VCLUME $=1.11737$ E 03 CM**3

11 VCLUME $=8.57093 \mathrm{E} 03 \mathrm{CM}$ CM*3
C UMULAT IVE VOLUME = CUMULATIVE VOLUME C UMULATIVE VOLUME =

5.06770 E 03 CM**3 $6.17777 E$ OS CM**3

CUMULATIVE VOLUME = CUMULATIVE VDLUME =

$1.11737 E O 3 C M * * 3$
$9.68830 E$ $03 \quad C M * * 3$ CUMULATIVE VOLUME $=$
CUMULATIVE VOLUME $=\mathbf{9 . 6 1 7 3 7 E} 03 \mathrm{CM} * * 3$

CUMULATIVE VOLUME $=1.11737 \mathrm{E} 03 \mathrm{CM} * 3$ CUMULATIVE VOLUME $=9.68830$ O $03 \quad \mathrm{CM} * * 3$

CUMULATIVE VOLUME $=1.11737 \mathrm{E} 03 \mathrm{CM**3}$ CUMULATIVE VOLUME $=9.68830503 \mathrm{CM}$.*3

VOIUME FRACTION OF THE CORE CONTAINING FISSILE MATERIAL $=0.31920 E$ O0

START TYPF $=0$

THE NEUTRONS WERE STARTED IN THE ARRAY WITH a FLAT DISTRIBUTION.

300 NFUTRONS WERE INITIALLY STARTEO

0.00250 MINUTES WERE REOUIRED FOR STARTING. 
SAMPLE PRDBLFM 194 AOUEOUS 4 METAL MIXED BOX MATRIX CALCULATION

GENERATION K-EFFECTIVE ELAPSEO TIME(MIN)

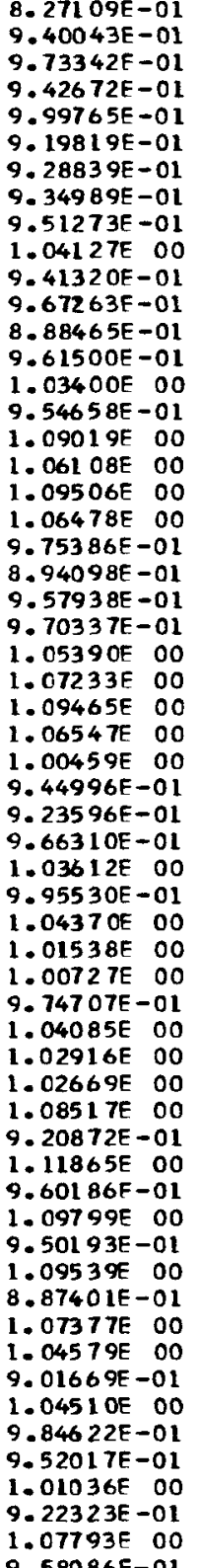

$1.58333 E-02$ $3.16667 E-02$ 4.71667E-02 $6.41667 E-02$ $8.21666 \mathrm{E}-02$ $9.75000 E-02$ $1.11333 E-01$ $1.25500 \mathrm{E}-\mathrm{O}$ $1.40167 E-01$ $1.56833 \mathrm{E}-01$ $1.72500 E-01$ $1.88000 E-O 1$ .02500E-O (.) (2.86167E-OI $2.84167 \mathrm{E}-0$ 3.01333E-0 $3.20167 E-01$ $3.35167 E-01$ $3.500006-0$ $3.66667 E-01$ 4.81667E-01 4.00167E-01 $4.39167 \mathrm{E}-0 \mathrm{O}$ $4.58333 E-01$ 4.750 OOE-O 4.91000E-O1 $5.06333 \mathrm{E}-0$ $5.21833 \mathrm{E}-0$ $5.38833 E-0$ $5.54333 E-0.1$ $5.70167 E-01$ $5.86667 E-0$ $6.02667 E-02$ $6.18833 E-01$ $6.35167 E-01$ 6.525 OOE -01 $6.69167 E-01$ $6.86000 E-01$ 7. $00167 E-01$ 7.20000E-OI 7.350 OOE -01 $7.53833 \mathrm{E}-01$ $7.68500 E-01$ $7.87167 E-01$ $8.01000 E-O$ $8.17500 E-O 1$ . $8.46667 E-01$ 8. 85000E-OL 9. $9.10167 \mathrm{E}-0$ $9.23500 \mathrm{E}-0$ $9.537 \cap \cap F-n 1$
AVG. K-EFF 1. $00000 E 00$ $.00000 \mathrm{E} O \mathrm{O}$ $9.73342 \mathrm{E}-0$ $9.58007 E-01$ $9.71926 \mathrm{E}-01$ 9.58859E-01 9. $52887 E-01$ $9.49904 E-01$ $9.50100 E-01$ $9.61496 \mathrm{E}-01$ $9.59254 E-01$ $9.60055 E-01$ $9.53547 E-01$ $9.54209 E-01$ $59940 E-O L$ 9.68623E-O1 $9.74402 E-01$ $9.74402 E-01$ 9.86125E-O $98560 \mathrm{E}-01$ $9.80986 E-01$ $9.79888 E-01$ $9.79453 \mathrm{~F}-01$ 9.82690E-01 $9.86425 E-01$ $9.90754 E-01$ $9.93627 E-01$ $9.94033 E-0$ $9.92281 E-01$ S. $89912 E-01$ S.89126E-0 9.90641E-01 9. $90794 E-01$ $9.92397 E-01$ $9.93073 E-01$ $9.93478 E-O L$ $9.92957 E-01$ 9. $94251 E-01$ 9. $95169 \mathrm{E}-01$ $9.95978 E-01$ $9.98207 E-01$ $9.96321 \mathrm{E}-01$ $9.99233 \mathrm{E}-01$ $9.98325 \mathrm{~F}-01$ $1.00059 E$ O0 $9.99470 E-01$ $1.00155 E$ O $9.99126 E-01$ 1. OOLOE OD $1.00160 E$ OO 1.00049E 00 $1.00049 E$ O 9.99280E-O 9. $9.99082 E-01$ $9.99508 \mathrm{~F}-0$ 9.98781F-n
DEVIATION

WARNING - ONLY 294 INDEPTR IX K-EFF 9. $39234 E-O 1$ 0.0

$1.53459 \mathrm{E}-02$

$1.65007 \mathrm{E}-02$

$1.74892 \mathrm{E}-02$

$1.48219 \mathrm{E}-02$

$1.24631 \mathrm{E}-02$

$1.05363 \mathrm{E}-02$

1. $35987 E-02$

$1.30684 \mathrm{E}-02$

$1.24370 \mathrm{E}-02$

$1.24370 E-02$

1.21287E-02

1.21287E-02

$1.12366 E-02$

1.39679E-O2

$1.49173 \mathrm{E}-02$

$1.48075 E-02$

$1.40199 \mathrm{E}-02$

$1.40659 \mathrm{E}-02$

1. $34244 E-02$

$1.34244 E-02$

1. $26606 \mathrm{E}-02$

$1.26606 \mathrm{E}-02$
$1.26842 \mathrm{E}-02$

$1.29132 \mathrm{E}-02$

$1.27362 \mathrm{E}-02$

$1.22626 \mathrm{E}-02$

1. $19454 \mathrm{E}-02$

$1.17681 \mathrm{E}-02$

1. $13960 \mathrm{E}-0$

$1.11263 E-02$

$1.07739 \mathrm{E}-02$

$1.05647 E-02$

$1.02717 \mathrm{E}-0$

$9.98258 \mathrm{E}-03$

$9.71536 E-03$

$9.53773 \mathrm{E}-\mathrm{C}$

9. $32946 \mathrm{E}-03$

$9.12314 E-03$

$9.16772 \mathrm{E}-03$

$9.13800 E-03$

$9.38058 E-03$

9.27645E-03

$9.27645 E-03$

$9.13520 E-03$

$0.30036 \mathrm{E}-03$

. $30036 E-03$

$0.09458 \mathrm{E}-03$

9.13211E-03

8.99711E-03

(2)

$8.70585 \mathrm{E}-03$

(8)

$8.50550 \mathrm{E}-03$

$8.47239 E-03$

$8.35450 F-n$
9. $39234 \mathrm{E}-01$

$9.65725 E-01$

$9.72408 \mathrm{E}-01$

$9.69194 \mathrm{E}-01$

$9.51676 E-01$

$9.62113 \mathrm{E}-01$

$9.56578 \mathrm{E}-0 \mathrm{~L}$

$9.62521 \mathrm{E}-01$

$9.69135 \mathrm{E}-01$
$9.67853 \mathrm{E}-01$

$9.67853 E-01$

$9.64624 E-O 1$

$9.64624 \mathrm{E}-01$

$9.69508 \mathrm{E}-01$

$9.67049 \mathrm{E}-01$

$9.67049 E-01$

$78848 E-01$

. $85794 E-01$

$9.89196 \mathrm{E}-01$

9. $87646 \mathrm{E}-01$

$9.83209 E-01$

$9.82470 E-01$

9.80564E-0 1

$9.83466 E-01$

9. $86333 \mathrm{E}-01$

9.90496 E-01

9.92991E-01

$9.93296 \mathrm{E}-01$

9. $89765 \mathrm{E}-01$

$9.89743 E-01$

$9.91637 E-01$

$9.92665 E-01$

9.93561E-OI

$9.93878 \mathrm{E}-01$

9.94012E-01

$9.93127 \mathrm{E}-01$

$9.94376 \mathrm{E}-01$

$9.95291 E-01$

$9.96755 E-01$

$9.98602 E-01$

$9.96364 E-01$

$9.98755 E-01$

$1.00019 E 00$

$9.99465 E-01$

$1.00128 E$ OO

1.00082E 00

$1.00082 E$ OD

$1.00171 \mathrm{E} 00$

9.00073 O

$1.00047 E$ OO

1.0004

$9.99677 \mathrm{E}-01$

$9.98222 \mathrm{E}-01$

$9.99411 E-01$

$9.9863 \cap \mathrm{N}=\mathrm{n} 1$ 


\begin{tabular}{|c|c|}
\hline 60 & $1.02921 E C O$ \\
\hline 61 & $1.01395 \mathrm{~F} 00$ \\
\hline 62 & $1.02812 E \quad 00$ \\
\hline 63 & $1.00757 E \quad 00$ \\
\hline 64 & $9.29862 E-01$ \\
\hline 65 & $1.12910 E O O$ \\
\hline 66 & $1.03928 \mathrm{E} \quad 00$ \\
\hline 67 & $1.04074 \mathrm{E} \quad 00$ \\
\hline 68 & $9.67696 E-01$ \\
\hline 69 & $9.57595 F-01$ \\
\hline 70 & $9.15400 F-01$ \\
\hline 71 & $3.38099 E-01$ \\
\hline 72 & $9.57619 E-01$ \\
\hline 73 & $1.01200 E 0$ \\
\hline 74 & $9.99665 F-01$ \\
\hline 75 & $1.00535 E 00$ \\
\hline 76 & $9.51288 \mathrm{~F}-01$ \\
\hline 77 & $9.50677 F-01$ \\
\hline 78 & $9.92980 \mathrm{~F}-01$ \\
\hline 79 & $9.97849 F-01$ \\
\hline 80 & $9.70942 \mathrm{~F}-01$ \\
\hline 81 & $1.02024 \mathrm{~F} 00$ \\
\hline 82 & $1.03598 E 00$ \\
\hline 83 & $9.46282 \mathrm{E}-01$ \\
\hline 84 & $1.00451 E 00$ \\
\hline 85 & $1.03590 F$ OD \\
\hline 86 & $9.97147 F-01$ \\
\hline 87 & $8.94114 E-01$ \\
\hline 88 & $1.01991 \mathrm{E} 00$ \\
\hline 89 & $9.99144 F-01$ \\
\hline 90 & $1.00324 E \quad 00$ \\
\hline 91 & $1.02294 E \quad 00$ \\
\hline 92 & $1.02598 E \quad 00$ \\
\hline 93 & $1.00346 F 00$ \\
\hline 94 & $9.93435 E-01$ \\
\hline 95 & $1.01991 \mathrm{~F} 00$ \\
\hline 96 & $1.03280 E \quad 00$ \\
\hline 97 & $9.42863 F=01$ \\
\hline 98 & $1.00042 F \quad 00$ \\
\hline 99 & $9.96061 F-01$ \\
\hline 100 & $9.57447 F-01$ \\
\hline 101 & $1.02913 E \quad 00$ \\
\hline 102 & $1.00057 E 00$ \\
\hline 103 & $1.07187 \mathrm{~F}$ \\
\hline
\end{tabular}

$9.66833 E-01$ $9.82667 E-01$ $9.99167 \mathrm{E}-01$ $1.01467 E 00$ $1.02917 E 00$ $1.04833 \mathrm{E} 00$ $1.06467 E$ OD $1.08250 E$ OO 1.09800E DO 1.11717 O

$1.14467 E 00$ O $1.17417 E \quad 00$ 1.28750 O 00 $1.21750 E$ OO $1.23217 E 00$ $1.24917 E$ OD $1.26550 E$ DO $1.28183 E 00$ $1.30000 E 00$ $1.31833 E 00$ $1.33417 E \quad 00$ $1.35017 E 00$ $1.37017 E 00$ $1.38517 E 00$ $1.39967 \mathrm{~F} \mathrm{OO}$ $1.41667 \mathrm{E} \mathrm{OO}$ $1.43217 E$ OD $1.44750 E$ OO $1.46417 \mathrm{E} 00$ 1.481 DOE OO $1.49683 E 00$ $1.51350 E$ OO $1.52933 E$ OO $1.54067 E$ OO 1.56083E OO . $57633 E$ OO . $.62133 \mathrm{E} 00$ $1.63667 \mathrm{E} O 0$
$9.99306 E-01$ $9.99554 E-01$ $1.00003 E 00$ $1.00015 \mathrm{E} \quad 00$ $9.99020 E-01$ $1.00108 \mathrm{EF} 00$ $1.00168 \mathrm{~F} 00$ $1.00228 \mathrm{~F} 00$ $1.00176 E$ OO $1.00169 E$ EO

$9.98073 E-O 1$ $9.98073 E-01$ $9.97700 E-01$ $9.97727 E-01$ $9.97831 \mathrm{E}-01$ $9.97202 E-01$ $9.96582 \mathrm{E}-01$ $9.96534 E-01$ $9.96551 E-01$ $9.96223 E-01$ $9.96527 E-0$ $9.97020 E-01$ $9.96393 E-01$ 9. $96492 E-01$ $9.96967 \mathrm{E}-\mathrm{O}$ $9.96969 F-01$ $9.95759 \mathrm{E}-01$ S.96039E-01 $9.96075 E-01$ $9.96156 E-01$ $9.96457 E-01$ $9.96785 \mathrm{E}-0$ $9.96858 \mathrm{~F}-01$ $9.96821 E-01$ $9.97069 E-01$ $9.97449 E-01$ .96875E 0 . $9.96903 E-01$ $0608=0$ $9.96867 \mathrm{E}-0$

$9.96867 E-01$
$9.57609 E-01$

$\begin{array}{ll}8.22612 E-03 & 9.99089 E-01 \\ 8.08904 E-03 & 9.99240 E-01 \\ 7.96819 E-03 & 9.99642 E-01 \\ 7.83687 E-03 & 9.99805 E-01 \\ 7.79221 E-03 & 9.98706 E-01 \\ 7.94138 E-03 & 1.00062 E \text { O0 } \\ 7.84151 E-03 & 1.00098 E 00 \\ 7.74257 E-03 & 1.00138 E 00 \\ 7.64353 E-03 & 1.00105 E 00 \\ 7.52804 E-03 & 1.00109 E 00 \\ 7.52480 E-03 & 9.99942 E-01\end{array}$

.00109E 00

WRNING - ONLY 283 INDEPENDENT FISSION POINTS WERE GENERATED. $7.77787 \mathrm{E}-03 \quad 9.97704 \mathrm{E}-01$

$7.58207 \mathrm{E}-03 \quad 9.97283 \mathrm{E}-01$

$7.47606 \mathrm{E}-0 \mathrm{Z} \quad 9.97283 \mathrm{E}-01$

$7.37378 \mathrm{E}-03 \quad 9.9745 \mathrm{E}-01$

$7.30066 \mathrm{E}-03 \quad 9.96701 \mathrm{E}-01$

$7.22936 \mathrm{E}-03 \quad 9.96015 \mathrm{E}-01$

$7.13420 \mathrm{E}-03 \quad 9.95956 \mathrm{E}-01$

$7.04081 \mathrm{E}-03 \quad 9.95969 \mathrm{E}-01$

$6.95788 \mathrm{E}-03 \quad 9.95652 \mathrm{E}-01$

$6.87601 \mathrm{E}-03 \quad 9.95968 \mathrm{E}-01$

$6.80713 E-03 \quad 9.96390 E-0$

$6.75188 \mathrm{E}-03 \quad 9.95920 \mathrm{E}-01$

$6.67003 \mathrm{E}-03 \quad 9.96134 \mathrm{E}-\mathrm{O}$

$6.60645 \mathrm{E}-03 \quad 9.96602 \mathrm{E}-0$

$6.52720 E-03 \quad 9.96662 E-01$

$6.56267 E-03 \quad 9.95560 E-01$

$6.49211 E-03 \quad 9.96057 E-01$

$6.41732 \mathrm{E}-03 \quad 9.96172 \mathrm{E}-01$

$6.34458 \mathrm{E}-03 \quad 9.96259 \mathrm{E}-01$

$6.28023 \mathrm{E}-03 \quad 9.96578 \mathrm{E}-01$

$6.21879 \mathrm{E}-03 \quad 9.96929 \mathrm{E}-0 \mathrm{~L}$

$6.15048 E-03 \quad 9.97039 E-01$

$6.08347 \mathrm{E}-03 \quad 9.97 \mathrm{C}$.

$6.02295 E-03 \quad 9.97403 E-D L$

5.97OTE-03

$50.97197 E-01$

5.8737E 03 (.97147E-OL

$5.91272 E-03$ Q.

$5.71832 E-03 \quad 9.96564 E-0$

$5.66104 E-03$

$\begin{array}{ll}5.66104 \mathrm{E}-03 & 9.96872 \mathrm{E}-01 \\ 5.65374 \mathrm{E}-03 & 9.97538 \mathrm{E}-01\end{array}$

OFISSION PROBABILITIES BY UNIT.

THFRE ARE NBXMAX * NBYMAX * NEZMAX UNITS IN AN ARRAY. 
SAMPLE PROBLFM 194 AOUEOUS 4 METAL MIXED BOX MATRIX CALCULATION

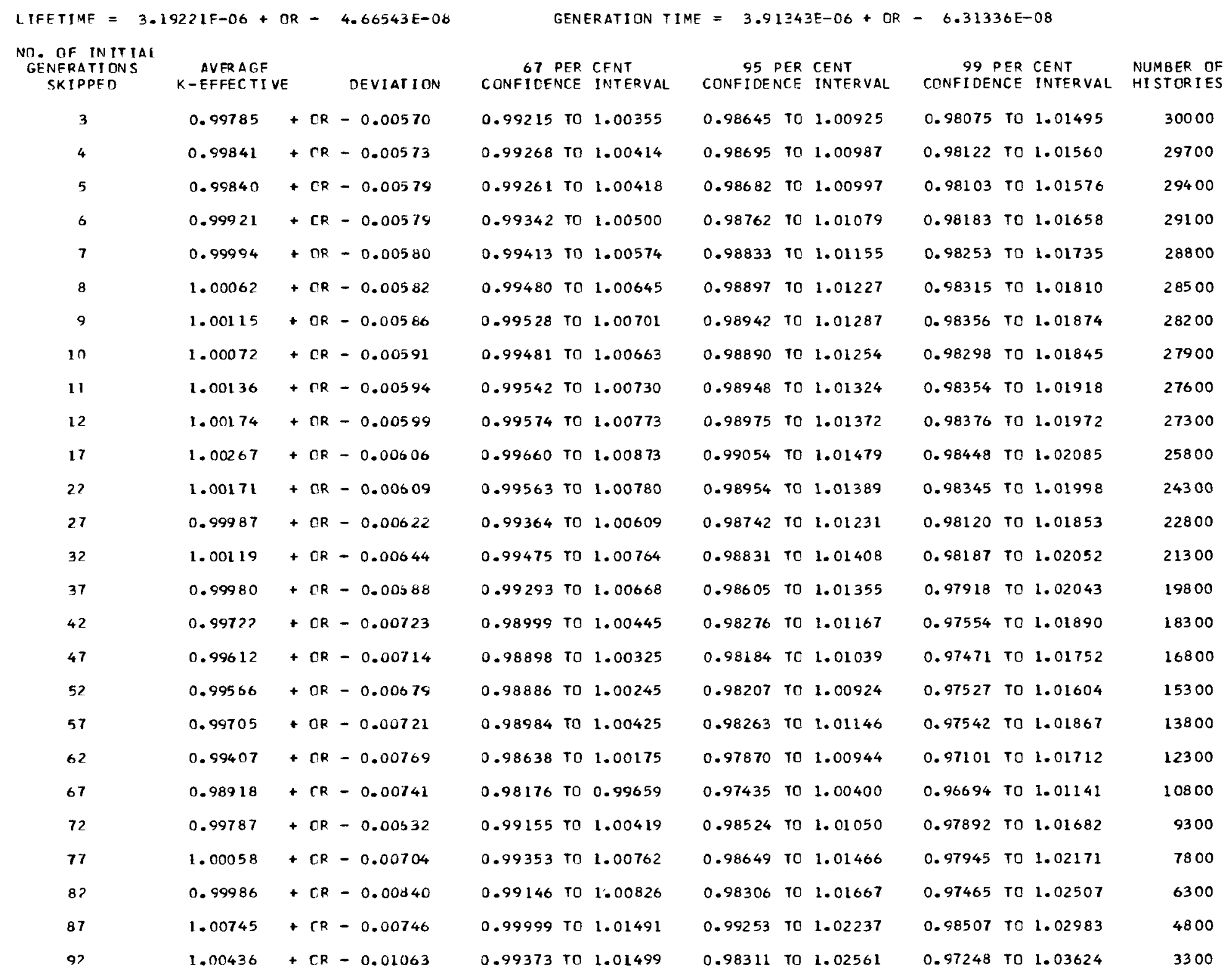


NO. OF INITIAL

SERATI ON
SKIPPED

97

AVERAGE

Deviation - EFFECTIVE

DEVIATION

1.00925

$+C R-0.01563$

\section{PER CENT}

CONFICENCE INTERVA

0.99362 T0 1.02488
95 PER CENT
CONFIDENCE INTERVAL

0.97799 10 1.04051 $\begin{array}{cl}99 \text { PER CENT } & \text { NUMBER OF } \\ \text { CONFIDENCE INTERVAL } & \text { HISTORIES }\end{array}$

0.96236 TO 1.05613

1800 


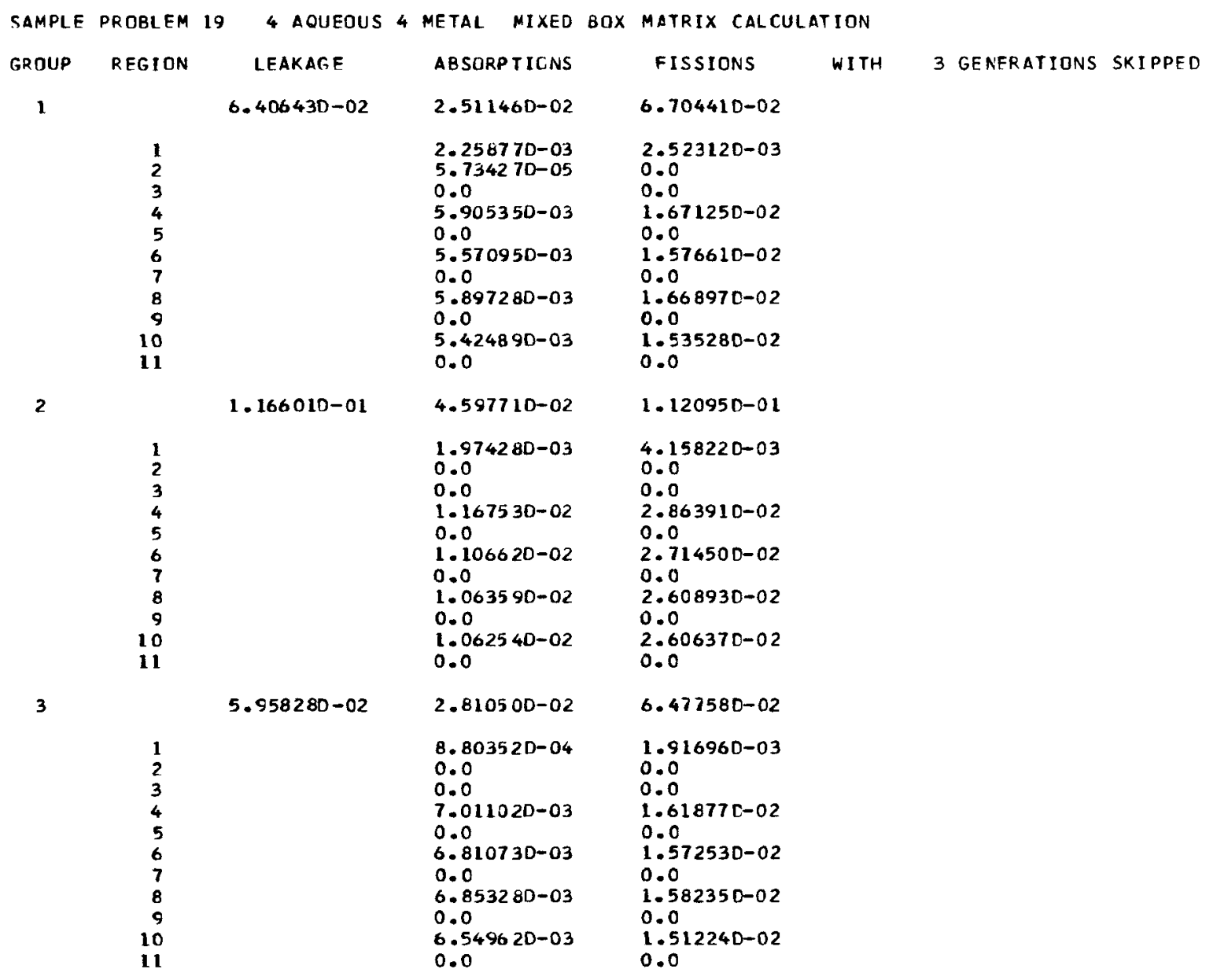


SAMPLE PROBIFM 194 AQUEOUS 4 METAL MIXED BOX MATRIX CALCULATION

GRTUP REGION

LFAKAGE

ABSORPTIONS

FISSIONS

II TH

4

$9.078350-02$

$4.673630-02$

$1.025200-01$

1.257410-03

0.0

$1.206930-02$

0.0

$.123120-02$

$1.095340-02$

$1.122490-02$

0.0

$6.955890-02$

$4.400520-02$

$1.459760-03$

0.0

$1.078270-02$

$0.078270-02$

$1.064890-02$

$1.064890-02$
0.0

$1.087220-02$

$1.024150-02$

$2.606800-03$

0.0

$2.651540-02$

0.0

$2.467410-02$

0.0

$2.40638 \mathrm{C}-02$

0.0

2. 46603D-02

0.0

9. $26068 \mathrm{C}-02$

3.C6293 C-03

0.0

0.0
$2.269400-02$

2. $24124 \mathrm{C}-02$

0.0

2.288240-02

0.0

$2.155500-02$
0.0

6

$2.760980-02$

$1.51974 \mathrm{D}-02$

$2.924120-02$

$1.933240-03 \quad 3.712490-03$

$$
0.0
$$

$3.464620-03$

0.0
$3.070620-03$

0.0

$3.580330-03$

0.0

$3.14858 D-03$
0.0

3.7
0.0
0.0

$6.668130-03$

0.0

5. $909830-03$

0.0

6. 890840-03

0.0
$6.059870-03$

0.0 
SAMPLE PROBLEM 194 AOUEOUS 4 METAL MIXED BOX MATRIX CALCULATION

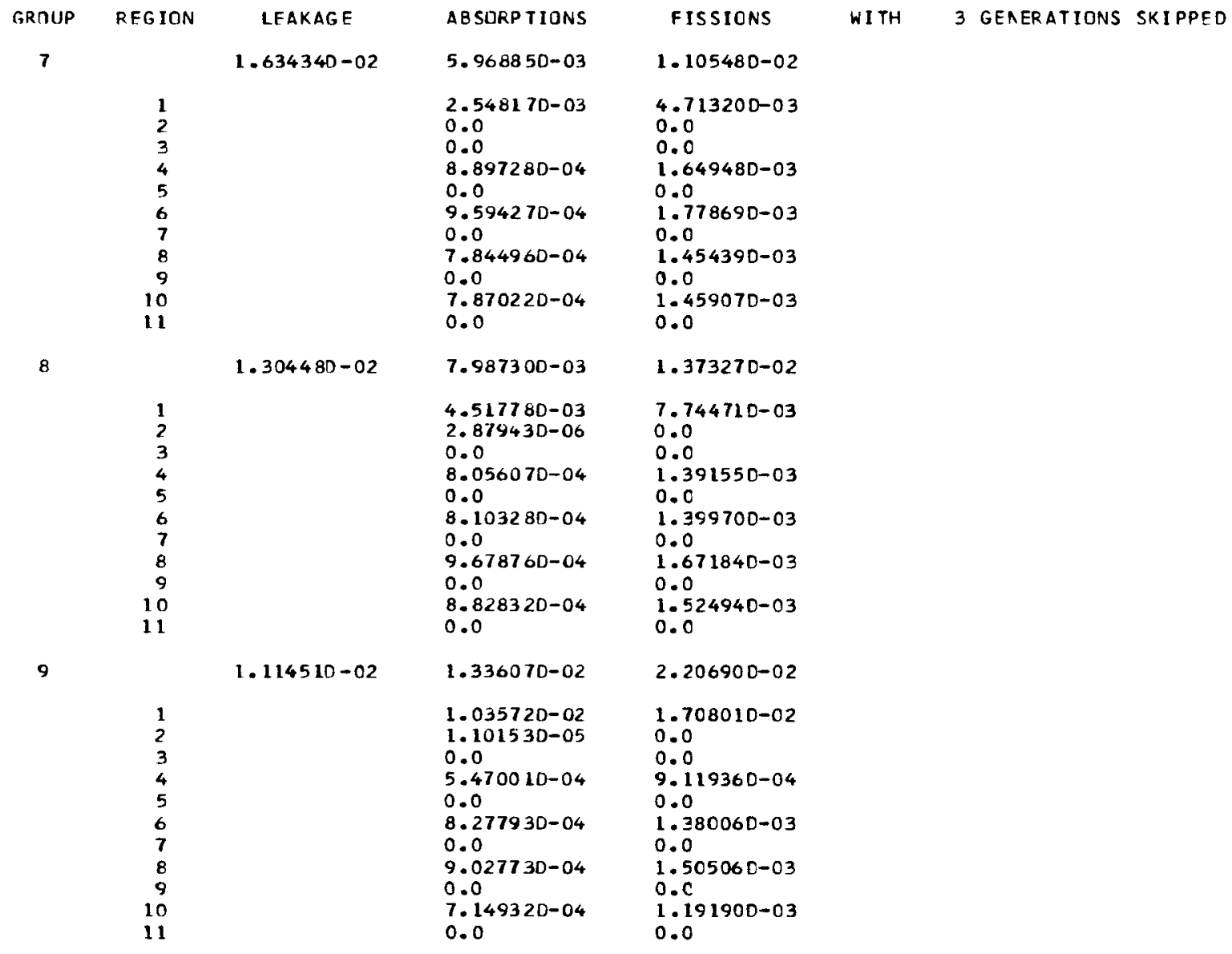


SAMPLE PROBLEM 194 AOUEOUS 4 METAL MIXED BOX MATRIX CALCULATION

\begin{tabular}{|c|c|c|c|c|c|c|c|}
\hline GROUP & REGION & LEAKAGE & ABSORP TIONS & FISSIONS & WITH & 3 GENERATIONS & SKIPPED \\
\hline \multirow[t]{2}{*}{10} & & $6.88144 D-03$ & $1.498600-02$ & $2.357950-02$ & & & \\
\hline & $\begin{array}{r}1 \\
2 \\
3 \\
4 \\
5 \\
6 \\
7 \\
8 \\
9 \\
10 \\
11\end{array}$ & & $\begin{array}{l}1.293070-02 \\
1.405600-05 \\
0.0 \\
4.216130-04 \\
0.0 \\
4.424910-04 \\
0.0 \\
6.427950-04 \\
0.0 \\
5.344120-04 \\
0.0\end{array}$ & $\begin{array}{l}2.033330-02 \\
0.0 \\
0.0 \\
6.704810-04 \\
0.0 \\
7.036830-04 \\
0.0 \\
1.022220-03 \\
0.0 \\
8.498620-04 \\
0.0\end{array}$ & & & \\
\hline \multirow[t]{2}{*}{11} & & $6.064170-03$ & $7.238400-03$ & $1.068380-02$ & & & \\
\hline & $\begin{array}{r}1 \\
2 \\
3 \\
4 \\
5 \\
6 \\
7 \\
8 \\
9 \\
10 \\
11\end{array}$ & & $\begin{array}{l}5.690140-03 \\
2.206250-05 \\
0.0 \\
3.865270-04 \\
0.0 \\
3.945590-04 \\
0.0 \\
3.582780-04 \\
0.0 \\
3.868320-04 \\
0.0\end{array}$ & $\begin{array}{l}8.35692 \mathrm{D}-03 \\
0.0 \\
0.0 \\
5.893190-04 \\
0.0 \\
6.015660-04 \\
0.0 \\
5.462490-04 \\
0.0 \\
5.85785 \mathrm{C}-04 \\
0.0\end{array}$ & & & \\
\hline \multirow[t]{2}{*}{12} & & $6.414260-03$ & $7.830100-03$ & $8.132150-03$ & & & \\
\hline & $\begin{array}{r}1 \\
2 \\
3 \\
4 \\
5 \\
6 \\
7 \\
8 \\
9 \\
10 \\
11\end{array}$ & & $\begin{array}{l}6.291140-03 \\
3.932620-05 \\
0.0 \\
4.319550-04 \\
0.0 \\
4.484750-04 \\
0.0 \\
3.579700-04 \\
0.0 \\
2.612290-04 \\
0.0\end{array}$ & $\begin{array}{l}6.485160-03 \\
0.0 \\
0.0 \\
4.744020-04 \\
0.0 \\
4.925450-04 \\
0.0 \\
3.931460-04 \\
0.0 \\
2.868990-04 \\
0.0\end{array}$ & & & \\
\hline
\end{tabular}


SAMPLE PROBLEM 194 AOUEOUS 4 METAL MIXED BOX MATRIX CALCULATION

\begin{tabular}{|c|c|c|c|c|c|c|c|}
\hline GROUP & REG ION & LEAKAGE & AB SORP TIONS & FISSIONS & WITH & 3 GENERATIONS & S SKIPPED \\
\hline \multirow[t]{2}{*}{13} & & $6.208430-03$ & $6.632030-03$ & $1.152050-02$ & & & \\
\hline & $\begin{array}{l}1 \\
2 \\
3 \\
4 \\
5 \\
6 \\
7 \\
8 \\
9 \\
10 \\
11\end{array}$ & & $\begin{array}{l}5.352200-03 \\
5.898290-05 \\
0.0 \\
4.112980-04 \\
0.0 \\
3.136890-04 \\
0.0 \\
3.658580-04 \\
0.0 \\
1.300060-04 \\
0.0\end{array}$ & $\begin{array}{l}9.174650-03 \\
0.0 \\
0.0 \\
7.902960-04 \\
0.0 \\
6.027440-04 \\
0.0 \\
7.029840-04 \\
0.0 \\
2.498020-04 \\
0.0\end{array}$ & & & \\
\hline \multirow[t]{2}{*}{14} & & $4.504190-03$ & $1.284600-02$ & $2.591640-02$ & & & \\
\hline & $\begin{array}{l}1 \\
2 \\
3 \\
4 \\
5 \\
6 \\
7 \\
8 \\
9 \\
10 \\
11\end{array}$ & & $\begin{array}{l}1.181890-02 \\
7.463880-05 \\
0.0 \\
1.816600-04 \\
0.0 \\
3.348560-04 \\
0.0 \\
2.487240-04 \\
0.0 \\
1.872240-04 \\
0.0\end{array}$ & $\begin{array}{l}2.387560-02 \\
0.0 \\
0.0 \\
3.892410-04 \\
0.0 \\
7.174930-04 \\
0.0 \\
5.329390-04 \\
0.0 \\
4.011630-04 \\
0.0\end{array}$ & & & \\
\hline \multirow[t]{2}{*}{15} & & $7.34613 D-03$ & $6.374140-02$ & $1.235670-01$ & & & \\
\hline & $\begin{array}{r}1 \\
2 \\
3 \\
4 \\
5 \\
6 \\
7 \\
8 \\
9 \\
10 \\
11\end{array}$ & & $\begin{array}{l}6.152730-02 \\
2.879080-04 \\
0.0 \\
5.539980-04 \\
0.0 \\
5.082450-04 \\
0.0 \\
5.478100-04 \\
0.0 \\
3.161750-04 \\
0.0\end{array}$ & $\begin{array}{l}1.196710-01 \\
0.0 \\
0.0 \\
1.120620-03 \\
0.0 \\
1.028070-03 \\
0.0 \\
1.108100-03 \\
0.0 \\
6.395540-04 \\
0.0\end{array}$ & & & \\
\hline
\end{tabular}


SAMPLF PRTBLFM 194 AQUEOUS 4 METAL MIXED BOX MATRIX CALCULATION

\begin{tabular}{|c|c|c|c|c|c|c|}
\hline GRRUP & REGION & LEAKAGE & ABSORPTIUNS & FISSIONS & HITH & 3 GENERATIONS SKIPPED \\
\hline 16 & & $7.353650-03$ & $1.404090-01$ & $2.793190-01$ & & \\
\hline & $\begin{array}{r}1 \\
2 \\
3 \\
4 \\
5 \\
6 \\
7 \\
8 \\
5 \\
10 \\
11\end{array}$ & & $\begin{array}{l}1.370830-01 \\
9.273130-04 \\
0.0 \\
4.957980-04 \\
0.0 \\
4.843180-04 \\
0.0 \\
7.392790-04 \\
0.0 \\
6.793740-04 \\
0.0\end{array}$ & $\begin{array}{l}2.743570-01 \\
0.0 \\
0.0 \\
1.025540-03 \\
0.0 \\
1.001800-03 \\
0.0 \\
1.529180-03 \\
0.0 \\
1.405270-03 \\
0.0\end{array}$ & & \\
\hline TOTAL $=$ & & $5.135060-01$ & $4.861360-01$ & $9.578590-01$ & & \\
\hline FL $\triangle P S F D$ & IME & $1.65517 \mathrm{MINUTES}$ & & & & \\
\hline
\end{tabular}




\section{$\bullet$}

SAMPLF PROBIFM 194 AOUEOUS 4 NETAL MIXEO BOX MATRIX CALCULATION

\begin{tabular}{|c|c|c|c|c|c|}
\hline UN IT & POSI & TION & & & COFACTOR \\
\hline NUMBFF & $x y$ & 2 & $B O X$ & TYPE & K-EFFECTIVE \\
\hline 1 & $\mathbf{l}$ & 1 & & 2 & $9.44449 E-01$ \\
\hline 2 & 2 & 1 & & 1 & $9.61593 E-01$ \\
\hline 3 & 1 & $\mathbf{l}$ & & 3 & $9.48397 E-01$ \\
\hline 4 & 2 & 1 & & 1 & $9.61444 E-01$ \\
\hline 5 & 1 & 2 & & 4 & $9.46371 \mathrm{E}-01$ \\
\hline 6 & 21 & 2 & & 1 & $9.64612 \mathrm{E}-01$ \\
\hline 7 & 1 & 2 & & 5 & $9.51019 \mathrm{E}-01$ \\
\hline 8 & 2 & 2 & & 1 & $9.61632 E-01$ \\
\hline
\end{tabular}


SAMPLE PROBLEM 194 AOUEOUS 4 METAL MIXED BOX MATRIX CALCULATION

FISSION PROBABILITY MATRIX BY UNIT

1. 1 . $I$ P IS THE PROBABILITY THAT A NEUTRON BORA IN UNIT I CAUSES A NEXT GENERATION FISSION IN UNIT J.

1. 11 $7.38 \mathrm{E}-01$ (1) $217.28 \mathrm{E}-02$ (1. 3) $6.22 \mathrm{E}-02$ (1, 4) $4.46 \mathrm{E}-02$ (1, 51 $7.76 \mathrm{E}-0211.613 .20 \mathrm{E}-02$

(1. 7) $3.15 E-02$ ( $1.812 .92 E-02$

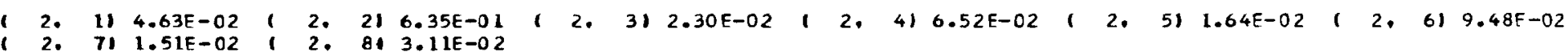

QI उ.11E-O

13. $116.40 E-02$ (3. $214.03 E-02$ (3. 3) $7.08 E-01$, 3. 4) $7.84 E-0213,513.05 E-0213.612 .67 E-02$

(3. $718.11 E-02$ ( 3. $813.69 E-02$

1. $112.35 E-02$, 4. $216.46 E-02$, 4. $314.11 E-02$, $4,416.76 E-01$, $4,511.52 E-02 \quad 14,611.64 E-02$

$819.64 E-02$

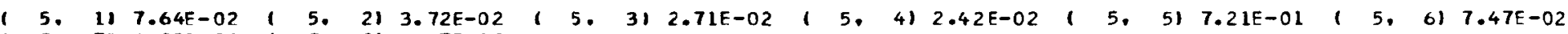

5. $716.93 E-02,5,814.47 E-02$

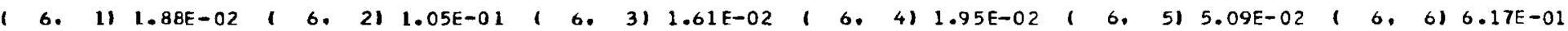

6. 7) $2.29 E-02$ ( 6. 8) $5.97 \mathrm{E}-02$

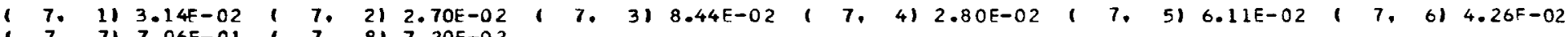

7. $717.06 \mathrm{E}-01$ ( 7. $817.20 \mathrm{E}-02$

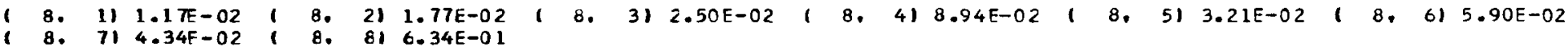


MAMLE PROBLEM 19 A AOUEOUS 4 METAL MIXED BOX MATRIX CALCULATION

\section{SNURCE VFCTOR BY UNIT}

$$
\begin{array}{cc}
\text { UNIT } & \text { VECTOR } \\
1 & 1.65533 E-01 \\
2 & 1.49830 F-01 \\
3 & 1.43115 E-01 \\
4 & 1.34681 E-01 \\
5 & 1.45637 E-01 \\
6 & 1.23401 \mathrm{E}-01 \\
7 & 1.33803 \mathrm{E}-01 \\
8 & 1.36990 \mathrm{E}-01
\end{array}
$$

AVERAGE UNIT SELF MULTIPLICATION $=6.79370 E-01$ TOR- $1.61587 E-02$ ITHE PROBABILITY THAT A NEUTRON BORN IN A UNIT PRODUCES A FISSION IN THAT SAME UNIT.I 
SAMPLF PROBLEM 194 AOUEOUS 4 METAL miXED BOX MATRIX CALCULATION

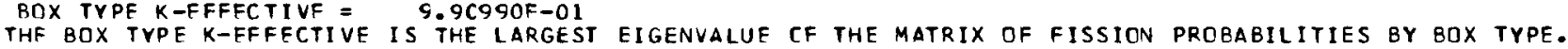

FISSINN PROBABILITY MATRIX BY BOX TYPE

1. JI P IS THF PROBABILITY THAT A NEUTRON BORN IN BOX TYPE I CAUSES A NEXT GENERATION FISSION IN BOX TYPE J.

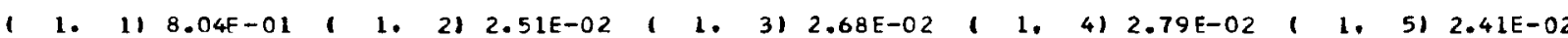

12. $111.78 \mathrm{~F}-01$ (2. $217.38 \mathrm{E}-01$ (2. $316.22 \mathrm{E}-02$ (2. 4) $7.76 \mathrm{E}-02$ (2. $513.15 \mathrm{E}-02$

13. $111.82 E-01$ (3. 2) E.40E-02 (3. 31 7.08E-01 $13.413 .05 E-02$ ( 3. 5) $8.11 E-02$

$14.111 .81 E-01$, 4. 21 7.64E-02 $14.312 .71 E-02$, 4. $417.21 E-01$, 4, 51 $6.93 E-02$

15. $111.69 \mathrm{E}-01$ (5. $213.14 E-02$, 5. $318.44 E-02$, $5.416 .11 E-02$ ( 5, 5) $7.06 E-01$ 


\section{$\bullet$}

SAMPLF PRORLFM 194 AQUEOUS 4 METAL MIXED BOX MATRIX CALCULATION

SOURCF VECTMR BY BOX TYPE

$$
\begin{array}{cc}
\text { BOX TYPF } & \text { VFCTOR } \\
1 & 4.88506 F-01 \\
2 & 1.34042 \mathrm{~F}-01 \\
3 & 1.24418 \mathrm{~F}-\mathrm{Cl} \\
4 & 1.30431 \mathrm{~F}-01 \\
5 & 1.22603 \mathrm{~F}-01
\end{array}
$$


SAMPLF PROBLEM 19 \& AOUEOUS 4 METAL MIXED BOX MATRIX CALCULATION

$$
\begin{array}{cc} 
& \text { COFACTOR } \\
\text { BOX TYPE } & \text { K-EFFECTIVE } \\
1 & 8.92911 E-01 \\
2 & 9.36202 E-01 \\
3 & 9.40733 E-01 \\
4 & 9.37133 E-01 \\
5 & 9.42324 E-01
\end{array}
$$


AMPLF PROBLFM 194 AOUEOUS 4 NETAL MIXED BOX MATRIX CALCULATION

**** FISSION DFNSITIFS ****

\begin{tabular}{|c|c|c|c|c|c|}
\hline & & RFGION & $\begin{array}{l}\text { FISSION } \\
\text { DFN SITY }\end{array}$ & $\begin{array}{l}\text { PERCENT } \\
\text { OEVIATIIN }\end{array}$ & $\begin{array}{c}\text { TOTAL } \\
\text { FISSICNS }\end{array}$ \\
\hline$B \cap x$ & TYPF & $\begin{array}{l}1 \\
2 \\
3\end{array}$ & $\begin{array}{l}2.515 F-05 \\
0.0 \\
0.0\end{array}$ & $\begin{array}{l}1.10 \\
0.0 \\
0.0\end{array}$ & $\begin{array}{l}5.0 \subseteq 7 F-01 \\
0.0 \\
0.0\end{array}$ \\
\hline$B \cap x$ & TYPF & $\begin{array}{l}1 \\
2\end{array}$ & $\begin{array}{l}1.131 F-04 \\
0.0\end{array}$ & $\begin{array}{l}1.98 \\
0.0\end{array}$ & $\begin{array}{l}1.264 E-01 \\
0.0\end{array}$ \\
\hline$B \cap x$ & TYPF & $\begin{array}{l}1 \\
2\end{array}$ & $\begin{array}{l}1.086 E-C 4 \\
0.0\end{array}$ & $\begin{array}{l}2.35 \\
0.0\end{array}$ & $\begin{array}{l}1.213 E-01 \\
0.0\end{array}$ \\
\hline $\operatorname{Bnx}$ & TYPF & $\begin{array}{l}1 \\
2\end{array}$ & $\begin{array}{l}1.100 E-C 4 \\
0.0\end{array}$ & $\begin{array}{l}2.38 \\
0.0\end{array}$ & $\begin{array}{l}1.229 E-01 \\
0.0\end{array}$ \\
\hline $\operatorname{BOX}$ & TYPE & $\begin{array}{l}1 \\
2\end{array}$ & $\begin{array}{l}1.051 E-C 4 \\
0.0\end{array}$ & $\begin{array}{l}2.44 \\
0.0\end{array}$ & $\begin{array}{l}1.174 E-01 \\
0.0\end{array}$ \\
\hline
\end{tabular}


SAMPLE PROBLEM 194 AOUEOUS 4 METAL MIXED BOX MATRIX CALCULATION

\begin{tabular}{|c|c|c|c|c|c|c|}
\hline \multirow{2}{*}{$\begin{array}{l}\text { FLUXES } \\
\text { GRQUP }\end{array}$} & \multicolumn{2}{|c|}{$\begin{array}{l}\text { FOR ROX TYPE } \\
\text { REGION }\end{array}$} & RFGION & 2 & REGICN & 3 \\
\hline & Flux & $\begin{array}{l}\text { PERCENT } \\
\text { DE VIAT ION }\end{array}$ & FLUX & $\begin{array}{l}\text { PERCENT } \\
\text { DEVIATIION }\end{array}$ & FLUX & $\begin{array}{l}\text { PERCENT } \\
\text { DEVIATION }\end{array}$ \\
\hline 1 & $3.408 F-05$ & $3 \quad 2.09$ & $2.353 E-05$ & $5 \quad 2.98$ & $2.000 E-05$ & $5 \quad 3.33$ \\
\hline$i$ & $6.310 E-05$ & 1.80 & $4.255 E-05$ & 2.19 & 3. $516 \mathrm{E}-05$ & 2.19 \\
\hline 3 & $3.116 F-05$ & 1.85 & $2.209 E-05$ & 3.04 & $2.060 E-05$ & 3.02 \\
\hline 4 & $4.414 E-05$ & 1.57 & $3.225 E-05$ & 2.08 & $3.064 E-05$ & 2.35 \\
\hline 5 & $4.41 \mathrm{CE}-05$ & 1.55 & $3.140 E-05$ & 1.98 & $2.631 E-05$ & 2.40 \\
\hline 6 & 3.C72E-05 & 1.51 & $1.985 \mathrm{E}-05$ & 2.54 & $1.375 \mathrm{E}-05$ & 4.02 \\
\hline 7 & $2.289 E-05$ & 1.59 & $1.422 E-05$ & 2 & $9.606 \mathrm{E}-06$ & 4.01 \\
\hline 8 & $1.984 E-05$ & 1.51 & $1.174 \mathrm{~F}-05$ & 2.89 & $7.741 \mathrm{E}-06$ & 4.79 \\
\hline 9 & $1.873 F-05$ & 1.58 & $1.076 F-05$ & 3.10 & $6.486 E-06$ & 4.48 \\
\hline 10 & $1.205 E-05$ & 2.17 & $7.037 E-06$ & 3.6 & $4.065 E-06$ & 5.63 \\
\hline 11 & $1.058 \mathrm{E}-05$ & 2.23 & $6.231 E-06$ & 3.40 & $3.834 \mathrm{E}-06$ & 5.81 \\
\hline 12 & $1,111 \mathrm{~F}-05$ & 2.01 & $5.994 \mathrm{E}-06$ & 3.59 & $3.906 F-06$ & 5.62 \\
\hline 13 & $9.397 \mathrm{~F}-06$ & 1.82 & $5.149 E-06$ & 3.94 & $3.158 E-06$ & 6.48 \\
\hline 14 & & & $1.414 E-06$ & 4.45 & & \\
\hline 15 & $1.326 \mathrm{~F}-05$ & 1.52 & $8.833 E-06$ & 3.42 & $5.012 E-06$ & 4.72 \\
\hline 16 & $1.092 f-05$ & & $1.24 \mathrm{BE}-05$ & 3.34 & $6.54 \mathrm{aE}-06$ & 4.45 \\
\hline
\end{tabular}




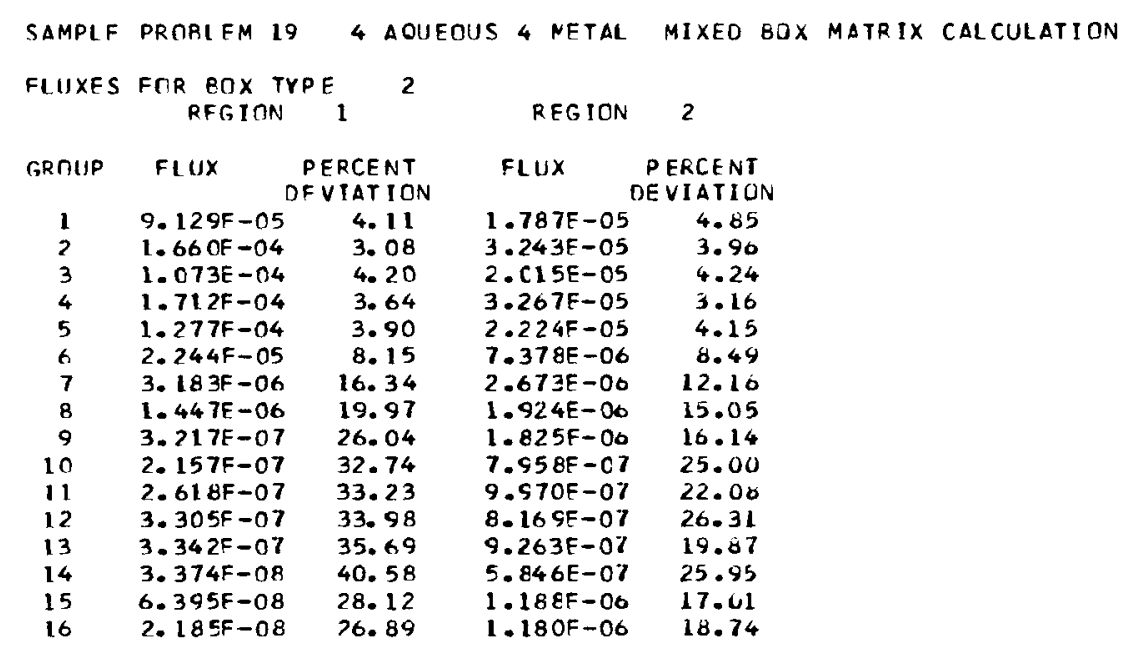


SAMPLE PROBLEM 194 aOUEOUS 4 METAL mixeo bOX MATRIX Calculation

\begin{tabular}{ccccc} 
FLUXES FOR BOX TYPE & 3 & REGION & 2 \\
RROUP & FLUX & $\begin{array}{c}\text { PERCENT } \\
\text { REGION }\end{array}$ & FLUX & \multicolumn{2}{c}{$\begin{array}{c}\text { PERCENT } \\
\text { DEVIATIJV }\end{array}$} \\
1 & $8.585 E-05$ & 4.84 & $1.844 E-05$ & 4.76 \\
2 & $1.666 F-04$ & 3.37 & $3.334 E-05$ & 3.51 \\
3 & $1.026 F-04$ & 4.32 & $2.093 E-05$ & 4.51 \\
4 & $1.593 E-04$ & 3.53 & $2.995 E-05$ & 3.82 \\
5 & $1.236 F-04$ & 3.48 & $2.339 E-05$ & 3.95 \\
6 & $1.872 E-05$ & 8.64 & $6.450 E-06$ & 8.31 \\
7 & $3.296 E-06$ & 16.46 & $2.804 E-06$ & 14.55 \\
8 & $1.445 E-06$ & 19.73 & $1.713 E-06$ & 15.80 \\
9 & $5.926 E-07$ & 20.08 & $1.724 E-06$ & 17.00 \\
10 & $1.125 F-07$ & 30.34 & $1.354 E-06$ & 23.36 \\
11 & $3.104 E-07$ & 31.03 & $6.229 E-07$ & 31.67 \\
12 & $3.311 E-07$ & 32.29 & $8.613 E-07$ & 24.35 \\
13 & $2.885 E-07$ & 36.37 & $8.976 E-07$ & 23.07 \\
14 & $7.518 E-08$ & 33.25 & $7.994 E-07$ & 24.16 \\
15 & $4.537 F-08$ & 32.09 & $1.209 E-06$ & 17.97 \\
16 & $1.584 F-08$ & 26.01 & $8.713 E-07$ & 18.18
\end{tabular}


SAMPLE PROBLEM 194 AOUEOUS 4 METAL MIXED BOX MATRIX CALCULATION

\begin{tabular}{|c|c|c|c|c|}
\hline \multirow{2}{*}{$\begin{array}{l}\text { FLUXES } \\
\text { GRNUP }\end{array}$} & $\begin{array}{l}\text { R BOX TY } \\
\text { REGION }\end{array}$ & 1 & REG I CN & 2 \\
\hline & FLUX & $\begin{array}{l}\text { PERCENT } \\
\text { PE VIATION }\end{array}$ & FLUX & $\begin{array}{l}\text { PERCENT } \\
\text { DEVIATION }\end{array}$ \\
\hline 1 & $9.097 E-05$ & 4.56 & $1.92 \angle E-05$ & 4.80 \\
\hline 2 & $1.632 E-04$ & 3.59 & $3.576 E-05$ & 3.52 \\
\hline 3 & $1.002 E-04$ & 4.88 & $1.859 \mathrm{gE}-05$ & 4.79 \\
\hline 4 & $1.606 E-04$ & 3.70 & $2.998 E-05$ & 3.46 \\
\hline 5 & $1.280 E-04$ & 4.11 & $2.296 \mathrm{E}-05$ & 4.35 \\
\hline 6 & $2.187 E-05$ & 7.99 & $5.722 \mathrm{E}-06$ & 8.73 \\
\hline 7 & $2.742 E-06$ & 20.51 & $2.468 \mathrm{E}-06$ & 16.52 \\
\hline 8 & $1.797 E-06$ & 18.42 & $2.047 E-06$ & 15.90 \\
\hline 9 & $6.102 E-07$ & 19.65 & $2.088 \mathrm{E}-06$ & \\
\hline 10 & $2.627 E-07$ & 22.20 & $1.1 E 5 E-06$ & 18.08 \\
\hline 11 & $3.126 \mathrm{E}-07$ & 33.93 & $1.141 E-06$ & 22.72 \\
\hline 12 & $1.877 E-07$ & 31.67 & $1.182 E-06$ & 23.32 \\
\hline 13 & $2.182 E-07$ & 31.45 & $1.38 \geq E-06$ & 18.85 \\
\hline 14 & $4.921 E-08$ & 39.02 & $5.644 E-07$ & 28.85 \\
\hline 15 & $3.718 F-08$ & 26.02 & $1.260 E-06$ & 18.76 \\
\hline 16 & 1. $570 \mathrm{~F}-08$ & 22.58 & $1.184 E-06$ & 16.65 \\
\hline
\end{tabular}


SAMPLE PRORLFM 19 \& ADUEDUS 4 METAL MIXEO BOX MATRIX CALCULATION

\begin{tabular}{|c|c|c|c|c|}
\hline FLUXFS & $\begin{array}{l}\text { FOR BOX TY } \\
\text { RFGION }\end{array}$ & $Y P E_{1}$ & REGION & 2 \\
\hline GROUP & Flux & $\begin{array}{l}\text { PERCENT } \\
\text { DE VIATI ON }\end{array}$ & FL UX & $\begin{array}{l}\text { PERCENT } \\
\text { DEVIATION }\end{array}$ \\
\hline 1 & $8.563 F-05$ & 4.31 & $1.887 E-05$ & 4.85 \\
\hline 2 & $1.587 \mathrm{~F}-04$ & 3.57 & $3.266 E-0 S$ & 3.49 \\
\hline 3 & $1.038 F-04$ & 3. 93 & $2.059 E-05$ & 4.63 \\
\hline 4 & $1.664 E-04$ & 3.66 & $3.2 \mathrm{C9E}-05$ & 3.38 \\
\hline 5 & $1.230 F-04$ & 3.76 & $2.235 E-05$ & 4.12 \\
\hline 6 & $2.065 E-05$ & 7.91 & $6.425 F-00$ & 8.70 \\
\hline 7 & $2.927 \mathrm{E}-06$ & 19.94 & $3.706 E-06$ & 12.36 \\
\hline 8 & $1.808 \mathrm{~F}-06$ & 19.91 & $2.568 E-06$ & 13.55 \\
\hline 9 & $5.597 F-07$ & 23.78 & $2.318 F-06$ & 13.40 \\
\hline 10 & $2.057 F-07$ & 28.95 & $1.227 \mathrm{E}-06$ & 21.45 \\
\hline 11 & $3.163 E-07$ & 34.44 & $1.203 E-06$ & 19.81 \\
\hline 12 & $1.551 \mathrm{~F}-07$ & 33.50 & $9.552 E-07$ & 22.50 \\
\hline 13 & 9.11 F -08 & 42.20 & $8.686 E-07$ & 21.79 \\
\hline 14 & $7.387 E-08$ & 42.99 & $6.146 E-07$ & 28.72 \\
\hline 15 & $2.685 F-08$ & 34.90 & $9.755 F-07$ & 20.25 \\
\hline 16 & $1.994 F-08$ & 25.23 & $1.018 F-06$ & 16.27 \\
\hline
\end{tabular}


0.8246 Tn 0.8477 0.8477 ro 0.8708 Tก 0.8939 0.8939 Tก 0.9170 0.9170 in 0.9401

0.9401 in 0.9632

0.9632 To 0.9863

0.9863 to 1.0094

$1.0094 \mathrm{~m} 1.0325$

1.0325 Tn 1.0556

1.0556 tr 1.0787

1.0787 in 1.1018

1.1018 Tn 1.1249
1.1249 Tn 1.1480

0.8246 Tก 0.8477

0.8477 TO 0.8708

0.8477 to 0.8708
0.8708 tก 0.8939

0.8939 tr 0.9170

0.9170 in 0.9401

0.9401 ti 0.963 ?

0.9632 to 0.9863

0.9632 th 0.9863
0.9863 to 1.0094

$\begin{array}{lll}0.9863 & \text { Th } & 1.0094 \\ 1.0094 & \text { in } 1.0325\end{array}$

1.0094 Tn 1.0325
1.0325 tr 1.0556

1.0556 T0 1.0787

1.0787 TO 1.1018

1.1018 TO 1.1249

0.8746 TO 0.8477 0.8477 Tि 0.8708

0.8708 in 0.8439

0.8939 TO 0.9170

0.9170 Tก 0.5401

0.9401 TO 0.9632

0.9632 in 0.9863

0.9863 TO 1.0094

$\begin{array}{ll}1.0094 & \text { Tก } 1.0325 \\ 1.0325 \text { Tก } 1.0556\end{array}$

1.0556 TO 1.0787

1.0787 Tn 1.1018

1.1018 TO 1.1249

1.1249 in 1.1480
FRE QUENCY For generaticns

**

*****

$* * * * * * * *$

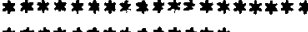

$* * * * \# * * * * * \neq * *$

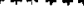

*

* freoueney fok generaticns 29 to 103

$*$

$* * * * * * * 4$

\section{$* * * * * * * 4$}

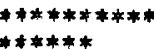

**********

$* * *$

$*$

frequeney for generaticns 54 to 103
$* *$
$* *$
$* * * * * * * *$
$* * *$
$* * * * * * * * * * * * * * *$
$* * * * * * * * * * *$
$* * * * *$

$* * * * *$
4 TO 103 
4 AOUEOUS 4 METAL MIXED BOX MATRIX CALCULATION

FRE QUENCY FOR GENERATIONS

0.8246 Tก 0.8477

0.8477 TO 0.8708

0.8708 T0 0.8939

0.8939 TO 0.9170

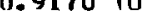

0.940

***

0.9863 Tn 1.0094

$* * * * * * * * * *$

$1.0094 \mathrm{~m} 1.0325$

$* * * * * *$

***

1.0556 Tn 1.0787

1.0787 TO 1.1018

1.1018 TO 1.1249

1.1249 ro 1.1480

********** END OF FILE ON UNIT 


\section{REFERENCES}

I G E Whitesides and N F Cross, "KENO - A Multigroup Monte Carlo Criticality Program," C ГС-5 (1969)

2 Robert $V$ Meghreblian and David K Holmes, REACTOR ANALYSIS, McGraw-Hill (1060)

3 J E Powell and C P Wells DIFFERENTIAL EQUATIONS, Ginn Company (1950)

4 G E Whitesides, "Adjoint Blasing in Monte Carlo Criticality Calculations," Transactions of the American Nuclear Society Volume II, Number 1 (June, 1968)

5 I R Knight and L M Petrie, " 16 and 123 Group Weighting Functions for KENO," ORNL-TM-4660 (1975)

6 N M Greene, I L Lucius, W E Ford, III, J E White, R Q Wright, and I M Petrie "AMPX - A Modular Code System for Generatıng Coupled Multigroup Neutron-Gamma Libraries from ENDF/B," ORNL-TM-3706 (to be published)

$7 \mathrm{~W}$ W Engle, Jr, "A USERS MANUAL FOR ANISN - A One-Dimensiondl Discrete Ordinates Transport Code with Anısotropic Scatterıng." K-1693 (March, 1967)

8 D C Irving and R M Freestone, Jr, "05R, A General Purpose Monte Carlo Transport Code," ORNL-3622 (February 1965)

9 W A Rhoddes and F R Mynatt, "The DOT III Two-Dimensional Discrete Ordinates Transport Code," ORNL-TM-4280 (September, 1973)

10 J T Thomas, "Critical Three-Dimensional Arrays of U(93 2)-Metal Cylinders," Nuclear science and Engineering, 52, 350, (November, 1973)

11 G E Whitesides, "The Use of Difterential Current Albedos in Monte Carlo Criticality Calculations," Transactions of the American nuclear Society, 12, 889, (November, 1969)

12 D C Irving and J T Mihalczo, "Monte Carlo Calculations for Enriched Uranium Metal Assemblies," I rans American Nucl Soc , 7, 284, (November, 1964)

$13 \mathrm{~J} \mathrm{~T}$ Mihalczo, "Multiplication Factor of Uranium Metal by One-Velocity Monte Carlo Calculations," ORNL-TM-1220 (August 19, 1965)

$14 \mathrm{~J} T$ Thomas, "Critical Three-Dimensional Arrays of Neutron-Interacting Units," Part II, ORNL-TM-868, (July, 1964) 
0

0 


\section{INTERNAL DISTRIBUTION}

1-2. Central Research Library

3-12. CSD Library, $4500 \mathrm{~N}$

13. Document Reference Section - Y-12

14-16. Laboratory Records

17. Laboratory Records - Record Copy

18. ORNL Patent Office

19-20. Radiation Shielding Information Center, 6025

21. Research and Technical Support Division, ORO

22. D. E. Bartine

23. A. A. Brooks

24. J. A. Bucholz

25. H. P. Carter

26. C. E. Clitford

27-51. N. F. Cross

52. F. L. Culler

53. J. P. Drago

54. H. R. Dyer

55. G. F. Flanagan

56. W. E. Ford, III

57. P. B. Fox

58. N. M. Greenc

59 G. R. Handley

60. R. F. Hibbs
61. T. J. Hoffman (consultant)

62. C. M. Hopper

63. J. R. Knight

64. J. L. Lucius

65. D. W. Magnuson

66. J. D. McLendon

67. W. T. Mee

68. G. W. Morrison

69. F. R. Mynatt

70. C. L. Newlon

71. E. M. Oblow

72-96. L. M. Petrie

97. H. Postma

98. D. L. Selby

99. J. G. Sullivan

100. J. H. Swanks

101. R. G. Taylor

102. J. T. Thomas

103. K. R. Turnbull

104. P. R. Vanstrum

105. C. R. Weisbin

106. G. E. Whitesides 


\section{EXTERNAL DISTRIBUTION}

107 F M Alcorn, Nuclear Safety Officer, Babcock \& Wilcox Co, P O Box 1260, Lynchburg, VA 24505

108 R C Ashline, Allıed General Nuclear Services, P O Box 847, Barnwell, SC 29812

109-133 Argonne Code Center, Argonne National Laboratory, Argonne, IL 60439

134 Dr Ricardo Artigas, General Electric Co, MC 273, 175 Curtner Avenue, San Jose, CA 95125

135 R E Best, Nuclear Fuel Services, Inc, 6000 Executive Boulevard, Suite 600, Rockville, MD 20852

136 S R Bierman, Bdttelle Northwest, Bldg 209E, Rıchland, WA 99352

137 C L Brown, Battelle Northwest, P O Box 999, Richland, WA 99352

138 W R Carpenter, Allied Chemical Corp, P O Box 2204, Idaho Falls, ID 83401

139 L L Carter, Los Alamos Scientific Laboratory, P O Box 1663, Los Alamos, NM 87544

140 R R Carter, Atlantıc Richfield Hanford Co, Box 250, Richland, WA 99352

141 Jack Chalmers, Health and Safety Executive, Nucledr Installations Inspectorate, Sılkhouse Court, Tithebarn Strect, Liverpool L2 21Z, ENGLAND

142 J T Ching, Energy, Inc, P O Box 736, Iddho Falls, ID 83401

143 Hugh Clark, E I DuPont De Nemours Co, Savannah River Laboratory, Alken, SC 29801

144 E D Clayton, Bdttelle Northwest, Bldg 209E, Richland, WA 99352

145 D F Cronin, Jr, United Nuclear Corp, P O Box 26, Wood River Junction, RI 02894

146 D M Dawson, General Electric Co, P O Box 780, Wilmington, NC 28401

147 Deanne Dickınson, Atomics Internatıondl, Bldg 886, Rocky Flats Div, P O Box 888, Golden, CO 80401

148 J L Feuerbacher, Goodyear Atomic Corp, P O Box 628, Piketon, OH 45661

149 John K Fox, Kerr-McGee Corp, Cimmaron Plant, Cresent, OK 73028

150 E M Gelbard, Argonne National Laboratory, Bldg 208, 9700 S Cass Avenue, Argonne, IL 60439

151 Thomas Gutman, Nucl Lic \& Saf Supervisor, Combustion Engineering, Inc, Windsor, CT 06095

152 G E Hansen, Los Alamos Scientific Laboratory, P O Box 1663, Los Alamos, NM 87544

153 L E Hansen, Exxon Nuclear Co, Inc, 2101 Horn Rapıds Road, Richland, WA 99352

154 Dan Harton, Control Data Corp, 9041 Executive Park Drive, Suite 313, Knoxville, TN 37919

155 Herb Henryson, Argonne National Laboratory, Argonne, IL 60439

156 D L Hetrick, Savannah River Laboratory, Aiken, SC 29801

157 Rosalıne Huang, NUS Corp, 2351 Resedrch Blvd, Rockvılle, MD 20850

158 D C Hunt, Atomics International, Rocky Flats Dıv, P O Box 888, Golden, CO 80401

159 Norman Ketelach, Transportation Branch, Nuclear Regulatory Commission, 7920 Norfolk Ave, Bethesdd, MD 20014

160 G R Kiel, Atlantıc Richfield Hanford Co, P O Box 250, Richland, WA 99352

161 Phil Kier, Argonne National Laboratory, Argonne, IL 60439

162 Ryoheı Kiyose, University of Tokyo, Dept of Nuclear Engineering, Hongo Motofuj1-Cho, Bunkyo Ku, Tokyo, JAPAN

163 Jerry Klotzkin, Argonne National Laboratory, Bldg 208, Argonne, IL 60439

164 Brian Koponen, Lawrence Livermore Ldboratory, P O Box 808, Livermore, CA 94550

165 Peggy Lambert, Duke Power Co, P O Box 2178, Charlotte, NC 28247

166 Pierre R Lecorche. CEN-Saclay, BP No 2, 91190, Gif sur Yvette, FRANCE

167 R C Lloyd, Battelle Northwest, Bldg 209E, Rıchland, WA 99352

168 Charles Marotta, Transportation Branch, Nuclear Regulatory Commıssıon, 7920 Norfolk Ave, Bethesda, MD 20014

169 Thomas McCreless, Jr , ERDA, Materidls Licensing Div , Washington, DC 20545 
170. Brian McGregor, Australian Atomic Energy Commission, AAEC Research Establishment, Private Mailbag, Sutherland 2232, N.S.W. AUSTRALIA

171. J. O. Mingle, Dept. of Nuclear Engineering, Ward Hall, Kansas State University, Manhattan, KS 66502

172. J. G. Moore, United Kingdom Atomic Energy Authority, Safety and Reliability Directorate, Wighshaw Lane, Culcheth, Warrington, WA 3 4NE, ENGLAND

173. R. J. Morford, NL Industries, Suite 1701, 919 Market Street, Wilmington, DE 19801

174. W. G. Morrison, Allied Chemical Corp., P.O. Box 2204, CPP 637, Idaho Falls, ID 83401

175-180. R. H. Odegaarden, Transportation Branch, Nuclear Regulatory Commission, 7920 Norfolk Ave., Bethesda, MD 20014

181. D. R. Oden, Battelle Northwest, Richland, WA 99352

182. J. I. Paulk, State University of Mississippi, Dept. of Nuclear Engineering, State College, MS 39762

183. Hugh Paxton, Los Alamos Scientific Laboratory, P.O. Box 1663, Los Alamos, NM 87544

184. George Perry, TVA, Chattanooga, TN 37401

185. Jeffrey Philbin, Sandia Laboratories, Division 5221, P.O. Box 5800, Albuquerque, NM 87115

186. Kenneth Ridgway, ERDA, 799 Roosevelt Road, Glen Ellyn, IL 60137

187. John Ridihalgh, Ridihalgh and Associates, 2112 Iuka Ave., Columbus, OH 43201

188. J. N. Rogers, Sandia Laboratories, Division 8321, P.O. Box 969, Livermore, CA 94550

189. Jack Rollins, Nuclear Assurance, 24 Executive Park West, Atlanta, GA 30329

190. M. E. Rose, Mathematical and Computer Sciences Program, Molecular Sciences and Energy Research, Division of Physical Research, U.S. Energy Research and Development Administration, Washington, DC 20545

191. R. E. Schmidt, NUS Corp., 4 Research Place, Rockville, MD 20850

192. K. R. Schultz, Atomic Energy Control Board, P.O. Box 1046, Ottawa, CANADA, K1P 5S9

193. Lee Simmons, Science Applications, Inc., Clinton Bldg., 2109 Clinton Ave., Huntsville, AL 35805

194. D. R. Smith, Los Alamos Scientific Laboratory, P.O. Box 1663, Los Alamos, NM 87544

195. Richard Smith, Bechtel Corp., 333 Hegenberger Road, Oakland, CA 94621

196. P. Y. Soong, NUS Corp., 2351 Research Blvd., Rockville, MD 20850

197. R. L. Stevenson, Transportation Branch, Nuclear Regulatory Commission, 7920 Norfolk Ave., Bethesda, MD 20014

198. C. D. Swanson, Control Data Corporation/HQN07L, P.O. Box 0, Minneapolis, MN 55440

199. Hans Toffer, Douglas United Nuclear, P.O. Box 490, Richland, WA 99352

200. Taz Thompson, General Electric Co., 175 Curtner Ave., San Jose, CA 95125

201. F. G. Welfare, Babcock \& Wilcox Co., P.O. Box 1260, Lynchburg, VA 24505

202. J. C. Zink, School of Aerospace, Mechanical and Nuclear Engineering, The University of Oklahoma, Room 200, 865 Asp Ave., Norman, OK 73069

203-360. Given Distribution as shown in TID-4500, Mathematics and Computers (25 copies NTIS). 